UNIVERSIDADE DE SÃO PAULO

ESCOLA DE ENGENHARIA DE SÃO CARLOS

RACHEL PASSOS DE OLIVEIRA SANTOS

\title{
Valorização de biomassa lignnocelulósica e de polímero reciclado: materiais preparados a partir da eletrofiação de PFT, fibra de sisal e seus componentes majoritários
}





\section{Valorização de biomassa lignnocelulósica e de polimero reciclado: materiais preparados a partir da eletrofiação de PET, fibra de sisal e seus componentes majoritários}

Versão Corrigida Original na Unidade

Tese apresentada à Escola de Engenharia de São Carlos, da Universidade de São Paulo, como parte dos requisitos para obtenção do Título de Doutora em Ciências.

Área de Concentração:

Desenvolvimento, Caracterização e Aplicação de Materiais.

Orientadora: Profa. Dra. Elisabete Frollini 


\section{AUTORIZO A REPRODUÇÃO E DIVULGAÇÃO TOTAL OU PARCIAL DESTE TRABALHO, POR QUALQUER MEIO CONVENCIONAL OU ELETRÔNICO, PARA FINS DE ESTUDO E PESQUISA, DESDE QUE CITADA A FONTE.}

Passos de Oliveira Santos, Rachel

P237v Valorização de biomassa lignocelulósica e de polímero reciclado:

materiais preparados a partir da eletrofiação de PET, fibra de sisal e seus componentes majoritários / Rachel Passos de Oliveira Santos; orientadora Elisabete Frollini. São Carlos, 2017.

Tese [Doutorado] - Programa de Pós-Graduação em Ciência e Engenharia de Materiais e Area de Concentração em Desenvolvimento, Caracterização e Aplicação de Materiais - Escola de Engenharia de São Carlos da Universidade de São Paulo, 2017.

1. PET reciclado. 2. Fibra de sisal. 3. Celulose. 4. Lignina. 5. Eletrofiação. 6. Fibras ultrafinas. 7. Nanofibras. I. Título. 


\section{FOLHA DE JULGAMENTO}

Candidata: Bacharel RACHEL PASSOS DE OLIVEIRA SANTOS.

Título da tese: "Valorização de biomassa lignocelulósica e de polímero reciclado: materiais preparados a partir da eletrofiação de PET, fibra de sisal e seus componentes majoritários".

Data da defesa: 02/06/2017.

Comissão Julgadora:

Profa. Associada Elisabete Frollini

(Orientadora)

(Instituto de Química de São Carlos/IQSC)

Dr. Caue Ribeiro de Oliveira

( Empresa Brasileira de Pesquisa Agropecuária/EMBRAPA)

Profa. Dra. Marcia Cristina Branciforti

(Escola de Engenharia de São Carlos/EESC)

Prof. Dr. Adhemar Colla Ruvolo Filho

(Universidade Federal de São Carlos/UFSCar)

Prof. Titular Holmer Savastano Junior

(Faculdade de Zootecnia e Engenharia de Alimentos/FZEA-USP)

Coordenador do Programa de Pós-Graduação em Ciências e Engenharia de Materiais:

Prof. Titular Antonio José Felix de Carvalho

Presidente da Comissão de Pós-Graduação:

Prof. Associado Luis Fernando Costa Alberto

\section{Resultado:}

APROUADA Aprovada

AnROVADA


APROVADA 



\section{A minha pequena e ao mesmo tempo grande familia: Ninha mãe Maria Lisette, mew pai Hamilton e minha irma Garolina, por todo amor, incentivo e apoio incondicionais. \\ Amo muito vocês.}





\section{Agradecimentos}

Primeiramente a Deus, por simplesmente tudo;

À minha orientadora Profa. Dra. Elisabete Frollini pela orientação, dedicação, paciência, confiança e amizade ao longo destes anos. Obrigada pela enorme contribuição na minha formação pessoal/profissional e pela oportunidade de desenvolver este trabalho; Aos meus avós, Josina e José Manoel [In memoriam], por sempre estarem presentes, mesmo que em pensamento.

Ao Armando Neto e tia Gelse, que fazem parte da minha família;

À Zara, Bela e Lola por todas as alegrias, companheirismo e amor incondicional; À minha melhor amiga Nízia Sophia. Muito obrigada por estar sempre presente mesmo quando distantes uma da outra;

À minha querida amiga Martha. Muito obrigada por todo incentivo e carinho mesmo vivendo cada uma em um continente diferente;

À tia Laure por todos os sábios conselhos recebidos;

Aos amigos queridos de convívio quase que diário Ana, Anderson, Chicolina, Danilo, Deinha, Lulu, Pati, Thamis e Will. Obrigada por todo o apoio e auxílio [nos bons e maus momentos] e todas as muitas alegrias que compartilhamos juntos desde que, por uma feliz coincidência, nos conhecemos;

Aos meus amigos queridos [muitos dos quais estão distantes, porém jamais serão esquecidos] Erikinha, Fergolino, Cris, Dani, Bibi e Elaine;

Aos amigos, companheiros de laboratório e ex integrantes do Grupo de Materiais Macromoleculares e Fibras Lignocelulósicas;

Aos amigos, alunos, ex alunos e Prof. Dr. Sérgio Paulo Campana Filho do Grupo de FísicoQuímica Orgânica;

À querida amiga Marcia Zambon, técnica do Grupo;

Ao técnico Luiz Ramos. Muito obrigada pela paciência e dedicação na realização das análises térmicas e mecânicas;

Ao técnico Márcio de Paula. Muito obrigada pelo excelente convívio, paciência e grande dedicação nas análises de Microscopia Eletrônica de Varredura;

Ao Prof. Dr. Stephen J. Eichhorn pela orientação, ensinamentos e oportunidade de desenvolver o estágio de doutorado sanduíche no Cellulose and Natural Materials Group; 
Aos meus queridos e inesqueciveis amigos que me acompanharam durante minha incrivel jornada em Exeter: Anna, Nandula e Kanishka, Alex, Daniel, Sahand, Victor, Masitah, Charles, Nor, Ellen e Kelly;

Aos demais funcionários do Instituto de Química de São Carlos presentes na Central de Análises Químicas, Biblioteca Professor Dr. Johannes Rüdiger Lechat, Oficina Mecânica, Setor Financeiro, Oficina de vidro, dentre outros setores. Muito obrigado pelos diversos serviços prestados;

Ao Instituto de Química de São Carlos e Programa Ciência e Engenharia de Materiais, pelo apoio institucional e infraestrutura;

A CAPES, pela bolsa concedida e ao CNPq e FAPESP, pelo suporte financeiro. 
"Learning never exhausts the mind." Leonardo da Vinci 



\section{$\mathcal{R}_{\text {esumo }}$}

SANTOS, R. P. O. Valorização de biomassa lignocelulósica e de polímero reciclado: materiais preparados a partir da eletrofiação de PET, fibra de sisal e seus componentes majoritários. 2017. 183 p. Tese [Doutorado] - Escola de Engenharia de São Carlos, Universidade de São Paulo, São Carlos, 2017.

0 objetivo do presente estudo foi agregar valor a fibras de sisal, a dois dos componentes principais de fibras lignocelulósicas [celulose e lignina] e a PET reciclado, via produção de materiais com elevado valor agregado. Neste contexto, foram investigadas condições que levassem a mats constituídos por nanofibras/fibras ultrafinas, alinhadas [coletor rotativo] e não alinhadas [coletor estático], a partir da eletrofiação de soluções contendo essas matérias-primas, combinadas ou não [PET/sisal, PET/celulose e/ou lignina, PET/CNC [combinado ou não com OM]], em TFA. Parâmetros de solução, como razão PET/componente da biomassa e tempo de dissolução, foram diversificados, assim como parâmetros de processo (taxa de vazão da solução e velocidade de rotação do coletor utilizado, por exemplo]. Os resultados de DMA indicaram a influência positiva do alinhamento das fibras nos superiores valores de E' [tanto para os mats de PET/sisal, quanto para os mats de PET/celulose e/ou lignina e PET/CNC [combinado ou não com OM)] e também foi possivel observar que não houve uma influência significativa desse alinhamento na $T_{g}$ do PET nestes materiais. Como exemplo, o valor de E' (a $30{ }^{\circ} \mathrm{C}$ ] para o mat de fibras alinhadas, com razão de sisal/PET = 0,40 [S/PET $0.40-\mathrm{A}$ dir], caracterizado na direção preferencial de alinhamento das fibras, foi superior [765,0 MPa], em comparação ao valor apresentado pelo mat de fibras orientadas aleatoriamente, de composição correspondente, S/PET , $40\left[\mathrm{E}^{\prime}=358,0 \pm 1,5 \mathrm{MPa}\right.$. A molhabilidade dos mats foi intrinsicamente dependente da razão fibra de sisal/PET e variou de altamente hidrofóbico ( $\mathrm{PET}_{\text {ref, }} \mathrm{ACA}$ de $134^{\circ}$ ), a super hidrofilico [S/PET ${ }_{0,40}, A C A$ de $\mathrm{O}^{\circ}$ ). Observou-se que, as principais influências da presença de lignina foram na morfologia achatada das fibras e no aumento do alongamento na ruptura dos materiais, de aproximadamente $90 \%$, comparativamente a $\mathrm{PET}_{\text {ref. }}$ A presença da celulose resultou principalmente em um elevado diâmetro médio das fibras (valores de até 365,9 \pm 139,7 nm] e módulo de Young dos materiais [com valores de até 360,4 \pm 41,5 MPa], comparativamente ao apresentado pelos mats contendo PET e este polímero combinado com lignina. Os resultados mostraram que os CNCs exerceram uma ação efetiva como agentes de reforço, principalmente nos mats constituídos por fibras orientadas aleatoriamente de PÉT, considerando as propriedades mecânicas apresentadas por esses materiais [como resistência à ruptura de 4,6 \pm 0,5 MPa), em comparação ao mat $\mathrm{PET}_{\text {ref }}$ (resistência à ruptura $=1,8 \pm 0,2 \mathrm{MPa}$ ]. $\mathrm{O} \mathrm{OM}$ atuou como agente compatibilizante entre o PET reciclado e os CNCs, principalmente com relação ao superior valor de módulo de Young de $\mathrm{PET} / \mathrm{OM} / \mathrm{CNC}[354,2 \pm$ 46,1 MPa], em comparação ao valor apresentado por PET/CNC $[19,9 \pm 3,9 \mathrm{MPa}$. Assim, os objetivos do presente trabalho foram atingidos com a preparação via eletrofiação, até onde se tem conhecimento, pela primeira vez, de mats de fibras alinhadas e não alinhadas baseadas em biomassa lignocelulósica nativa e dois de seus principais constituintes [celulose e lignina]. Os materiais preparados apresentam uma vasta gama de possíveis aplicações, como sistemas de filtração de ar, por exemplo.

\section{Palavras-chave: PET reciclado; Fibra de sisal; Celulose; Lignina; Eletrofiação;}

Fibras ultrafinas; Nanofibras. 



\section{Abstract}

SANTOS, R. P. O. Valuation of lignocellulosic biomass and recycled polymer: materials prepared from the electrospinning of PET, sisal fiber and its major. 2017. $183 \mathrm{f}$. Tese [Doutorado] - Escola de Engenharia de São Carlos, Universidade de São Paulo, São Carlos, 2017.

The aim of the present investigation was to add value to sisal fibers, to two of the major components of lignocellulosic fibers [cellulose and lignin] and recycled PET via preparation of materials with high added value. In this context, conditions that lead to mats of nanofibers and ultrathin fibers were investigated, aligned [rotating drum collector] and nonaligned [stationary collector], via electrospinning of solutions containing these raw materials, combined or not $\{\mathrm{PET} /$ sisal fiber, PET/cellulose and/or lignin, PET/CNC [combined or not with castor oil [CO]]\} in TFA. Solution parameters such as the ratio of PET/biomass component and dissolution times were diverse, as well as process parameters [e.g. solution flow rate and rotational speed of the collector]. The DMA results indicated the positive influence of fiber alignment on the higher storage modulus - E' [for mats of PET/sisal, PET/cellulose and/or lignin and PET/CNC [combined or not with CO)] and it was also possible to observe no significant influence of fiber alignment on the $T_{9}$ of PET for these mats. The value of E' [at $30^{\circ} \mathrm{C}$ ] for the aligned fibers mat with sisal/PET ratio $=0.40\left[\mathrm{~S} / \mathrm{PET}_{0.40}-\mathrm{A}\right.$ dir], characterized in the preferred direction of fiber alignment, was higher [765.0 $\mathrm{MPa}$ ] when compared to the value presented by the randomly oriented fibers mat of the corresponding composition, S/PET $T_{0.40} \quad\left[E^{\prime}=358.0 \pm 1.5 \mathrm{MPa}\right.$ ). The wettability of the mats was intrinsically dependent on the sisal/PET fiber ratio and ranged from highly hydrophobic [PET ref, ACA of $134^{\circ}$ ] to super hydrophilic [S/PET ${ }_{0.40}, A C A$ of $0^{\circ}$ ]. It was observed that the main influences of the presence of lignin was on the flat fibers morphology and on the increase of the elongation-at-break of the materials of approximately $90 \%$ compared to $\mathrm{PET}_{\text {ref. }}$ The presence of cellulose resulted mainly in a high average fiber diameter [values up to $365.9 \pm 139.7 \mathrm{~nm}$ ) and elastic modulus of the materials [values up to $360.4 \pm 41.5 \mathrm{MPa}$ ] compared to the ones presented by mats containing PET and by this polymer combined with lignin. The results showed that the CNCs were efficient as reinforcing agents, especially in the mats composed of randomly oriented fibers of PET, considering the mechanical properties presented by these materials [such as ultimate tensile strength of $4.6 \pm 0.5 \mathrm{MPa}$ ) compared to $\mathrm{PET}_{\text {ref }}$ mat [ultimate tensile strength $=1.8 \pm 0.2 \mathrm{MPa}$. $\mathrm{CO}$ acted as a compatibilizing agent between recycled PET and CNCs, mainly regarding the superior elastic modulus value of PET/OM/CNC [354.2 \pm 46.1 MPa] compared to PET/CNC mat [19.9 $\pm 3.9 \mathrm{MPa}$ ]. Therefore, the goals of the present study were reached for the first time with the preparation of aligned and nonaligned fiber mats based on native lignocellulosic biomass and two of its main constituents [cellulose and lignin], to the best of our knowledge. The prepared materials have a wide range of possible applications, such as air filtration systems, for example.

\section{Ceywords: Recycled PET; Sisal fiber; Cellulose; Lignin; Electrospinning; Ultrathin}

fibers; Nanofibers. 



\section{Lista de Figuras}

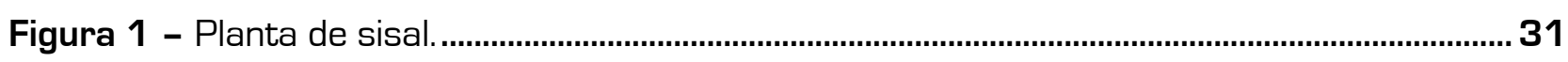

Figura 2 - Produção e exportação de sisal no Brasil. ........................................................................ 32

Figura 3 - Representação da estrutura da fibra lignocelulósica de sisal e seus principais

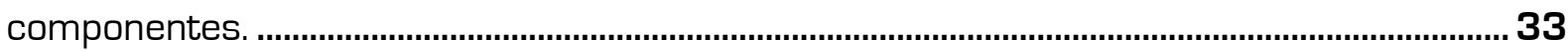

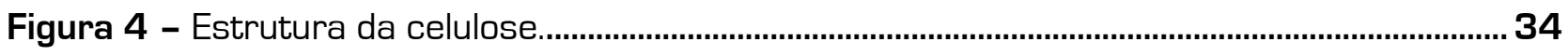

Figura 5 - Representação esquemática das ligações hidrogênio intermoleculares e



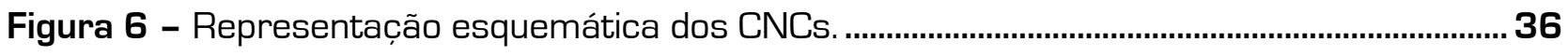

Figura 7 - Estruturas químicas das unidades de açúcares presentes nas hemiceluloses. ........ 37

Figura 8 - Álcoois precursores nas reações de formação da macromolécula de lignina. ......... 38

Figura 9 - Conceito estrutural de lignina de faia........................................................................... 39

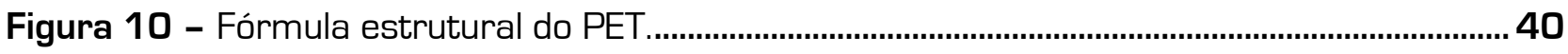

Figura 11 - Usos finais do PET reciclado no Brasil em 2015........................................................ 41



Figura 13 - Número de trabalhos publicados e indexados na base de dados SCOPUS

envolvendo a palavra-chave "Electrospinning" no período de 2000 a Dezembro de 2016.43

Figura 14 - Representação esquemática de algumas formas para nano-objetos. ..................... 44

Figura 15 - Representação esquemática do funcionamento da técnica de eletrofiação........... 45

Figura 16 - Representação esquemática do funcionamento da técnica de eletrofiação utilizando-se como coletor um tambor metálico rotativo. ........................................................53

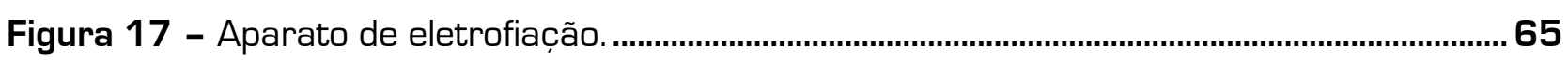

Figura 18 - Mat preparado com a utilização do coletor estático. ..................................................66

Figura 19 - Espectros de IV para [a] PET reciclado e seu respectivo mat $\mathrm{PET}_{\text {ref, }}$ [b] Mats $\mathrm{PET}_{\text {ref }}$ e

$\mathrm{S} / \mathrm{PET}_{0,40}$

Figura 20 - Principais componentes da fibra lignocelulósica de sisal e seus principais sítios reativos susceptíveis à esterificação pelo TFA ..........................................................................69

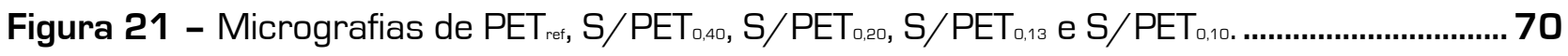

Figura 22 - Diâmetro médio das fibras, área média do poro e porosidade média dos mats obtidos via eletrofiação. ............................................................................................................ 71

Figura 23 - Histogramas do diâmetro de fibra dos mats $\mathrm{PET}_{\text {ref, }} \mathrm{S} / \mathrm{PET}_{0,40}, \mathrm{~S} / \mathrm{PET}_{0,20,} \mathrm{~S} / \mathrm{PET}_{0,13}$ e $\mathrm{S} / \mathrm{PET}_{0,10}$ 74

Figura 24 - Micrografias, respectivas imagens codificadas por cores, escala de orientação de cores, I.A. e O.P.M. dos mats PET ref $-A$, S/PET $0,40-A, S / P E T_{0,20}-A, S / P E T_{0,13}-A$ e S/PET 0 o, -A.

Figura 25 - Histogramas do diâmetro de fibra dos mats $P E T_{\text {ref }}-A, S / P E T_{0,40}-A, S / P E T_{0,20}-A$, 
S/PET $0,13-A$ e S/PET $0,10-A$

Figura 26 - ACA para os mats preparados utilizando-se o coletor estático e rotativo

Figura 27 - Curvas dTG para [a] PET reciclado e seu respectivo mat PET $_{\text {ret, }}$ (b) Mats PET $_{\text {ref }} \mathrm{e}$

S/PET $T_{0,10}$ e [c] Mats S/PET 0,$40 ; \mathrm{S} / \mathrm{PET}_{0,20} ; \mathrm{S} / \mathrm{PET}_{0,13} ; \mathrm{S} / \mathrm{PET}_{0,10}$ [atmosfera de $\mathrm{N}_{2}$, fluxo de 50 $\mathrm{mL} \min ^{-1}$ e taxa de aquecimento de $10{ }^{\circ} \mathrm{C} \min ^{-1}$


curva tan $\delta$ ] mats/coletor rotativo, caracterizados na direção preferencial de alinhamento das fibras [ "dir"] e direção oposta ao alinhamento preferencial [ "op"].

Figura 29 - Representação esquemática da fibra lignocelulósica de sisal e seus principais componentes, assim como as possíveis interações com a cadeia de PET.

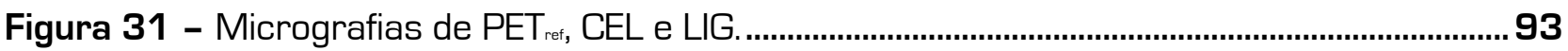

Figura 32 - Histogramas do diâmetro de fibra de PET ref e CEL.......................................................93

Figura 33 - [a] Diâmetro médio das fibras, [b] Área média dos poros e [c] Porosidade média dos mats obtidos via eletrofiação.

Figura 34 - Micrografias de PETC/48 h, PETC/72 h, PETL/48 h, PETL/72 h, PETCL/48 h e PETCL/72 h.

Figura 35 - Histogramas do diâmetro de fibra de PETC/48 h, PETC/72 h, PETL/48 h, PETL/72 h, PETCL/48 h e PETCL/72 h

Figura 36 - Ângulo de contato de avanço [máximo, erros de \pm 6,8 [PET ref] a \pm 0,6 [PETC/48

h]], ângulo de contato de recuo [mínimo, erros de \pm 1,66 [PETL/72 h] a \pm 0,17 [PETCL/72 h]] e imagens da gota de água após o primeiro segundo de contato com a superfície dos mats. 102

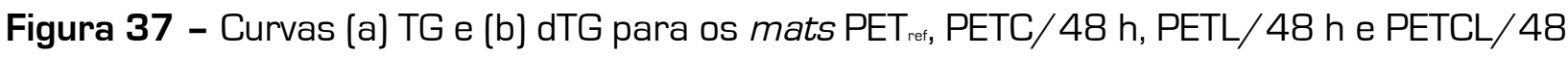
h [atmosfera de $\mathrm{N}_{2}$, fluxo de $50 \mathrm{~mL} \mathrm{~min}^{-1}$ e taxa de aquecimento de $10{ }^{\circ} \mathrm{C} \mathrm{min}{ }^{-1}$ ].

Figura 38 - Curvas DSC para os mats PET ref, PETC/72 h, PETL/72 h e PETCL/72 h [atmosfera de $\mathrm{N}_{2}$, fluxo de $50 \mathrm{~mL} \min ^{-1}$ e taxa de aquecimento de $10{ }^{\circ} \mathrm{C} \mathrm{min}{ }^{-1}$ ]. 105

Figura 39 - [a] Módulo de armazenamento - E' [a 30 `C] e [b] Temperatura de transição vítrea

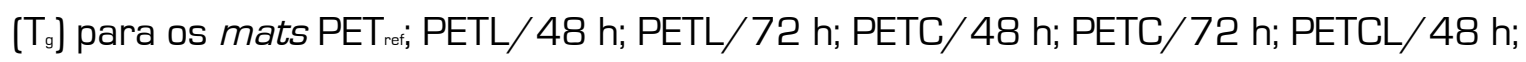
PETCL/72 h 106

Figura 41 - Micrografias, respectivas imagens codificadas por cores, escala de orientação de cores, I.A. e O.P.M. dos mats PET-A1, PET-A2 e PET-A3. 116

Figura 42 - Histogramas do diâmetro das fibras de PET-A1, PET-A2 e PET-A3.. 116

Figura 43 - Diâmetro médio das fibras, área média dos poros e porosidade média dos mats PET-A1, PET-A2, PET-A3, PETC-A1, PETC-A2, PETC-A3, PETL-A1, PETL-A2, PETL-A3, PETCLA1, PETCL-A2 e PETCL-A3.

Figura 44 - Micrografias, respectivas imagens codificadas por cores, escala de orientação de cores, I.A. e O.P.M. dos mats PETC-A1, PETC-A2 e PETC-A3. 120

Figura 45 - Histogramas do diâmetro das fibras de PETC-A1, PETC-A2 e PETC-A3. 120

Figura 46 - Micrografias, respectivas imagens codificadas por cores, escala de orientação de 
cores, I.A. e O.P.M. dos mats PETL-A1, PETL-A2 e PETL-A3.

Figura 47 - Histogramas do diâmetro das fibras de PETL-A1, PETL-A2 e PETL-A3.

Figura 48 - Micrografias, respectivas imagens codificadas por cores, escala de orientação de cores, I.A. e O.P.M. dos mats PETCL-A1, PETCL-A2 e PETCL-A3.

Figura 49 - Histogramas do diâmetro das fibras de PETCL-A1, PETCL-A2 e PETCL-A3. ........ 124

Figura 51 - Módulo de armazenamento - E' [a 30 `C] para os mats [a] PET-A1, PET-A2 e PETA3; [b] PETL-A1, PETL-A2 e PETL-A3; [c] PETC-A1, PETC-A2 e PETC-A3; (d) PETCL-A1, PETCL-A2 e PETCL-A3. Os materiais foram caracterizados tanto na direção preferencial de alinhamento das fibras [siglas contendo a terminação "dir" no final], quanto na direção oposta ao alinhamento preferencial das fibras [siglas contendo a terminação "op" no final).

Figura 52 - $T_{9}$ dos mats [a] PET-A1, PET-A2 e PET-A3; [b] PETL-A1, PETL-A2 e PETL-A3; [c] PETC-A1, PETC-A2 e PETC-A3; (d) PETCL-A1, PETCL-A2 e PETCL-A3. Os materiais foram caracterizados tanto na direção preferencial de alinhamento das fibras [siglas contendo a terminação "dir" no final], quanto na direção oposta ao alinhamento preferencial das fibras [siglas contendo a terminação "op" no final). 132

Figura 53 - Resistência à ruptura dos mats [a] PET-A1, PET-A2 e PET-A3; [b] PETL-A1, PETL-A2 e PETL-A3; [c] PETC-A1, PETC-A2 e PETC-A3; [d] PETCL-A1, PETCL-A2 e PETCL-A3. Os materiais foram caracterizados tanto na direção preferencial de alinhamento das fibras [siglas contendo a terminação "dir" no final], quanto na direção oposta ao alinhamento preferencial das fibras [siglas contendo a terminação "op" no final).

Figura 54 - Módulo de Young dos mats [a] PET-A1, PET-A2 e PET-A3; [b] PETL-A1, PETL-A2 e PETL-A3; [c] PETC-A1, PETC-A2 e PETC-A3; [d] PETCL-A1, PETCL-A2 e PETCL-A3. Os materiais foram caracterizados tanto na direção preferencial de alinhamento das fibras [siglas contendo a terminação "dir" no final], quanto na direção oposta ao alinhamento preferencial das fibras [siglas contendo a terminação "op" no final).

Figura 55 - Alongamento na ruptura dos mats [a] PET-A1, PET-A2 e PET-A3; [b] PETL-A1, PETL-A2 e PETL-A3; [c] PETC-A1, PETC-A2 e PETC-A3; [d] PETCL-A1, PETCL-A2 e PETCLA3. Os materiais foram caracterizados tanto na direção preferencial de alinhamento das fibras [siglas contendo a terminação "dir" no final], quanto na direção oposta ao alinhamento preferencial das fibras [siglas contendo a terminação "op" no final).

Figura 56 - Espectros de IV para PET ref, PET/OM, PET/CNC e PET/OM/CNC....................... 149

Figura 57 - Micrografias de PET ref, PET/OM, PET/CNC e PET/OM/CNC................................ 150

Figura 58 - Histogramas do diâmetro das fibras de PET ref, PET/OM, PET/CNC e $\mathrm{PET} / \mathrm{OM} / \mathrm{CNC}$

Figura 59 - Diâmetro médio das fibras, área média do poro e porosidade média dos mats $\mathrm{PET}_{\text {ret, }} \mathrm{PET} / \mathrm{OM}, \mathrm{PET} / \mathrm{CNC}, \mathrm{PET} / \mathrm{OM} / \mathrm{CNC}, \mathrm{PET}-\mathrm{A}, \mathrm{PET} / \mathrm{OM}-\mathrm{A}, \mathrm{PET} / \mathrm{CNC}-\mathrm{A}$ e $\mathrm{PET} / \mathrm{OM} / \mathrm{CNC}-\mathrm{A}$. 
Figura 61 - Histogramas do diâmetro das fibras de PET-A, PET/OM-A, PET/CNC-A e $\mathrm{PET} / \mathrm{OM} / \mathrm{CNC}-\mathrm{A}$

Figura 62 - Ângulo de contato aparente em função do tempo entre a gota de água e a superfície dos mats [a] Preparados com a utilização do coletor estático e [b] Preparados com a utilização do coletor rotativo.

Figura 63 - Curvas [a] TG e [b] dTG dos mats PET ref, PET/OM, PET/CNC e PET/OM/CNC [atmosfera de $\mathrm{N}_{2}$, fluxo de $50 \mathrm{~mL} \mathrm{~min}^{-1}$ e taxa de aquecimento de $10{ }^{\circ} \mathrm{C} \mathrm{min}^{-1}$ ]. 158

Figura 64 - Curvas DSC dos mats PET ref, PET/OM, PET/CNC e PET/OM/CNC [atmosfera de $\mathrm{N}_{2}$, fluxo de $50 \mathrm{~mL} \min ^{-1}$ e taxa de aquecimento de $\left.10{ }^{\circ} \mathrm{C} \min ^{-1}\right]$.

Figura 65 - [a] E' [a 30 'C] e [b] Tos dos mats preparados com a utilização do coletor estático; [c] E' [a 30 'C] e [d] $T_{9}$ dos mats preparados com a utilização do coletor rotativo. Estes materiais foram caracterizados tanto na direção preferencial de alinhamento das fibras [siglas contendo a terminação "dir" no final], quanto na direção oposta ao alinhamento preferencial das fibras [siglas contendo a terminação "op" no final].

Figura 66 - Interações entre o PET/OM/CNCs.

Figura 67 - Resistência à ruptura para os mats [a] Preparados com a utilização do coletor estático e [b] Preparados com a utilização do coletor rotativo. Estes materiais foram caracterizados tanto na direção preferencial de alinhamento das fibras (siglas contendo a terminação "dir" no final], quanto na direção oposta ao alinhamento preferencial das fibras [siglas contendo a terminação "op" no final].

Figura 68 - Módulo de Young para os mats [a] Preparados com a utilização do coletor estático e [b] Preparados com a utilização do coletor rotativo. Estes materiais foram caracterizados tanto na direção preferencial de alinhamento das fibras [siglas contendo a terminação "dir" no final], quanto na direção oposta ao alinhamento preferencial das fibras [siglas contendo a terminação "op" no final). 165

Figura 69 - Alongamento na ruptura para os mats [a] Preparados com a utilização do coletor estático e [b] Preparados com a utilização do coletor rotativo. Estes materiais foram caracterizados tanto na direção preferencial de alinhamento das fibras [siglas contendo a terminação "dir" no final], quanto na direção oposta ao alinhamento preferencial das fibras [siglas contendo a terminação "op" no final). 


\section{Lista de Tabelas}

Tabela 1 - Composição das soluções em TFA, tipo de coletor utilizado e os respectivos códigos de referência dos mats.

Tabela 2 - Composição dos mats e seus respectivos códigos de referência. 89

Tabela 3 - Viscosidade dinâmica das soluções precursoras dos mats obtidos via eletrofiação.

Tabela 4 -Temperaturas características da decomposição térmica e correspondentes perdas de massa de PET ref, PETC/48 h, PETC/72 h, PETL/48 h, PETL/72 h, PETCL/48 h e PETCL/72 h.

Tabela 5 - $\mathrm{T}_{\mathrm{m}}, \Delta \mathrm{H}_{\mathrm{f}}$ e $\mathrm{I}_{\mathrm{c}}$ para PET ref, PETC/48 h, PETC/72 h, PETL/48 h, PETL/72 h, PETCL/48 h e PETCL/72 h.

Tabela 6 -Parâmetros de eletrofiação adotados e os respectivos códigos de referência dos mats preparados.

Tabela 7 - Composição dos mats preparados, tipo de coletor utilizado e os respectivos códigos de referência.

Tabela 8 - Temperaturas características da decomposição térmica e correspondentes perdas de massa dos mats $\mathrm{PET}_{\text {ref, }} \mathrm{PET} / \mathrm{OM}, \mathrm{PET} / \mathrm{CNC}$ e PET/OM/CNC.

Tabela 9 - $\mathrm{T}_{\mathrm{m}}, \Delta \mathrm{H}_{\mathrm{f}}$ e $\mathrm{I}_{\mathrm{c}}$ de PET ref, PET/OM, PET/CNC e PET/OM/CNC. 159 



\section{Lista de Abreviaturas, Siglas e Símbolos}

- PLA - Ácido poliláctico

- TFA - Ácido trifluoroacético

- PVA - Álcool polivinílico

- DMA - Análise Dinâmico-Mecânica [Dynamical Mechanical Analysis]

- ACA - Ângulo de contato de avanço

- $\quad$ AC - Ângulo de contato

- ABIPET - Associação Brasileira da Indústria do PET

- $\mathrm{KBr}$ - Brometo de potássio

- $\Delta \mathbf{H}_{\mathrm{t}}$ - Calor de fusão

- $\Delta \mathbf{H}_{\mathrm{f}}^{\circ}$ - Calor de fusão para o PET $100 \%$ cristalino

- DSC - Calorimetria Exploratória Diferencial [Differential Scanning Calorimetry]

- LiCl - Cloreto de lítio

- K - Constante viscosimétrica

- Ic - Cristalinidade

- $\rho_{\text {estera }}$ - Densidade da esfera

- $\rho_{\text {sourasa }}$ - Densidade da solução

- DCM - Diclorometano

- DMAC - N,N-Dimetilacetamida

- DMF - N,N-Dimetilformamida

- IV - Espectroscopia na região do Infravermelho

- $\varphi_{\omega}$ - Fraçãoem massa

- GP - Grau de Polimerização

- HFIP - Hexafluoroisopropanol

- $\mathrm{NaOH}-$ Hidróxido de sódio

- I.A. - Índice de alinhamento

- IDH - Índice de Desenvolvimento Humano

- MFI - Índice de fluidez [Melt Flow Index]

- $\gamma-\mathrm{Fe}_{2} \mathrm{O}_{3}$ - Maghemita

- MEV - Microscopia Eletrônica de Varredura

- E' - Módulo de armazenamento

- CNC - Nanocristal de celulose [Cellulose Nanocrysta]

- nHA - Nanohidroxiapatita

- OM - Óleo de mamona

- O.P.M. - Orientação preferencial média

- ISO - Organização Internacional de Normalização (International Organization for Standardization]

- NMMO - Óxido de N-metilmorfolina

- WL - Perda de massa [Weight loss]

- PCL - Policaprolactona

- PS - Poliestireno

- PES - Polietersulfona 
- PE - Polietileno

- PEG - Polietileno glicol

- PET - Poli [tereftalato de etileno]

- PVP - Polivinilpirrolidona

- $\mathbf{T}_{\mathrm{m}}$ - Temperatura de fusão cristalina

- $\mathbf{T}_{\mathrm{p}}$ - Temperatura de máxima taxa de perda de massa

- $\mathbf{T}_{\mathbf{g}}$ - Temperatura de transição vítrea

- $\mathbf{T}_{\text {onset }}$ - Temperatura onset

- $\mathbf{t}$ - Tempo de queda da esfera

- TG - Termogravimetria

- THF - Tetraidrofurano

- UAG - Unidade Anidroglicosídica

- UV - Ultravioleta

- $\quad \boldsymbol{\mu}$ - Viscosidade dinâmica 


\section{Sumário}

Contextualização da pesquisa desenvolvida ...................................................................... 27

Revisão Bibliográfica ......................................................................................................... 31

1. Fibra lignocelulósica de sisal .........................................................................

1.1 Principais constituintes da fibra .....................................................................................34



1.1.1.1 Nanocristais de celulose [CNCs]....................................................................35

1.1.2 Hemiceluloses [polioses] ..........................................................................................36

1.1.3 Lignina .................................................................................................................

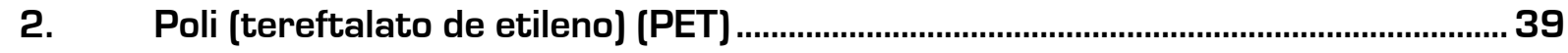

2.1 Reciclagem do PET .........................................................................................................40

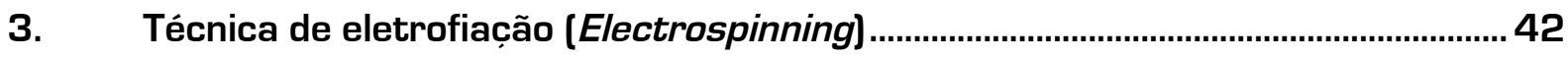

3.1 Definição de fibras ultrafinas e nanofibras .........................................................................43

3.2 Fundamentos da técnica de eletrofiação.........................................................................44

3.2.1 Preparação de fibras orientadas .................................................................................. 51

3.3 Eletrofiação aplicada à biomassa lignocelulósica .............................................................53

3.4 Eletrofiação aplicada a soluções baseadas em PET reciclado .......................................56

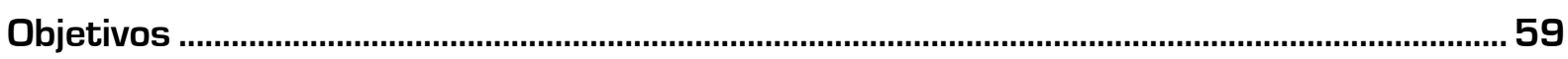

Apresentação/Estruturação do Trabalho …………………………………………….61

Capítulo 1. Materiais bio-baseados obtidos à partir da eletrofiação de soluções de fibra lignocelulósica de sisal e PET reciclado: fibras alinhadas e não alinhadas..........................63

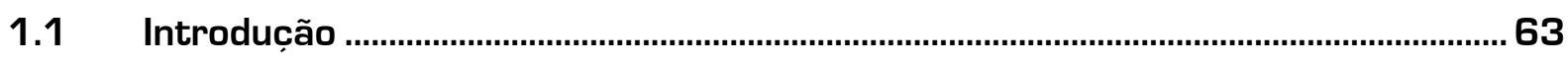

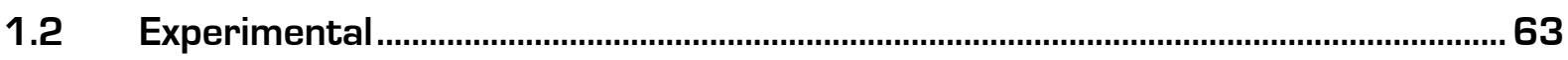

1.2.1 Materiais ...........................................................................................................................63

1.2.2 Métodos.............................................................................................................................. 64

1.2.2.1 Processo de eletrofiação...................................................................................64

1.2.2.2 Caracterização dos não-tecidos (mats]..........................................................66

1.2.2.2.1 Espectroscopia na região do Infravermelho (IV) ………........................66

1.2.2.2.2 Microscopia Eletrônica de Varredura (MEV] ………………………........67

1.2.2.2.3 Ângulo de contato (AC] .............................................................................67

1.2.2.2.4 Termogravimetria (TG] ….........................................................................67

1.2.2.2.5 Análise Dinâmico-Mecânica (DMA] .............................................................67 
1.3.1 Espectroscopia na região do Infravermelho [IV] .....................................................68

1.3.2 Microscopia Eletrônica de Varredura [MEV].................................................................69

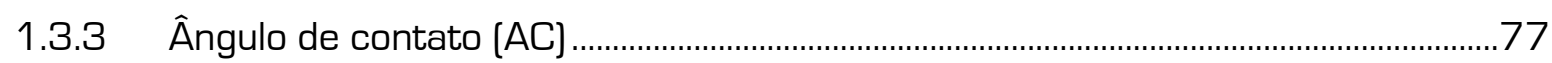

1.3.4 Termogravimetria [TG] ..............................................................................................

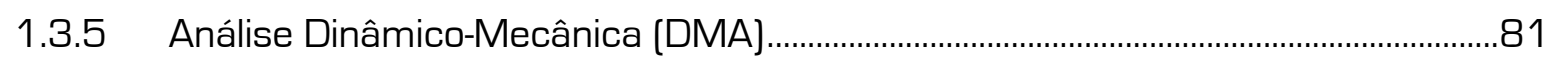

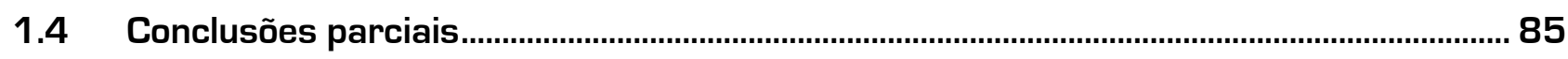

Capítulo 2. Materiais bio-baseados obtidos à partir da eletrofiação de soluc̣ões de

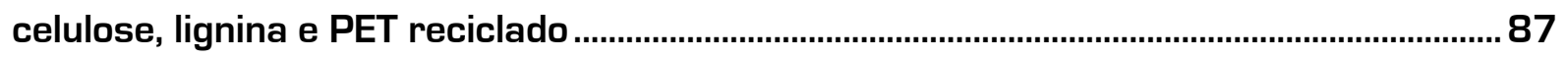

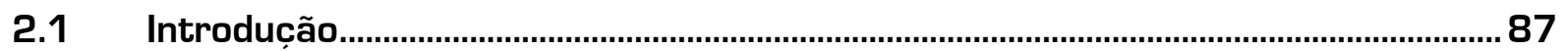

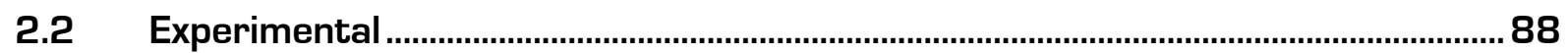

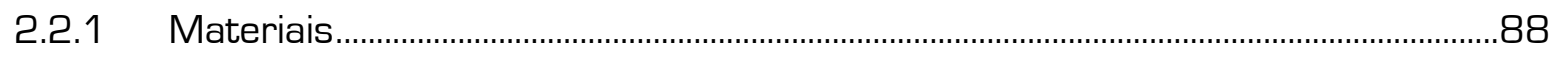

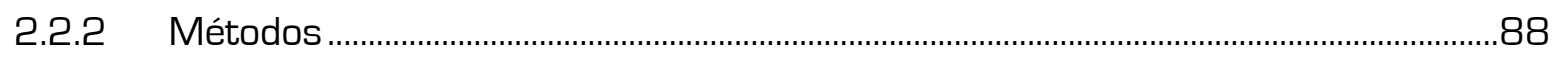

2.2.2.1 Determinação da viscosidade dinâmica das soluções .......................................... 88

2.2.2.2 Processo de eletrofiação ......................................................................................... 89

2.2.2.3 Caracterização dos não-tecidos [ mats] ............................................................. 90

2.2.2.3.1 Espectroscopia na região do Infravermelho (IV] .......................................... 90

2.2.2.3.2 Microscopia Eletrônica de Varredura (MEV]............................................. 91

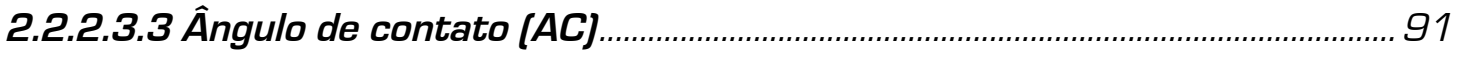

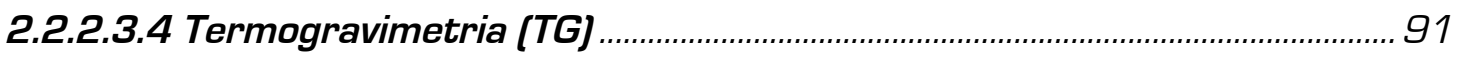

2.2.2.3.5Calorimetria Exploratória Diferencial [DSC].............................................. 91

2.2.2.3.6Análise Dinâmico-Mecânica [DMA]............................................................. 91

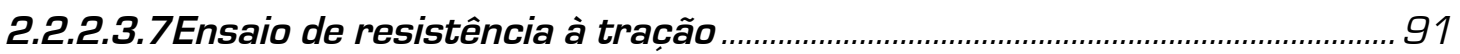

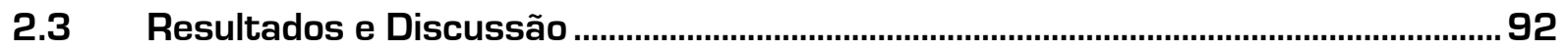

2.3.1 Espectroscopia na região do Infravermelho [IV] ......................................................92

2.3.2 Microscopia Eletrônica de Varredura [MEV]...............................................................93

2.3.3 Ângulo de contato [AC] ........................................................................................ 102

2.3.4 Termogravimetria [TG] ............................................................................................ 103

2.3.5 Calorimetria Exploratória Diferencial [DSC] ................................................................ 105



2.3.7 Ensaio de resistência à tração....................................................................................... 108



Capítulo 3. Eletrofiação de soluções preparadas a partir de celulose, lignina e PET reciclado visando a produção de mats com fibras alinhadas ............................................ 113

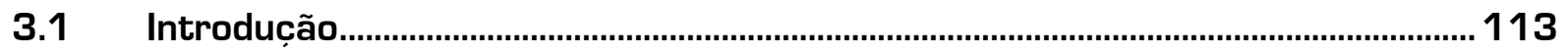

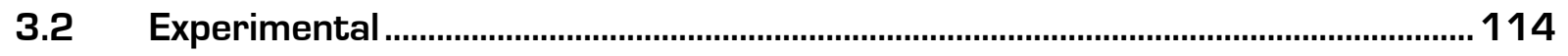

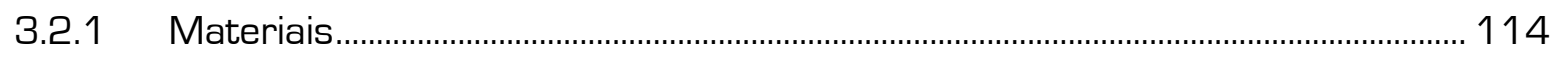

3.2.2 Métodos ........................................................................................................................ 114 
3.2.2.1 Processo de eletrofiação ........................................................................................114

3.2.2.2 Caracterização dos mats .................................................................................... 115

3.2.2.2.1Microscopia Eletrônica de Varredura (MEV] ............................................ 115

3.2.2.2.2Ângulo de contato [AC] ............................................................................ 115

3.2.2.2.3Análise Dinâmico-Mecânica [DMA].................................................................. 115

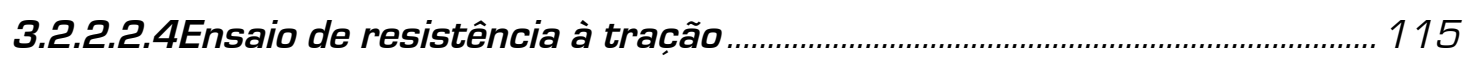

3.3 Resultados e Discussão ...................................................................................... 115

3.3.1 Microscopia Eletrônica de Varredura [MEV].............................................................115

3.3.2 Ângulo de contato [AC] ...........................................................................................125

3.3.3 Análise Dinâmico-Mecânica [DMA]...............................................................................128

3.3.4 Ensaio de resistência à tração..................................................................................133

3.4 Conclusões parciais................................................................................................143

Capítulo 4. Preparação via eletrofiação de materiais baseados em PET reciclado, CNCs e OM: fibras alinhadas e não alinhadas ............................................................................. 145



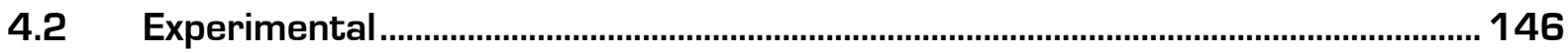

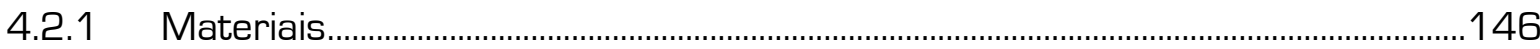

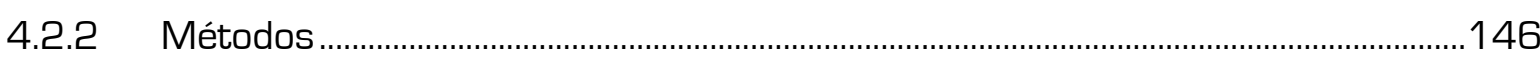

4.2.2.1 Processo de eletrofiação .................................................................................... 146

4.2.2.2 Caracterização dos mats .................................................................................... 148

4.2.2.2.1Espectroscopia na região do Infravermelho (IV]..................................... 148

4.2.2.2.2Microscopia Eletrônica de Varredura (MEV].......................................... 148

4.2.2.2.3Ângulo de contato [AC] .......................................................................... 148

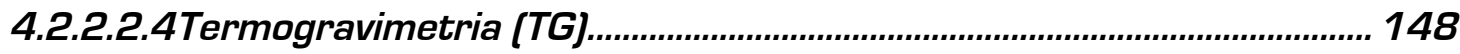

4.2.2.2.5Calorimetria Exploratória Diferencial [DSC] ........................................... 142

4.2.2.2.6Análise Dinâmico-Mecânica [DMA]............................................................. 148

4.2.2.2.7Ensaio de resistência à tração..................................................................... 148

4.3 Resultados e Discussão ........................................................................................... 148

4.3.1 Espectroscopia na região do Infravermelho [IV]....................................................148

4.3.2 Microscopia Eletrônica de Varredura [MEV]............................................................149

4.3.3 Ângulo de contato [AC] ....................................................................................156

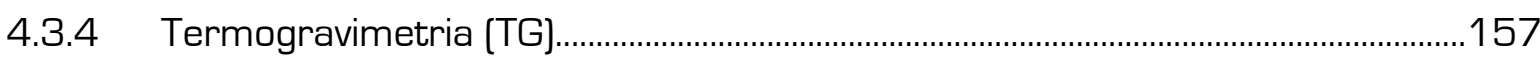

4.3.5 Calorimetria Exploratória Diferencial (DSC)..............................................................158

4.3.6 Análise Dinâmico-Mecânica [DMA]..............................................................................160

4.3.7 Ensaio de resistência à tração................................................................................163

4.4 Conclusões parciais..........................................................................................................168 
Conclusões gerais

Referências Bibliográficas. 


\section{Contextualização da pesquisa desenvolvida}

Consideráveis esforços vêm sendo empregados na preparação e utilização de materiais poliméricos bio-baseados ["bio-based"], como os obtidos através de fontes renováveis/naturais, em substituição ao uso de materiais sintéticos oriundos de fontes petroquímicas (BARONCINI et al., 2016; RODRIGUES et al., 2015; SANTOS et al., 2015). Neste contexto, destaca-se a utilização de materiais lignocelulósicos, como as fibras de sisal, por exemplo, por serem de origem renovável e apresentarem propriedades como biodegradabilidade, elevada disponibilidade [o Brasil é o maior produtor e exportador mundial de sisal'] e notáveis propriedades físico-mecânicas [THAKUR; THAKUR, 2014].

A preparação e utilização de materiais baseados em poli [tereftalato de etileno] [PET] reciclado também desperta crescente interesse. O PET reciclado vem sendo cada vez mais utilizado visando a maximização da exploração do resíduo sólido urbano, com a produção de materiais com favoráveis propriedades e custos [DE OLIVEIRA SANTOS et al., 2014].

O presente trabalho se insere em um amplo projeto que iniciou com a preparação e caracterização de macro-compósitos baseados em PET reciclado e fibras de sisal [DE OLIVEIRA SANTOS et al., 2014]. Neste estudo, buscou-se avaliar não somente a ação da fibra de sisal como agente de reforço da matriz de PET, mas também a utilização de plasticizantes e agentes compatibilizantes naturais, como o óleo de mamona [OM], visando à melhoria das interações entre a fibra lignocelulósica e a matriz polimérica [DE OLIVEIRA SANTOS et al., 2014].

0 projeto teve continuidade com a preparação de materiais, além da escala macrométrica, também na submicrométrica e nanométrica, a partir dos componentes isolados da fibra lignocelulósica [como a celulose, também na forma de nanocristais, e a macromolécula de lignina], em combinação com o PET reciclado. Assim, teve-se como objetivo a busca de aplicações diversificadas para o PET reciclado e fibras lignocelulósicas, e que possam thes conferir um maior valor agregado.

Dentre as diversas técnicas para a produção de materiais tanto na escala submicrométrica quanto na nanométrica, a técnica de eletrofiação apresenta grande destaque, por se tratar de uma técnica relativamente simples e que permite a preparação de fibras

\footnotetext{
'Disponivel em http://www.conab.gov.br/OlalaCMS/uploads/arquivos/16_02_04_11_15_32_sisal_conjuntura_esp ecial_retrospectiva_2015-1.pdf, acesso em 06/04/17.
} 
contínuas, com diâmetros variando da ordem de micrômetros até alguns nanômetros [CHENG et al., 2017; NGADIMAN et al., 2013]. Contudo, poucos trabalhos têm sido publicados relatando a eletrofiação da biomassa lignocelulósica. A maioria destes trabalhos tem usado, no preparo das soluções a serem submetidas ao processo de eletrofiação, o sistema de solventes líquido iônico/ $N, N$-Dimetilformamida [DMF] e fibras lignocelulósicas pós-tratamento alcalino, com o objetivo de eliminar os constituintes da fibra como a lignina e hemiceluloses (AHN et al., 2012; KANG et al., 2013).

No grupo de pesquisa onde o presente trabalho foi desenvolvido, Grupo de Materiais Macromoleculares e Fibras Lignocelulósicas [MacromoLignocell] buscou-se um solvente alternativo ao uso de líquido iônico/DMF para a dissolução de fibras lignocelulósicas, no caso a fibra de sisal, sem a necessidade de um pré-tratamento das mesmas. Neste estudo, Rodrigues et al. [2015] demonstraram com sucesso que a técnica de eletrofiação pode ser aplicada a soluções baseadas na fibra de sisal nativa, com a utilização de ácido trifluoroacético [TFA] como solvente. Os principais componentes da fibra lignocelulósica nativa foram separados, devido à dissolução em TFA, com subsequente reconstrução das fibras na escala sub-micrométrica [fibras ultrafinas) e nanométrica, via técnica de eletrofiação.

Materiais preparados a partir de PET, via eletrofiação, tendem a possuir um elevado caráter hidrofóbico, devido à baixa energia de superfície [LI et al., 2013), assim como inferiores propriedades mecânicas. Esse caráter hidrofóbico do PET pode limitar sua utilização em certas aplicações, como em sistemas biológicos. Nestes sistemas a membrana hidrofóbica de PET pode exibir uma menor resistência ao fenômeno de incrustação [deposição de soluções ou partículas na superfície e/ou poros da membrana, comprometendo negativamente a performance da mesma], em comparação a membranas de caráter hidrofílico [DONG et al., 2007). Assim, um aumento da hidrofilicidade de membranas de PET pode representar um eficiente método para atenuar, por exemplo, essa susceptibilidade ao fenômeno de incrustação de membranas [ZHANG et al., 2011).

Com base nos projetos que foram e vêm sendo realizados pelo grupo de pesquisa em que o presente trabalho se insere, levando-se em consideração também a necessidade de aplicações diversificadas para o PET reciclado, assim como um aumento da hidrofilicidade do mesmo, foram preparados não- tecidos (ou mats, como serão a partir daqui chamados] via eletrofiação de soluções de fibra de sisal e PET reciclado (utilizando-se como solvente o TFA]. 0 presente estudo, até onde se sabe, foi pioneiro na combinação de biomassa lignocelulósica e polímero reciclado, como o PET, para a produção de materiais híbridos contendo fibras na escala sub-micrométrica e nanométrica. Ainda, foram preparados mats baseados em PET reciclado, combinados ou não com fibras lignocelulósicas de sisal, buscando-se a produção de fibras orientadas e a avaliação da influência da orientação das fibras nas propriedades finais 
dos materiais, como nas propriedades termo-mecânicas e na porosidade/hidrofilicidade dos mesmos.

No presente trabalho a celulose e a lignina, principais constituintes da fibra lignocelulósica, foram utilizados como materiais de partida para a preparação, via eletrofiação, de nanofibras [fibras com espessura $\leq 100 \mathrm{~nm}$ ]/fibras ultrafinas [fibras com espessuras no intervalo de $100 \mathrm{~nm}$ a $1000 \mathrm{~nm}$ ) baseadas em PET reciclado. Este estudo, até onde se sabe, também foi pioneiro na avaliação da contribuição conjunta e separada de dois dos principais constituintes da fibra lignocelulósica de sisal nas propriedades finais dos mats preparados. Também foram preparados mats baseados em PET reciclado/celulose/lignina buscando-se a obtenção de fibras orientadas e a avaliação, novamente, da influência da orientação das fibras em propriedades como as termo-mecânicas, por exemplo.

Ainda, no presente trabalho foram preparados mats baseados em PET reciclado e nanocristais de celulose [Cellulose Nanocrystals, CNCs], com o objetivo de avaliar a contribuição da celulose, em sua forma nanocristalina, nas propriedades finais dos materiais produzidos. Adicionalmente, visando uma maior interação entre os nanocristais de celulose e o polímero reciclado, foi utilizado o $\mathrm{OM}$, buscando-se avaliar a possível ação do mesmo como agente compatibilizante. $\mathrm{O} \mathrm{OM}$, por possuir domínios polares e apolares em sua estrutura química, pode viabilizar interações atrativas com grupos presentes tanto na estrutura da celulose, como no PET. Também foram preparados mats de PET reciclado/nanocristais de celulose buscando-se a obtenção de fibras orientadas, assim como a avaliação da influência da orientação das mesmas nas propriedades finais dos materiais produzidos. 


\section{Revisão Bibliográfica}

\section{Fibra lignocelulósica de sisal}

O sisal [Figura 1] pertence à família Agavaceae, subfamília Agavoidea, gênero Agave e espécie Agave sisalana. Esta planta apresenta sistema radicular fibroso e em forma de tufo. A planta de sisal não possui caule, suas folhas são destituídas de pecíolos [haste delgada na qual as folhas se ligam ao caule] e pode chegar a aproximadamente dois metros de altura. No Brasil, a espécie cultivada e de maior utilização para fins comerciais da fibra é a Agave sisalana.

Figura 1 - Planta de sisal.

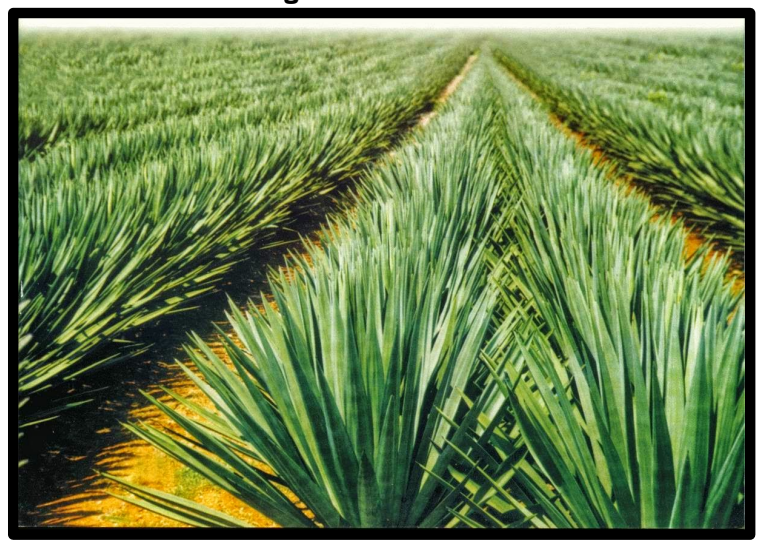

Fonte: http://www.brasilagricola.com/2015/04/cultivo-do-sisal-no-brasil.html.

O Brasil é isoladamente o maior produtor mundial de sisal, seguido pela Tanzânia e o Quênia. Em 2015 o Brasil produziu aproximadamente 90.000 ton de fibra de sisal [Figura 2], o que representou um aumento de mais de 50\% na produção com relação ao ano de 2012. Ainda, o Brasil exportou em 2015 aproximadamente 65.000 ton de fibra de sisal, aproximadamente 10\% a menos do que foi exportado no ano de 2012 [Figura 2). ${ }^{2}$

\footnotetext{
${ }^{2}$ Disponível em http://www.londonsisalassociation.org/brazilian-sisal-fibre.php, acesso em 21/12/16.
} 
Figura 2 - Produção e exportação de sisal no Brasil.



Fonte: Adaptação de http:/ / www.londonsisalassociation.org/brazilian-sisal-fibre.php.

Por se tratar de uma das principais fibras duras [fibra vegetal fiável e que possui elevada resistência mecânica e resiliência] produzida no mundo, a produção de sisal corresponde a 70\% da produção comercial de todas as fibras desse tipo. No Brasil, a fibra de sisal rende cerca de oitenta milhões em divisas além de gerar mais de meio milhão de empregos na sua cadeia de serviços. A Bahia é responsável por 96\% da produção de fibra nacional, em segundo lugar está Pernambuco, seguido da Paraíba, Rio Grande do Norte e Ceará [SANTOS, 2012]. A receita cambial gerada pela cultura do sisal fez ingressar em 2015 mais de $\mathrm{R} \$ 400$ milhões na economia do Território do Sisal [área de 21.256,50 $\mathrm{Km}^{2}$ que compreende 20 municípios no estado da Bahia]. Assim, ao se considerar o volume transacionado no mercado interno, que foi estimado em $\mathrm{R} \$ 80$ milhões, observase que o valor bruto da produção da cadeia do sisal atingiu aproximadamente $R \$ 500$ milhões.

\footnotetext{
${ }^{1}$ Disponível em

http://www.conab.gov.br/OlalaCMS/uploads/arquivos/16_02_04_11_15_32_sisal_conjuntura_esp ecial_retrospectiva_2015-1.pdf, acesso em 21/12/16.
} 
A cultura do sisal possui grande relevância socioeconômica e ambiental para os municípios que compõem o Território do Sisal. Este território é considerado a região mais pobre do estado da Bahia, com um Índice de Desenvolvimento Humano (IDH) médio de 0,589. A agaveicultura concentra-se em áreas de pequenos produtores, com predomínio do trabalho familiar, assim a cultura do sisal proporciona a maior geração de empregos e renda da região. ${ }^{2}$

O sisal, devido à sua facilidade de cultivo e tempo para extração em torno de 9 meses, é uma das principais fibras naturais utilizadas. A fibra lignocelulósica de sisal é composta por celulose, hemiceluloses [polioses] e lignina, também podem estar presentes em sua composição pequena porcentagem de proteínas, lipídeos, como gorduras e ceras, e cinzas. A proporção relativa de celulose, hemiceluloses e lignina correlaciona-se intimamente com o tipo de espécie e características de plantio tais como solo, umidade e clima [REDDY; YANG, 2005].

A estrutura da fibra lignocelulósica de sisal da escala macrométrica até a nanométrica, bem como seus principais constituintes, está representada esquematicamente na Figura $\mathbf{3}$.

Figura 3 - Representação da estrutura da fibra lignocelulósica de sisal e seus principais componentes.

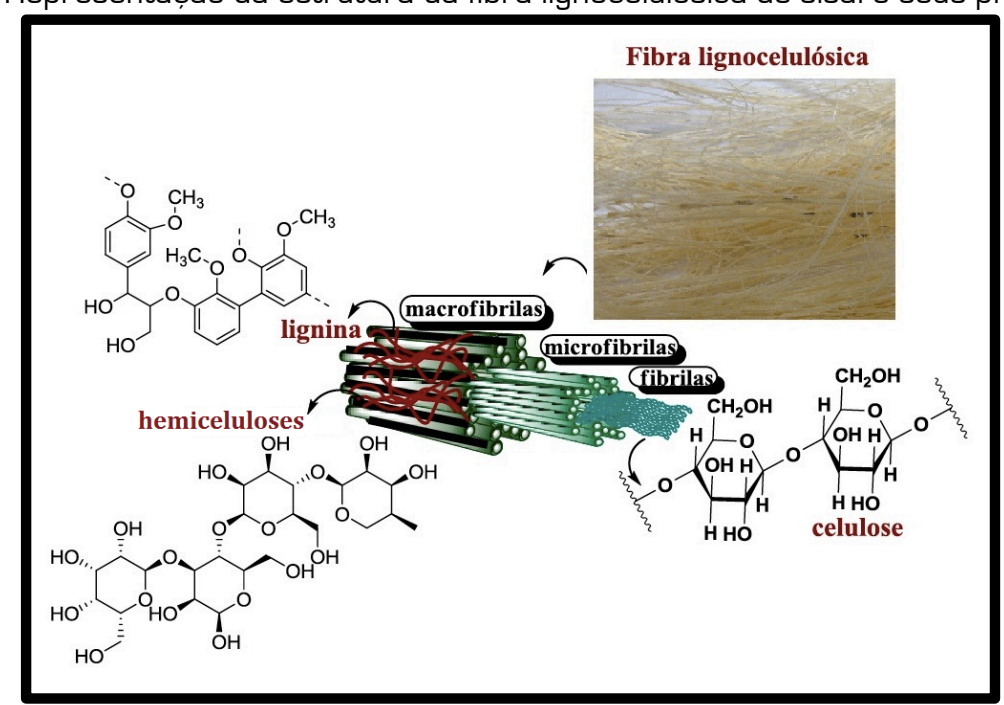

Fonte: Adaptação de Rodrigues [2014] a partir de Santos [2012].

Destaca-se que a celulose é o componente mais abundante na parede celular do sisal, após vem as hemiceluloses e finalmente a lignina. Estes componentes serão discutidos mais detalhadamente nas próximas seções.

No presente trabalho foi utilizada a fibra lignocelulósica de sisal visando a valorização da mesma. Este material foi utilizado também devido a outros fatores, como seu curto ciclo crescimento e elevado teor de celulose [aproximadamente 65\% [DE OLIVEIRA SANTOS et al., 2014]], o que faz com que a fibra de sisal seja um excelente agente de reforço em compósitos poliméricos, por exemplo [DE OLIVEIRA et

\footnotetext{
${ }^{2}$ Disponível em http://www.londonsisalassociation.org/brazilian-sisal-fibre.php, acesso em 21/12/16.
} 
al., 2017; DE OLIVEIRA SANTOS et al., 2014). Ainda, outro fator estimulante para o uso dessa fibra foi, como anteriormente mencionado, o Brasil ser o maior produtor mundial de sisal, no entanto aproximadamente 70\% [somente no ano de 2015] da produção interna de fibra foi exportada.

\subsection{Principais constituintes da fibra}

\subsubsection{Celulose}

A Celulose é o mais importante componente estrutural de plantas, sendo uma fonte inesgotável de matéria-prima para a crescente demanda por produtos biocompatíveis. Este polímero orgânico [mais abundante no mundo] representa aproximadamente 1.5 trilhões de toneladas do total de biomassa produzida anualmente [KIM et al., 2015].

Composta por uma cadeia linear de moléculas de glicose aneladas, com conformação do tipo fita-plana (MOON et al., 2011), a cadeia de celulose [Figura 4] possui como unidade de repetição [Unidade Anidroglicosídica [UAG]] dois anéis de anidroglicose $\left[\left[\mathrm{C}_{6} \mathrm{H}_{12} \mathrm{O}_{6}\right]_{n}\right.$, sendo $n$ dependente da fonte de obtenção da celulose]. Ainda, os anéis de anidroglicose são unidos via ligação glicosídica $\beta$ - $(1 \rightarrow 4$ ] [ligação covalente de um átomo de oxigênio entre o carbono C1 de um anel de glicose e o carbono C4 de um anel adjacente [ligação 1-4)] (AZIZI SAMIR; ALLOIN; DUFRESNE, 2005).

Figura 4 - Estrutura da celulose.

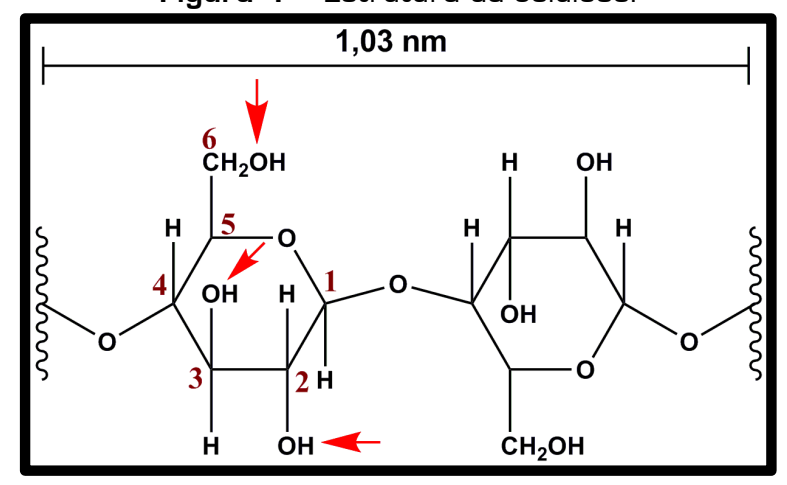

Fonte: Adaptação de Rodrigues [2014].

A configuração linear da cadeia de celulose deve-se à estabilização das ligações via ligação hidrogênio intramolecular [Figura 5], entre os grupos hidroxilas e os oxigênios dos anéis adjacentes. Assim, a celulose é considerada um polímero relativamente estável, pois a rede de ligações intra e intermoleculares de hidrogênio (Figura 5) confere uma alta rigidez axial às fibrilas desse polissacarídeo [TASHIRO; KOBAYASHI, 1991]. 
Figura 5 - Representação esquemática das ligações hidrogênio intermoleculares e intramoleculares.

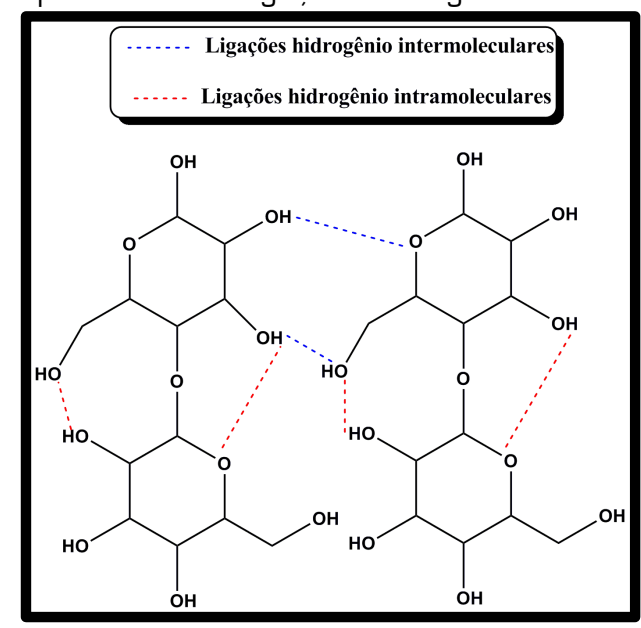

Fonte: Autoria própria.

No presente trabalho, celulose de sisal foi utilizada como material de partida para a produção de mats baseados em PET reciclado, visando avaliar a influência desse polissacarídeo nas propriedades finais dos materiais contendo polímero reciclado.

\subsubsection{Nanocristais de celulose [CNCs]}

A celulose em sua forma nativa apresenta regiões não-cristalinas e cristalinas, sendo ambas passíveis de serem isoladas para a produção de CNCs [Figura 6], via controlado processo de hidrólise ácida. Os CNCs são nanomateriais, com formato de haste ou "whisker" ["bigode"], baseados nesse polissacarídeo e que podem ser isolados de matérias-primas celulósicas de forma fácil e eficiente (WANASEKARA et al., 2016). Esses nanomateriais podem ser definidos como uma forma fibrosa de celulose, com alto grau de cristalinidade, produzidos via hidrólise ácida de plantas e animais que contenham esse polissacarídeo em suas composições, apresentando espessuras no intervalo de $3-5 \mathrm{~nm}$ e comprimento na faixa de 50-500 nm [ELAZZOUZI-HAFRAOUl et al., 2008]. 
Figura 6 - Representação esquemática dos CNCs.

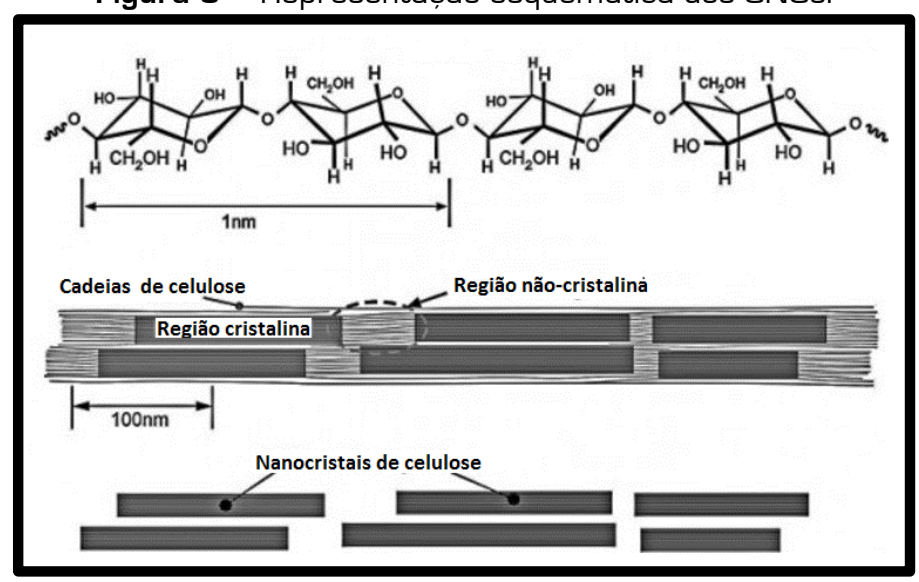

Fonte: Adaptação de

http:// www.thecambodiaherald.com/science/detail/4?page=23\&token=MzFh NjczZWQwMmYyMWM3Yzlh.

Assim, os CNCs podem ser produzidos via hidrólise ácida, ou também hidrólise enzimática, de vários materiais, tais como polpa celulósica de tunicados [YU et al., 2016], algodão (PEDDIREDDY et al., 2016) e de sisal (MARIANO; CERCENÁ; SOLDI, 2016). As dimensões do produto final dependerão fortemente da fonte de material celulósico precursora [EICHHORN, 2011]. Ainda, CNCs apresentam grande potencial como agentes de reforço de materiais poliméricos devido a propriedades como elevada razão de aspecto [relação entre comprimento e largura], elevado módulo elástico (em torno de 120-150 GPa) e excelentes propriedades térmicas e químicas [VALLEJOS; PERESIN; ROJAS, 2012).

No presente trabalho foram utilizados CNCs, obtidos comercialmente, visando avaliar a possivel atuação dos mesmos como agentes de reforço de fibras nanométricas/ultrafinas de PET reciclado.

\subsubsection{Hemiceluloses [polioses]}

As hemiceluloses são polissacarídeos e correspondem ao segundo componente majoritário de fibras lignocelulósicas. Presentes na parede celular de plantas, esse polissacarídeo, juntamente com a celulose e a lignina, contribui significativamente para a rigidez da mesma [RODRIGUES, 2014]. As hemiceluloses, diferentemente da celulose, são macromoléculas heterogêneas compostos por pentoses [xilose e arabinose], hexoses [manose, glucose e galactose] e ácidos derivados de açúcares [TATAR et al., 2014].

A xilose é o principal constituinte da massa hemicelulósica em plantas lignocelulósicas [com o teor variando entre 25-35\%] [EBRINGEROVÁ; HEINZE, 2000), sendo que as hemiceluloses representam aproximadamente $20-30 \%$ de toda a biomassa encontrada na natureza [BÖRJESSON; WESTMAN, 2016]. As xiloses, principais hemiceluloses encontradas em plantas como o sisal, possuem uma estrutura linear de resíduos de $\beta$-1,4-D-xilanopiranose ligados, podendo conter como ramificações grupos 
acetila, arabinosila e glicoronosila, dependendo da fonte botânica [SPIRIDON; POPA, 2008). A Figura 7 apresenta as estruturas químicas das unidades de açúcares presentes nas hemiceluloses.

Figura 7 - Estruturas químicas das unidades de açúcares presentes nas hemiceluloses.



Recentemente, hemiceluloses têm atraído especial atenção devido ao seu grande potencial como matérias-primas para a produção de álcool combustivel (WANG et al., 2017). Ainda, como outras aplicações, esses polissacarídeos também são utilizados nas indústrias de embalagens (EBRINGEROVÁ; HEINZE, 2000), indústria alimentícia [BOUAZIZ et al., 2016] e para fins biomédicos [ZHANG; XIE; GAN, 2005].

\subsubsection{Lignina}

A macromolécula de lignina está entre as matérias-primas naturais mais abundantes no planeta, perdendo apenas para a celulose. Na parede celular a lignina ligase a biopolímeros como a celulose e hemiceluloses, mantendo os mesmos coesos, e atua como uma espécie de barreira para a umidade e enzimas, por exemplo, impedindo a entrada dos mesmos na estrutura lignocelulósica (FEOFILOVA; MYSYAKINA, 2016; SEN; PATIL; ARGYROPOULOS, 2015]. Ainda, a lignina é biodegradável, representa aproximadamente 30\% do carbono orgânico em toda a biosfera (RODRIGUES, 2014], 
absorve a radiação ultravioleta [UV] da luz solar (PENG; LIU; CAO, 2015) e pode ser encontrada como um subproduto da indústria de papel, estando disponível em grande quantidade e a um baixo custo [DA SILVA et al., 2013].

A lignina, enquanto macromolécula, apresenta estrutura complexa e pode ser sintetizada por reações combinadas de acoplamento fenólico, induzidas por radicais livres que são enzimaticamente gerados. Neste mecanismo de polimerização em cadeia clássico, três lignóis [Figura 8) agem como monômeros em reações com o radical em crescimento [RODRIGUES, 2014].

Figura 8 - Álcoois precursores nas reações de formação da macromolécula de lignina.

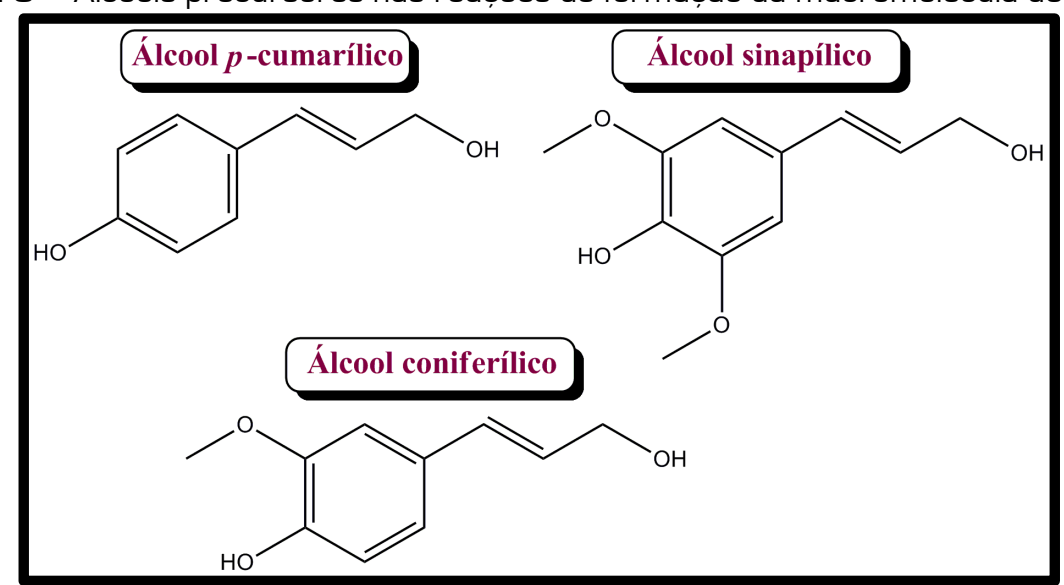

Fonte: Autoria própria.

Há uma grande diversidade de macromoléculas de lignina que podem ser formadas, devido ao elevado número de possíveis sequências durante o curso de reação. Assim, como exemplo, podemos utilizar o conceito estrutural de lignina de faia (Figura 9] proposto por Nimz (1974). 
Figura 9 - Conceito estrutural de lignina de faia.

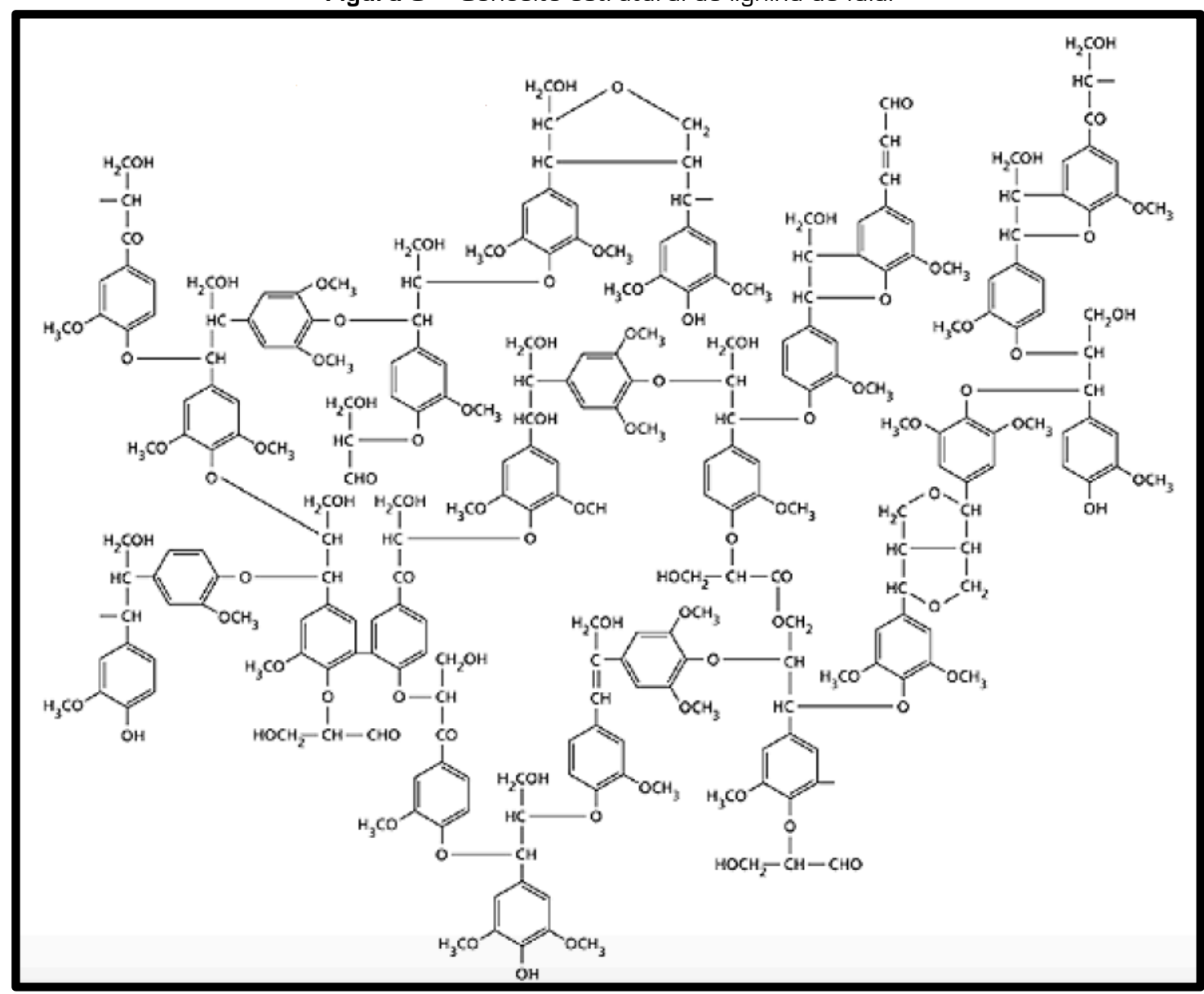

Fonte: Nimz [1974].

No presente trabalho foram utilizadas como matérias-primas para a preparação de mats de PET reciclado, via eletrofiação, a fibra lignocelulósica de sisal, a polpa celulósica de sisal, como mencionado anteriormente, e a lignina obtida via processo Organosolv do bagaço de cana de açúcar. Este processo consiste na separação da lignina da biomassa lignocelulósica com a utilização de solventes orgânicos, como etanol ou uma mistura deste com água, fazendo-se uso de condições mais brandas de reação [SCHMETZ et al., 2016; SINGH; DHEPE, 2016].

\section{Poli [tereftalato de etileno] (PET)}

O PET é um poliéster que apresenta em sua cadeia, além de anéis benzênicos, grupos ésteres [R-CO-O-R']. A cadeia alifática [cadeia aberta e não cíclica] e o oxigênio na cadeia principal de sua estrutura química [Figura 10) conferem a esse polímero flexibilidade, a temperaturas acima de sua transição vítrea. No entanto, o grupo benzênico presente na estrutura do PET confere a esse polímero rigidez e elevada estabilidade hidrolítica [SANTOS, 2012]. 
Figura 10 - Fórmula estrutural do PET.



Fonte: Autoria própria.

O PET apresenta massa molar ponderal média variável [com valores na faixa de 15.000-45.000 $\mathrm{g} \mathrm{mol}^{1}$ ] e sua densidade é de aproximadamente 1,38 $\mathrm{g} \mathrm{cm}^{3}$. Esse polímero também apresenta uma extensa faixa de porcentagens de cristalinidade [devido a variações no processo de cristalização do PET], que possibilitam variações significativas nas propriedades mecânicas do mesmo. Ainda, o PET apresenta temperatura de transição vítrea $\left[T_{9}\right]$ de aproximadamente $75{ }^{\circ} \mathrm{C}$ e temperatura de fusão cristalina $\left[T_{m}\right]$ em torno de $265^{\circ} \mathrm{C}$ (ISOLDI, 2003; SANTOS, 2012).

A transparência no estado não cristalino e a baixa permeabilidade a gases [principalmente $\mathrm{O}_{2}$ e $\mathrm{CO}_{2}$ ] tornaram o PET matéria-prima importante para a indústria de embalagens, principalmente de garrafas de refrigerantes (BILLMEYER JR., 1995). Em 2014, somente no Brasil, foram produzidos aproximadamente 610 kton de PET. ${ }^{3}$

\subsection{Reciclagem do PET}

A reciclagem do PET tem despertado cada vez mais atenção, impulsionada pelas pressões da sociedade como um todo em reduzir o volume de resíduos urbanos gerados, gerenciar de forma mais eficiente os mesmos e consequentemente diminuir problemas ambientais advindos da falta de gerenciamento, como a poluição. Os produtos baseados em PET apresentam, em condições naturais, lenta taxa de decomposição [cerca de 300 anos], assim, os processos de reciclagem representam uma forma econômica e viável de reduzir os resíduos baseados nesse polímero (DEL MAR CASTRO LÓPEZ et al., 2014;

\section{KHOONKARI et al., 2015].}

Com relação ao processo de reciclagem, este pode ser classificado em quatro categorias distintas: primária, secundária, terciária e quaternária. As reciclagens primária e secundária são conhecidas como reciclagem mecânica, mas o que diferencia uma da outra é que, na primária, polímeros pré-consumo são utilizados, já na secundária são usados polímeros pós-consumo. A reciclagem terciária denomina-se também reciclagem química, já a quaternária é a reciclagem energética. No Brasil, de acordo com Associação Brasileira da Indústria do PET [ABIPET], o principal tipo de reciclagem empregado é a reciclagem mecânica e, no presente trabalho, o PET reciclado utilizado foi gerado via esse tipo de reciclagem. Assim, o presente trabalho abordará o tema reciclagem com foco na

\footnotetext{
${ }^{3}$ Disponivel em http://www.abipet.org.br/index.html?method=mostrarDownloads\&categoria.id=3, acesso em 06/04/17.
} 
reciclagem mecânica do PET pós-consumo.

De acordo com a 10ª Edição do Censo da Reciclagem do PET no Brasil realizado pela ABIPET, o PET reciclado é principalmente utilizado como matéria-prima nas indústrias produtoras de resinas insaturadas e alquídicas [Figura 11]. ${ }^{3}$

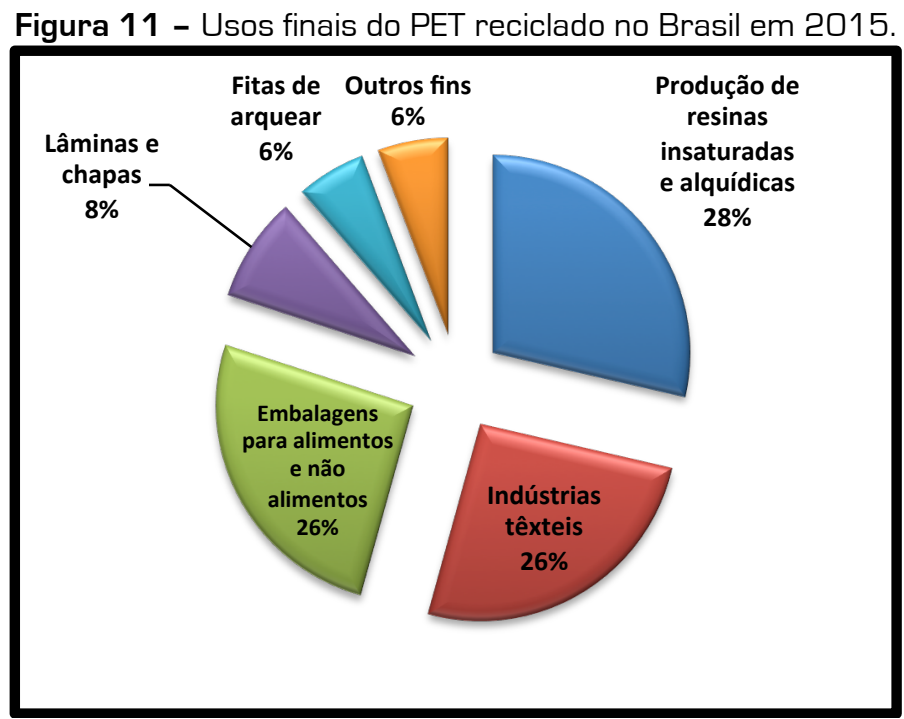

Fonte: http://www.abipet.org.br.

Ainda, segundo a 10 $10^{\mathrm{a}}$ Edição do Censo da Reciclagem do PET no Brasil, a crise econômica que intensificou em 2015 afetou importantes setores como o têxtil, químico, automotivo e de transportes. Estes setores apresentaram quedas de quase $50 \%$ em suas atividades, refletindo negativamente sobre a reciclagem do PET, pois são os grandes consumidores dessa matéria-prima reciclada. Assim, houve uma queda na quantidade reciclada de PET e a taxa de reciclagem em 2015 correspondeu a 51\% (Figura 12).

\footnotetext{
${ }^{3}$ Disponivel em http://www.abipet.org.br/index.html?method=mostrarDownloads\&categoria.id=3, acesso em 06/04/17.
} 
Figura 12 - Evolução da reciclagem do PET no Brasil.

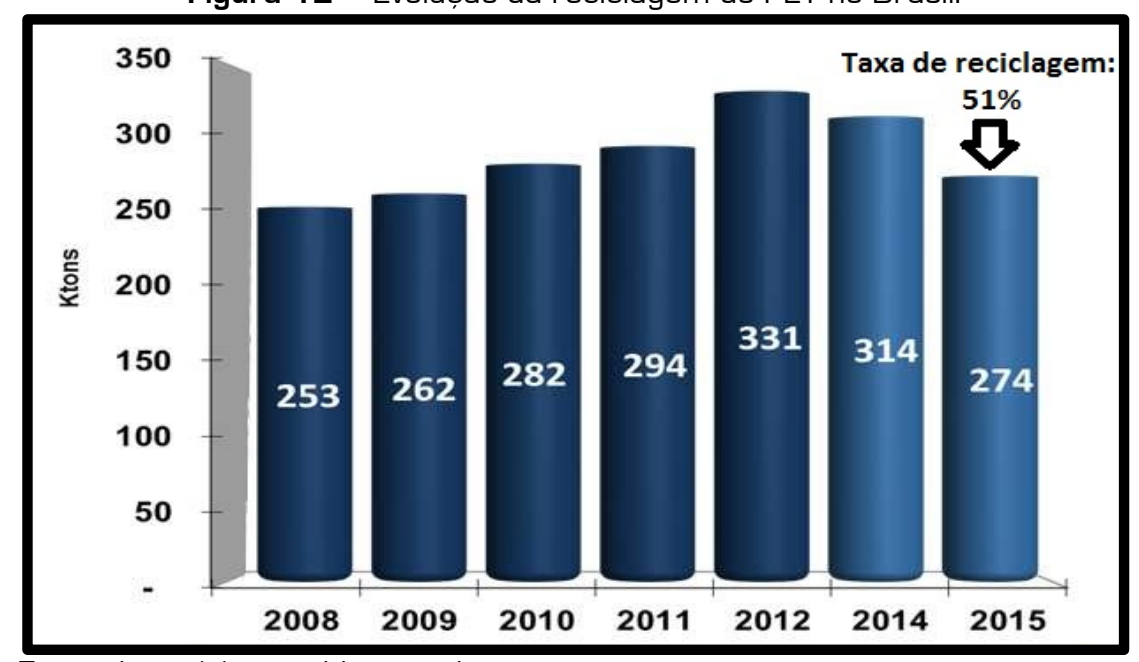

Fonte: http://www.abipet.org.br.

No presente estudo o PET reciclado mecanicamente foi usado para a produção de mats, via técnica de eletrofiação, visando uma aplicação que apresente maior valor agregado para esse polímero reciclado.

\section{Técnica de eletrofiação [Electrospinning]}

0 acelerado desenvolvimento de materiais na escala nano tem despertado grande atenção devido à possibilidade de obtenção de materiais com excelentes propriedades, os quais podem possuir propriedades mecânicas superiores [EZATPOUR et al., 2014], elevada área superficial [PENG et al., 2016] e uma grande variedade de propriedades/funcionalidades superficiais [RIVERO et al., 2015).

Ao longo dos últimos anos, muitas investigações têm levado à utilização de nanomateriais fibrosos, os quais muitas vezes são multifuncionais, em uma vasta gama de aplicações, tais como no setor eletrônico [em supercapacitores] (LIU et al., 2017), no setor energético [em células de combustíveis e armazenamento de hidrogênio] [PENG et al., 2016], no setor biológico/médico [na engenharia de tecidos, dispositivos médicos e próteses neurológicas] [GABRIEL et al., 2017] e em outros setores como o de biotecnologia [para aplicações como membranas de filtração, por exemplo] [BAE; BAEK; CHOI, 2016].

Dentre as várias técnicas utilizadas para a produção de fibras poliméricas em escalas sub-micrométricas e nanométricas, pode-se destacar a eletrofiação, uma técnica relativamente simples e versátil, que possibilita a preparação de fibras contínuas com diâmetros variando da ordem de micrômetros até alguns nanômetros. A Figura 13 apresenta como exemplo de relevância do uso da técnica de eletrofiação, o crescente número de trabalhos publicados e indexados na base de dados SCOPUS envolvendo a palavra-chave "Electrospinning", no período entre os anos 2000 a Dezembro de 2016. 
Figura 13 - Número de trabalhos publicados e indexados na base de dados SCOPUS envolvendo a palavrachave "Electrospinning" no período de 2000 a Dezembro de 2016.

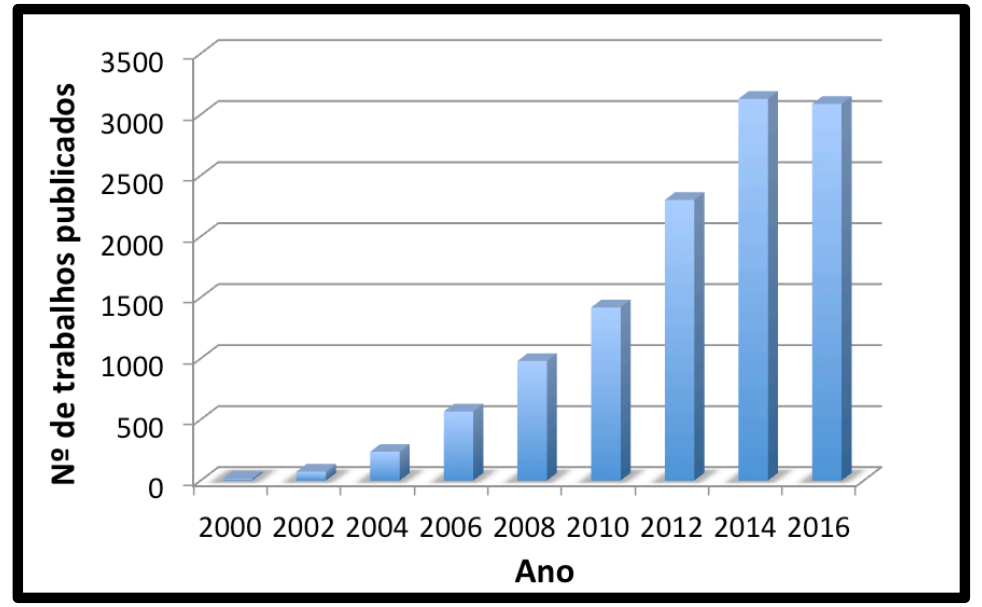

Fonte: Autoria própria.

A Figura 13 mostra que no intervalo entre os anos 2000 a Dezembro de 2016, houve um crescimento de 16 para 3000 trabalhos publicados e indexados na base de dados SCOPUS envolvendo a palavra-chave "Electrospinning", o que evidencia a relevância e o crescente uso dessa técnica para a preparação de novos materiais. No presente trabalho, a técnica de eletrofiação foi utilizada para a preparação de mats de composição mista, baseados em PET reciclado e biomassa lignocelulósica.

\subsection{Definição de fibras ultrafinas e nanofibras}

A técnica de eletrofiação possibilita a produção de nanofibras e fibras ultrafinas, assim, faz-se importante que estes critérios sejam definidos.

A terminologia normativa definida pela norma ISO / TS 27687 (publicada no final de Setembro/2008] ["Nanotechnology - terminology and definitions for the "nanoobjects", i.e., Nanoparticle, nanofiber and nanoplate" [Figura 14]] pode ser utilizada para a definição de nano-objetos:

[i] Nano: intervalo de dimensão entre 1 e $100 \mathrm{~nm}$;

[ii] Objetos nano: materiais com uma, duas ou três dimensões no domínio nano. 
Figura 14 - Representação esquemática de algumas formas para nano-objetos.

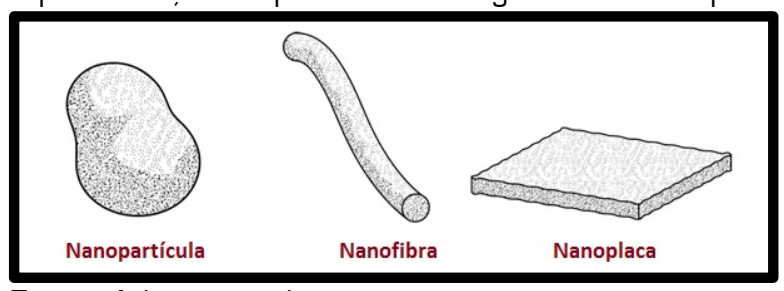

Fonte: Adaptação de

https://ansidotorg.blogspot.com.br/2015/09/nanotechnologystandards.html\#gref.

Na Figura 14 podemos observar que a nanopartícula é um nanomaterial que possui suas três dimensões na escala nano, já as nanofibras são nano-objetos que possuem duas dimensões na escala nano, sendo que a terceira dimensão é significantemente superior. Ainda, a nanoplaca apresenta apenas uma de suas dimensões na escala nano.

As fibras ultrafinas podem ser definidas, como adotado por alguns autores [HUANG et al., 2003; ZHANG et al., 2016], como fibras com espessuras no intervalo de $100 \mathrm{~nm}$ a $1000 \mathrm{~nm}$.

\subsection{Fundamentos da técnica de eletrofiação}

A técnica de eletrofiação consiste na geração de fibras, através do estiramento das cadeias poliméricas presentes em um jato eletrificado de uma solução viscosa de um polímero (ou no polímero fundido, dependendo da configuração do equipamento de eletrofiação], devido a repulsões eletrostáticas entre as cargas de superfície e a evaporação do solvente, no caso do uso de soluções (HUANG et al., 2003; LI; XIA, 2004). Assim, fibras em escala sub-micrométrica e nanométrica são produzidas a partir da aplicação de um campo eletrostático de alta voltagem [1-45 kV, usualmente], o qual é operado entre uma agulha metálica [de diâmetro variável] e um coletor metálico. A Figura 15 apresenta um esquema típico de eletrofiação. 
Figura 15 - Representação esquemática do funcionamento da técnica de eletrofiação.



Fonte: Autoria própria.

Na técnica de eletrofiação, a elevada voltagem aplicada é utilizada para criar um jato de solução polimérica eletricamente carregado, ou para fundir o polímero pela pipeta ou agulha metálica. Assim, antes de atingir o coletor, ocorre a evaporação do solvente no jato de solução ou a solidificação do polímero fundido, e o mesmo é coletado como uma rede interconectada de fibras [DEITZEL et al., 2001; RENEKER; YARIN, 2008).

Um eletrodo é colocado dentro da solução de fiação/polímero fundido ou, alternativamente, em contato com a ponta da agulha onde está presente a solução polimérica, enquanto outro eletrodo é colocado no coletor. A extremidade da agulha, que contém a solução polimérica mantida pela sua tensão superficial, é submetida ao campo elétrico, induzindo carga na superfície do líquido.

Um jogo de forças, no qual age a repulsão mútua de cargas de mesma polaridade e a contração das cargas superficiais para o contra-eletrodo, leva à geração de uma força coulombiana que é diretamente oposta à tensão superficial [FANG; RENEKER, 1997). Com o aumento da intensidade do campo elétrico, ocorre o alongamento da superfície hemisférica do fluido na extremidade da agulha, adquirindo a forma de uma superfície cônica, denominada cone de Taylor [TAYLOR, 1969]. Ainda, com o aumento do campo elétrico, este pode adquirir um valor crítico, no qual ocorre a superação da tensão superficial do fluido pela força de repulsão eletrostática, fazendo com que o jato de fluido carregado seja ejetado do cone de Taylor. Assim, o jato de solução polimérica descarregada passa por processos de instabilidade e alongamento, fazendo com que este se torne longo e fino. Concomitantemente, ocorre a evaporação do solvente e a consequente formação de fibras poliméricas carregadas.

Nos casos em que a técnica de eletrofiação envolve massas fundidas poliméricas, há a solidificação do jato descarregado enquanto o mesmo se desloca pelo ar (HUANG et al., 2003]. Com relação ainda ao jato de solução polimérica carregado, existem seis forças 
principais que agem em cada segmento infinitesimal do mesmo: [1] Força gravitacional; [2] Forças eletrostáticas que conduzem o jato carregado da ponta da agulha até o coletor; [3] Forças coulombianas de repulsão, as quais tentam separar as espécies de mesma polaridade adjacentes presentes no jato de solução e são, portanto, responsáveis pelo alongamento do mesmo até o coletor; [4] Forças viscoelásticas, as quais tentam evitar o estiramento do jato de solução carregado; [5] Tensão superficial, a qual também age contra o estiramento da superfície do jato carregado; [6] Forças de arrasto geradas pelo atrito entre o jato carregado e o ar circundante. Devido a combinação dessas forças, o jato carregado eletricamente atravessa o ar em uma trajetória reta apenas por uma curta distância, após, passa por processos de instabilidade e alongamento, como mencionado anteriormente, até se solidificar e depositar-se sob a forma de fibras no coletor (MIT-

\section{UPPATHAM; NITHITANAKUL; SUPAPHOL, 2004].}

Geralmente, o processo de eletrofiação de soluções poliméricas é realizado à temperatura ambiente, sob condições atmosféricas. Também é aconselhável que o processo seja realizado dentro de uma câmara especial com sistema de ventilação, devido à volatilidade e toxicidade de muitos solventes e/ou polímeros utilizados. Ainda, faz-se necessária a utilização de uma fonte de tensão com um amplo intervalo de kVs e consequente cuidado para evitar o contato com o jato carregado, durante a realização do experimento, e a geração de faíscas, que podem comprometer a integridade dos mats formados [RODRIGUES, 2014].

Na técnica de eletrofiação, os parâmetros envolvidos no processo desempenham um papel fundamental, tanto nos processos cinéticos, relacionados ao jato de solução polimérica, como também na morfologia das fibras formadas. Esses parâmetros incluem: [a] propriedades intrínsecas da solução polimérica ou parâmetros de solução, tais como concentração, condutividade, tensão superficial e massa molar média do polímero; [b] condições operacionais tais como tensão aplicada, taxa de vazão e distância entre a ponta da agulha e o coletor; [c] fatores ambientais como temperatura da solução polimérica e umidade relativa. Assim, controlando-se esses parâmetros, dentre outros, podem ser produzidas fibras com diferentes morfologias e diâmetros (WEI et al., 2010).

Os parâmetros da solução estão intimamente relacionados com as propriedades físico-químicas tanto dos polímeros como dos solventes utilizados, assim como também as interações do tipo polímero-solvente. A concentração do polímero, assim como a viscoelasticidade da solução, são parâmetros muito importantes. Para a obtenção de fibras uniformes e de morfologia mais cilíndrica, sem que haja a presença de partículas esféricas [denominadas beads] ou fibras com contas, faz-se necessário um certo grau de emaranhamento de cadeias na solução polimérica, o que corresponde a um valor de concentração [viscoelasticidade] mínimo. Assim, com o aumento da concentração de polímero e mantendo-se fixos os demais parâmetros do processo, há uma tendência ao aumento no diâmetro das fibras. 
A baixas concentrações de polímero, a formação de fibras mais finas é favorecida, no entanto, o grau de emaranhamento das cadeias poliméricas é pequeno, o que pode causar uma instabilidade capilar na extremidade do jato, podendo evoluir para um espalhamento eletrostático [fenômeno conhecido como electrospraying], ao invés da eletrofiação. Como consequência deste fenômeno, beads podem ser formados ou mesmo fibras com contas [COSTA et al., 2012]. Com relação à formação de beads durante o processo de eletrofiação, o diâmetro dos mesmos e o espaçamento entre eles está diretamente relacionado com o diâmetro das fibras formadas.

Quando do aparecimento de beads, quanto mais finas as fibras formadas, menor a distância entre os beads e menor será o diâmetro dos mesmos [JAEGER; SCHÖNHERR; VANCSO, 1996]. Ainda, elevadas viscosidades das soluções poliméricas a serem eletrofiadas favorecem a formação de fibras sem a presença de beads (FONG; CHUN; RENEKER, 1999].

A formação do cone de Taylor, como mencionado anteriormente, está diretamente relacionada com a tensão superficial da solução polimérica. Para que haja a formação do mesmo, a voltagem aplicada deve ser suficientemente alta para que as forças eletrostáticas superem a tensão superficial da gota. Ou seja, há um valor de voltagem crítico à partir do qual inicia-se o processo de eletrofiação [COSTA et al., 2012). Assim, a redução da tensão superficial da solução polimérica favorece a formação de fibras sem beads (FONG; CHUN; RENEKER, 1999).

Nasouri, Shoushtari e Mojtahedi [2015], em seu estudo, avaliaram a influência da tensão superficial na eletrofiação de soluções de polivinilpirrolidona (PVP], em várias concentrações, utilizando como solventes o etanol e DMF. Neste estudo foi observado que a eletrofiação de soluções de PVP em etanol a concentrações acima de 6\% em massa, e em soluções de PVP em DMF a concentrações acima de 12 \% em massa de polímero, produziram fibras livres de defeitos, como os beads, por exemplo. Portanto, foi possivel concluir que com o aumento da concentração de PVP nas soluções, houve um aumento do emaranhamento de cadeias e consequente aumento da viscosidade da solução, fazendo com a tensão superficial da mesma fosse ultrapassada com a consequente geração de fibras sem defeitos.

A condutividade elétrica da solução polimérica desempenha importante papel na morfologia das fibras produzidas, via técnica de eletrofiação. Geralmente, o aumento da condutividade elétrica da solução, com a adição de um sal, por exemplo, resulta em maior mobilidade dos íons em solução e, com a aplicação de um campo elétrico externo, há a orientação das cargas e um maior alongamento da gota, com consequente redução no diâmetro das fibras formadas (COSTA et al., 2012). Destaca-se que o aumento na densidade de cargas da solução também reduz a probabilidade de formação de fibras com contas e beads [FONG; CHUN; RENEKER, 1999]. 
A adição de partícula metálica ou mesmo nanotubo de carbono à solução polimérica também pode favorecer a formação de fibras sem contas e com diâmetros reduzidos. Rodrigues et al. [2016], em seu estudo, observaram que fibras produzidas à partir da eletrofiação de soluções de PBAT contendo 0,1\% e 0,5\% de nanotubos de carbono, apresentaram diâmetros reduzidos em comparação às fibras produzidas à partir de solução de PBAT sem a adição dos nanotubos.

Em um processo de eletrofiação, não é possível que sejam feitas recomendações gerais com relação a concentrações particulares, viscosidades resultantes, condutividades elétricas e tensões superficiais. Os valores ideias para estes parâmetros podem variam consideravelmente a depender do sistema polímero-solvente adotado. Ainda, a rápida evaporação do solvente adotado, no caso daqueles com baixo ponto de ebulição e alta pressão de vapor, pode influenciar negativamente o processo de eletrofiação à partir de soluções poliméricas, com consequente geração de regiões filmogênicas [GREINER; WENDORFF, 2007].

Dentro dos parâmetros de processamento envolvidos na técnica de eletrofiação, a voltagem aplicada é um fator crucial. Durante o processo de eletrofiação, há a formação de fibras apenas quando se aplica uma voltagem acima do valor limite de voltagem necessário para que o jato de solução polimérica carregado seja ejetado do cone de Taylor [LI; WANG, 2013]. No entanto, a influência da voltagem aplicada no diâmetro das fibras formadas apresenta controvérsias (RENEKER; CHUN, 1996; ZHANG et al., 2005).

Doustgani [2015], em seu estudo, observou que fibras formadas via eletrofiação de policaprolactona $[\mathrm{PCL}$ ] e nanohidroxiapatita $[\mathrm{nHA}$ ] apresentaram uma diminuição de diâmetro quando eletrofiadas utilizando-se uma voltagem aplicada de 19 kV, em comparação com o diâmetro das fibras formadas aplicando-se uma voltagem de $10 \mathrm{kV}$. Todos os demais parâmetros do processo foram mantidos constantes e somente variouse a voltagem aplicada. No entanto, foi observado um acréscimo no diâmetro das fibras formadas quando aplicou-se uma voltagem de 22 kV, em comparação ao diâmetro das fibras formadas utilizando-se a voltagem de $19 \mathrm{kV}$. Assim, este estudo possibilitou concluir-se que, o aumento da tensão aplicada durante a eletrofiação, leva a um maior fluxo de solução para fora do capilar/ponta da agulha, o que contribui para o aumento do diâmetro das fibras formadas [ZHANG et al., 2005]. No entanto, se as forças eletrostáticas levarem a uma maior extensão do jato de solução polimérica, em comparação com a taxa de fluxo utilizada, o diâmetro das fibras diminuirá com o aumento da tensão aplicada [LEE et al., 2004]. Assim, o diâmetro das fibras será determinado por um balanço entre esses dois efeitos.

A distância entre o coletor das fibras e a ponta da agulha também é um fator importante, pois deve-se usar uma distância tal para que haja a total evaporação do solvente e, concomitantemente, esta distância deve possibilitar que o campo elétrico estabilize de forma efetiva o cone de Taylor, garantindo a formação das fibras [GOMES et 
al., 2007]. Assim, se a distância entre a ponta da agulha e o coletor é muito pequena, não haverá tempo suficiente para que a fibra se solidifique antes de alcançar o coletor. Contrariamente, se a distância entre a ponta da agulha e o coletor é muito grande, fibras com contas ou mesmo beads poderão ser formados (LI; WANG, 2013). Ainda, Doustgani [2015], em seu estudo, observou que fibras formadas via eletrofiação de PCL e nHA apresentaram uma diminuição significativa no diâmetro quando eletrofiadas utilizando-se uma distância entre a ponta da agulha e o coletor de $25 \mathrm{~cm}$, em comparação com o diâmetro das fibras formadas utilizando-se uma distância de $5 \mathrm{~cm}$ [306 nm e 597 nm de diâmetro, respectivamente]. Nesse estudo, foi possível concluir que a variação na distância entre a ponta da agulha e o coletor tem influência direta sobre o tempo que o jato de solução leva para solidificar-se e atingir o coletor, assim como na intensidade do campo elétrico produzido.

Longas distâncias entre a ponta da agulha e o coletor propiciam um maior tempo para que o jato de solução polimérica se alongue, sob ação do campo elétrico produzido, antes que as fibras atinjam e se depositem no coletor. Portanto, há uma maior tendência de diminuição no diâmetro das fibras com o aumento da distância entre a ponta da agulha e o coletor.

Com relação à taxa de fluxo da solução polimérica, em geral, baixas taxas de fluxo permitem com que a solução polimérica tenha tempo suficiente para ser polarizada. Assim, há tempo suficiente para que o solvente evapore durante o processo de eletrofiação, com a formação de fibras uniformes e com pequenos diâmetros. No entanto, se a taxa de fluxo é muito elevada, pode ocorrer a formação de beads com diâmetros reduzidos, ao invés de fibras contínuas de pequeno diâmetro, como consequência do curto tempo para que o solvente evapore e as fibras atinjam o coletor (LI; WANG, 2013).

Doustgani [2015), em seu estudo, observou que fibras formadas via eletrofiação de PCL e nHA apresentaram, com o aumento da taxa de fluxo de 0,1 $\mathrm{mL} \mathrm{h}^{-1}$ para $5 \mathrm{~mL} \mathrm{~h}^{-1}$, um aumento no diâmetro das fibras produzidas de aproximadamente 40\% (mantendo-se constantes os demais parâmetros de eletrofiação]. Com o aumento da taxa de fluxo há um aumento da gota de solução polimérica suspensa na ponta da agulha, assim, há um aumento no diâmetro do jato polimérico formado e, consequentemente, no diâmetro das fibras produzidas.

Khezli, Zandi e Barzin [2016], em seu estudo, observaram também um aumento no diâmetro médio das fibras de polietersulfona [PES] de aproximadamente 90\%, com o aumento da taxa de fluxo da solução polimérica de 0,1 $\mathrm{mL} \mathrm{h}^{-1}$ para 0,7 $\mathrm{mL} \mathrm{h}^{-1}$.

No processo de eletrofiação, é crescente a preocupação com parâmetros ambientais, como temperatura da solução polimérica e umidade relativa, por exemplo, devido a forte influência que os mesmos podem apresentar no aparecimento de fibras com contas ou beads e no diâmetro e superfície das mesmas. 
Mit-uppatham, Nithitanakul e Supaphol [2004], em seu estudo, observaram que um aumento na temperatura da solução polimérica a ser eletrofiada, de $30{ }^{\circ} \mathrm{C}$ para $60{ }^{\circ} \mathrm{C}$, levou a uma diminuição no diâmetro médio das fibras de nylon 6.0, de 98 nm para 90 nm. Assim, neste estudo, foi possível concluir-se que, como as concentrações de ambas as soluções foram fixadas em um mesmo valor, a elevação na temperatura da solução resultou em uma expansão das moléculas do polímero, levando a uma redução no grau de emaranhamento da cadeia polimérica e, consequentemente, uma redução na viscosidade da solução. Com a redução na viscosidade da solução houve também uma redução da força viscoelástica, que contrabalança as forças de estiramento coulombianas, levando a uma redução no diâmetro das fibras formadas. Ainda, com o aumento de temperatura da solução, os autores observaram um aumento no número de fibras depositadas no coletor, o que corrobora o que foi observado em outros trabalhos envolvendo a influência desse parâmetro na técnica de eletrofiação [DEMIR et al., 2002).

Com relação à influência da umidade relativa no processo de eletrofiação, a elevada umidade relativa pode levar à formação de fibras com um maior diâmetro [no caso da eletrofiação de soluções poliméricas de polímeros hidrofóbicos em solventes orgânicos, como o DMF e o tetraidrofurano [THF]] devido à neutralização das cargas do jato polimérico e a redução das forças de alongamento do mesmo (LI; WANG, 2013; PUTTI et al., 2015). No entanto, a elevada umidade relativa também pode levar à formação de fibras com menor diâmetro, no caso da eletrofiação de soluções de polímeros hidrofílicos, como o álcool polivinílico [PVA] em água, por exemplo.

Pelipenko et al. [2013), em seu estudo, relataram uma diminuição no diâmetro médio das fibras formadas à partir da eletrofiação de soluções de PVA em água, com o aumento da umidade relativa do ambiente. Neste estudo, observou-se que com o aumento da umidade relativa de 4\% para 50\%, houve uma diminuição na taxa de evaporação da água, com consequente maior alongamento do jato de solução polimérica e a produção de fibras com diâmetros reduzidos (de aproximadamente $230 \mathrm{~nm}$ para $50 \mathrm{~nm}$, respectivamente).

A umidade também pode afetar a morfologia das fibras produzidas via eletrofiação. Wang e Pan [2015), em seu estudo, observaram que com o aumento da umidade relativa de 15\% para $60 \%$, na preparação de mats à partir de soluções de Ácido poliláctico [PLA]/Diclorometano [DCM]/N,N-Dimetilacetamida [DMAC], ocorreu um aumento na presença de nano poros na superfície das fibras. Assim, os autores observaram que com valores de umidade relativa de $45 \%$ a $60 \%$, além do aumento de nano poros na superfície das fibras, os mesmos apresentaram-se densamente distribuídos na superfície das mesmas. Estes resultados confirmam o importante papel da umidade relativa na formação de nano poros na superfície das fibras, devido ao efeito dinâmico de separação de fases polímero-solvente, assim como devido à taxa de evaporação do solvente.

Na eletrofiação de um polímero hidrofóbico a água atua como um não-solvente e 
uma espécie de "pele" é rapidamente formada na interface ar-jato de solução polimérica. Assim, ocorre a formação de poros em ambientes com umidade relativa elevada [geralmente a partir de 30\% de umidade relativa], o que não ocorre com polímeros de caráter hidrofílico, como o PVA, por exemplo [COSTA et al., 2012]. Em um ambiente com elevada umidade relativa, à medida que o jato polimérico é ejetado no ar, ocorre a rápida evaporação do solvente na superfície do jato, enquanto que o solvente dentro do jato se difunde para a superfície do mesmo, simultaneamente. Assim, a temperatura do jato de solução polimérica decresce drasticamente, o que contribui para uma separação de fases induzida termicamente. Além disso, o vapor de água ao redor da fibra penetra parcialmente no jato de solução polimérica levando a uma separação de fases induzida pelo mesmo. Há também parte do vapor que forma gotas de água na superfície do jato devido ao esfriamento do ar durante a evaporação da água. Com a umidade relativa elevada, ocorre uma maior deposição de gotas de água na superfície do jato. Assim, à medida que as gotas de água são removidas do jato durante a solidificação da solução polimérica, mais gotas deixam suas impressões, sob a forma de poros, na superfície das fibras. Ainda, uma elevada umidade relativa também leva à penetração de mais vapor de água no jato de solução polimérica, o que leva à formação de poros também no interior das fibras (WANG; PAN, 2015).

\subsubsection{Preparação de fibras orientadas}

A técnica de eletrofiação não se limita somente a produção de mats de fibras orientadas aleatoriamente. A orientação de fibras ao longo de uma direção preferencial é de grande interesse na produção, por exemplo, de nanofibras que podem ser utilizadas como material de reforço em matrizes poliméricas. Esses materiais apresentam muitas vantagens em relação aos materiais fibrosos macroscópicos, tais como pequenas quantidades desses materiais nanoestruturados podem apresentar o mesmo efeito de reforço obtido por grandes quantidades das fibras macroscópicas. Ainda, em materiais compósitos, a elevada área específica superficial entre as nanofibras e a matriz pode promover processos de relaxação, os quais podem melhorar a resistência ao impacto desses materiais, com a consequente rápida dissipação de tensão e, portanto, rápida absorção de energia durante o impacto [CASSU; FELISBERTI, 2005; GREINER; WENDORFF, 2007). Cai et al. [2016], em seu estudo, observaram que mats de acetato de celulose compostos por nanofibras alinhadas uniaxialmente apresentaram, por exemplo, uma resistência à ruptura cerca de sete vezes superior ao apresentado por mats de acetato de celulose compostos por fibras orientadas aleatoriamente.

Outra vantagem na preparação de mats de fibras orientadas é que os mesmos podem ser utilizados como substituintes de matrizes extracelulares em áreas como a engenharia de tecidos, permitindo que as células humanas cultivadas nesses materiais 
possuam uma direção preferencial de proliferação. Assim, as células em crescimento tendem a seguir a orientação das nanofibras que compõem a matriz. Essa matriz de nanofibras também pode apresentar como vantagens uma alta resistência mecânica e elevada tenacidade [BAJl et al., 2010; GREINER; WENDORFF, 2007). He et al. [2014], em seu estudo, prepararam nanofibras alinhadas uniaxialmente de celulose contendo CNCs em sua composição. Nesse estudo, observou-se que esses materiais biocompativeis permitiram um rápido crescimento de células foliculares dentárias humanas. Ainda, o alinhamento das nanofibras afetou fortemente a direção da organização dessas células, fazendo com que os materiais preparados possam ser utilizados como tecidos artificiais em órgãos humanos [como vasos sanguíneos, tendões, nervos, dentre outros tecidos], nos quais a orientação celular seja fator crucial para a performance dos mesmos.

0 desafio de se controlar a orientação espacial das fibras poliméricas, produzidas via eletrofiação, pode ser alcançado basicamente via métodos mecânicos ou eletrostáticos. Dentre os métodos eletrostáticos, inclui-se a substituição dos coletores de fibras tradicionais por eletrodos paralelos estáticos [BAJl et al., 2010]. A substituição dos coletores por materiais dielétricos, como coletores de maior permissividade elétrica, possibilitou o ajuste do perfil do campo eletromagnético, com a requisição de menores valores de potencial elétrico para a formação de fibras alinhadas [COSTA et al., 2012].

Com relação aos métodos mecânicos para a preparação, via eletrofiação, de fibras alinhadas, podem ser utilizados dois tipos de coletores neste processo. Podem ser utilizados o coletor de disco rotativo ou o coletor de tambor metálico rotativo [BAJl et al., 2010]. 0 presente trabalho envolveu a utilização do coletor de tambor metálico rotativo para a obtenção de fibras alinhadas.

0 coletor de tambor metálico rotativo (Figura 16), geralmente, possibilita um maior controle do diâmetro das fibras coletadas, em comparação ao uso de coletores tradicionais estáticos, com base na velocidade de rotação do tambor (KATTA et al., 2004). O tambor metálico é capaz de rotacionar a elevadas velocidades [mais de 1000 rpm] e orientar as fibras de forma circunferencial. Ainda, o alinhamento das fibras é induzido pela rotação do tambor e o grau de alinhamento aumenta, geralmente, de acordo com a velocidade de rotação. A baixas velocidades de rotação, fibras não-alinhadas podem ser obtidas. No entanto, a elevadas velocidades, uma força centrífuga é desenvolvida nas proximidades da circunferência do tambor rotativo, a qual proporciona um maior alongamento das fibras antes de serem coletadas pelo tambor. Assim, podem ser produzidas fibras com um grau de orientação maior e com uma distribuição de diâmetros deslocada para menores valores, devido ao elevado estiramento imposto às fibras [MEDEIROS et al., 2008]. No entanto, a velocidades de rotação muito elevadas, pode haver o rompimento do jato de fibra durante sua deposição, com consequente obtenção de fibras descontínuas [BAJl et al., 2010]. Este método de eletrofiação pode ser complicado, pois a velocidade de rotação do tambor precisa ser bem controlada para a 
produção de fibras com um maior grau de alinhamento [JUNOH et al., 2014].

Mubyana et al. [2016], em seu estudo, observaram a influência do alinhamento de fibras de PCL em propriedades como a tensão de falha dos materiais. Neste estudo, observou-se que mats de fibras alinhadas de PCL, de aproximadamente $18 \mu \mathrm{m}$ de espessura, apresentaram maior resistência à ruptura [aproximadamente $9 \mathrm{MPa}$ ] em comparação a mats, de aproximadamente mesma espessura, de fibras orientadas aleatoriamente de PCL [aproximadamente $3 \mathrm{MPa}$ de tenacidade).

Figura 16 - Representação esquemática do funcionamento da técnica de eletrofiação utilizando-se como coletor um tambor metálico rotativo.

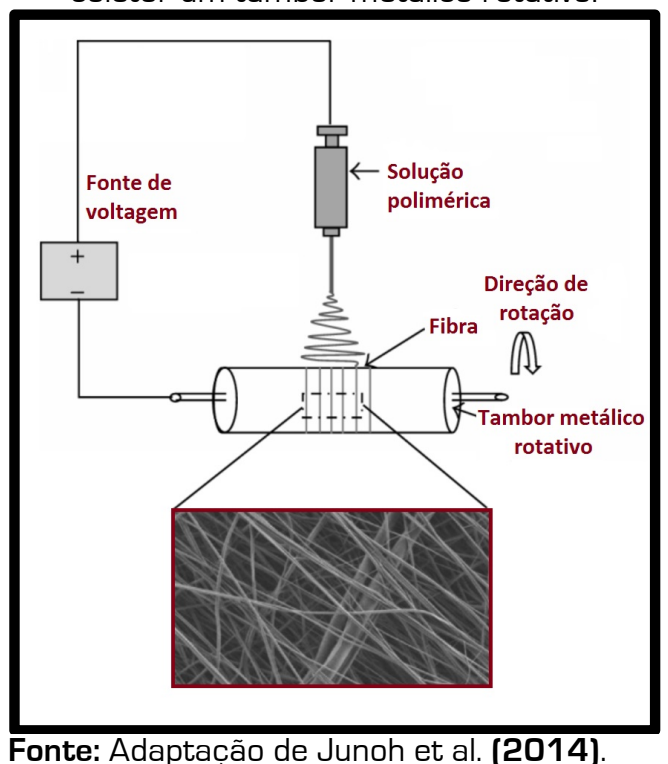

No presente trabalho, visou-se a preparação, via eletrofiação, de fibras alinhadas baseadas em PET reciclado e biomassa lignocelulósica, utilizando-se o coletor de tambor metálico rotativo.

\subsection{Eletrofiação aplicada à biomassa lignocelulósica}

A utilização de celulose como matéria-prima para a produção de fibras, via técnica de eletrofiação, tem se destacado cada vez mais devido a importantes fatores, tais como menos impactos ambientais associados, esgotamento das fontes de carbono fóssil e o efeito positivo com relação à geração de gases de efeito estufa, além da biodegradabilidade desse polissacarídeo. No entanto, esta tarefa apresenta certo grau de dificuldade, devido a limitada solubilidade da celulose em solventes voláteis e adequados para o processo de eletrofiação. Outra dificuldade são os desafios da dinâmica estrutura da cadeia das moléculas de celulose [como a rigidez da cadeia] em solução. De fato, todos os solventes utilizados na literatura para a dissolução da celulose apresentam baixa volatilidade e interagem fortemente com os grupos presentes na estrutura deste polissacarídeo. Consequentemente, dificulta-se o mecanismo de solidificação do jato de solução, durante o processo de eletrofiação, ou ainda o mesmo se torna impossível 
[HÄRDELIN et al., 2012]. A eletrofiação da celulose, sem que haja a necessidade de qualquer modificação na estrutura química da mesma, em diversos sistemas de solventes, tais como óxido de N-metilmorfolina [NMMO]/água [KIM et al., 2006], hidróxido de sódio $[\mathrm{NaOH}] /$ Ureia/Tioureia [JAHANBAANI et al., 2016], cloreto de lítio [LiCl]/DMAC [YUN et al., 2008) e líquidos iônicos (HÄRDELIN et al., 2012; HOU et al., 2016), tem sido objeto de estudo e relatada em diversos trabalhos da literatura.

Ainda, também tem sido extensivamente produzidas fibras via eletrofiação de derivados de celulose, como o acetato de celulose, por exemplo. Mats de acetato de celulose produzidos via eletrofiação de soluções dos mesmos em sistemas de solventes como acetona/DCM [SULTANA; ZAINAL, 2016] e ácido acético/água [YANG et al., 2016], por exemplo, encontram diversas aplicações, tais como em filtros de cigarro, fraldas de alta absorção, membranas semipermeáveis para processos de separação e também em aplicações biomédicas [KONWARH; KARAK; MISRA, 2013).

Além da eletrofiação de derivados de celulose, CNCs são cada vez mais utilizados como agentes de reforço em compósitos de nanofibras produzidas via eletrofiação de uma extensa variedade de matrizes poliméricas. Peresin et al. [2014], em seu estudo, prepararam mats via eletrofiação de soluções de PVA contendo CNCs dispersos. Após a preparação dos mats, estes foram esterificados em fase vapor, utilizando-se como agente reticulante o anidrido maleico. Neste estudo observou-se que os mats de PVA/CNCs reticulados apresentaram uma melhoria na resistência à tração de aproximadamente 34\% [em uma umidade relativa de 50\%] em comparação com o apresentado por mats de PVA puro. Rojas et al. [2009), em seu estudo, prepararam fibras em forma de fita de poliestireno [PS] reforçadas com CNCs. Neste estudo, observou-se que a incorporação dos CNCs às fibras de PS levou a um aumento do módulo vítreo das fibras, devido à sua percolação mecânica, formando uma rede rígida e contínua unida por ligações de hidrogênio em uma matriz hidrofóbica. A compreensão da interface entre os CNCs e as matrizes poliméricas, bem como a orientação dos mesmos dentro das fibras eletrofiadas, é um fator crítico para explicar e explorar as propriedades mecânicas destes materiais compósitos. Fortes interações entre a matriz e os CNCs podem levar a uma mais eficiente transferência de força dentro das fibras e os CNCs, orientados ao longo do eixo das mesmas. Assim, pode ocorrer uma consequente melhoria das propriedades mecânicas anisotrópicas, como a rigidez axial, destes materiais nanofibrosos (WANASEKARA et al., 2016]. Neste contexto, Wanasekara et al. [2016], em seu estudo, investigaram via Microscopia Eletrônica de Transmissão [TEM] e Espectroscopia Raman, a orientação de CNCs em fibras de PVA e PS produzidas via eletrofiação. Os resultados obtidos neste estudo sugerem uma orientação aleatória dos CNCs nas fibras de PVA e PS, exceto em algumas regiões, nas fibras de PVA, em que os CNCs estão orientados na seção transversal e ao longo do eixo das fibras.

Embora a técnica de eletrofiação destaque-se por sua versatilidade e possibilidade 
de preparação de fibras em escala sub-micrométrica e nanométrica, há uma notável falta de investigação na aplicação dessa técnica considerando como matéria-prima a biomassa lignocelulósica, ou seja, fibras lignocelulósicas cujos principais componentes são a celulose, hemiceluloses e lignina [RODRIGUES et al., 2015).

Apenas alguns estudos têm sido publicados abordando a eletrofiação de biomassa lignocelulósica e, em todos eles, faz-se necessária a utilização de biomassa pré-tratada com solução alcalina aquosa (com o objetivo de eliminar os teores de lignina e hemiceluloses da mesma], e como sistema de solventes líquido iônico, como o 1-etil-3metilimidazol e DMF, como co-solvente [AHN et al., 2012; KANG et al., 2013]. Na busca por alternativas à utilização desses solventes, assim como por um solvente que possa dissolver as fibras lignocelulósicas sem a necessidade de um pré-tratamento, Rodrigues et al. [2015], em seu estudo, preparou fibras ultrafinas e nanofibras via eletrofiação de soluções de biomassa lignocelulósica nativa, sem qualquer pré-tratamento químico, e TFA. Neste estudo as fibras lignocelulósicas de sisal foram dissolvidas em TFA fpor $48 \mathrm{~h}$ a temperatura ambiente] e, pós eletrofiação da solução, foi obtida uma rede homogênea de fibras ultrafinas. Assim, neste estudo, os principais componentes da fibra lignocelulósica nativa foram separados, devido à dissolução dos mesmos em TFA, e subsequentemente as fibras foram reconstruídas em escala sub-micrométrica, via técnica de eletrofiação.

Fanta et al. (1984), em seu estudo, observou que a hidrólise de palha de trigo, com TFA $1 \mathrm{~N}$ por $7 \mathrm{~h}$, levou à degradação parcial da lignina e hemiceluloses, enquanto que as macromoléculas de celulose não foram afetadas. Posteriormente a esse estudo, Morrison, Stewart (1998) e Dong et al. [2009) também reportaram a não despolimerização da celulose após 8 dias de solubilização em TFA 99\% a $37{ }^{\circ} \mathrm{C}$ e a 16 h em TFA [>99\%] a 60 ${ }^{\circ} \mathrm{C}$, respectivamente.

A fibra lignocelulósica de sisal, por possuir um elevado teor de celulose, favorece a eletrofiação das hemiceluloses e da lignina, quando os três componentes são eletrofiados conjuntamente. A estrutura linear da celulose favorece o alinhamento de suas cadeias durante o processo de eletrofiação, contrariamente ao que ocorre com as hemiceluloses. No caso da lignina, não há a formação de fibras via processo de eletrofiação, por se tratar de uma macromolécula tridimensional [protolignina] e, portanto, necessitar para sua dissolução a quebra de ligações covalentes para romper sua rede 3D [RODRIGUES, 2014].

No presente trabalho foi explorada a preparação de mats, via eletrofiação de soluc̣ões baseadas em biomassa lignocelulósica nativa, assim como de seus constituintes celulose e lignina, utilizando o TFA como solvente. Ainda, também foi explorada a adição de CNCs à soluções baseadas em PET reciclado e posterior eletrofiação das mesmas. 


\subsection{Eletrofiação aplicada a soluções baseadas em PET reciclado}

O PET cada vez mais é utilizado como matéria-prima para a preparação de nanofibras/fibras ultrafinas via técnica de eletrofiação (KAYACl; AYTAC; UYAR, 2013; KE, 2016; LEE; CHO, 2015; VELEIRINHO et al., 2014]. Este polímero vem sendo muito utilizado devido a características, tais como baixo custo e interessantes propriedades estruturais, além de possuir boas propriedades para a eletrofiação (MA et al., 2005; VELEIRINHO; LOPES-DA-SILVA, 2009]. Ainda, na eletrofiação de soluções baseadas em PET, alguns solventes/sistemas de solventes podem ser utilizados, tais como o TFA, TFA/DCM e hexafluoroisopropanol (HFIP) (VELEIRINHO; REI; LOPES-DA-SILVA, 2008).

Veleirinho et al. [2014), em seu estudo, preparou mats de PET e PET/quitosana que demonstraram boa performance como materiais de implante em cirurgias para a reparação de hérnia incisional. Neste estudo, o PET foi escolhido como uma das matériasprimas por apresentar, quando eletrofiado juntamente com a quitosana, boas propriedades, como por exemplo, para ser utilizado como substrato para a adesão de fibroblastos e na proliferação celular. Ainda, este estudo também demonstrou a necessidade de maiores investigações em ordem de um melhor entendimento dos riscos associados com a implantação em humanos de materiais na escala sub-micrométrica e nanométrica. Kayaci, Aytac e Uyar (2013) reportaram a preparação, via eletrofiação, de nanofibras de PET modificadas com ciclodextrina para o aprisionamento de compostos voláteis orgânicos, como um novo material para ser utilizado nos processos de filtração da água.

Apesar da técnica de eletrofiação ser extensivamente utilizada na preparação de uma ampla variedade de materiais baseados em PET, existem poucos estudos relatando o uso dessa técnica aplicada a soluções de PET reciclado (SANTOS et al., 2015; SHI; NAGUIB, 2016; STRAIN et al., 2015; ZANDER; GILLAN; SWEETSER, 2016]. Strain et al. [2015], em seu estudo, prepararam resistentes membranas, via eletrofiação de PET reciclado, para processos envolvendo a filtração de fumaça. Zander, Gillan e Sweetser [2016] prepararam, via técnica de eletrofiação, membranas baseadas em PET reciclado avaliando com sucesso a performance e a eficiência das mesmas em processos de microfiltração.

Os materiais baseados em PET, preparados via técnica de eletrofiação, devido à natureza química desse polímero, podem apresentar um elevado caráter hidrofóbico, como consequência da sua baixa energia de superfície e rugosidade da mesma, assim como insatisfatórias propriedades mecânicas [LI et al., 2013). A hidrofobicidade desses materiais pode representar um empecilho para certas aplicações, como exemplo em sistemas biológicos. Nestes sistemas, membranas hidrofóbicas podem exibir uma menor resistência ao fenômeno de incrustação (no qual partículas indesejadas acumulam-se na superfície das membranas, o que pode prejudicar o desempenho das mesmas], em comparação com membranas de caráter hidrofílico [DONG et al., 2007). Assim, um 
aumento do caráter hidrofílico dessas membranas baseadas em PET constitui-se em um eficiente método para atenuar esse fenômeno de incrustação [ZHANG et al., 2011]. Muitas investigações visando um aumento da hidrofilicidade do PET têm sido reportadas, por exemplo, Li et al. [2013), em seu estudo, prepararam via eletrofiação materiais compósitos de PET/PVA de caráter super hidrofilico.

Nesse contexto, o presente trabalho visou a preparação de nanofibras/fibras ultrafinas de caráter hidrofílico a partir da eletrofiação de fibra de sisal e PET reciclado, utilizando o TFA como solvente. Ainda, também foram produzidas nanofibras/fibras ultrafinas de PET reciclado e componentes majoritários da fibra lignocelulósica, como a celulose e a lignina. 


\section{Objetivos}

O objetivo central do presente trabalho consistiu na valorização de fibras de sisal e de dois dos componentes principais de fibras lignocelulósicas, a celulose e lignina, assim como na valorização do PET reciclado, para a produção, via técnica de eletrofiação, de materiais com elevado valor agregado.

Pretendeu-se também, até onde se tem conhecimento, de forma inovadora, avaliar a influência da presença de nanocristais de celulose [CNCs] nas propriedades de mats baseados em PET reciclado, assim como a possível atuação do óleo de mamona [OM], como agente compatibilizante entre a matriz polimérica hidrofóbica e a celulose [hidrofilica] em sua forma nanocristalina.

Também pretendeu-se avaliar o impacto do alinhamento das fibras produzidas nas propriedades mecânicas, termo-mecânicas e na hidrofilicidade/hidrofobicidade dos materiais, comparativamente aos mats constituídos por fibras não alinhadas. 


\section{Apresentação/Estruturação do Trabalho}

Com o objetivo de facilitar a leitura do presente trabalho, este foi estruturado em capítulos. Cada capítulo tem como objetivo abordar os diferentes aspectos envolvidos na eletrofiação tanto da biomassa lignocelulósica, quanto de seus componentes principais, celulose [também na forma nancristalina] e lignina, assim como do PET reciclado. Assim, cada capítulo apresenta uma breve introdução, referente ao que foi realizado em cada etapa, a descrição da parte experimental, os resultados obtidos e discutidos e, finalmente, a conclusão parcial com relação ao que foi apresentado e discutido. 0 esquema a seguir mostra a estrutura escolhida para a apresentação dos resultados obtidos em cada etapa do presente trabalho.

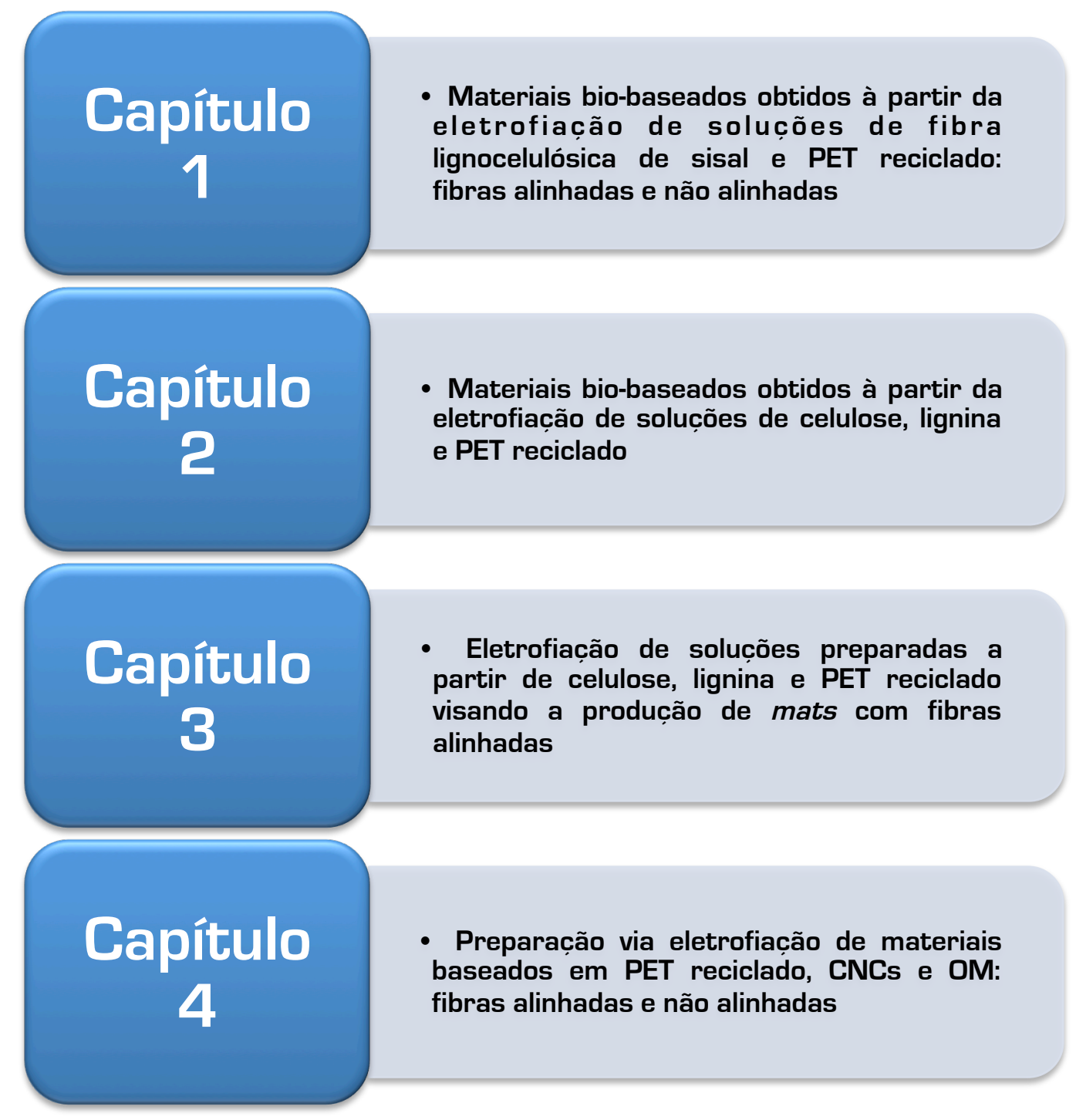




\section{Capítulo 1. Materiais bio-baseados obtidos à partir da eletrofiação de soluções de fibra lignocelulósica de sisal e PET reciclado: fibras alinhadas e não alinhadas}

\subsection{Introdução}

Neste capítulo relata-se a preparação de nanofibras/fibras ultrafinas via eletrofiação de soluções baseadas em PET reciclado e fibra lignocelulósica de sisal. Previamente à realização deste trabalho le como um dos fatores motivacionais para a realização do mesmo], no grupo de pesquisa em que o mesmo se insere, foi investigada a preparação de fibras em escala submicrométria e nanométrica à partir da eletrofiação de soluções baseadas na fibra nativa de sisal, sem qualquer pré-tratamento, e TFA como solvente [RODRIGUES et al., 2015].

Neste capítulo é relatada também a produção de fibras orientadas em uma direção preferencial de alinhamento. Destaca-se que neste trabalho foram eletrofiadas soluções contendo diferentes razões de fibra de sisal/PET reciclado, com o objetivo de avaliar as diferentes propriedades finais dos materiais bio-baseados, em função da razão fibra de sisal/PET reciclado usada. Também visou-se avaliar a influência do grau de orientação das fibras nas propriedades finais dos materiais produzidos.

Até onde chega nosso conhecimento, este trabalho foi pioneiro em combinar biomassa lignocelulósica nativa [fibra de sisal] com polímero reciclado, no caso PET reciclado, para a preparação de materiais híbridos em escala sub-micrométrica e nanométrica, via técnica de eletrofiação.

\subsection{Experimental}

\subsubsection{Materiais}

Como materiais de partida, utilizou-se o PET reciclado [Índice de fluidez [MFI] de $36,4 \mathrm{~g}$ [10 min] [DE OLIVEIRA SANTOS et al., 2014]] gentilmente cedido pelo Gruppo Mossi \& Ghisolfi [M\&G, São Paulo, S.P.]. As fibras de sisal utilizadas no presente trabalho [64,9\% de celulose; $11,7 \%$ de lignina; $25,4 \%$ de hemiceluloses; $7,1 \%$ de umidade; $0,4 \%$ de teor de cinzas; cristalinidade [ $\left.I_{c}\right]$ de 58\% [DE OLIVEIRA SANTOS et al., 2014]] foram adquiridas da empresa Sisal Sul Indústria e Comércio Ltda. [São Paulo, S.P.].

Antes de serem utilizadas, as fibras foram submetidas a um processo de extração 
em um sistema de refluxo com etanol/cicloexano [Synth] [1:1, v:v] por 10 min, sendo então lavadas com água, à temperatura ambiente, e secas em estufa de circulação de ar a $105{ }^{\circ} \mathrm{C}$, até massa constante. Este pré-tratamento teve como objetivo a eliminação de extrativos orgânicos como ceras [constituídas principalmente por moléculas apolares, as quais podem prejudicar possiveis interações fibra-PET reciclado], dentre outras impurezas inorgânicas [compostos inorgânicos de cálcio, sódio, potássio e sílica, aderidos às fibras sob a forma de sais]. Após este tratamento, as fibras extraídas foram moídas em um moinho de rotor vertical com facas móveis e fixas [aço inox malha 30] da MARCONI, modelo MA048, e novamente secas em estufa à vácuo a 60 $\mathrm{C}$, até massa constante.

Como solvente, utilizou-se o ácido trifluoroacético [TFA] [Mallinckrodt Chemicals] da forma como foi recebido.

\subsubsection{Métodos}

\subsubsection{Processo de eletrofiação}

O processo de eletrofiação foi realizado à partir de soluções de TFA preparadas da seguinte maneira: [i] solução de referência de PET [15 $\mathrm{g} \mathrm{dL}^{-1}$ ] e [ii] quatro soluções contendo uma mistura de fibra de sisal e PET reciclado a uma concentração fixa de fibras [ $2 \mathrm{~g} \mathrm{dL}^{-1}$ ] e diferentes concentrações do polímero reciclado [5 $\mathrm{g} \mathrm{dL}^{-1}, 10 \mathrm{~g} \mathrm{dL}^{-1}, 15 \mathrm{~g} \mathrm{dL}^{-1} \mathrm{e}$ $20 \mathrm{~g} \mathrm{dL}^{-1}$ ]. Todas as soluções foram mantidas sob vigorosa agitação por $72 \mathrm{~h}$ [com exceção da solução de referência de PET reciclado, a qual foi mantida sob agitação por 24 h], a temperatura ambiente, até a completa dissolução de seus componentes [formação de uma solução monofásica]. Destaca-se que a concentração de fibras de sisal em TFA foi escolhida com base em um estudo prévio, como mencionado anteriormente, realizado por Rodrigues et al. [RODRIGUES et al., 2015), em que $2 \mathrm{~g} \mathrm{dL}^{-1}$ foi a concentração mais adequada para o processo de eletrofiação, assim como foi a concentração limite para que fosse evitada a gelificação pós dissolução do sisal em TFA.

A eletrofiação foi realizada à temperatura ambiente utilizando-se um aparato de eletrofiação EC-DIG da IME Technologies [Geldrop, Holanda] (Figura 17).

As condições para a realização do processo de eletrofiação utilizadas, tais como distância entre a ponta da agulha e o coletor, tempo de eletrofiação, voltagem e taxa de vazão da solução, foram estabelecidas após testes prévios em que foram determinadas as condições mais adequadas para a realização dos experimentos. Destaca-se que nestes testes prévios foram levados em consideração critérios como a viscosidade das soluções [visando-se a obtenção de uma solução com viscosidade que permitisse a realização do processo de eletrofiação], formação de beads e o diâmetro das fibras formadas. 
Figura 17 - Aparato de eletrofiação.

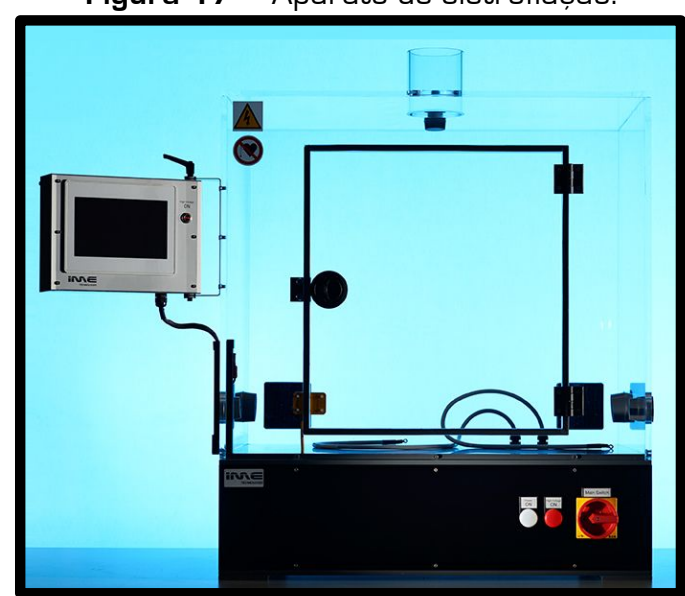

Fonte: http:/ / www.imetechnologies.nl/Products/Platforms/ECDIG/.

As soluções a serem eletrofiadas foram acondicionadas em tubos capilares, com diâmetro interno de $1 \mathrm{~mm}$ e diâmetro externo de 1,6 mm, os quais foram conectados a uma bomba para o controle da taxa de vazão da solução. A agulha metálica [com 0,45 mm de diâmetro interno] foi então conectada a uma fonte de tensão com voltagem positiva de $25 \mathrm{kV}$.

A distância entre a ponta da agulha e o coletor foi de $8 \mathrm{~cm}$ em todos os casos, com exceção das amostras S/PET $T_{0,40}$ e S/PET $T_{0,40}-\mathrm{A}$ [Tabela 1], nas quais foi utilizada uma distância de $4 \mathrm{~cm}$ (a qual mostrou ser a distância mais adequada para a preparação de fibras livres da formação de beads, por exemplo]. Como aparato coletor de fibras, foram utilizadas chapas delgadas de vidro acopladas ao contra eletrodo [coletor estático metálico] e também foi utilizado um coletor de tambor metálico rotativo $[12,5 \times 5,5 \mathrm{~cm}$, comprimento $\times$ largura, da INSTOR Projetos e Robótica Ltda., Porto Alegre, RS], de acordo com a representação esquemática da Figura 16. Destaca-se que na preparação dos materiais utilizando-se o coletor estático, a taxa de vazão da solução foi de 5,5 $\mu \mathrm{L}$ min $^{1}$, com a utilização do coletor rotativo, a velocidade de rotação adotada foi de 3600 rpm e a taxa de vazão, em todos os casos, foi de 25,5 $\mu \mathrm{L} \mathrm{min}$.11 $^{-}$

A Tabela 1 sumariza a composição das soluções preparadas [utilizando-se o TFA como solvente], tipo de coletor utilizado e os respectivos códigos de referência usados para identificar os mats produzidos. 
Tabela 1 - Composição das soluções em TFA, tipo de coletor utilizado e os respectivos códigos de referência

\begin{tabular}{|c|c|c|c|c|}
\hline $\begin{array}{l}\text { Fibra de sisal } \\
\text { [g] }\end{array}$ & $\begin{array}{l}\text { PET reciclado } \\
{[\mathrm{g}]}\end{array}$ & $\begin{array}{l}\text { Razão de fibra de } \\
\text { sisal/PET reciclado }\end{array}$ & Tipo de coletor & $\begin{array}{l}\text { Código de } \\
\text { referência }\end{array}$ \\
\hline 0,06 & 0,15 & 0,40 & estático & $\mathrm{S} / \mathrm{PET}_{0,40}$ \\
\hline 0,06 & 0,30 & 0,20 & estático & $\mathrm{S} / \mathrm{PET}_{0,20}$ \\
\hline 0,06 & 0,45 & 0,13 & estático & $\mathrm{S} / \mathrm{PET}_{0,13}$ \\
\hline 0,06 & 0,60 & 0,10 & estático & $\mathrm{S} / \mathrm{PET}_{0,10}$ \\
\hline- & 0,45 & 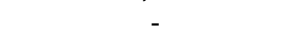 & estático & $\mathrm{PET}_{\text {ref }}$ \\
\hline 0,06 & 0,15 & 0,40 & rotativo & $\mathrm{S} / \mathrm{PET}_{0,40}-\mathrm{A}$ \\
\hline 0,06 & 0,30 & 0,20 & rotativo & $\mathrm{S} / P E T_{0,20}-\mathrm{A}$ \\
\hline 0,06 & 0,45 & 0,13 & rotativo & $\mathrm{S} / \mathrm{PET}_{0,13}-\mathrm{A}$ \\
\hline 0,06 & 0,60 & 0,10 & rotativo & $S / P E T_{0,10}-A$ \\
\hline - & 0,45 & - & rotativo & $P E T_{\text {ret }}-A$ \\
\hline
\end{tabular}

O processo de eletrofiação foi realizado por 80 min, quando da utilização do coletor estático, e por $40 \mathrm{~min}$, ao ser utilizado o coletor rotativo. Os mats preparados apresentaram espessura média de 0,12 \pm 0,05 mm, a qual foi determinada utilizando-se um micrômetro. Ainda, os materiais produzidos utilizando-se o coletor estático [Figura 18] apresentaram um diâmetro médio de 5,25 $\pm 1,06 \mathrm{~cm}$ e os materiais produzidos com o uso do coletor rotativo apresentaram dimensões médias de 3,32 \pm 0,79 x 15,20 $\pm 1,10$ cm [largura x comprimento].

Figura 18 - Mat preparado com a utilização do coletor estático.

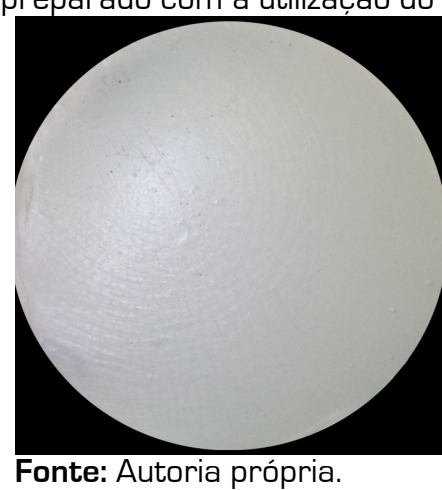

A temperatura média calculada durante os processos de eletrofiação foi de 26,3 \pm $2,2{ }^{\circ} \mathrm{C}$ e umidade relativa calculada de 45,3 \pm 4,7\%. Este controle de temperatura e umidade foi feito com o auxílio de um dispositivo de ar-condicionado e um equipamento desumidificador de ar.

\subsubsection{Caracterização dos não-tecidos [mats]}

\subsection{Espectroscopia na região do Infravermelho [IV]}

Para a obtenção dos espectros na região do Infravermelho, foi utilizado um equipamento da marca BOMEM, modelo MB-102. As pastilhas foram preparadas na proporção de $1 \mathrm{mg}$ de amostra para $100 \mathrm{mg}$ de brometo de potássio [KBr]. Previamente à realização da análise, as amostras e o KBr foram secos em estufa de circulação de ar a $105^{\circ} \mathrm{C}$ por $4 \mathrm{~h}$. 


\subsection{Microscopia Eletrônica de Varredura (MEV]}

As análises de MEV foram realizadas em um equipamento da Zeiss DSM 940, modelo 440. Foi utilizada uma voltagem de aceleração de $20 \mathrm{kV}$ e, previamente a esta análise, as amostras foram recobertas com uma fina camada de ouro (material condutor], utilizando-se para o recobrimento o equipamento Coating System MED 020 Baltec. 0 diâmetro médio das fibras, área média dos poros e porosidade média dos mats [assim como o índice de alinhamento [I.A.] e a orientação preferencial média das fibras [O.P.M.]] foram determinados utilizando-se três micrografias diferentes para cada amostra, com o auxílio do software de processamento de imagem ImageJ 1.45 [National Institutes of Health, Bethesda, Estados Unidos].

\subsubsection{3 Ângulo de contato [AC]}

O ângulo de contato dinâmico entre a gota de água deionizada e a superfície dos mats foi medido, a $25{ }^{\circ} \mathrm{C}$, utilizando-se o goniômetro CAM 200 da KSV Instruments [Helsinque, Finlândia], equipado com um software de análise de imagem CAM 2008. Uma gota de água deionizada [aproximadamente $5 \mu \mathrm{L}$ ] foi depositada na superfície dos mats [1 $\mathrm{cm} \times 1 \mathrm{~cm}$ ) que estavam fixados a uma lamínula de vidro. Os ângulos de contato, para ambos os lados da gota, foram calculados em função do tempo após $1 \mathrm{~s}$ de contato entre a gota e o substrato. Assim, em cada cálculo do ângulo de contato foram realizadas 500 medidas, coletadas individualmente a cada $1 \mathrm{~s}$ de intervalo.

\subsection{Termogravimetria [TG]}

As análises termogravimétricas foram realizadas em um analisador termogravimétrico da Shimadzu, modelo TFA-50TA. As amostras [8 mg ] foram inseridas em um porta-amostra de platina e aquecidas a uma taxa de $10{ }^{\circ} \mathrm{C} \mathrm{min}{ }^{-1}$ de $25{ }^{\circ} \mathrm{C}$ a $800{ }^{\circ} \mathrm{C}$, sob atmosfera de nitrogênio $\left[\mathrm{N}_{2}\right]$, com um fluxo de gás de $50 \mathrm{~mL} \mathrm{~min}{ }^{-1}$. Previamente a esta análise, as amostras foram secas em estufa de circulação de ar a $105^{\circ} \mathrm{C}$ por $4 \mathrm{~h}$.

\subsection{Análise Dinâmico-Mecânica [DMA]}

As análises de DMA foram realizadas em um equipamento da TA Instruments, modelo Q800, equipado com uma garra de tensão para filmes, no modo multi-frequência. Amostras com $6,4 \mathrm{~mm}$ de largura, $5 \mathrm{~mm}$ de comprimento [distância entra as duas garras] e espessura média de 0,12 \pm 0,05 mm foram analisadas de acordo com as seguintes condições experimentais: amplitude de $4 \mu \mathrm{m}$, frequência de $1 \mathrm{~Hz}$, força estática de $0,25 \mathrm{~N}$ e taxa de aquecimento de $3{ }^{\circ} \mathrm{C} \mathrm{min}^{-1}$, de $0{ }^{\circ} \mathrm{C}$ a $200{ }^{\circ} \mathrm{C}$. Foram testados no mínimo três corpos de prova de cada amostra. Previamente a esta análise, as amostras foram secas em estufa de circulação de ar a $80{ }^{\circ} \mathrm{C}$ por $4 \mathrm{~h}$. 


\subsection{Resultados e Discussão}

\subsubsection{Espectroscopia na região do Infravermelho (IV)}

A Figura 19 apresenta os espectros na região de IV para o PET reciclado, utilizado como material de partida no presente trabalho, e os espectros de PET ref e S/PET 0,40 [Tabela 1].

Figura 19 - Espectros de IV para [a] PET reciclado e seu respectivo mat PET ref, (b] Mats PET ref $_{\text {e S/PET }}$ o.40.

[a]

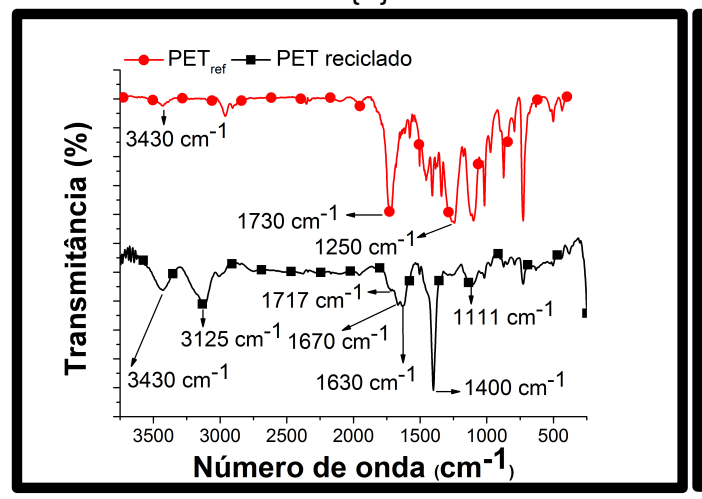

Fonte: Santos et al. [2015] [b]

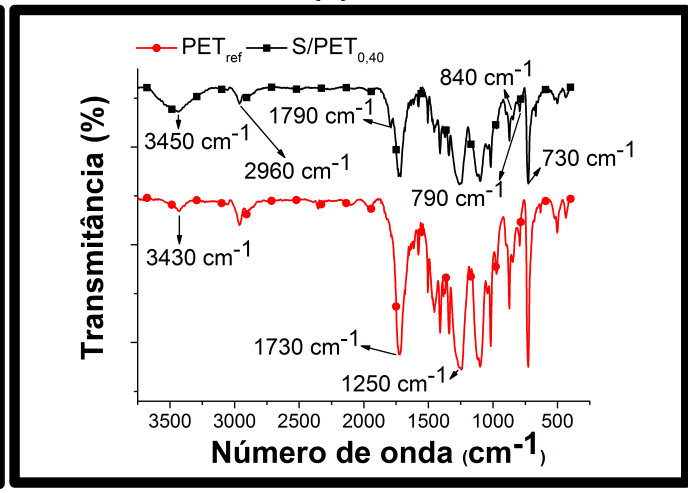

Pode-se observar que o espectro do PET reciclado [Figura 19-[a]] apresenta uma região com três bandas em aproximadamente 1630-1720 $\mathrm{cm}^{-1}$. Essas bandas podem ser atribuídas ao estiramento da ligação $-\mathrm{C}=0$ presentes em um grupo éster conjugado [aproximadamente $1730 \mathrm{~cm}^{-1}$ ], como na estrutura química do PET, assim como na estrutura do ácido tereftálico (subproduto da degradação hidrolítica do PET, que pode ocorrer durante o processo de reciclagem]. 0 espectro do PET reciclado [Figura 19-[a]] também apresenta uma banda intensa e fina em $1400 \mathrm{~cm}^{-1}$, típica da deformação angular da ligação $\mathrm{C}-\mathrm{O}-\mathrm{H}$ de grupos carboxílicos, os quais podem ser relacionados também à presença de ácido tereftálico. Ainda, observa-se também no espectro desse polímero reciclado uma banda em aproximadamente $3125 \mathrm{~cm}^{-1}$, a qual corresponde à deformação axial da ligação $\mathrm{C}-\mathrm{H}$ de grupos aromáticos presentes na estrutura do PET (Figura 10] [SANTOS et al., 2015].

No espectro de PET ref [Figura 19] observa-se uma banda em $3430 \mathrm{~cm}^{-1}$, que pode ser atribuída aos grupos hidroxilas terminais presentes na estrutura do polímero, embora essa banda seja menos intensa do que a observada para o PET reciclado [mesmo no de onda, Figura 19-[a]]. Não obstante, observa-se também no espectro de PET ret [Figura 19] outras bandas características do polímero reciclado [Figura 19-[a]].

Em todos os espectros das amostras contendo PET reciclado e sisal em suas composições, i.e., S/PET $T_{0,40}$ [Figura 19-[b]], S/PET $T_{0,20}, \mathrm{~S} / \mathrm{PET}_{0,13}$ e $\mathrm{S} / \mathrm{PET}_{0,10}$ [Figuras não mostradas], além das bandas características do polímero reciclado [Figura 19-[a]], foram observadas bandas correspondentes aos grupos presentes na estrutura da celulose, como grupos hidroxila [aproximadamente em $3400 \mathrm{~cm}^{-1}$ ] e deformações axiais da ligação $\mathrm{C}-\mathrm{H}$ [aproximadamente em $2900 \mathrm{~cm}^{-1}$ ], por exemplo. Ainda, no espectro de S/PET 0,40 
[Figura 19-[b]], também foram observadas bandas típicas de material lignocelulósico. Os picos nas regiões de $1630 \mathrm{~cm}^{-1}$ e $1505 \mathrm{~cm}^{-1}$ podem ser atribuídos às vibrações da estrutura aromática da lignina, enquanto que a banda em aproximadamente $1730 \mathrm{~cm}^{-1}$ pode ser atribuída à ligação $-\mathrm{C}=\mathrm{O}$ do grupo acetila ou grupos $\mathrm{COOH}$ presentes na estrutura das hemiceluloses [SANTOS et al., 2015]. A banda que ocorre na mesma região do estiramento da ligação $-\mathrm{C}=0$ presente na estrutura do $\mathrm{PET}$, pode também ser atribuída a uma soma das contribuições, tanto do polímero reciclado, quanto das hemiceluloses [SANTOS et al., 2015].

0 TFA pode atuar como agente esterificante de grupos hidroxila, como os presentes nas estruturas químicas dos componentes lignocelulósicos das fibras de sisal, denominados celulose, hemiceluloses e lignina [Figura 20, reação de esterificação].

Figura 20 - Principais componentes da fibra lignocelulósica de sisal e seus principais sítios reativos susceptiveis à esterificação pelo TFA .

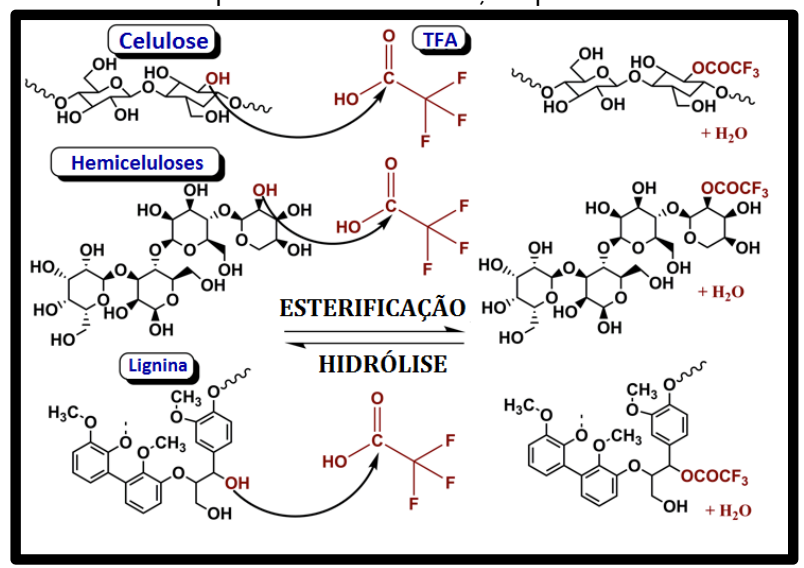

Fonte: Adaptado de Santos et al. [2015].

Assim, no caso de esterificação (Figura 20), uma banda correspondente à absorção de grupos trifluoroacetilas [1790 $\mathrm{cm}^{-1}$ ] seria observada no espectro de IV do material regenerado (MONTAÑO-LEYVA et al., 2011). Embora um pequeno "ombro" possa ser observado nos espectros dos mats contendo sisal, como no espectro de $\mathrm{S} / \mathrm{PET}_{0,40}\left[1790 \mathrm{~cm}^{-1}\right.$, Figura 19-[b]], sabe-se que a exposição constante ao ar [devido à presença da umidade] leva a uma completa hidrólise dos grupos trifluoroacetilas [HASEGAWA et al., 1992) [Figura 20, reação de hidrólise]. Rodrigues et al. [2015], em seu estudo, reportaram a ausência de bandas na região de $1790 \mathrm{~cm}^{-1}$ para a fibra lignocelulósica de sisal eletrofiada, após dois dias de secagem à temperatura ambiente, indicando a hidrólise de quaisquer possíveis grupos trifluoroacetilas resultantes da reação de esterificação.

\subsubsection{Microscopia Eletrônica de Varredura [MEV]}

A Figura 21 apresenta as micrografias dos mats $\mathrm{PET}_{\text {ref, }} \mathrm{S} / \mathrm{PET}_{0,40}, \mathrm{~S} / \mathrm{PET} \mathrm{T}_{0,20}$, $\mathrm{S} / \mathrm{PET}_{0,13}$ e S/PET $\mathrm{T}_{0,10}$, preparados com o uso do coletor estático. 
Figura 20 - Micrografias de PET ref, S/PET $T_{0,40}, \mathrm{~S} / \mathrm{PET}_{0,20}, \mathrm{~S} / \mathrm{PET}_{0,13}$ e S/PET $\mathrm{T}_{0,10}$

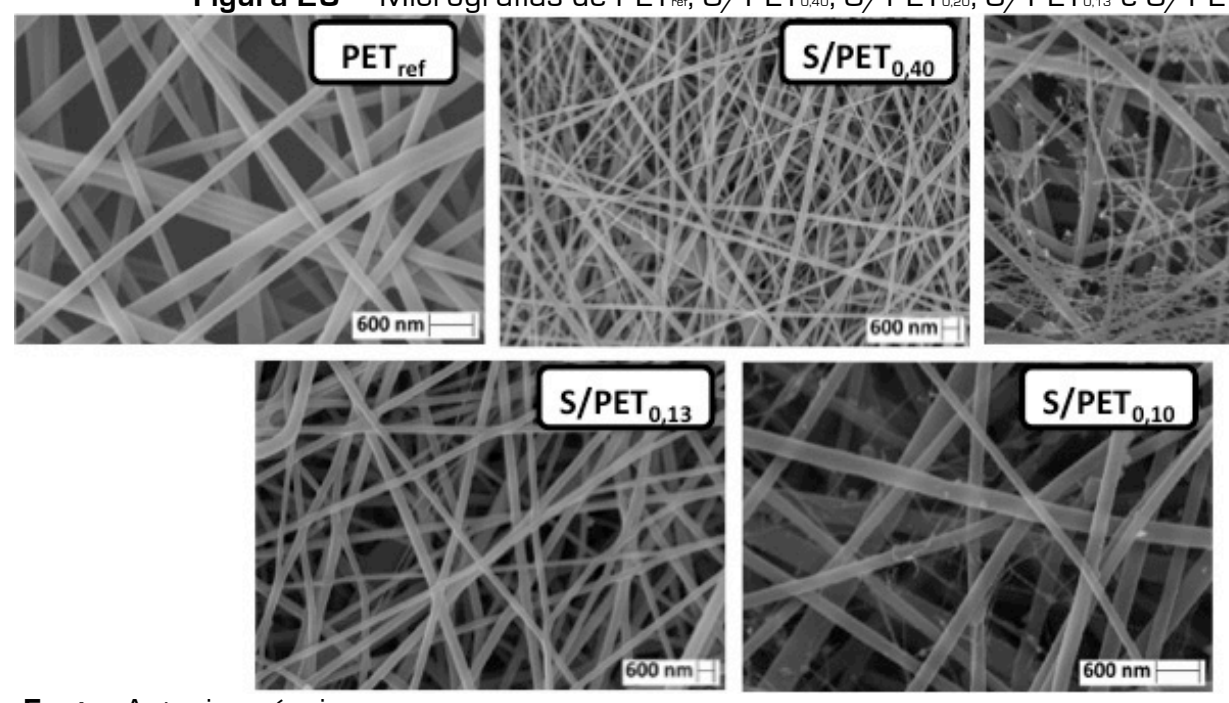

$\mathrm{S} / \mathrm{PET}_{0,20}$

Fonte: Autoria própria.

A Figura 22 apresenta o diâmetro médio das fibras, área média do poro e porosidade média dos mats obtidos via eletrofiação. 
Figura 21 - Diâmetro médio das fibras, área média do poro e porosidade média dos mats obtidos via eletrofiação.

[a]

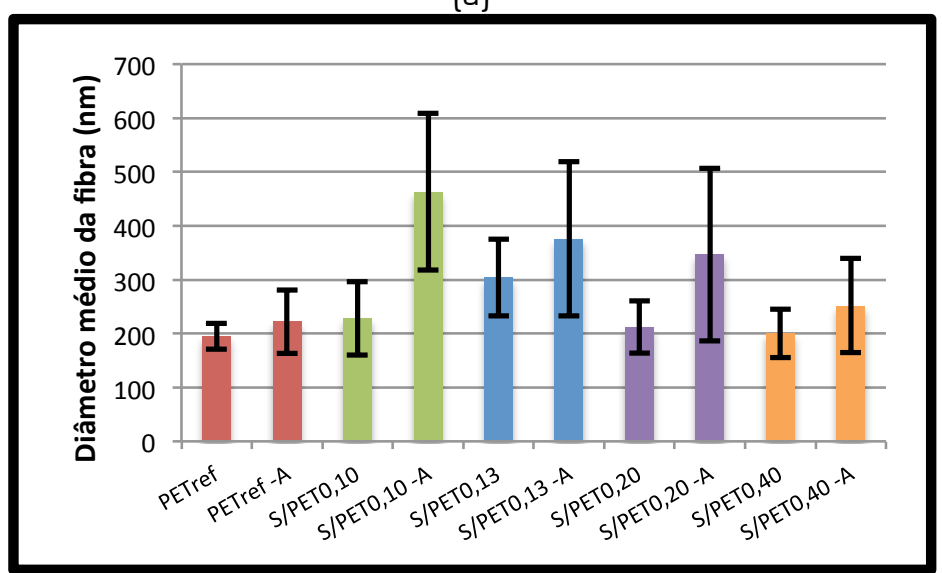

[b]

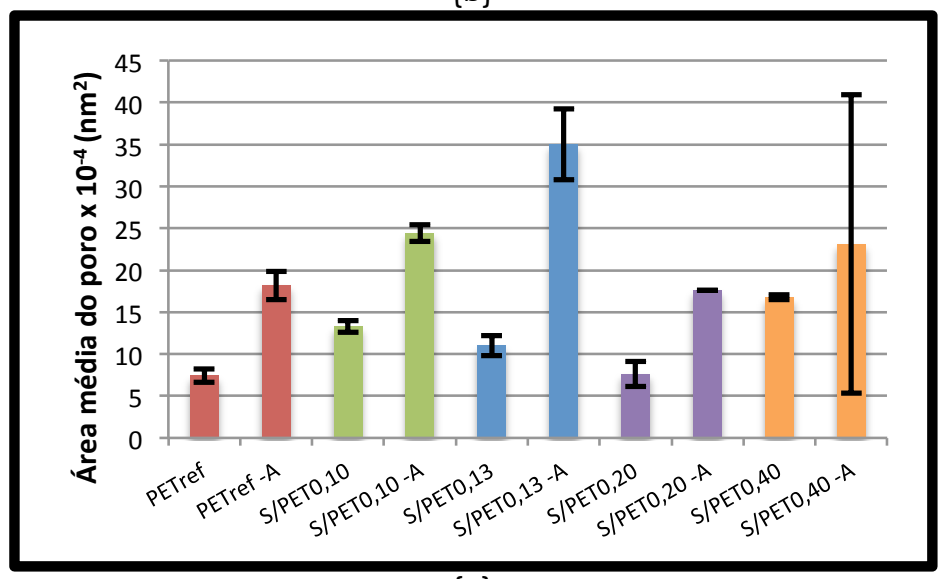

[c]



Fonte: Autoria própria.

Observa-se na micrografia de $\mathrm{PET}_{\text {ref }}$ (Figura 21] uma rede de fibras [aleatoriamente orientadas] homogênea, com diâmetros de fibra variando entre 185 a 284 nm, com diâmetro médio de 195,2 \pm 24,1 nm [Figura 22-[a]], indicando a formação de fibras ultrafinas [ou submicrométricas, diâmetros acima de $100 \mathrm{~nm}$ e abaixo de $1 \mu \mathrm{m}$ ). Ainda, de acordo com a Figura 22-[a], não foram observadas diferenças significativas com relação ao diâmetro médio das fibras de $\mathrm{PET}_{\text {ref }}$ e $\mathrm{PET}_{\text {ref }}-\mathrm{A}$ lo qual apresentou uma rede de fibras com diâmetros variando de 120 a 360 nm, com diâmetro médio de 222,4 59,1nm]. 
No entanto, ao se comparar os valores de desvio-padrão do diâmetro médio de $P E T_{\text {ref }}$ e $\mathrm{PET}_{\text {ref }}-\mathrm{A}\{ \pm$ 24,1 nm e \pm 59,1 nm, respectivamente [Figura 22-[a]] observa-se que os valores do diâmetro das fibras de $\mathrm{PET}_{\text {ref }}$ foram mais convergentes, em comparação aos valores do diâmetro das fibras de $\mathrm{PET}_{\text {ret }}-\mathrm{A}$ [o que representa uma maior distribuição dos valores de diâmetro das fibras deste mat [Figura 25], em comparação a PET ref [Figura 23)].

Veleirinho et al. [2008], em seu estudo, reportaram a preparação de mats, via técnica de eletrofiação, à partir de PET e utilizando o mesmo solvente [TFA] considerado no presente trabalho. Neste estudo foram preparadas fibras com diâmetros médios de 194 nm, 330 nm e 505 nm, aumentando-se a concentração de PET [massa/volume] na composição das soluções [10\%, 20\% e 30\%, respectivamente]. Assim, o diâmetro médio das fibras de $\mathrm{PET}_{\text {ret }}$ [195,2 \pm 24,1 nm, em uma concentração de 15\% massa/volume] obtidas no presente estudo foi semelhante ao das fibras obtidas por Veleirinho et al. [VELEIRINHO; REI; LOPES-DA-SILVA, 2008] para uma concentração de polímero de 10\% massa/volume [fibras com diâmetro médio de $194 \mathrm{~nm}$ ].

Nos mats [preparados com o uso do coletor estático] contendo fibra de sisal em suas composições (Figura 21), duas redes de fibras distintas, com fibras entrecruzandose, foram observadas, uma rede de fibras mais espessas $\{200,1 \pm 45,3 \mathrm{~nm}$ [S/PET 0.40 ,

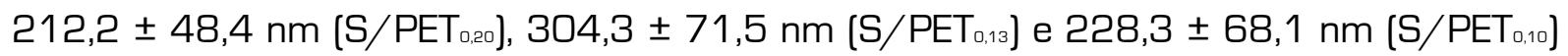
[Figura 22-[a]]\} e outra com fibras mais finas [81,2 $\pm 16,1 \mathrm{~nm}$ [S/PET $\left.\mathrm{P}_{0,40}\right], 35,3 \pm 6,2 \mathrm{~nm}$ [S/PET $T_{0,20}$, 54,2 \pm 14,6 nm [S/PET 0,13$]$ ].

A rede de fibras mais finas de S/PET 0,10 apresentou fibras com diâmetros abaixo do limite confiável para a determinação dos mesmos via software de processamento de imagem ImageJ 1.45. Ambas as redes distintas de fibras apresentaram as mesmas orientadas aleatoriamente. Assim, pode-se concluir que uma rede de fibras possivelmente corresponde principalmente a fibras de PET reciclado [rede de fibras ultrafinas homogênea, como observado para $\mathrm{PET}_{\text {ret }}$ (Figura 21], com um diâmetro médio de fibra muito superior ao da outra rede de fibras mais finas] e a outra rede possivelmente corresponde principalmente aos componentes da fibra de sisal [nanofibras [presentes em menor quantidade] com diâmetro médio inferior ao da outra rede de fibras mais espessas].

Foi observada a presença de alguns beads ao longo da rede de fibras de S/PET $\mathrm{P}_{0,20} \mathrm{e}$ $\mathrm{S} / \mathrm{PET}_{0,10}$ (Figura 21), fazendo-se necessário futuras investigações visando otimizar as condições de eletrofiação, minimizando a ocorrência desses erros. Apesar da presença de beads, até onde se tem conhecimento, o presente trabalho foi pioneiro na investigação do comportamento de um polímero reciclado e fibra lignocelulósica nativa, quando eletrofiados à partir de uma solução contendo ambos em sua composição. A indicação de eletrofiação separada do PET reciclado e das fibras de sisal, observada no presente trabalho, pode ser atribuída às diferenças na solubilidade dos componentes em TFA e nas 
constantes dielétricas de ambos os componentes (parâmetros que possivelmente afetaram o processo de eletrofiação das soluções mistas de PET/sisal, levando à eletrofiação separada do polímero reciclado e dos componentes da fibra lignocelulósica, como a celulose]. Esse fenômeno também foi observado por Jung et al. [2007) na eletrofiação de soluções de PET/quitina em HFIP. Neste estudo, as micrografias das amostras revelaram fibras de morfologia contínua, com fibras muito finas interceptando outras mais espessas.

Para os mats preparados com o uso do coletor estático, enquanto observou-se que o PET e o sisal eletrofiaram separadamente, uma tendência na direção do aumento no diâmetro médio das fibras, atribuída à presença de PET, também foi notada quando o sisal estava presente \{diâmetros de 195,2 \pm 24,1 nm [PET rê] até 304,3 \pm 71,5 nm [S/PET 0.13 ] [Figura 22-[a]]\}, ambos os mats obtidos à partir da eletrofiação de soluções com a mesma concentração de polímero reciclado [Tabela 1]].

A presença dos componentes lignocelulósicos e as diferentes razões de fibra de sisal/PET [Tabela 1] levaram a soluções com elevadas viscosidades, em comparação a $\mathrm{PET}_{\text {ref, }}$ o que pode influenciar o diâmetro médio das fibras de PET. No entanto, a tendência com relação ao aumento no diâmetro das fibras também pode indicar que os componentes lignocelulósicos [principalmente celulose] foram, pelo menos parcialmente, eletrofiados em combinação com as cadeias de PET, com a consequente geração de fibras ultrafinas híbridas. Lignina [o componente minoritário da fibra de sisal, 11,7\%, item 1.2.1], uma macromolécula aromática, possivelmente eletrofiou em combinação com o PET [polímero contendo anéis aromáticos em sua estrutura química [Figura 10]]. Embora nenhuma outra evidência conclusiva tenha sido obtida a partir das imagens de MEV [Figura 21], os resultados com relação à temperatura de transição vítrea [ $T_{g}$, item 1.3.5] dos mats corroboram essa hipótese.

Para os mats preparados utilizando-se o coletor estático, visando explorar melhor a influência da presença de fibra lignocelulósica no diâmetro médio das fibras mais espessas [consideradas como sendo principalmente compostas por PET], foram calculados histogramas de distribuição de frequência de diâmetro, sendo realizadas pelo menos 100 medidas para cada amostra de fibras. A Figura 23 apresenta os histogramas obtidos para $\mathrm{PET}_{\text {ref }}$ e os demais materiais preparadas via eletrofiação. 
Figura 22 - Histogramas do diâmetro de fibra dos mats PET ref, S/PET $T_{0,40}, \mathrm{~S}_{\mathrm{PET}} \mathrm{PE}_{0,20}, \mathrm{~S} / \mathrm{PET}_{0,13}$ e S/PET 0.10.



Fonte: Autoria própria.



Observa-se nos histogramas da Figura 23 que, para as fibras mais espessas, a presença da fibra lignocelulósica na composição das mesmas levou não somente a valores de diâmetros médios maiores, mas também influenciou na maior distribuição do diâmetro das fibras, em comparação com o histograma de $\mathrm{PET}_{\text {ref. }}$ Este fato também é corroborado comparando-se os desvios-padrão de PET ref $[ \pm 24,1 \mathrm{~nm}$, Figura 22-[a]] com o dos mats contendo sisal em suas composições $\{ \pm 45,3 \mathrm{~nm}, \pm 48,4 \mathrm{~nm}, \pm 71,5 \mathrm{~nm}$ e $\pm 68,1 \mathrm{~nm}$ para S/PET $0,40, \mathrm{~S} / \mathrm{PET}_{0,20}, \mathrm{~S} / \mathrm{PET}_{0,13}$ e S/PET 0,10 , respectivamente [Figura 22-[a]]\}.

Com relação à área média dos poros dos mats preparados com o uso do coletor estático [Figura 22-[b]], também foi observado um aumento nestes valores [com exceção de $\left.S / P E T_{0,20}\right]$ com a adição de sisal à composição dos materiais [13,3 $\pm 0,7 \times 10^{4} \mathrm{~nm}^{2}$ [S/PET $\left.T_{0,10}\right], 11,0 \pm 1,2 \times 10^{4} \mathrm{~nm}^{2}\left[\mathrm{~S} / \mathrm{PET}_{0,13}\right], 7,6 \pm 1,5 \times 10^{4} \mathrm{~nm}^{2}\left[\mathrm{~S} / \mathrm{PET}_{0,20}\right]$ e 16,8 $\pm 0,3 \mathrm{x}$ $10^{4} \mathrm{~nm}^{2}$ [S/PET $\left.T_{0,40}\right]$ ], em comparação ao mat contendo apenas polímero reciclado em sua composição ( $\mathrm{PET}_{\text {ret, }} 7,4 \pm 0,8 \times 10^{4} \mathrm{~nm}^{2}$ ]. Pode-se observar também, com relação aos valores de porosidade média [Figura 22-[c]] dos mats preparados com o uso do coletor estático, uma tendência, no geral, de aumento progressivo para esta propriedade [18,5 \pm 0,4\% [S/PET ${ }_{0,10}$ ], 27,6 \pm 7,4\% [S/PET $T_{0,13}$ ], 30,2 \pm 7,9\% [S/PET $\mathrm{P}_{0,20}$ ] e 48,7 \pm 4,5\% [S/PET $\left.T_{0,40}\right]$ com o aumento da proporção de sisal/PET reciclado na composição dos materiais [Tabela 1]. Destaca-se que esse aumento da área média do poro e porosidade média para os mats S/PET $T_{0,40}, \mathrm{~S} / \mathrm{PET}_{0,20}, \mathrm{~S} / \mathrm{PET}_{0,13}$ e S/PET $\mathrm{T}_{0,10}$ [Figura 22-(b],[c]] é uma possivel consequência da maior heterogeneidade das fibras formadas, com a adição de sisal à composição desses materiais, e a possível eletrofiação separada e conjunta do PET reciclado e dos componentes da fibra lignocelulósica.

A Figura 24 apresenta as micrografias, as respectivas imagens codificadas por cores e a escala de orientação de cores, assim como o I.A. e a O.P.M. das fibras para os mats, preparados com o uso de um coletor rotativo, $\mathrm{PET}_{\text {ref }}-\mathrm{A}, \mathrm{S} / \mathrm{PET}_{0,40}-\mathrm{A}, \mathrm{S} / \mathrm{PET} \mathrm{T}_{0,20}-\mathrm{A}$, S/PET $0,13-A$ e S/PET $0,10-A$ [Tabela 1]. 
Figura 23 - Micrografias, respectivas imagens codificadas por cores, escala de orientação de cores, I.A. e O.P.M. dos mats PET ret $-A, S / P E T_{0,40}-A, S / P E T_{0,20}-A, S / P E T_{0,13}-A$ e S/PET $0.10-A$.

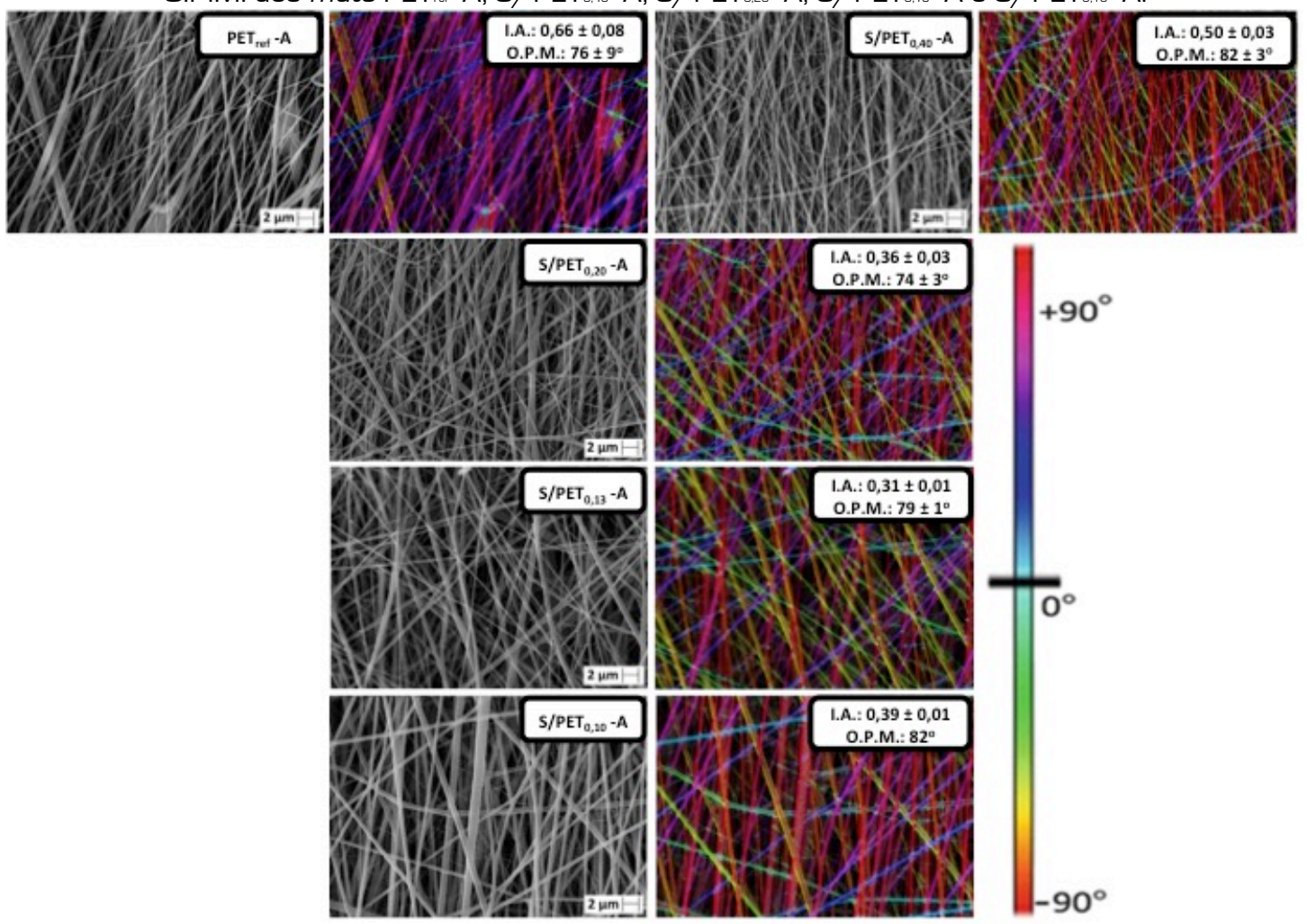

Fonte: Autoria própria.

A Figura 25 apresenta os histogramas do diâmetro de fibra dos mats $P E T_{\text {ref }}-A$, S/PET $0,40-A, S / P E T_{0,20}-A, S / P E T_{0,13}-A$ e S/PET $T_{0,10}-A$, preparados com o uso do coletor rotativo.

Figura 24 - Histogramas do diâmetro de fibra dos mats $P E T_{\text {ret }}-A, S / P E T_{0,40}-A, S / P E T_{0,20}-A, S / P E T_{0,13}-A$ e $\mathrm{S} / \mathrm{PET}_{0,10}-\mathrm{A}$.

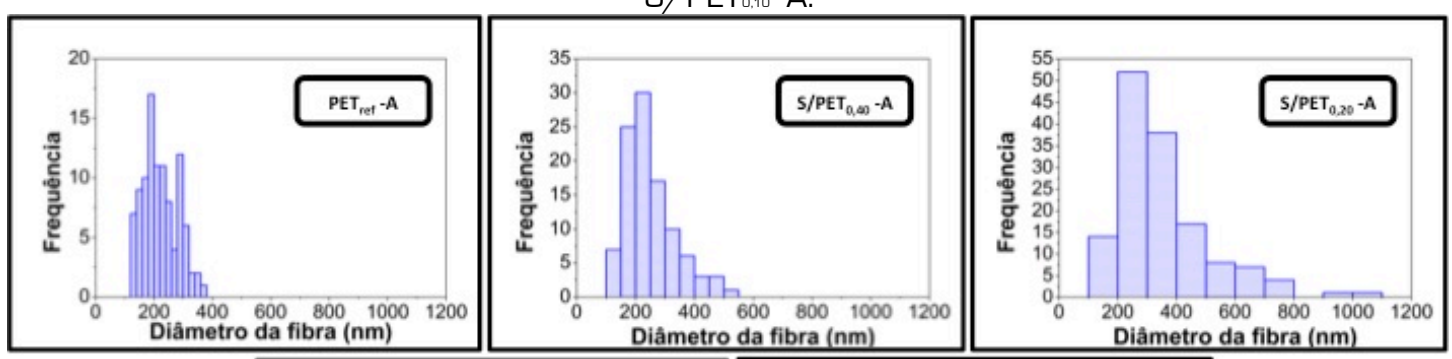

Fonte: Autoria própria.

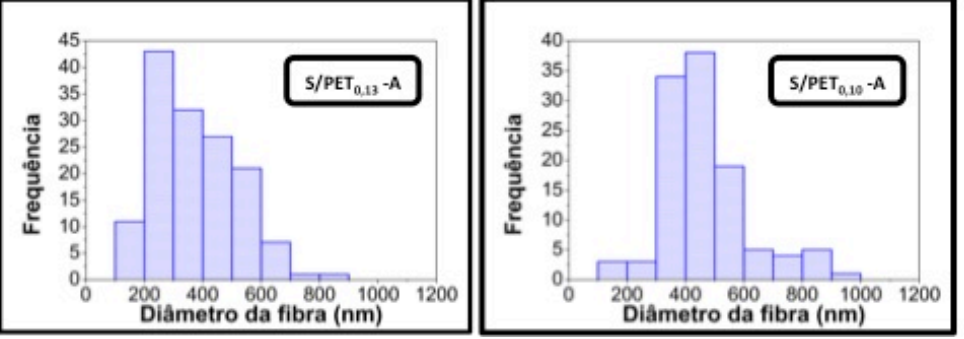

Observa-se nos histogramas da Figura 25 que, assim como nos histogramas da Figura 23 para os mats preparados com o uso do coletor estático, houve uma maior 
variação nos valores dos diâmetros das fibras contendo sisal em suas composições, em comparação às fibras de $\mathrm{PET}_{\text {ref }}-\mathrm{A}$. Em concordância com o que foi apresentado nas micrografias da Figura 21, observou-se na Figura 24 que todos os mats contendo sisal em suas composições apresentaram duas redes de fibras distintas. Assim, uma rede foi formada por fibras mais espessas $\left\{251,9 \pm 87,5 \mathrm{~nm}\right.$ [S/PET , $\left.40_{0}-A\right], 346,7 \pm 160,7 \mathrm{~nm}$ \{S/PET $T_{0,20}-\mathrm{A}$ ], 375,8 \pm 143,2 nm [S/PET $0,13-\mathrm{A}$ ] e 462,9 \pm 145,4 nm [S/PET 22-[a]]\} e outra por fibras tão finas que, consequentemente, os diâmetros ficaram abaixo do limite confiável para determinação dos mesmos via software de processamento de imagem ImageJ 1.45. Este resultado para os mats preparados com o uso do coletor rotativo corrobora a hipótese de que, possivelmente, ocorreu, pelo menos em parte, a eletrofiação separada do PET reciclado e dos componentes da fibra lignocelulósica de sisal [como também foi observado para os materiais preparados utilizando-se o coletor estático]. Ainda, observou-se na micrografia de S/PETo,13 -A [Figura 24] a presença de beads entre as distintas redes de fibras formadas.

No geral, não foram observadas diferenças significativas nos diâmetros médios das fibras mais espessas dos mats [contendo sisal em suas composições] preparados com o uso do coletor rotativo $\left\{251,9 \pm 87,5 \mathrm{~nm}\left[\mathrm{~S} / \mathrm{PET}_{0,40}-\mathrm{A}\right.\right.$ ], 346,7 \pm 160,7 nm [S/PET $\mathrm{P}_{0,20}-\mathrm{A}$ ], 375,8 \pm 143,2 nm [S/PET $\left.{ }_{0,13}-A\right]$ e 462,9 \pm 145,4 nm [S/PET $\left.T_{0,10}-A\right]$ [Figura 22-[a]]\}, em comparação aos diâmetros médios das fibras mais espessas dos mats (de mesma composição] preparados utilizando-se o coletor estático $\left\{200,1 \pm 45,3 \mathrm{~nm}\right.$ [S/PET $\mathrm{P}_{0,40}$ ],

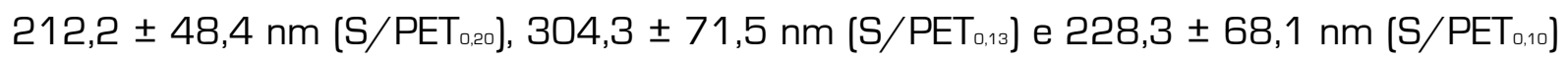
[Figura 22-[a]]\}. Também foi possivel observar na Figura 22-[a] que os valores de diâmetro médio das fibras dos mats contendo sisal em suas composições, preparados com o uso do coletor rotativo, apresentaram-se mais divergentes, em comparação aos valores apresentados pelas fibras dos mats, de mesma composição, preparados utilizando-se o coletor estático. Este fato é suportado ao compararmos os superiores valores de desvio-padrão apresentados pelos materiais preparados com o uso do coletor rotativo, com os valores inferiores apresentados pelos materiais preparados utilizando-se o coletor estático $\left\{ \pm 87,5 \mathrm{~nm}\right.$ [S/PET ${ }_{0,40}-\mathrm{A}$ ], \pm 160,7 nm [S/PET $\mathrm{P}, 20-\mathrm{A}$ ], \pm 143,2 nm [S/PET $\mathrm{P}_{0,13}-\mathrm{A}$ ], $\pm 145,4 \mathrm{~nm}\left[\mathrm{~S} / \mathrm{PET}_{0,10}-\mathrm{A}\right] \mathrm{com} \pm$ 45,3 nm [S/PET $\mathrm{P}_{0,40}$ ], \pm 48,4 nm [S/PET $\mathrm{PE}_{0,20}$ ], $\pm 71,5 \mathrm{~nm}\left[\mathrm{~S} / \mathrm{PET}_{0,13}\right.$ ] e \pm 68,1 nm [S/PET 0,10 [Figura 22-[a]]\}.

Com relação aos valores de área média do poro [Figura 22-[b]] e porosidade média [Figura 22-[c]] para os materiais preparados com o uso do coletor rotativo, observa-se que, assim como apresentado pelos mats preparados com o uso do coletor estático [Figura 22-[b],[c]], houve também, no geral, um aumento nesses valores com a adição de sisal à composição dos materiais, em comparação aos valores apresentados por $\mathrm{PET}_{\text {ref }}-\mathrm{A}$. Este fato é uma possivel consequência também da maior heterogeneidade das fibras formadas, com a adição de sisal à composição desses materiais, e a possível eletrofiação tanto separada como conjunta do PET reciclado e dos componentes da fibra 
lignocelulósica.

Observa-se na Figura 22-[b], com relação à área média do poro, que os mats preparados com o uso do coletor rotativo apresentaram valores $\left\{18,2 \pm 1,7 \times 10^{4} \mathrm{~nm}^{2}\right.$ [PET ref $-A$ ], 24,4 $\pm 1,0 \times 10^{4} \mathrm{~nm}^{2}$ [S/PET $0,10-A$ ], 35,0 $\pm 4,2 \times 10^{4} \mathrm{~nm}^{2}$ [S/PET $0,13-A$ ], 17,6 x $10^{4} \mathrm{~nm}^{2}\left[\mathrm{~S} / \mathrm{PET}_{0,20}-\mathrm{A}\right]$ e 23,1 $\pm 17,8 \times 10^{4} \mathrm{~nm}^{2}$ [S/PET $\mathrm{P}_{0,40}-\mathrm{A}$ ] [Figura 22-(b)]\}, no geral, superiores e mais divergentes, em comparação com os valores apresentados pelos mats de mesma composição, mas preparados utilizando-se o coletor estático $\left\{7,4 \pm 0,8 \times 10^{4}\right.$ $\mathrm{nm}^{2}$ [PET $\mathrm{Pef}_{\text {ref }}-\mathrm{A}$ ], 13,3 $\pm 0,7 \times 10^{4} \mathrm{~nm}^{2}$ [S/PET $\mathrm{P}_{0,10}-\mathrm{A}$ ], 11,0 $\pm 1,2 \times 10^{4} \mathrm{~nm}^{2}$ [S/PET $0,13-\mathrm{A}$ ], 7,6 $\pm 1,5 \times 10^{4} \mathrm{~nm}^{2}\left[\mathrm{~S} / \mathrm{PET}_{0,20}-\mathrm{A}\right.$ ] e 16,8 $\pm 0,3 \times 10^{4} \mathrm{~nm}^{2}$ [S/PET $\mathrm{P}_{0,40}-\mathrm{A}$ ] [Figura 22-[b]]\}.

No geral, não foi possível observar uma tendência nos valores de porosidade média dos mats preparados com o uso do coletor rotativo $\{12,3 \pm 0,2 \%$ (PET ref $-A], 24,4 \pm 0,8 \%$


$\left[\mathrm{S} / \mathrm{PET}_{0,40}-\mathrm{A}\right]$ [Figura 22-[c]]\},em comparação com o apresentado pelos materiais de mesma composição, mas preparados utilizando-se o coletor estático $\left\{15,9 \pm 2,7 \%\right.$ [PET ret $_{\text {ret }}$, $18,5 \pm 0,4 \%$ [S/PET $\mathrm{P}_{0,10}$ ], 27,6 \pm 7,4\% [S/PET $\mathrm{P}_{0,13}$ ], 30,2 \pm 7,9\% [S/PET $\mathrm{P}_{0,20}$ ] e 48,7 \pm 4,5\% [S/PET 0,40$]$ [Figura 22-[c]]\}.

Destaca-se que os mats preparados com o uso do coletor rotativo, contendo sisal em suas composições [S/PET $T_{0,40}$-A, S/PET P,20 $_{0}$-A, S/PET $T_{0,13}$-A e S/PET $T_{0,10}$-A], devido, possivelmente, à heterogeneidade das fibras formadas [formação de duas redes distintas de fibras, Figura 24], apresentaram I.A. [Figura 24] inferior ao observado para o mat contendo apenas polímero reciclado em sua composição [PET ref $_{-}-A$, Figura 24].

\subsection{3 Ângulo de contato $[A C]$}

A caracterização das propriedades hidrofílicas/hidrofóbicas de um material é essencial para a detecção de possíveis aplicações do mesmo. Além disso, a possibilidade de controlar essas propriedades pode ser extremamente útil, quando é solicitado ou desejado um certo grau de hidrofilicidade/hidrofobicidade do material produzido. Assim, visando avaliar os efeitos dos componentes da fibra de sisal nas propriedades de superfície dos mats, foram medidos os ângulos de contato entre a superfície dos mesmos e a gota de água. Os resultados do ângulo de contato de avanço [ACA], que corresponde ao máximo valor do ângulo de contato, são apresentados na Figura 26. 
Figura 25 - ACA para os mats preparados utilizando-se o coletor estático e rotativo .

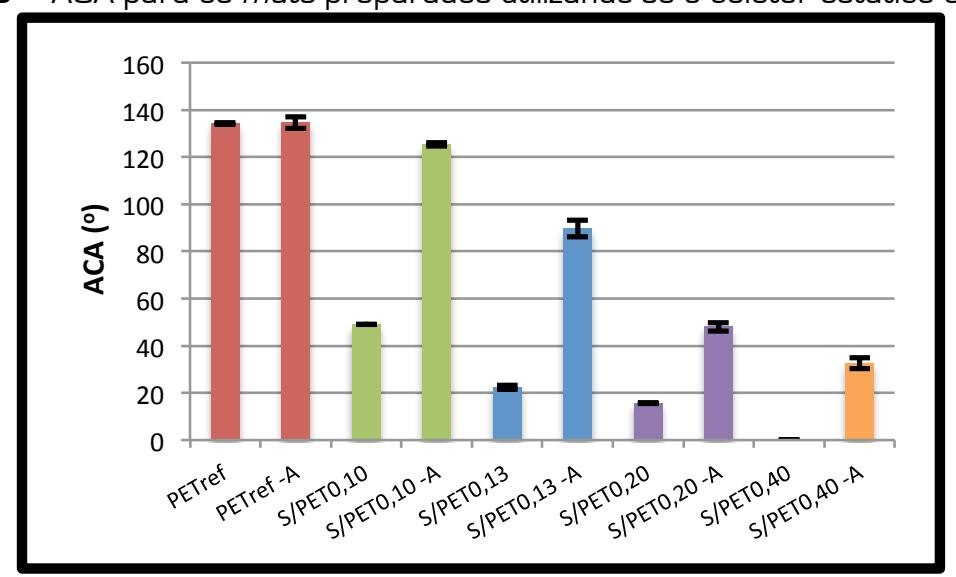

Fonte: Autoria própria.

A adição de fibras de sisal na composição dos mats (tanto os preparados com a utilização do coletor estático, como os preparados com o uso do coletor rotativo] levou a materiais com superfícies com propriedade hidrofílica, consideravelmente diferenciada daquela de $P E T_{\text {ret, }}$ principalmente para os materiais preparados utilizando-se o coletor estático. Assim, para estes mats, o ACA diminuiu de 134,2 $\pm 0,3^{\circ}$ [PET ref para 49,0 \pm 0,1


instantânea da gota de água pela superfície do mat], conforme aumentou-se a razão fibra de sisal/PET reciclado na composição desses materiais (Figura 26). Destaca-se que, no geral, houve um aumento progressivo nos valores de porosidade média dos mats preparados com o uso do coletor estático [Figura 22-[c]], conforme aumentou o teor de sisal na composição dos mesmos, o que pode ter contribuído também para o aumento da hidrofilicidade da superfície desses materiais.

Observa-se na Figura 26 que, para os materiais preparados com o uso do coletor rotativo, houve a diminuição nos valores do ACA, conforme aumentou-se a razão fibra de sisal/PET na composição dos mesmos. No entanto, essa diminuição nos valores foi consideravelmente menos acentuada que para os mats preparados com o uso do coletor estático [Figura 26].

Para os materiais preparados utilizando-se o coletor rotativo, o ACA [Figura 26] diminuiu de 134,6 $\pm 2,4^{\circ}\left(\mathrm{PET}_{\text {ret }}-\mathrm{A}\right]$ para $125,4 \pm 0,7^{\circ}$ [S/PET $\mathrm{P}, 10^{-A}$ ], 89,7 $\pm 3,5^{\circ}\left[\mathrm{S} / \mathrm{PET}_{0,13}\right.$ A], 48,0 \pm 1,9 $9^{\circ}\left[\mathrm{S} / \mathrm{PET}_{0,20}-\mathrm{A}\right.$ ) e 32,5 $\pm 2,3^{\circ}$ [S/PET $\mathrm{P}, 40-\mathrm{A}$, com a absorção da gota de água pela superfície do mat após aproximadamente $40 \mathrm{~s}$ de contato]. Ainda, de acordo os valores de desvio padrão do ACA da Figura 26, observa-se que os valores de ACA dos mats preparados com o uso do coletor rotativo apresentaram-se mais divergentes, em comparação aos valores apresentados pelos materiais preparados com o uso do coletor estático. Assim, pode-se concluir que, quando as fibras orientadas em uma direção preferencial de alinhamento foram geradas, estas apresentaram superfícies menos hidrofílicas, em comparação às fibras, de mesma composição, preparadas com o uso do coletor estático. Este fato sugere que, na eletrofiação de soluções mistas de PET reciclado 
e sisal, com a mudança do tipo de coletor de estático para rotativo, e também na taxa de vazão das soluções [de 5,5 $\mu \mathrm{L} \min ^{-1}$ para 25,5 $\mu \mathrm{L} \min ^{-1}$ ], a celulose e hemiceluloses eletrofiaram, majoritariamente, em combinação com as cadeias de PET [formação de fibras híbridas], com contribuição significativa das cadeias hidrofóbicas de PET para as propriedades de superfície dos mats produzidos. Para estes materiais preparados com o uso do coletor rotativo, não foi observada qualquer tendência que relacionasse os valores de porosidade média [Figura 22-[c]] e o caráter hidrofóbico/hidrofilico da superfície dos mesmos.

Não se pode deixar de considerar que, como mencionado anteriormente, a mudança observada nos valores do ACA [Figura 26] é um indicativo da presença de grupos polares das fibras de sisal na superfície dos mats, o que favorece as interações com a gota de água. Assim, possivelmente, esses resultados indicam que, tanto para as fibras produzidas com o uso do coletor estático, quanto para as fibras produzidas utilizando-se o coletor rotativo, onde os componentes do sisal foram eletrofiados separadamente das cadeias de PET e/ou nas fibras onde esses componentes foram eletrofiados conjuntamente [fibras híbridas], muitos grupos polares, principalmente os presentes na estrutura da celulose [componente majoritário da fibra de sisal], estavam orientados em direção à superfície.

O elevado valor do ACA entre a gota de água e a superfície de PET $T_{\text {ref }}$ (Figura 26] contrasta consideravelmente com os pequenos ângulos quando as fibras de sisal estão presentes na composição dos mats. Com a incorporação das fibras de sisal foram geradas superfícies super hidrofílicas, fato observado principalmente para S/PET 0,40 , na qual a gota de água, como mencionado anteriormente, foi instantaneamente absorvida após $1 \mathrm{~s}$ de contato com a superfície da amostra [Figura 26). As propriedades de superfície, como a molhabilidade, possuem uma forte dependência com a morfologia e composição das membranas (LI et al., 2013, 2009; MA et al., 2005). Assim, enquanto a água não foi capaz de penetrar na superfície de $P E T_{\text {ref }}$ e $P E T_{\text {ref }}-A$, a presença das fibras de sisal eletrofiadas criou uma superfície inerentemente hidrofílica, a qual por sua vez permitiu que a água penetrasse e enchesse pelo menos parte dos microporos presentes entre as fibras [Figura 21 e Figura 24].

\subsubsection{Termogravimetria [TG]}

A Figura 27 apresenta as curvas dTG para o PET reciclado e os mats obtidos via eletrofiação [utilizando-se o coletor estático]. 
Figura 26 - Curvas dTG para [a] PET reciclado e seu respectivo mat $\mathrm{PET}_{\text {ref, }}$ (b) Mats $\mathrm{PET}_{\text {ret }}$ e S/PET (b.10 $_{\text {e [c] }}$ Mats S/PET ${ }_{0,40} ; \mathrm{S} / \mathrm{PET}_{0,20} ; \mathrm{S} / \mathrm{PET}_{0,13} ; \mathrm{S} / \mathrm{PET}_{0,10}$ [atmosfera de $\mathrm{N}_{2}$, fluxo de $50 \mathrm{~mL} \mathrm{~min}^{-1}$ e taxa de aquecimento de $10^{\circ} \mathrm{C} \min ^{-1}$



Fonte: Santos et al. [2015].

PET reciclado e seu respectivo mat $\mathrm{PET}_{\text {ref }}$ exibiram curvas TG [Figuras não mostradas] e dTG [Figura 27-[a]] similares. Também foi observado, para ambas as curvas, no intervalo de aproximadamente $340-500^{\circ} \mathrm{C}$, um único estágio de perda de massa, o qual pode ser atribuído à decomposição do polímero reciclado. Ambas as amostras apresentaram a temperatura de máxima taxa de perda de massa [ $\mathrm{T}_{\mathrm{p}}$ ] em $448{ }^{\circ} \mathrm{C}$ [Figura 27-[a]]. Ainda, de acordo com a Figura 27-[a] e diferentemente da curva dTG do PET

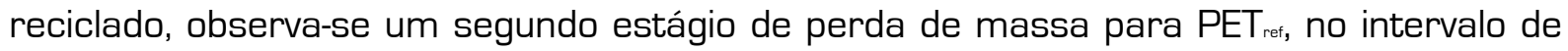
aproximadamente $530-700{ }^{\circ} \mathrm{C}$, com $\mathrm{T}_{\mathrm{p}}$ de aproximadamente $600{ }^{\circ} \mathrm{C}$. Este estágio pode estar associado à decomposição de possíveis contaminantes que permaneceram na composição do polímero, mesmo pós processo de reciclagem mecânica.

A curva dTG para a fibra de sisal eletrofiada [obtida em um estudo prévio] apresentou $T_{p}$ de $350{ }^{\circ} \mathrm{C}$, a qual foi atribuída à decomposição das hemiceluloses, seguida da decomposição da celulose [RODRIGUES et al., 2015]. Nas curvas dTG dos mats contendo sisal em suas composições [Figura 27-[c]], a $T_{p}$ do primeiro pico, atribuída à decomposição das hemiceluloses e celulose, variou de $270{ }^{\circ} \mathrm{C}$ (mat com a maior proporção de sisal/PET, S/PET ${ }_{0,40}$ ] até $320{ }^{\circ} \mathrm{C}$ (mat com a menor proporção de sisal/PET, $\mathrm{S} / \mathrm{PET}_{0,10}$. A maior proporção de sisal/PET em S/PET $\mathrm{T}_{0,40}$, possivelmente, favoreceu a eletrofiação das cadeias de celulose em combinação com as do polímero reciclado. Assim, o pico em $270{ }^{\circ} \mathrm{C}$ [ S/PET $T_{0,40}$, Figura 27-[c] ] pode ser atribuído principalmente à 
decomposição das cadeias de hemiceluloses. A lignina [o componente minoritário da fibra de sisal, 11,7\%, item 1.2.1], uma macromolécula aromática, provavelmente foi eletrofiada em combinação com as cadeias de PET, polímero com grupos aromáticos em sua estrutura [Figura 10]. Ainda, no mat contendo a menor proporção de sisal/PET [S/PET $\mathrm{P}_{0,10}$ ], os principais componentes da fibra lignocelulósica [celulose e hemiceluloses], possivelmente, foram majoritariamente eletrofiados separadamente das cadeias do polímero reciclado. Assim, o valor da $\mathrm{T}_{\mathrm{p}}$ do primeiro pico de $\mathrm{S} / \mathrm{PET}_{0,10}\left[320{ }^{\circ} \mathrm{C}\right.$, Figura 27 [c]] é observado em uma temperatura próxima à $T_{p}$ da fibra de sisal eletrofiada $\left[350{ }^{\circ} \mathrm{C}\right.$ ] [RODRIGUES et al., 2015). Os outros mats exibiram valores de $T_{p}$ do primeiro pico da curva dTG entre $2700^{\circ} \mathrm{C}$ e $320^{\circ} \mathrm{C}$ [Figura 27-(c)].

A influência das fibras de sisal na temperatura de máxima taxa de perda de massa do PET reciclado, pode ser observada devido aos baixos valores de $T_{\mathrm{p}}$ apresentados nas curvas dTG dos mats contendo sisal em suas composições [428-445 'C, Figura 27-[c]], em comparação à $T_{p}$ da curva dTG de PET $_{\text {ref }}$ [448 ${ }^{\circ}$ C, Figura 27-[a], (b)]. Nas fibras de composição híbrida produzidas a celulose poderia ser "protegida" pelo PET, o que poderia deslocar a decomposição térmica desse polissacarídeo, presente na composição das fibras, para temperaturas mais altas, em comparação às fibras lignocelulósicas, produzidas via eletrofiação e sem PET reciclado em suas composições. No entanto, o valor da $T_{p}$ seria menor do que o apresentado na curva dTG das fibras de PET sem polissacarídeo em suas composições $\left\{448{ }^{\circ} \mathrm{C}, \mathrm{PET}_{\text {ref }}\right.$ [Figura 27-[a],[b]]\}.

Este conjunto de resultados termogravimétricos parece reforçar a hipótese de que os componentes lignocelulósicos da fibra de sisal [principalmente celulose] podem ter eletrofiado parcialmente em combinação com as cadeias de PET reciclado.

\subsubsection{Análise Dinâmico-Mecânica [DMA]}

A Figura 28-[a],(b) apresenta os resultados de E' [a 30 'C] e da $T_{9}$ [obtida à partir do máximo da curva tan $\delta$ [SANTOS et al., 2015]] dos mats preparados com a utilização do coletor estático. Já a Figura 28-[c],(d) apresenta os resultados de E' (a 30 `C) e da $\mathrm{T}_{9}$ dos mats preparados com a utilização do coletor rotativo. Destaca-se que estes mats foram caracterizados tanto na direção perpendicular ao eixo do coletor de tambor metálico rotativo [direção preferencial de alinhamento das fibras], quanto na direção paralela ao eixo do coletor [direção oposta ao alinhamento preferencial das fibras]. 


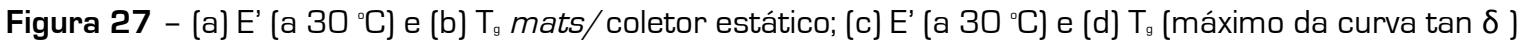
mats/coletor rotativo, caracterizados na direção preferencial de alinhamento das fibras [ "dir"] e direção a) oposta ao alinhamento preferencial [ "op"]

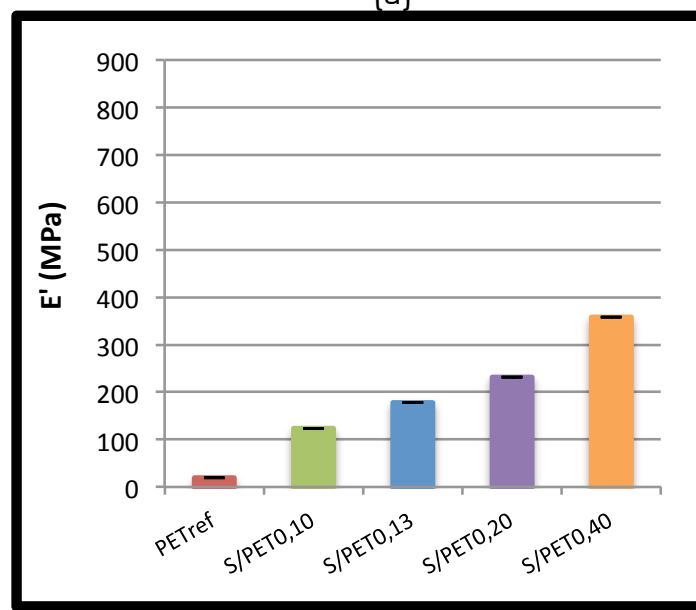

[c]



Fonte: Autoria própria. [b]

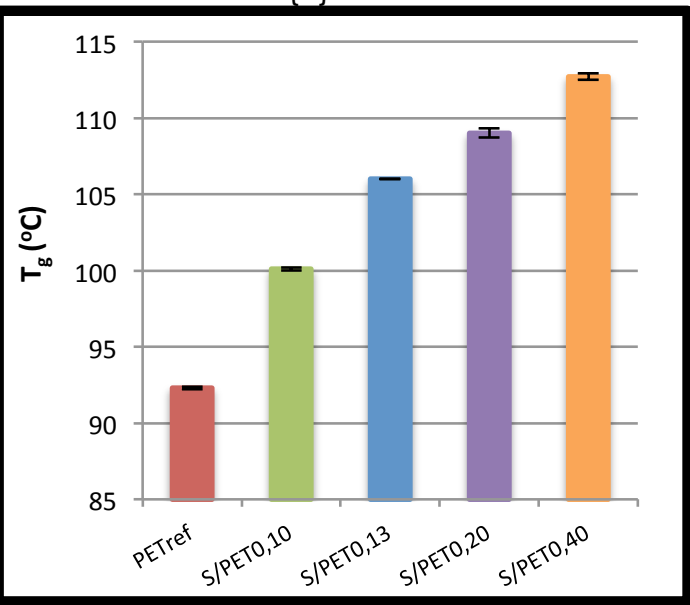

[d]



Observa-se na Figura 28-[a] que os mats [preparados com a utilização do coletor estático] contendo fibra de sisal em suas composições apresentaram mais elevado valor de E' [a 30 `C], em comparação com o apresentado pela amostra controle PET ret. Os valores de E' aumentaram com o aumento da razão sisal/PET na composição dos mats [de 19,2 \pm 0,3 MPa [PET ref] até 358,0 \pm 1,5 MPa [S/PET $\left.T_{0,40}\right]$, o que sugere que a fibra de sisal foi a responsável pelo aumento de E'. A variação nos valores de E' não foi suficiente para indicar uma ampla variação na rigidez dos materiais. Destaca-se a reduzida espessura e a alta porosidade média [Figura 22-[c]] dos mats avaliados. No entanto, esses resultados mostram que a presença dos componentes da fibra de sisal na composição dos mats diminuiu a mobilidade dos segmentos das cadeias do PET, indicando interações entre o polímero reciclado e os componentes do sisal em nível molecular [Figura 29]. 
Figura 28 - Representação esquemática da fibra lignocelulósica de sisal e seus principais componentes, assim como as possiveis interações com a cadeia de PET.

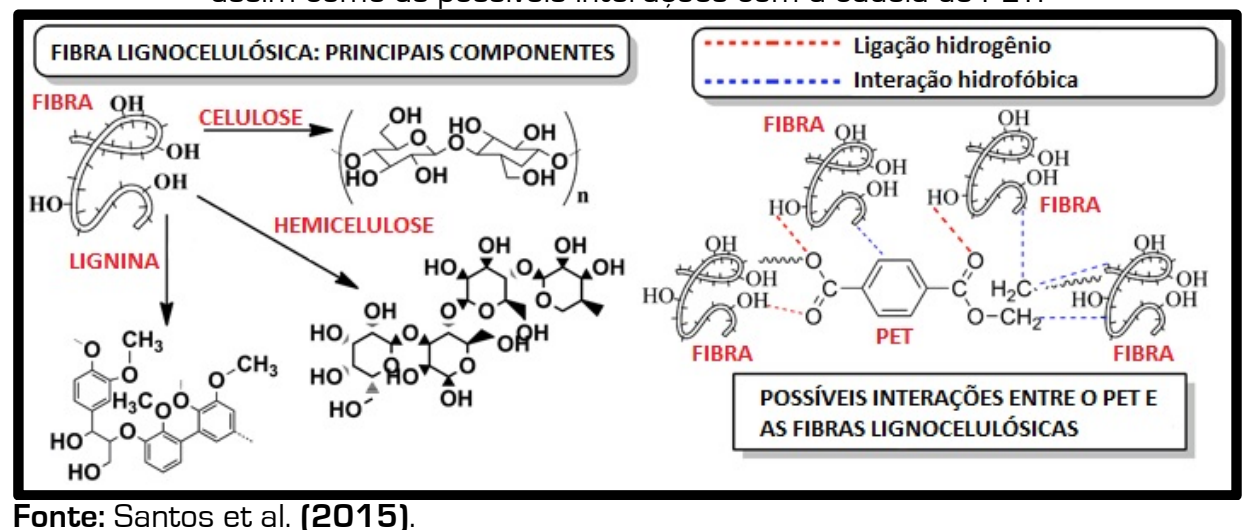

Pode-se observar na Figura 28-[b] que a incorporação das fibras de sisal na composição dos mats [preparados com o uso do coletor estático] levou a um aumento na $\mathrm{T}_{9}$ de até $20{ }^{\circ} \mathrm{C}\left[\mathrm{PET}_{\text {ref }}-\mathrm{T}_{9}=92,3 \pm 0,1{ }^{\circ} \mathrm{C}\right.$ e S/PET $\left.{ }_{0,40}-\mathrm{T}_{\mathrm{g}}=112,7 \pm 0,2{ }^{\circ} \mathrm{C}\right] .0$ aumento da proporção de fibra de sisal/PET na composição dos mats, possivelmente, favoreceu o estabelecimento de fortes interações intermoleculares entre esses componentes [Figura 29], as quais foram progressivamente dificultando os movimentos rotacionais das ligações covalentes presentes nos segmentos da cadeia polimérica. Este fato corrobora a hipótese de que o PET, pelo menos parcialmente, foi eletrofiado em conjunto com as fibras de sisal [item 1.3.2].

Nas micrografias dos mats preparados com o uso do coletor estático [Figura 21] foram observados pontos em que as fibras se interceptam, com a consequente criação de microporos entre as mesmas. Assim, o aumento progressivo na $T_{9}$ e E' [Figura 28-[a],(b)], com o aumento da razão fibra de sisal/PET na composição dos mats, é um indicativo de interações em um nível molecular entre os componentes da fibra lignocelulósica e as cadeias do polímero reciclado. Caso as cadeias de PET e os componentes do sisal tivessem somente eletrofiado separadamente, as interações entre ambas as fibras formadas ocorreriam principalmente nos pontos de intersecção, envolvendo as respectivas superfícies. No entanto, a variação observada, particularmente na $T_{9}$ dos mats [Figura 28-[b]], é um indicativo de que as interações entre os segmentos da cadeia do PET e os componentes do sisal ocorreram em nível molecular, o que indica a produção, via eletrofiação, de fibras híbridas (nas quais as distâncias intermoleculares favoreceriam fortes interações entre as mesmas].

Observa-se que os valores de E' [Figura 28-[c]] e de $T_{9}$ [Figura 28-[d]] para os mats preparados com o uso do coletor rotativo (tanto para os materiais caracterizados na direção preferencial de alinhamento das fibras, quanto para os caracterizados na direção oposta] apresentaram, no geral, a mesma tendência, com relação a essas propriedades, que os mats produzidos utilizando-se o coletor estático [Figura 28-[a],(b]]. Pode-se observar na Figura 28-[c] que os valores de E' para os materiais, caracterizados na 
direção preferencial de alinhamento das fibras, foram superiores e mais divergentes que os valores apresentados pelos materiais, de composição correspondente, caracterizados na direção oposta. Este fato pode ser atribuído à existência interações intermoleculares intensas entre as cadeias que constituem as fibras alinhadas, as quais proporcionam uma maior resistência às forças mecânicas, quando aplicadas ao longo da direção de alinhamento das fibras (KUPPAN; SETHURAMAN; KRISHNAN, 2015). Ainda, quando uma força é aplicada na direção preferencial de alinhamento das fibras, estas necessitam apenas de uma rotação mínima para se alinharem com relação à direção da força aplicada. Consequentemente, uma elevada porcentagem de fibras rapidamente resiste à deformação mecânica, conferindo ao material uma elevada rigidez. Contrariamente, quando a força é aplicada na direção oposta ao alinhamento preferencial das fibras, faz-se necessária uma maior rotação e reorientação das mesmas para que possam se alinhar com o eixo da força aplicada, com consequente menor rigidez das mesmas (KUMAR; VASITA, 2017; MUBYANA et al., 2016].

Os valores de E' para os materiais caracterizados na direção preferencial de alinhamento das fibras $\{212,0 \pm 10,2 \mathrm{MPa}$ [PET ref $-\mathrm{A}$ dir], 141,2 \pm 7,3 MPa [S/PET $0,10-\mathrm{A}$ dir], 256,1 \pm 50,1 MPa [S/PET $0,13-A$ dir], 344,9 \pm 34,9 MPa [S/PET $\mathrm{MPa}$ [S/PET $\mathrm{P}_{0,40}-\mathrm{A}$ dir] [Figura 28-[c]]\} foram, no geral, superiores e mais divergentes, em comparação aos valores apresentados pelos mats de composição correspondente, mas preparados com o uso do coletor estático $\left\{19,2 \pm 0,3 \mathrm{MPa}\left[\mathrm{PET}_{\text {ref }}\right], 123,5 \pm 0,1 \mathrm{MPa}\right.$ [S/PET $T_{0,10}$ ], 177,7 \pm 0,2 MPa [S/PET ${ }_{0,13}$ ], 231,4 \pm 0,9 MPa [S/PET ${ }_{0,20}$ ] e 358,0 \pm 1,5 MPa [S/PET $T_{0,40}$ [Figura 28-[a]]\}. No entanto, os valores de E' dos mats caracterizados na direção oposta ao alinhamento preferencial das fibras \{4,3 \pm 1,6 $\mathrm{MPa}_{\text {(PET }}$ ref $-\mathrm{A}$ op], 28,7


-A op] e 88,4 \pm 16,3 MPa [S/PET 0,40 -A op] [Figura 28-[c]]\} foram, no geral, inferiores e mais divergentes, em comparação com os materiais, de composição correspondente, preparados utilizando-se o coletor estático [Figura 28-[a]]. Assim, pode-se concluir que houve uma significativa influência da orientação das fibras na propriedade de E' e, consequentemente, na rigidez dos materiais.

Pode-se observar na Figura 28-[d] que não houve diferença significativa nos valores de $\mathrm{T}_{9}$ dos mats, de composição correspondente, caracterizados tanto na direção preferencial de alinhamento das fibras, quanto na direção oposta. Este fato indica que, possivelmente, o alinhamento ou não das fibras não interfere no movimento de rotação das ligações covalentes de segmentos das cadeias de PET e, portanto, não interfere na $T_{9}$ dos materiais.

Os resultados obtidos via análise de DMA dos materiais preparados com o uso do coletor rotativo também corroboram a hipótese da formação de fibras híbridas, via eletrofiação de soluções mistas de PET reciclado e fibra lignocelulósica de sisal. 


\subsection{Conclusões parciais}

Foi realizada com sucesso a eletrofiação à temperatura ambiente de soluções contendo diferentes razões de fibra lignocelulósica de sisal e PET reciclado, com a consequente geração de mats de nanofibras/fibras ultrafinas. Nesse processo de eletrofiação, destaca-se o uso de dois coletores diferentes [coletor metálico estático e coletor de tambor metálico rotativo], os quais levaram à produção tanto de fibras orientadas aleatoriamente, quanto de fibras alinhadas. Os resultados de DMA foram importantes, não somente para a caracterização do $E^{\prime}$ e da $T_{9}$ dos materiais (assim como para observar a influência, ou não, do alinhamento das fibras nessas propriedades], mas também para a elucidação das interações entre os componentes da fibra de sisal e as cadeias de PET. Esses resultados, em conjunto com os obtidos via análises de TG e MEV, mostraram que os componentes macromoleculares da fibra de sisal e as cadeias de PET, possivelmente, foram eletrofiados juntos, com a consequente produção de fibras híbridas, além daquelas geradas somente pelos componentes da fibra lignocelulósica ou apenas pelas cadeias de PET.

A molhabilidade dos mats foi intrinsicamente dependente da razão fibra de sisal/PET e variou de altamente hidrofóbico $\left[\mathrm{PET}_{\text {ref, }}\right.$ ACA de $134^{\circ}$, via medidas de ângulo de contato], a super hidrofílico [S/PET $\mathrm{P}_{0,40}$, ACA de $\mathrm{O}^{\circ}$, absorção instantânea da gota de água pela superfície do mat]. A mesma tendência nos valores de ACA foi observada para os mats preparados com o uso do coletor rotativo, no entanto, a diminuição nos valores de ACA foi menos acentuada.

Assim, o presente trabalho possibilitou a abertura de uma ampla gama de possibilidades, nas quais a biomassa lignocelulósica pode-se combinar com matrizes poliméricas para a melhoria e controle das propriedades finais dos materiais, como a rigidez e a hidrofilicidade. Os resultados obtidos no presente trabalho também contribuem para o avanço na preparação, via eletrofiação, de materiais compósitos baseados em celulose, com a utilização de um processo alternativo, em comparação aos processos em que, inicialmente, nanofibras de celulose ou CNCs são preparados e após dispersos na solução de um polímero termoplástico, previamente à realização do processo de eletrofiação. Outra possível aplicação importante a ser destacada é o uso dos materiais preparados no presente estudo como novos meios de filtração de ar, baseados em polímero reciclado e fibras lignocelulósicas, em substituição aos filtros tradicionais, muitas vezes contendo fibras de vido [de natureza abrasiva] em suas composições. 


\section{Capítulo 2. Materiais bio-baseados obtidos à partir da eletrofiação de soluções de celulose, lignina e PET reciclado}

\subsection{Introdução}

No grupo de pesquisa em que o presente trabalho se insere foi investigada a utilização de fibras lignocelulósicas de sisal como agentes de reforço em macrocompósitos de PET reciclado, visando a preparação de materiais com elevado valor agregado, utilizando polímero reciclado e biomassa lignocelulósica de sisal [DE OLIVEIRA SANTOS et al., 2014]. 0 estudo avançou com investigações referentes à obtenção de materiais estruturados na escala submicrométrica e nanométrica. Rodrigues et al. [2015] demonstraram que a técnica de eletrofiação pode ser aplicada para a produção de nanofibras e fibras ultrafinas à partir de soluções em TFA de biomassa lignocelulósica nativa, sem qualquer pré-tratamento. Posteriormente, Santos et al. [2015] relataram a preparação de mats baseados em fibras ultrafinas e nanofibras à partir da eletrofiação de soluções em TFA de fibra de sisal e PET reciclado.

Neste capítulo relata-se a utilização de PET reciclado, celulose e lignina como matérias-primas para a preparação, via eletrofiação, de mats de nanofibras/fibras ultrafinas, visando avaliar como celulose e lignina, adicionadas isoladamente, poderiam ser usadas para controlar as propriedades dos materiais obtidos.

Em acréscimo às caracterizações descritas no Capítulo 1, no presente capítulo as soluções a serem eletrofiadas tiveram suas viscosidades dinâmicas determinadas, o que foi viabilizado pela aquisição de um viscosímetro de queda de bola, apropriado para avaliar soluções baseadas em solventes voláteis, como o TFA. Ainda, como uma evolução da pesquisa realizada, os mats preparados foram avaliados com relação à sua resistência à tração e também foram determinados outros parâmetros, tais como entalpia de fusão $\left[\Delta \mathrm{H}_{\mathrm{f}}\right]$ e cristalinidade $\left[\mathrm{I}_{\mathrm{c}}\right]$ dos materiais, via análise de Calorimetria Exploratória Diferencial [DSC].

Assim, neste capítulo visou-se avaliar a contribuição conjunta e/ou separada de dois componentes principais de fibras lignocelulósicas, a celulose e a lignina, nas propriedades finais dos mats preparados. Destaca-se que foram explorados dois diferentes tempos de dissolução em TFA da celulose, lignina e polímero reciclado (48 h e 72 h] no preparo das soluções a serem eletrofiadas, visando avaliar a influência dos mesmos nas propriedades finais dos materiais produzidos. Até onde se tem 
conhecimento, este estudo é inédito.

\subsection{Experimental}

\subsubsection{Materiais}

A celulose de sisal foi gentilmente fornecida pela Companhia Lwarcel [Lençóis Paulista, S.P.J. Essa polpa celulósica foi produzida via processo Kraft de polpação com a sequência de branqueamento livre de cloro elementar, de acordo com o informado pelo fornecedor. No presente trabalho, a celulose de sisal, na forma de pó, foi utilizada após processo de mercerização [[ $\mathrm{NaOH}, 20 \%$ em massa, por 1 h a 0 $\mathrm{C}]$ : Grau de polimerização [GP] de 680, I. de 63\% e $\alpha$-celulose de 91\% [RODRIGUES et al., 2015]].

No presente estudo, a celulose de sisal foi utilizada pós processo de mercerização, visando facilitar sua dissolução em TFA. O processo de mercerização teve como objetivo ativar a celulose, levando a uma maior difusão do solvente na sua estrutura supramolecular (devido ao aumento da acessibilidade nas regiões cristalinas e dos cristalitos presentes na superfície desse polissacarídeo] [RODRIGUES, 2014]. Ainda, esse processo foi utilizado visando promover a purificação da celulose, removendo hemiceluloses e impurezas, tais como ceras e pectinas (as quais podem prejudicar, como mencionado anteriormente no Capítulo 1, possíveis interações entre a celulose e o PET reciclado).

A lignina, com massa molar média $\approx 4000 \mathrm{~g} \mathrm{~mol}^{-1}$ [DA SILVA et al., 2013], foi gentilmente doada pela Usina Dedini [Piracicaba, S.P.] e foi obtida via processo Organossolv, utilizando-se como matéria-prima o bagaço de cana de açúcar, como sistema de solventes o etanol/água e ácido sulfúrico como catalisador [DA SILVA et al., 2013].

\subsubsection{Métodos}

\subsubsection{Determinação da viscosidade dinâmica das soluc̣ões}

A viscosidade dinâmica das soluções foi determinada utilizando-se um viscosímetro de queda de bola da GILMONT Instruments. Este instrumento foi escolhido para a determinação da viscosidade devido à alta volatilidade do TFA, o que dificulta a utilização de outras técnicas para a medição da viscosidade, como a viscosimetria capilar. Para a realização das medidas, o viscosímetro foi imerso em um banho termostático a $25 \pm 0,2$ ${ }^{\circ} \mathrm{C}$ e a viscosidade das soluções foi calculada com base na Equação 1:

$$
\mu=\mathrm{K}\left(\rho_{\text {esfera }}-\rho_{\text {solução }}\right) t
$$

sendo: $\mu$ = viscosidade dinâmica [CP];

$\mathrm{K}=$ constante viscosimétrica de 36,7;

$\rho_{\text {estera }}=$ densidade da esfera $\left[\mathrm{g} \mathrm{cm}^{-3}\right]$; 
$\rho_{\text {solução }}=$ densidade da solução $\left[\mathrm{g} \mathrm{cm}^{3}\right]$;

$\mathrm{t}=$ tempo de queda da esfera [min]

\subsubsection{Processo de eletrofiação}

As soluções em TFA foram preparadas da seguinte forma: [a] solução de referência de PET reciclado [15 $\mathrm{g} \mathrm{dL}^{-1}$ ]; [b] duas soluções de referência com concentrações fixas de 2 $\mathrm{g} \mathrm{dL}^{-1}$ de lignina e celulose; (c) solução contendo uma mistura de PET reciclado/celulose a uma concentração fixa de PET (15 g dL ${ }^{-1}$, mesma concentração utilizada na preparação da solução de referência do polímero reciclado] e celulose na concentração de 1,3 $\mathrm{g} \mathrm{dL}^{-1}$; [d] solução contendo uma mistura de PET reciclado/lignina a uma concentração fixa de PET [15 $\mathrm{g} \mathrm{dL}^{-1}$ ] e lignina na concentração de 0,24 $\mathrm{g} \mathrm{dL}^{-1}$; [e] solução contendo uma mistura de PET reciclado/celulose/lignina nas concentrações fixas de $15 \mathrm{~g} \mathrm{dL}^{-1}, 1,3 \mathrm{~g} \mathrm{dL}^{-1}$ e 0,24 $\mathrm{g} \mathrm{dL}$ ', respectivamente. Ainda, para as soluções [c], [d] e [e] a celulose e/ou lignina foram adicionadas somente após $24 \mathrm{~h}$ de dissolução do PET reciclado em TFA.

Todas as soluções foram mantidas sob agitação mecânica, à temperatura ambiente, por períodos de $24 \mathrm{~h}$ para as soluções de referência [a], [b] e 48 h e 72 h para as soluções [c], [d] e [e]. A Tabela 2 resume a composição das soluções em TFA, o tempo de dissolução e os respectivos códigos de referência dos mats preparados.

Tabela 2 - Composição dos mats e seus respectivos códigos de referência.

\begin{tabular}{ccccc}
\hline $\begin{array}{c}\text { PET reciclado } \\
\text { [g dL'] }\end{array}$ & $\begin{array}{c}\text { Celulose } \\
\text { [g dL-1] }\end{array}$ & $\begin{array}{c}\text { Lignina } \\
\text { [g dL'] }\end{array}$ & $\begin{array}{c}\text { Tempo de } \\
\text { dissolução } \\
\text { [h] }\end{array}$ & $\begin{array}{c}\text { Código de } \\
\text { referência }\end{array}$ \\
\hline 15,00 & - & - & 24 & $\mathrm{PET}_{\text {rot }}$ \\
- & 2,00 & - & 24 & $\mathrm{CEL}$ \\
- & - & - & 24 & $\mathrm{LIG}$ \\
15,00 & 1,3 & - & 48 & $\mathrm{PETC} / 48 \mathrm{~h}$ \\
15,00 & 1,3 & 0,24 & 72 & $\mathrm{PETC} / 72 \mathrm{~h}$ \\
15,00 & - & 0,24 & 78 & $\mathrm{PETL} / 48 \mathrm{~h}$ \\
15,00 & - & 0,24 & 42 & $\mathrm{PETL} / 72 \mathrm{~h}$ \\
15,00 & 1,3 & 0,24 & 72 & $\mathrm{PETCL} / 48 \mathrm{~h}$ \\
15,00 & 1,3 & & 72 & $\mathrm{PETCL} / 72 \mathrm{~h}$ \\
\hline
\end{tabular}

Com base em um estudo prévio de Santos et al. [2015), foi escolhida a concentração/tempo de dissolução de $15 \mathrm{~g} \mathrm{dL}^{-1} / 24 \mathrm{~h}$ para a preparação da solução de referência de PET reciclado, os quais mostraram serem os mais adequados concentração/tempo de dissolução para o processo de eletrofiação desse polímero reciclado.

As concentrações das soluções de referência baseadas em celulose e lignina [dois componentes principais da fibra lignocelulósica de sisal] foram escolhidas com base em um estudo prévio [RODRIGUES et al., 2015]. Neste estudo, soluções de fibra de sisal em TFA foram preparadas na concentração de $2 \mathrm{~g} \mathrm{dL}^{-1}$, a qual se mostrou ser a concentração mais adequada para o processo de eletrofiação, assim como para que fosse evitada a gelificação das fibras de sisal após a dissolução [RODRIGUES et al., 2015).

O tempo utilizado para a preparação das soluções de referência de celulose e 
lignina em TFA foi escolhido com base no tempo de dissolução desses componentes individualmente. As concentrações de lignina e celulose nos mats contendo PET reciclado [PETC/48 h, PETC/72 h, PETL/48 h, PETL/72 h, PETCL/48 h e PETCL/72 h] foram selecionadas à partir de um estudo prévio [DE OLIVEIRA SANTOS et al., 2014], no qual a fibra lignocelulósica de sisal foi caracterizada com relação aos seus componentes teores de celulose e lignina de aproximadamente 65\% em massa e 12\% em massa, respectivamente]. Assim, com base nos teores de celulose e lignina do sisal, foi calculada a concentração de ambos em 0,06 g, a qual foi a máxima e mais adequada massa de fibra de sisal que foi dissolvida em TFA para o processo de eletrofiação [RODRIGUES et al., 2015]. 0 tempo de dissolução de $48 \mathrm{~h}$ foi escolhido com base no tempo de dissolução apenas da fibra de sisal em TFA para o processo de eletrofiação (RODRIGUES et al., 2015]. Já o tempo de dissolução de 72 h foi escolhido com base no tempo de preparação das soluções mistas de sisal e PET reciclado [SANTOS et al., 2015]. Ainda, foi avaliada a influência dos diferentes tempos de dissolução [48 h e 72 h] no processo de eletrofiação e nas propriedades finais dos materiais preparados.

O processo de eletrofiação foi realizado utilizando-se um aparato de eletrofiação ECDIG da IME Technologies [Geldrop, Holanda). As soluções a serem eletrofiadas foram acondicionadas em tubos capilares, com diâmetro interno de $1 \mathrm{~mm}$ e diâmetro externo de 1,6 mm, os quais foram conectados a uma bomba para o controle da taxa de vazão da solução [5,5 $\mu \mathrm{L} \min ^{-1}$ ]. A agulha metálica [com 0,45 mm de diâmetro interno] foi então conectada a uma fonte de tensão com voltagem positiva de $25 \mathrm{kV}$.

A distância entre a ponta da agulha e o coletor foi de $8 \mathrm{~cm}$ em todos os casos, com exceção de CEL e LIG, nas quais foi utilizada uma distância de $4 \mathrm{~cm}$. Em todos os casos, como aparato coletor de fibras, foram utilizadas chapas delgadas de vidro acopladas ao contra eletrodo [coletor metálico]. 0 processo de eletrofiação foi realizado por 80 min a uma temperatura de $25,2 \pm 1,6{ }^{\circ} \mathrm{C}$ e umidade relativa de $41,3 \pm 0,6 \%$.

Todos os parâmetros de eletrofiação descritos anteriormente mostraram-se os mais adequados para a investigação proposta e os mesmos foram estabelecidos com base em um estudo prévio [RODRIGUES et al., 2015; SANTOS et al., 2015). Os mats preparados apresentaram espessura média de 0,21 $\pm 0,15 \mathrm{~mm}$, a qual foi determinada utilizando-se um micrômetro, e diâmetro médio de 5,25 \pm 1,06 cm.

\subsubsection{Caracterização dos não-tecidos [mats]}

\subsection{Espectroscopia na região do Infravermelho [IV]}

A obtenção dos espectros na região do Infravermelho foi realizada de acordo com o que foi descrito no item 1.2.2.2.1 do Capítulo 1. 


\subsection{Microscopia Eletrônica de Varredura (MEV]}

As análises de MEV foram realizadas de acordo com o que foi descrito no item 1.2.2.2.2 do Capítulo 1. Para a determinação do diâmetro médio das fibras, área média do poro e porosidade dos mats, três micrografias diferentes para cada amostra foram analisadas utilizando-se o software de processamento de imagem ImageJ 1.45 [National Institutes of Health, Bethesda, Estados Unidos].

\subsubsection{3 Ângulo de contato $[A C]$}

As análises de AC foram realizadas de acordo com o que foi descrito no item

\subsubsection{3 do Capítulo 1.}

\subsection{Termogravimetria [TG]}

As análises termogravimétricas foram realizadas de acordo com o que foi descrito no item 1.2.2.2.4 do Capítulo 1.

\subsection{Calorimetria Exploratória Diferencial [DSC]}

As análises de DSC foram realizadas em um equipamento da Shimadzu, modelo DSC-50. As amostras [8 mg ] foram inseridas em um porta-amostra selado de platina e aquecidas a uma taxa de $10{ }^{\circ} \mathrm{C} \min ^{-1}$ de $25^{\circ} \mathrm{C}$ a $400{ }^{\circ} \mathrm{C}$, sob atmosfera de nitrogênio $\left[N_{2}\right]$,

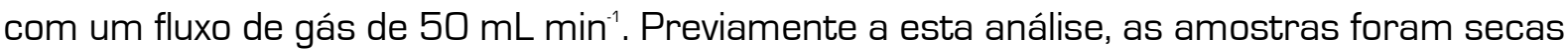
em estufa de circulação de ar a $105^{\circ} \mathrm{C}$ por $4 \mathrm{~h}$.

$O \mathrm{I}_{\mathrm{c}}$ do PET reciclado foi calculado com base no $\Delta \mathrm{H}_{\mathrm{f}}$ extraído dos dados de DSC, de acordo com a Equação 2 (SUPTHANYAKUL; KAABBUATHONG; CHIRACHANCHAI, 2016]:

$$
I_{c}=\frac{\Delta H_{f}}{\Delta H_{f}^{o} \times \varphi_{\omega}} \times 100
$$

sendo: $\Delta \mathrm{H}_{\mathrm{f}}=$ calor de fusão observado para o PET;

$\varphi_{\omega}=$ fração em massa de PET no material;

$\Delta \mathrm{H}^{\circ}{ }_{\mathrm{f}}=140 \mathrm{~J} \mathrm{~g}^{-1}$ para o PET 100\% cristalino [WELLEN, 2014].

\subsection{Análise Dinâmico-Mecânica [DMA]}

As análises de DMA foram realizadas de acordo com o que foi descrito no item

\subsubsection{5 do Capítulo 1.}

\subsection{Ensaio de resistência à tração}

Os ensaios de resistência à tração foram realizados em um equipamento da TA Instruments, modelo Q800, no modo tensão, a $25^{\circ} \mathrm{C}$. Amostras, com 6,4 mm de largura e 
$5 \mathrm{~mm}$ de comprimento [distância entre as duas garras], foram analisadas utilizando-se a


N. Foram testados no mínimo três corpos de prova de cada amostra. Previamente a esta análise, as amostras foram secas em estufa de circulação de ar a $80{ }^{\circ} \mathrm{C}$ por $4 \mathrm{~h}$.

\subsection{Resultados e Discussão}

\subsubsection{Espectroscopia na região do Infravermelho [IV]}

A Figura $\mathbf{3 0}$ mostra os espectros de IV para os mats $\mathrm{PET}_{\text {ref, }} \mathrm{PETC} / 48 \mathrm{~h}, \mathrm{PETL} / 48$ h e PETCL/48 h.

Figura 30 - Espectros de IV para os mats PET ${ }_{\text {ret }}$ PETC/48 h, PETL/48 h e PETCL/48 h.

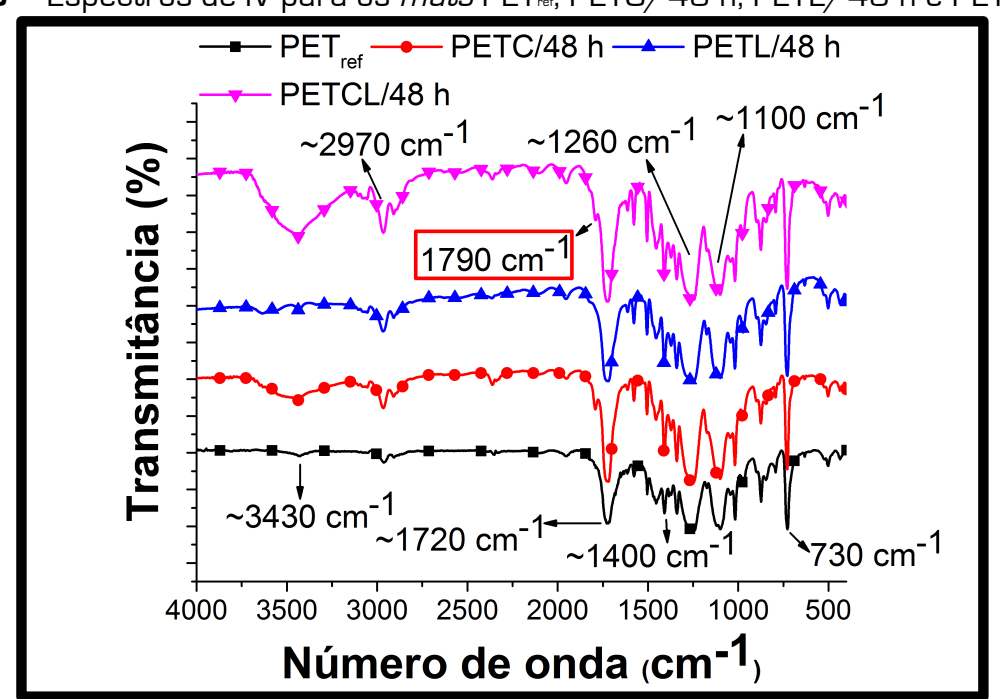

Fonte: Autoria própria.

Foi possivel observar nos espectros de PETC/48 h, PETL/48 h, PETCL/48 h [Figura 30), PETC/72 h, PETL/72 h e PETCL/72 h [Figuras não mostradas] as mesmas bandas apresentadas no espectro de $\mathrm{PET}_{\text {ref }}$ (Figura 30]. Os espectros das amostras contendo celulose em suas composições [PETC/48 h, PETCL/48 h (Figura 30], PETC/72 h e PETCL/72 h [Figuras não mostradas]] apresentaram um pequeno "ombro" em aproximadamente $1790 \mathrm{~cm}^{-1}$. O TFA [solvente utilizado no presente trabalho] pode atuar como agente esterificante de grupos hidroxila, como os presentes na estrutura da celulose e lignina [Figura 20, Reação de esterificação]. Esse pequeno "ombro" observado em torno de $1790 \mathrm{~cm}^{-1}$ é típico de carbonilas de grupos trifluoroacetilas [SILVERSTEIN; BASSLER; MORRIL, 1994]. A exposição ao ar e umidade pode levar a uma completa hidrólise desses grupos trifluoroacetilas, regenerando consequentemente a celulose e a lignina de partida [Figura 20, Reação de hidrólise] (HASEGAWA et al., 1992).

Rodrigues et al. [2015), em seu estudo, reportaram a ausência dessa banda em $1790 \mathrm{~cm}^{-1}$ no espectro da celulose de sisal eletrofiada. De acordo com Santos et al. [2015], nos espectros de mats contendo PET reciclado e fibra lignocelulósica de sisal, foi possivel observar somente um pequeno "ombro" em aproximadamente $1790 \mathrm{~cm}^{-1}$. 


\subsubsection{Microscopia Eletrônica de Varredura (MEV)}

A Fig. 31 apresenta as micrografias de PET ref, CEL e LIG.

Figura 29 - Micrografias de PET ref, CEL e LIG.
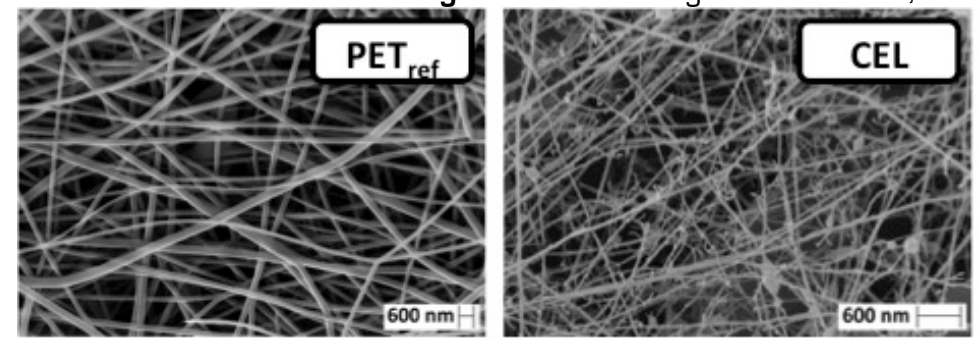

Fonte: Autoria própria.

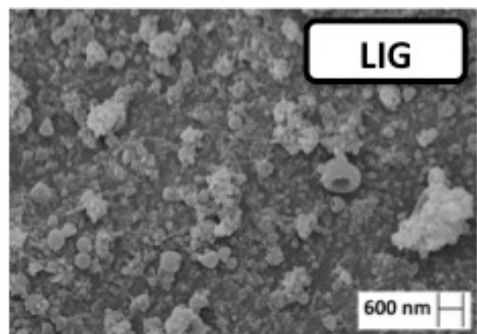

Os histogramas do diâmetro das fibras de PET ref e CEL são apresentados na Figura 32.

Figura 30 - Histogramas do diâmetro de fibra de PET $T_{\text {ref }}$ e CEL.

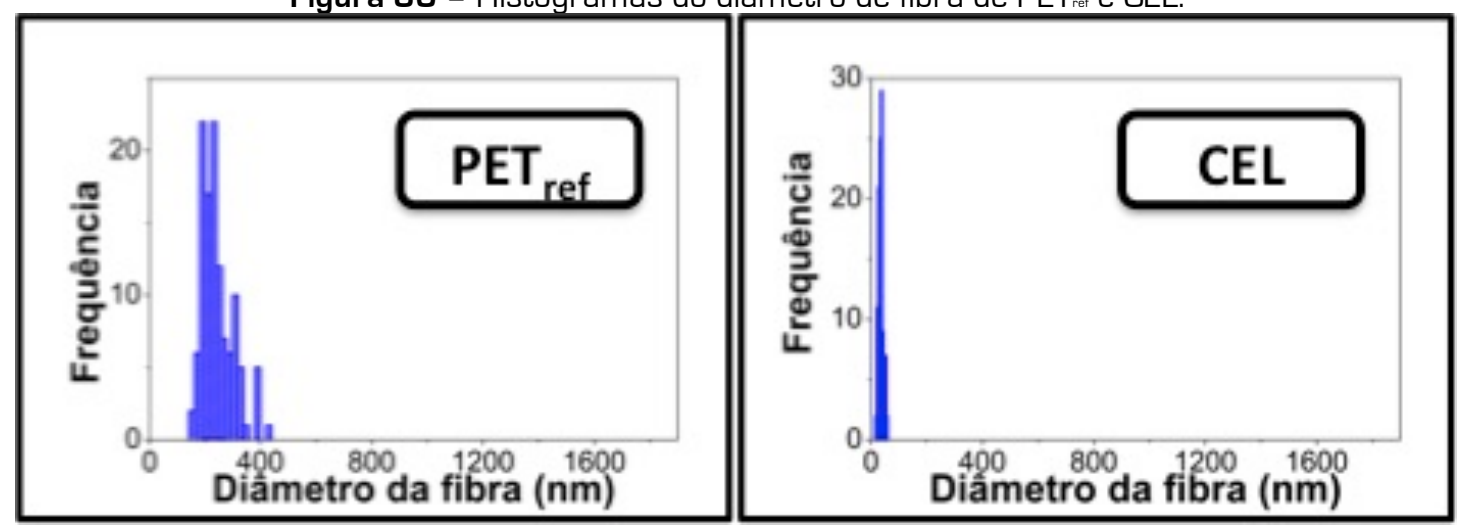

Fonte: Autoria própria.

Na Tabela 3 são apresentadas as viscosidades dinâmicas das soluções precursoras dos mats obtidos via eletrofiação. 
Tabela 3 - Viscosidade dinâmica das soluções precursoras dos mats obtidos via eletrofiação.

\begin{tabular}{cc}
\hline Amostra & $\begin{array}{c}\text { Viscosidade } \\
\text { dinâmica das } \\
\text { solucoões } \\
\text { precursoras [cP] }\end{array}$ \\
\hline $\mathrm{PET}_{\text {ret }}$ & $55,2 \pm 0,5$ \\
$\mathrm{CEL}$ & $441,0 \pm 6,0$ \\
$\mathrm{LIG}$ & $1,81 \pm 0,04$ \\
$\mathrm{PETC} / 48 \mathrm{~h}$ & $1101,0 \pm 8,0$ \\
$\mathrm{PETC} / 72 \mathrm{~h}$ & $2484,0 \pm 13,0$ \\
$\mathrm{PETL} / 48 \mathrm{~h}$ & $56,1 \pm 0,3$ \\
$\mathrm{PETL} / 72 \mathrm{~h}$ & $72,5 \pm 0,5$ \\
$\mathrm{PETCL} / 48 \mathrm{~h}$ & $2456,0 \pm 19,0$ \\
$\mathrm{PETCL} / 72 \mathrm{~h}$ & $4474,0 \pm 12,0$ \\
\hline
\end{tabular}

A Figura 33 apresenta o diâmetro médio das fibras, área média dos poros e porosidade média dos mats obtidos via eletrofiação. 
Figura 31 - [a] Diâmetro médio das fibras, [b] Área média dos poros e [c] Porosidade média dos mats obtidos via eletrofiação.

[a]

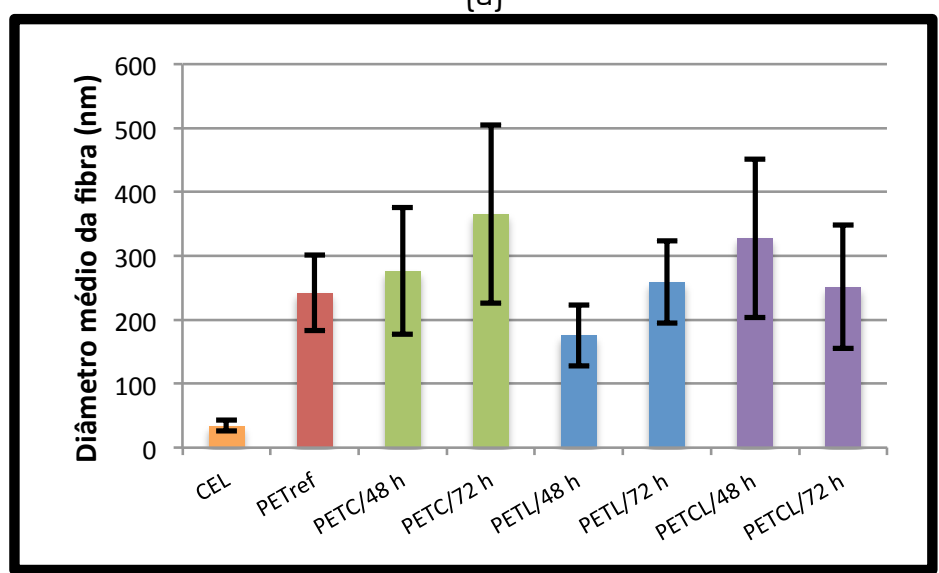

[b]

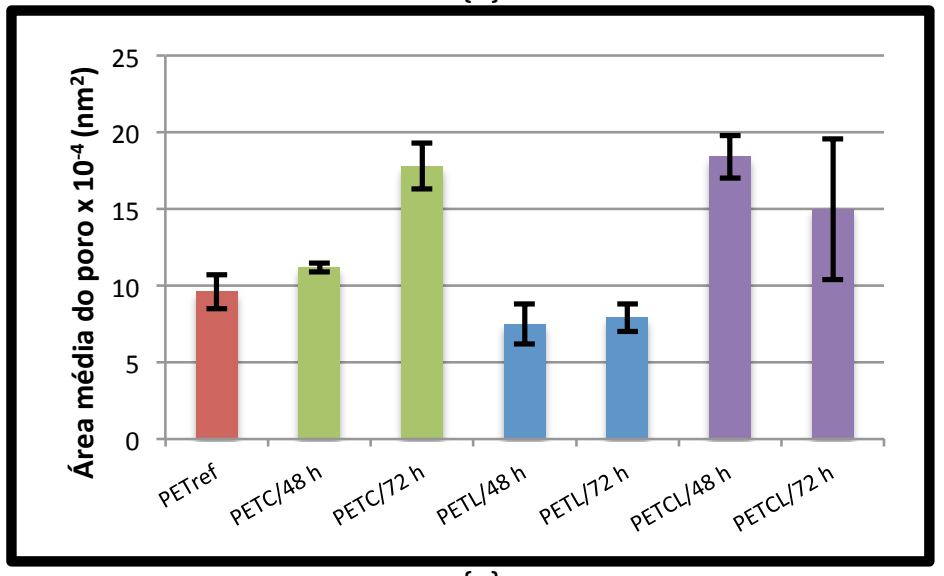

[c]

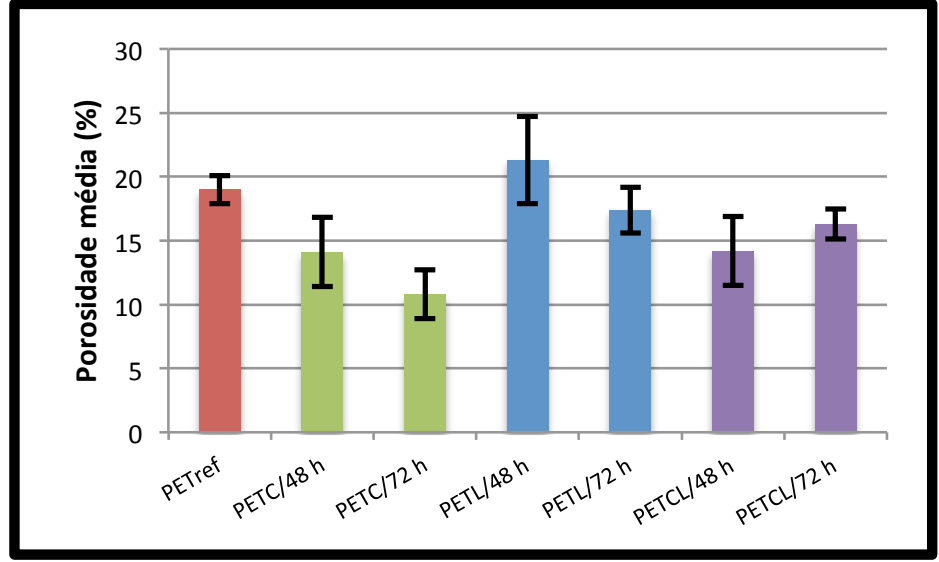

Fonte: Autoria própria.

Pode-se observar na micrografia de $\mathrm{PET}_{\text {ref }}$ [Figura 31] uma rede de fibras contínuas, em geral, homogêneas, composta por fibras ultrafinas com diâmetros variando de aproximadamente 150 a 430 nm [Figura 32], com um diâmetro médio de 242,4 \pm 59,1 $\mathrm{nm}$ [Figura 33-[a]]. Observa-se que as fibras ultrafinas de $\mathrm{PET}_{\text {ref }}$ não apresentam ramificações, orientaram-se de forma aleatória e o mat apresentou uma área média de poro e porosidade média de 9,6 $\pm 1,1 \times 10^{4} \mathrm{~nm}^{2}$ [Figura 33-[b]] e 19,0 \pm 1,1\% [Figura 
33-[c]], respectivamente.

Veleirinho et al. (2008), em seu estudo, obtiveram fibras ultrafinas à partir da eletrofiação de soluções de PET/TFA nas concentrações do polímero [massa/volume] de 10\%, 20\% e 30\%, com diâmetros médios de, respectivamente, $194 \pm 48$ nm, $330 \pm 146$ nm e $505 \pm 383$ nm. Assim, o diâmetro médio das fibras de PET ref $\{242,4 \pm$ 59,1 nm [Figura 33-[a]], em uma concentração de 15\% massa/volume\} obtidas no presente estudo foi superior ao das fibras obtidas por Veleirinho et al. [2008] para uma concentração de polímero de 10\% massa/volume [fibras com diâmetro médio de aproximadamente $194 \mathrm{~nm}$ ].

Na Figura 31 observa-se que a micrografia de CEL apresenta uma rede de fibras descontínuas e fibriladas, composta por nanofibras com diâmetros variando de aproximadamente $20 \mathrm{~nm}$ a $60 \mathrm{~nm}$ [Figura 32], com um diâmetro médio de 34,4 \pm 8,6 nm [Figura 33-[a]]. Observa-se também que as nanofibras de CEL orientam-se de forma aleatória e em sua rede pode-se notar a presença de defeitos, tais como algumas contas [denominadas beads] e a presença de regiões filmogênicas/achatadas. Yarin [1993], em seu estudo, atribuiu a formação de beads à instabilidade do jato de solução polimérica durante o processo de eletrofiação. Fong et al. (1999), em seu estudo, atribuíram à formação de beads durante o processo de eletrofiação à partir de soluções poliméricas a fatores, tais como a baixa viscosidade da solução polimérica e a menor densidade de cargas da rede e das forças elétricas associadas. Para o preparo de CEL, foi eletrofiada solução de celulose/TFA com viscosidade dinâmica de $441 \pm 6$ cP, [Tabela 3].

Rodrigues et al. [2015], em seu estudo, relataram que a baixa taxa de fluxo de 5,5

$\mu \mathrm{L} \min ^{-1}$ durante o processo de eletrofiação, mesma taxa utilizada no presente trabalho, favoreceu, possivelmente, a obtenção de uma rede de nanofibras de celulose de sisal heterogênea, com a presença de beads e regiões filmogênicas. Neste estudo, a presença destes defeitos na rede de nanofibras foi, provavelmente, consequência da taxa de fluxo abaixo do limiar para a voltagem utilizada [25 kV]. Assim, consequentemente, houve a evaporação precoce do solvente [TFA] na extremidade da agulha e à desestabilização do jato de solução polimérica durante a eletrofiação. Para taxas de fluxo maiores, como 25,5 $\mu \mathrm{L} \min ^{-1}, 45,5 \mu \mathrm{L} \min ^{-1}$ e 65,5 $\mu \mathrm{L}$ min $^{-1}$, observou-se neste estudo um decréscimo dos defeitos entre as redes de fibras. Ainda, neste estudo, a uma taxa de fluxo de solução de celulose de sisal/TFA de 5,5 $\mu \mathrm{L}$ min $^{-1}$, foram obtidas nanofibras com diâmetros da ordem de 40-60 nm [RODRIGUES et al., 2015]. Destaca-se que, no presente estudo, para fins comparativos, foi utilizada a taxa de fluxo de 5,5 $\mu \mathrm{L} \min ^{-1}$ na eletrofiação de solução de celulose/TFA, visando manter a mesma taxa de fluxo utilizada na eletrofiação das demais soluções.

Observa-se na micrografia de LIG [Figura 31] a formação de beads e aglomerados dos mesmos. Os beads apresentam formas irregulares e uma escala de tamanho variado 
[com diâmetros da ordem de aproximadamente 75-949 nm], com diâmetro médio de 203 $\pm 130 \mathrm{~nm}$. A macromolécula de lignina tem estrutura ramificada e não linear, o que praticamente impede a obtenção de fibras a partir de soluções da mesma [AHN et al., 2014]. O electrospraying observado neste estudo para a solução de lignina pode ser futuramente explorado sob uma perspectiva positiva. A técnica de electrospraying [visando a produção de partículas/beads], aliada ou não à técnica de eletrofiação, permite a produção de diferentes materiais de grande interesse para uma ampla gama de aplicações. Lavielle et al. [2013), em seu estudo, produziram compósitos auto-organizados à partir de diferentes soluções poliméricas de polietileno glicol [PEG] e PLA. Neste estudo, foram produzidos compósitos compostos por partículas de PLA e PEG [via electrospraying] e fibras destes polímeros produzidas via eletrofiação, visando a aplicação destes materiais em áreas como a biomédica e de filtração. Ainda, a técnica de electrospraying também pode ser utilizada na produção de partículas/beads para sistemas de liberação controlada de fármacos [CHANG et al., 2011; YE; KIM; PARK, 2010), a partir de soluções de proteínas e ácidos nucleicos (WANG et al., 2013), por exemplo.

A Figura 34 apresenta as micrografias de PETC/48 h, PETC/72 h, PETL/48 h, PETL/72 h, PETCL/48 h e PETCL/72 h. 
Figura 32 - Micrografias de PETC/48 h, PETC/72 h, PETL/48 h, PETL/72 h, PETCL/48 h e PETCL/72 h.
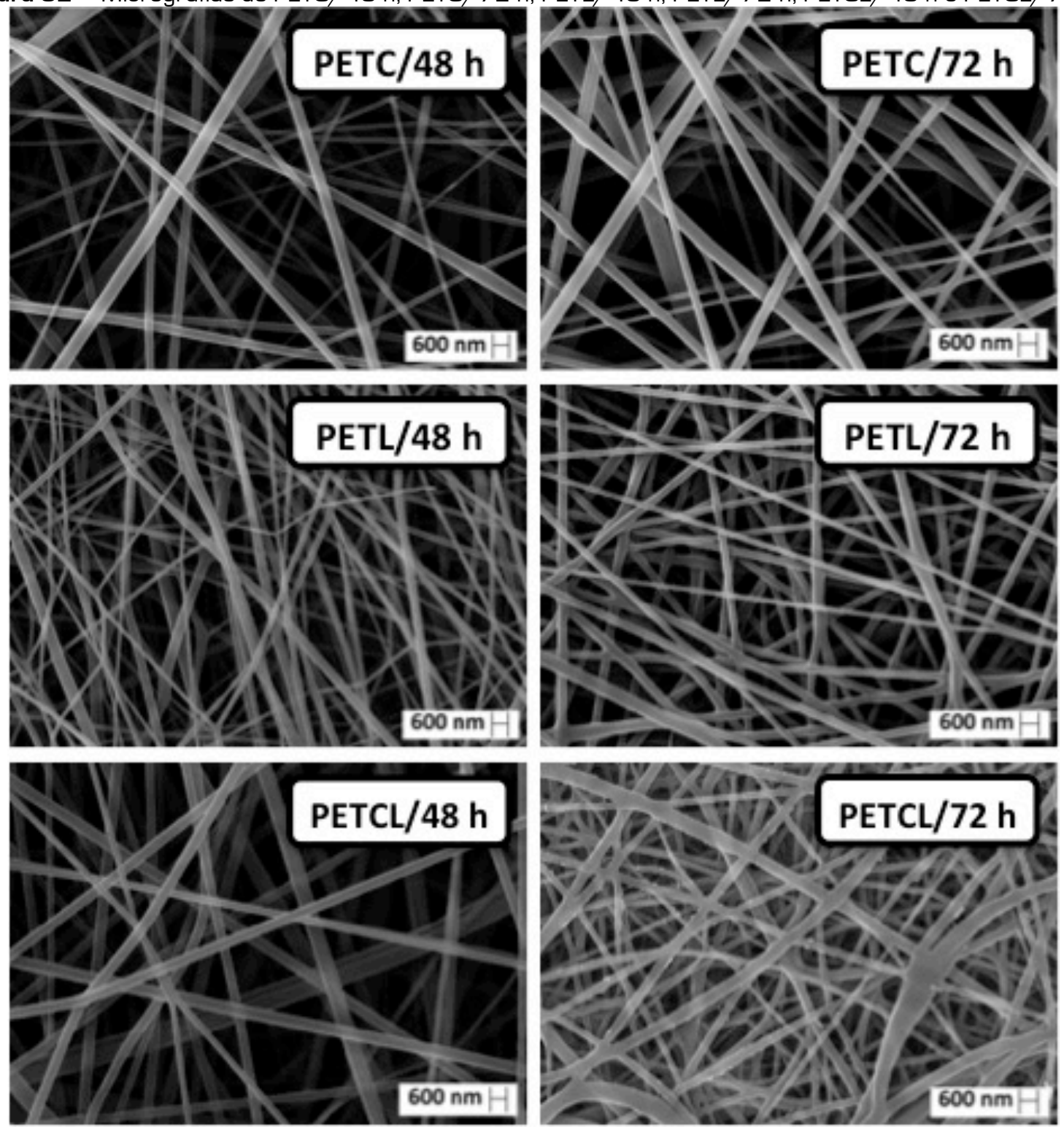

Fonte: Autoria própria.

Os histogramas do diâmetro das fibras de PETC/48 h, PETC/72 h, PETL/48 h, PETL/72 h, PETCL/48 h e PETCL/72 h são apresentados na Figura 35. 
Figura 33 - Histogramas do diâmetro de fibra de PETC/48 h, PETC/72 h, PETL/48 h, PETL/72 h,

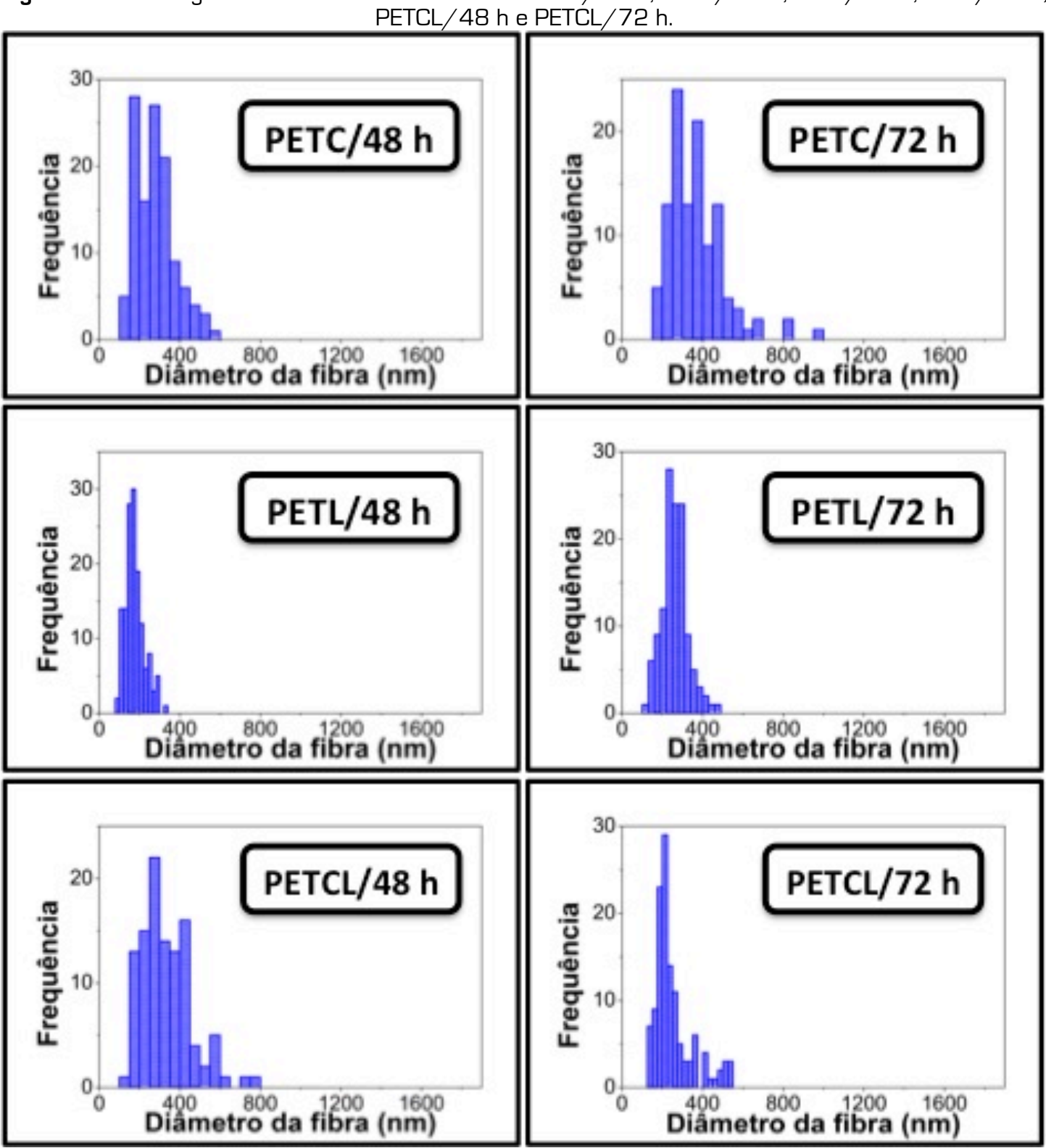

Fonte: Autoria própria.

Pode-se observar nas micrografias de PETC/48 h e PETC/72 h [Figura 34] uma rede de fibras contínuas, composta, respectivamente, por fibras ultrafinas com uma variação de diâmetros de aproximadamente 140 nm a 560 nm [Figura 35], com um diâmetro médio de 276,4 \pm 99,5 nm [Figura 33-[a]] e por fibras com uma variação de diâmetros de aproximadamente 150 nm a 980 nm [Figura 35], com um diâmetro médio de 365,9 \pm 139,7 nm [Figura 33-[a]], respectivamente.

De acordo com a Tabela 3, a solução preparada à partir de PET reciclado e celulose [solução precursora de PETC/48 h] apresentou um aumento substancial na

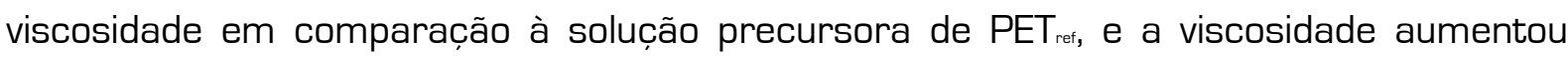
ainda mais quando se aumentou o tempo de preparação de 48 h para 72 h [no caso de PETC/72 h]. Assim, possivelmente, os grupos hidroxila das cadeias de celulose levaram à 
agregação, via ligações hidrogênio com grupos hidroxila de outras cadeias vizinhas e grupos carbonila das cadeias de PET. Este fenômeno foi favorecido pelo longo tempo de preparação da solução e consequente aumento da viscosidade. Ainda, esse comportamento deve-se, possivelmente, à presença de fibras com diâmetros maiores

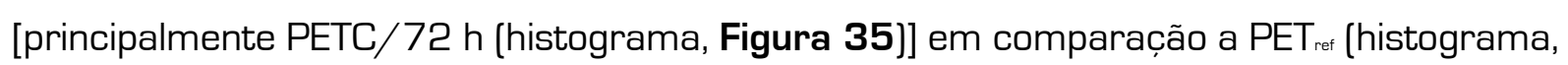
Figura 32). Destaca-se que, quando agregados estão presentes, não há uma "solução verdadeira", a qual corresponde a solutos dispersos molecularmente (ou seja, ausência de agregados]. No entanto, a presença de agregados é praticamente inevitável quando os solutos são macromoléculas constituídas por grupos polares (grupos hidroxila, por exemplo], os quais levam a fortes ligações hidrogênio intermoleculares. A combinação de celulose e PET reciclado levou a mats livres de beads (Figura 34), enquanto que beads foram formados via eletrofiação da solução de celulose/TFA [CEL, Figura 31].

Observa-se que as fibras ultrafinas de PETC/48 h e PETC/72 h [Figura 34] não apresentam ramificações, orientam-se de forma aleatória e os mats apresentam uma área média de poro e porosidade média de 11,2 \pm 0,3 x 10 $\mathrm{nm}^{2}$ e 14,1 $\pm 2,7 \%$ e 17,8 \pm $1,5 \times 10^{4} \mathrm{~nm}^{2}$ e 10,8 \pm 1,9\% [Figura 33-[b],[c]], respectivamente. Ainda, ao compararmos esses valores com os apresentados por $\mathrm{PET}_{\text {ref, }}$ observamos que a amostra controle de PET reciclado apresentou uma menor área média de poro e elevada porosidade $\{9,6 \pm 1,1 \times$ $10^{4} \mathrm{~nm}^{2}$ e 19,0 \pm 1,1\%, respectivamente [Figura 33-[b],[c]]\}. Agarwal et al. [2012], em seu estudo, obtiveram membranas de PET/Celulose à partir da eletrofiação de soluções de polissacarídeo/PET/TFA nas razões de 1:3:3. Neste estudo, foram obtidas fibras ultrafinas com diâmetro médio de $525 \pm 40 \mathrm{~nm}$, valor superior ao diâmetro médio das fibras de PET/celulose de PETC/48 h [Figura 33-[a]].

Na Figura 34, observa-se que a micrografia de PETL/48 h apresenta uma rede de fibras contínua e heterogênea, composta por nanofibras e fibras ultrafinas com diâmetros da ordem de 90-340 nm [Figura 35], com um diâmetro médio de 175,6 \pm 47,9 nm [Figura 33-[a]]. A micrografia de PETL/72 h [Figura 34] também apresenta uma rede de fibras contínua e heterogênea, composta por fibras ultrafinas com diâmetros que variam de aproximadamente 110-480 nm [Figura 35], com diâmetro médio de 259,5 \pm 64,5 nm [Figura 33-[a]]. Destaca-se que a presença de lignina não alterou significativamente o diâmetro médio das fibras formadas, ao compararmos com o diâmetro médio das fibras de $\operatorname{PET}_{\text {ref }}\{242,4 \pm 59,1 \mathrm{~nm}$, [Figura 33-[a]]\}. Observa-se que com o aumento do tempo de preparação das soluções de PET/lignina de $48 \mathrm{~h}$ para $72 \mathrm{~h}$, houve um ligeiro aumento na viscosidade das soluções [Tabela 3], o que sugere a agregação das cadeias de PET e lignina, levando a uma maior variação nos valores de diâmetros das fibras [Figura 35] e um maior achatamento das mesmas [Figura 34].

As fibras de PETL/48 h, assim como as fibras de PETL/72 h (Figura 34), apresentam algumas poucas ramificações e estão orientadas de forma aleatória. PETL/48 h e PETL/72 h apresentam área média de poro e porosidades médias 
semelhantes de, respectivamente, 7,5 $\pm 1,3 \times 10^{4} \mathrm{~nm}^{2}$ e 21,3 $\pm 3,4 \%$ e 7,9 $\pm 0,9 \times 10^{4}$ $\mathrm{nm}^{2}$ e 17,4 \pm 1,8\% [Figura 33-[b],[c]], mesma faixa, no geral, observada para a área média de poros e porosidade média de $\operatorname{PET}_{\text {ref }}\left\{9,6 \pm 1,1 \times 10^{4} \mathrm{~nm}^{2}\right.$ e $19,0 \pm 1,1 \%$, respectivamente [Figura 33-[b],[c]]\}, quando os respectivos erros são considerados. Como mencionado anteriormente, as fibras de PETL/48 h e PETL/72 h [Figura 34] apresentam um formato mais achatado, em comparação às fibras ultrafinas de formato mais cilíndrico de PET ref (Figura 31], PETC/48 h [Figura 34] e PETC/72 h [Figura 34]. Ahn et al. [2014], em seu estudo, investigaram a influência do teor de lignina na morfologia de fibras ultrafinas, obtidas via eletrofiação à partir de soluções desta macromolécula e celulose. Neste estudo, observou-se que com o aumento do teor de lignina $[0-40 \%$ em massa] na composição das fibras ultrafinas, foram observadas com mais frequência a presença de fibras de formato achatado e menos cilíndricas. Durante o processo de eletrofiação, no jato de líquido ejetado através da agulha, pode ser formada uma fina camada polimérica. Após a formação da camada, há a evaporação do solvente de seu interior e o colapso da pressão atmosférica com o tubo formado. Assim, a secção circular do tubo torna-se elíptica, ocorrendo a formação de fibras de morfologia achatada [KOOMBHONGSE; LIU; RENEKER, 2001].

A micrografia de PETCL/48 h [Figura 34] apresenta uma rede de fibras contínuas, em geral, homogênea, composta por fibras ultrafinas, orientadas aleatoriamente, com diâmetros variando de 150-750 nm (Figura 35], com diâmetro médio de 327,9 \pm 124,2 nm [Figura 33-[a]]. Diferentemente do apresentado por PETCL/48 h, pode-se observar na micrografia de PETCL/72 h [Figura 34] uma rede de fibras contínuas, heterogêneas, composta por fibras ultrafinas orientadas aleatoriamente, com diâmetros da ordem de 130 a 530 nm [Figura 35] e com diâmetro médio de 251,8 \pm 96,9 nm \{semelhante ao diâmetro médio das fibras ultrafinas de PET ret e PETCL/48 h, [Figura 33-[a]]\}.

Os resultados de viscosidade de PETCL/48 h e PETCL/72 h [Tabela 3] indicam que a presença de lignina, mesmo em pequena quantidade, possivelmente favoreceu 0 fenômeno de agregação de cadeias devido, provavelmente, a presença de grupos hidroxila [tanto fenólicos quanto alcóolicos] na estrutura dessa macromolécula, além dos grupos hidroxila presentes na estrutura da celulose. A estrutura não-linear da lignina pode afetar de forma significativa o volume hidrodinâmico dos agregados e, consequentemente, a viscosidade da solução. Assim, a presença de lignina e o tempo de preparação de 72 h levaram a uma solução altamente viscosa, assim como ao achatamento das fibras e ramificação das mesmas no mat PETCL/72 h (Figura 34). As fibras ultrafinas de PETCL/48 h [Figura 34] apresentaram um formato mais cilíndrico e sem ramificações [semelhante às fibras ultrafinas de PET ref (Figura 31] e PETC/48 h [Figura 34)]. Yarin et al. [2005], em seu estudo, atribuíram à formação de ramificações, as instabilidades das ondas estáticas do jato de solução, na presença de um campo elétrico cilíndrico, durante a 
eletrofiação. De acordo com esse estudo, as instabilidades nas regiões de alta curvatura, no topo das ondulações de maior comprimento de onda (devido ao desequilíbrio entre a tensão superficial do líquido e as forças elétricas], podem levar à formação de ramificações laterais do jato de solução polimérica, com a consequente geração de fibras ramificadas.

As fibras ultrafinas de PETCL/48 h [Figura 34] apresentaram uma área média de poro e porosidade média $\left\{18,4 \pm 1,4 \times 10^{4} \mathrm{~nm}^{2}, 14,2 \pm 2,7 \%\right.$, respectivamente [Figura 33-[b],[c]]\} semelhantes ao apresentado por PETCL/72 h [15,0 \pm 4,6 x 10 $\mathrm{nm}^{2}$ e 16,3 \pm 1,2\%, respectivamente [Figura 33-[b],[c]]]. No entanto, esses valores foram, respectivamente, superiores ao apresentado por $\mathrm{PET}_{\text {ref }}$ \{área média de poro [Figura 33[b]], principalmente para PETCL/48 h\} e inferiores ao apresentado, com relação à porosidade média, por PET ret [Figura 33-[c]].

\subsection{3 Ângulo de contato [AC]}

A Figura 36 apresenta o ângulo de contato de avanço [ACA, máximo], o ângulo de contato de recuo (mínimo], assim como as imagens da gota de água após o primeiro segundo de contato com a superfície dos mats.

Figura 34 - Ângulo de contato de avanço [máximo, erros de \pm 6,8 [PET ref] a \pm 0,6 [PETC/48 h]], ângulo de contato de recuo [mínimo, erros de \pm 1,66 [PETL/72 h] a \pm 0,17 [PETCL/72 h]] e imagens da gota de água

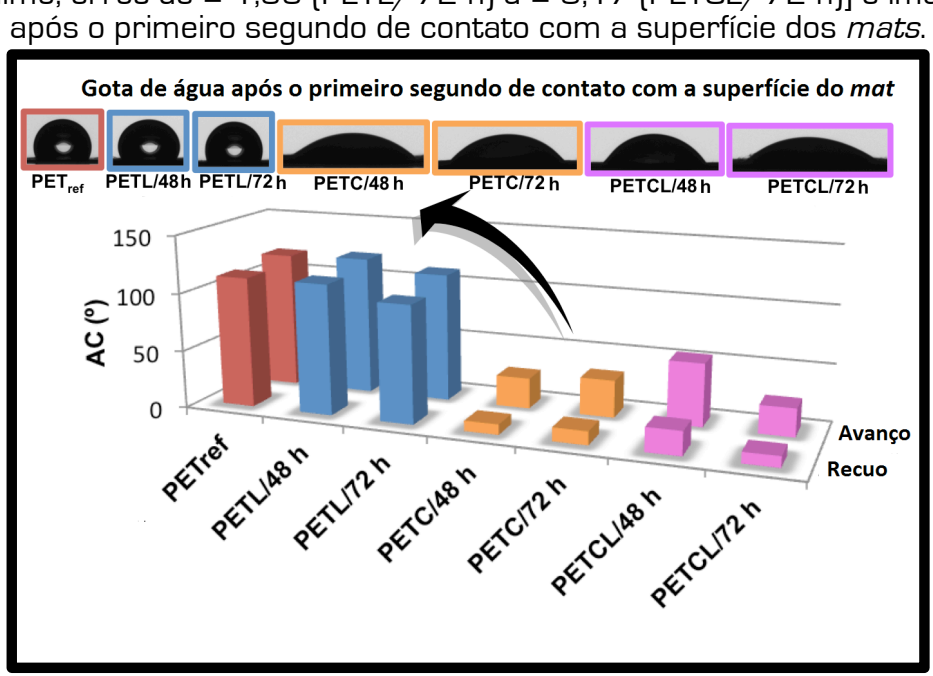

Fonte: Autoria própria.

Observa-se na Figura 36 que os mats PET ref, PETL/48 h e PETL/72 h apresentaram os maiores valores de ACA $\left[123,8 \pm 6,8^{\circ}, 118,6 \pm 3,8^{\circ}\right.$ e 111,2 $\pm 3,1^{\circ}$, respectivamente], após o primeiro segundo de contato da gota de água com a superfície dos materiais. Observou-se também que esses valores sofreram apenas uma pequena redução ao longo dos 500 s de análise, ou seja, os mats PET ref, PETL/48 h e PETL/72 h apresentaram superfícies hidrofóbicas, como consequência da baixa polaridade do PET e da lignina. PETC/48 h, PETC/72 h, PETCL/48 h e PETCL/72 h apresentaram ACA de $26,6 \pm 0,6^{\circ}, 32,6 \pm 6,2^{\circ}, 54,4 \pm 4,6^{\circ}$ e 24,3 $\pm 2,7^{\circ}$, respectivamente, após $1 \mathrm{~s}$ de 
deposição da gota na superfície dos mats. No entanto, como pode-se observar na Figura 36, ocorreu um rápido decréscimo nesses valores de $A C$ após 3 s de deposição da gota, com base na diferença entre o ACA $[t=1 \mathrm{~s}$ ) e o ângulo de contato de recuo $[t=3 \mathrm{~s}$ ). Esse pronunciado aumento na molhabilidade desses materiais, em comparação com $P E T_{\text {ret, }}$ PETL/48 h e PETL/72 h [Figura 36), deve-se à maior hidrofilicidade dos mesmos devido à presença de celulose [com grupos hidroxila em sua cadeia, Figura 4] em suas composições [JOSHI et al., 2015).

\subsubsection{Termogravimetria [TG]}

A Figura 37-[a],(b) apresenta as curvas TG e dTG para PET ref, PETC/48 h, PETL/48 h e PETCL/48 h.

Figura 35 - Curvas (a) TG e (b) dTG para os mats PET ret, PETC/48 h, PETL/48 h e PETCL/ 48 h [atmosfera de $\mathrm{N}_{2}$, fluxo de $50 \mathrm{~mL} \min ^{-1}$ e taxa de aquecimento de $10{ }^{\circ} \mathrm{C} \mathrm{min}^{-1}$ ).

[a]



Fonte: Autoria própria. (b)

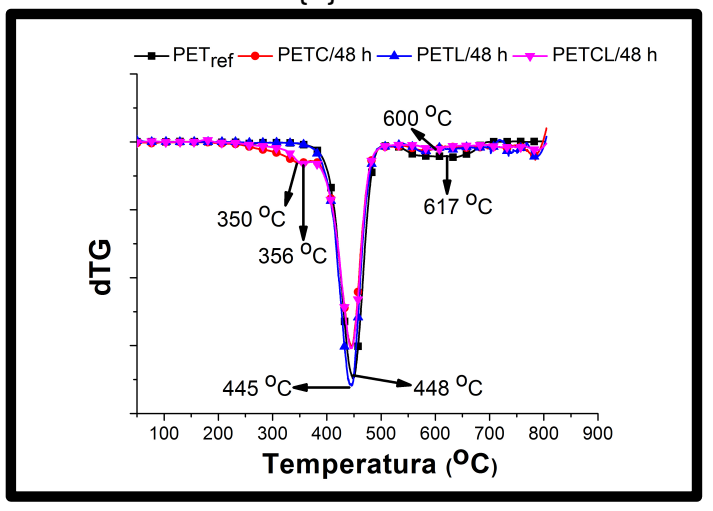

A Tabela 4 apresenta as temperaturas características de decomposição térmica e as perdas de massa correspondentes de PET ref, PETC/48 h, PETC/72 h, PETL/48 h, PETL/72 h, PETCL/48 h e PETCL/72 h. 
Tabela 4 -Temperaturas características da decomposição térmica e correspondentes perdas de massa de PET $_{\text {ret, }}$ PETC/48 h, PETC/72 h, PETL/48 h, PETL/72 h, PETCL/48 h e PETCL/72 h.

\begin{tabular}{|c|c|c|c|c|c|c|c|c|c|c|c|c|}
\hline \multirow[b]{2}{*}{ Amostra } & \multicolumn{4}{|c|}{ Estágio I } & \multicolumn{4}{|c|}{ Estágio II } & \multicolumn{4}{|c|}{ Estágio III } \\
\hline & $\begin{array}{c}\text { Intervalo } \\
{\left[{ }^{\circ} \mathrm{C}\right]}\end{array}$ & $\begin{array}{c}T_{\text {onset }} \\
{\left[{ }^{\circ} \mathbf{C}\right]^{*}}\end{array}$ & $\begin{array}{c}\mathrm{T}_{\mathrm{p}} \\
{\left[{ }^{\circ} \mathrm{C}\right]^{\star}} \\
\star\end{array}$ & $\underset{[\%]^{* *}}{W L}$ & $\begin{array}{c}\text { Intervalo } \\
{\left[{ }^{\circ} \mathrm{C}\right]}\end{array}$ & $\begin{array}{l}T_{\text {onset }} \\
{\left[{ }^{\circ} \mathrm{C}\right]}\end{array}$ & $\begin{array}{c}\mathrm{T}_{\mathrm{p}} \\
{\left[{ }^{\circ} \mathrm{C}\right]}\end{array}$ & $\begin{array}{l}\text { WL } \\
\text { [\%] }\end{array}$ & $\begin{array}{c}\text { Intervalo } \\
{\left[{ }^{\circ} \mathrm{C}\right]}\end{array}$ & $\begin{array}{l}T_{\text {onsot }} \\
{\left[{ }^{\circ} \mathrm{C}\right]}\end{array}$ & $\begin{array}{c}\mathrm{T}_{\mathrm{p}} \\
{\left[{ }^{\circ} \mathrm{C}\right]}\end{array}$ & $\begin{array}{l}\text { WL } \\
{[\%]}\end{array}$ \\
\hline$\overline{P E T_{\text {ref }}}$ & - & - & - & - & $338-504$ & 418 & 448 & 84 & $530-690$ & 554 & 617 & 13 \\
\hline PETC/48 h & 232-370 & 290 & 350 & 11 & $377-508$ & 415 & 445 & 71 & - & - & & - \\
\hline PETC/72 h & 289-359 & 303 & 333 & 7 & $364-508$ & 419 & 445 & 76 & - & - & & - \\
\hline PETL/48 h & - & - & - & - & $325-503$ & 414 & 445 & 80 & - & - & & - \\
\hline PETL/72 h & - & - & - & - & 338-493 & 417 & 444 & 83 & - & - & & - \\
\hline PETCL/48 h & 235-371 & 314 & 356 & 8 & $375-531$ & 420 & 445 & 73 & $552-636$ & 572 & 600 & 3 \\
\hline PETCL/72 h & 271-358 & 300 & 326 & 7 & $364-494$ & 424 & 449 & 75 & - & - & & - \\
\hline
\end{tabular}

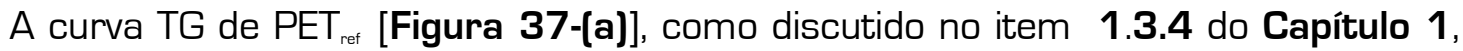
mostra um estágio de perda de massa no intervalo de aproximadamente $340-500^{\circ} \mathrm{C}$, com máxima taxa de perda de massa [ $T_{p}$, curva dTG, Figura 37-(b)] de $448{ }^{\circ} \mathrm{C}$. Neste estágio houve uma perda de massa de aproximadamente 80\% [Tabela 4], e o mesmo pode ser atribuído à decomposição do PET, através de cisões aleatórias de ligações éster na cadeia principal do polímero, resultando na formação de diferentes oligômeros (DIMITROV et al., 2013; JENEKHE; LIN; SUN, 1983]. Ainda, observa-se um segundo estágio de perda de

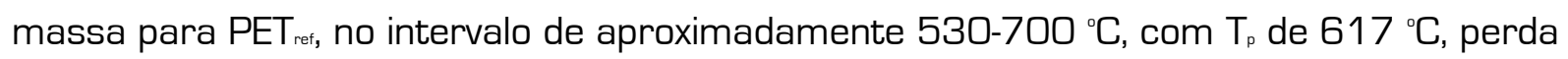
de massa de aproximadamente 10\% [Tabela 4], o qual pode estar associado à decomposição de possíveis contaminantes que permaneceram na composição do polímero, mesmo pós processo de reciclagem mecânica.

Observa-se nas curvas dTG de PETC/48 h, PETCL/48 h [Figura 37-[b]], PETC/72 h e PETCL/72 h (Figuras não mostradas), além do estágio de perda de massa com $T_{p}$ variando entre $445-449{ }^{\circ} \mathrm{C}$ [e que pode ser atribuído à decomposição do PET reciclado [Tabela 4]], um segundo estágio de perda de massa, no intervalo de temperatura de aproximadamente 230-370 ${ }^{\circ} \mathrm{C}$, com $T_{\mathrm{p}}$ variando entre 333-356 ${ }^{\circ} \mathrm{C}$ [Tabela 4). Este estágio pode ser atribuído à despolimerização da celulose (RODRIGUES et al., 2015; SANTOS et al., 2015], um dos constituintes desses mats, e também está presente nas curvas dTG dos mats contendo fibra de sisal e PET reciclado em suas composições [Figura 27-[c]]. Ainda, destaca-se que, diferentemente do observado nas curvas dTG dos mats contendo polímero reciclado/sisal em suas composições [Figura 27-[c]], não houve qualquer influência significativa da presença de celulose que levasse a um deslocamento para valores de temperatura mais baixos da $T_{p}$, referente à decomposição térmica do PET reciclado, nas curvas dTG de PETC/48 h, PETCL/48 h [Figura 37-[b]], PETC/72 h e PETCL/72 h [Figuras não mostradas].

Pode-se observar que a curva dTG de PETL/48 h [Figura 37-[b]] apresentou um

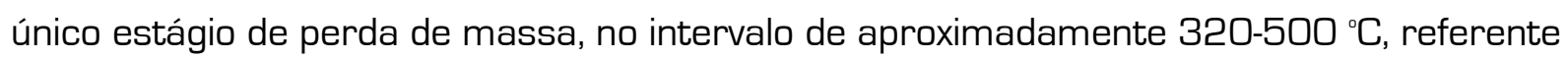
à decomposição do PET reciclado, possivelmente incorporando também a decomposição 
térmica da lignina. As curvas TG e dTG para PETL/72 h [Figuras não mostradas] foram similares àquelas de PETL/48 h [Figura 37-[a],[b]]. Este fato corrobora a hipótese de que a lignina provavelmente foi eletrofiada em combinação com as cadeias de PET, assim como observado nas curvas dTG dos mats de fibra lignocelulósica de sisal/PET reciclado [Figura 27-[c]].

\subsubsection{Calorimetria Exploratória Diferencial [DSC]}

A Figura 38 apresenta as curvas DSC de PET ref, PETC/72 h, PETL/72 h e PETCL/72 h, as quais foram obtidas visando principalmente avaliar a cristalinidade $\left[\mathrm{l}_{\mathrm{c}}\right.$, Tabela 5] do PET presente nos mats, através de seu pico de fusão.

Figura 36 - Curvas DSC para os mats PET re, PETC/72 h, PETL/72 h e PETCL/72 h [atmosfera de $\mathrm{N}_{2}$, fluxo de $50 \mathrm{~mL}$ min $^{-1}$ e taxa de aquecimento de $10^{\circ} \mathrm{C}$ min

Fonte: Autoria própria.

Os valores de temperatura de fusão $\left[\mathrm{T}_{m}\right]$, entalpia de fusão $\left[\Delta \mathrm{H}_{\mathrm{f}}\right]$ e cristalinidade $\left[\mathrm{l}_{c}\right]$ para o PET presente nos mats obtidos via eletrofiação estão apresentados na Tabela 5.

Tabela 5 - $\mathrm{T}_{\mathrm{m}}, \mathrm{H}_{\mathrm{f}}$ e l $\mathrm{l}_{\mathrm{c}}$ para PET ref, PETC/48 h, PETC/72 h, PETL/48 h, PETL/72 h, PETCL/48 h e

\begin{tabular}{|c|c|c|c|}
\hline \\
\hline Amostra & $\mathrm{T}_{\mathrm{m}}\left[{ }^{\circ} \mathrm{C}\right]^{*}$ & $\Delta \mathrm{H}_{\mathrm{f}}\left[\mathrm{J} \mathrm{g}^{-1}\right]^{\star *}$ & $\mathrm{I}_{\mathrm{c}}[\%]^{\star \star \star}$ \\
\hline $\mathrm{PET}_{\text {ref }}$ & 246 & 64,5 & 46 \\
\hline PETC/48 h & 246 & 59,3 & 46 \\
\hline PETC/72 h & 247 & 52,4 & 41 \\
\hline PETL/48 h & 247 & 69,3 & 50 \\
\hline PETL/72 h & 250 & 56,1 & 41 \\
\hline $\mathrm{PETCL} / 48 \mathrm{~h}$ & 246 & 58,6 & 46 \\
\hline PETCL/72 h & 249 & 41,6 & 33 \\
\hline
\end{tabular}

$\mathrm{T}_{\mathrm{m}}=$ Temperatura de fusão; " $\Delta \mathrm{H}_{\mathrm{t}}=$ entalpia de fusão; ${ }^{\prime \prime} \mathrm{I}_{\mathrm{c}}=$ Cristalinidade

A curva DSC de PET ref [Figura 38] apresenta, inicialmente, um pico endotérmico pouco intenso na região de $130{ }^{\circ} \mathrm{C}$, possivelmente referente à vaporização de umidade residual. Observa-se também outro pico endotérmico intenso na região de $250{ }^{\circ} \mathrm{C}$, associado à fusão da fração cristalina do PET. Este pico é observado em $248{ }^{\circ} \mathrm{C}$ na curva DSC do PET reciclado de partida (Figura não mostrada), utilizado para preparar a solução eletrofiada que gerou o mat $P E T_{\text {ref. }}$ PET ref apresentou $\mathrm{I}_{\mathrm{c}}$ de 46\% [Tabela 5], valor próximo ao apresentado pelo polímero reciclado de partida, que apresentou $\mathrm{I}_{\mathrm{c}}$ de $49 \%$. As curvas DSC de PETC/72 h [Figura 38], PETCL/72 h [Figura 38], PETC/48 h, PETL/48 h e 
PETCL/48 h [Figuras não mostradas] apresentaram, além do evento endotérmico de fusão da fração cristalina do PET, um pico exotérmico em $340{ }^{\circ} \mathrm{C}$, que pode ser atribuído ao evento de decomposição da celulose [DE OLIVEIRA SANTOS et al., 2014].

A presença de celulose ou de lignina nos mats não impactou de forma significativa o valor de $T_{m}$ do PET [Tabela 5]. Observa-se uma tendência de diminuição na cristalinidade quando o tempo de preparação da solução que gerou o mat passou de 48 h para 72 h. A maior viscosidade das soluções preparadas à partir de 72 h [Tabela 3] pode ter prejudicado o alinhamento das cadeias de PET durante a eletrofiação, diminuindo levemente os valores de $I_{\text {c. }}$.

\subsubsection{Análise Dinâmico-Mecânica [DMA]}

Os resultados para o módulo de armazenamento $\left[\mathrm{E}^{\prime}-30^{\circ} \mathrm{C}\right.$ ) e temperatura de transição vítrea do $\mathrm{PET}$ reciclado $\left[\mathrm{T}_{\mathrm{g}}\right.$, obtida à partir do máximo da curva de tan $\delta$ ] para

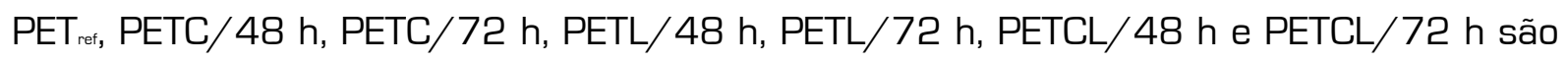
apresentados na Figura $\mathbf{3 9}$.

Figura 37 - (a) Módulo de armazenamento - E' (a 30 `C e e (b) Temperatura de transição vítrea $\left[\mathrm{T}_{\theta}\right.$ ) para os mats PET re; PETL/48 h; PETL/72 h; PETC/ 48 h; PETC/72 h; PETCL/ 48 h; PETCL/72 h.

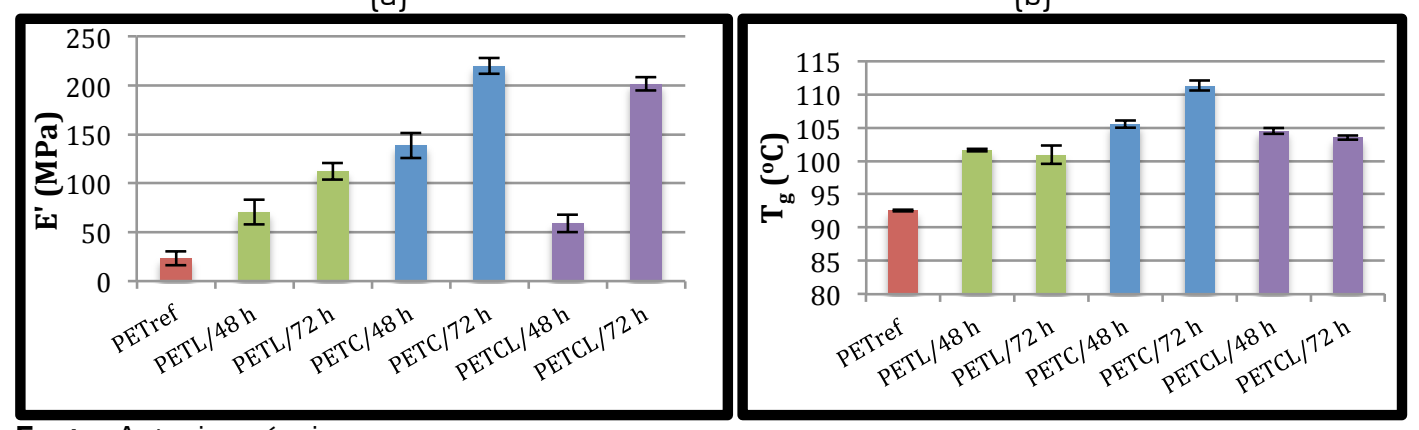

Fonte: Autoria própria.

Na Figura 39-[a] observa-se que houve um aumento do E' e consequente aumento da rigidez dos materiais obtidos via eletrofiação com relação à $\mathrm{PET}_{\text {ref, }}$ com a adição separada ou conjunta de lignina e celulose à solução polimérica. $P E T_{\text {ref }}$ apresentou um E', a 30 'C , de 23,3 \pm 7,1 MPa, já PETC/72 h apresentou um E’ de 219,8 \pm 7,9 MPa [maior valor de E' dentre todos os materiais obtidos via eletrofiação]. Com a adição de lignina à solução de PET e celulose, no preparo dos materiais obtidos via eletrofiação [PETCL/48 h e PETCL/72 h], houve um decréscimo de E' [59,2 \pm 9,1 MPa e 201,5 \pm 6,6 MPa, respectivamente), comparativamente à PETC/48 h e PETC/72 h [138,3 \pm 12,8 MPa e $219,8 \pm 7,9 \mathrm{MPa}$, respectivamente). Ainda, não se pode deixar de considerar que PETC/48 h, PETL/48 h e PETCL/48 h apresentaram valores de E' inferiores [Figura 39[a]], quando comparados aos valores de E' para os materiais de composições correspondentes $\{$ PETC/72 h, PETL/72 h e PETCL/72 h, respectivamente [Figura 39[a]]\}. Assim, pode-se concluir que o incremento no tempo de dissolução, de 48 h para $72 \mathrm{~h}$ no preparo dos materiais, favoreceu a formação de fibras mais homogêneas e mais 
rígidas [Figura 39-[a]].

Com base nos resultados apresentados [Figura 39-[a]], pode-se concluir que houve uma atuação efetiva da celulose como agente de reforço dos materiais contendo este polissacarídeo em suas composições [PETC/48 h, PETC/72 h, PETCL/48 h e PETCL/72 h], em comparação à $\mathrm{PET}_{\text {ret. }}$ Assim, possivelmente, houve um decréscimo da mobilidade dos segmentos das cadeias do PET com a inserção das cadeias de celulose, devido ao estabelecimento de interações intermoleculares entre grupos presentes na estrutura do PET e da celulose. Contudo, a adição de lignina à composição de PETCL/48 h e PETCL/72 h resultou, possivelmente, em um aumento de flexibilidade dos mesmos. A introdução de lignina às composições de PETCL/48 h e PETCL/72 h pode ter dificultado o estabelecimento de interações intermoleculares entre grupos presentes na estrutura do PET e da celulose, devido à presença dos anéis aromáticos presentes na estrutura da lignina.

Observa-se na Figura 39-[b] que os materiais obtidos via eletrofiação, com a adição separada ou conjunta de lignina e celulose à solução de PET (PETC/48 h, PETC/72 h, PETL/48 h, PETL/72 h, PETCL/48 h e PETCL/72 h), apresentaram valores de $\mathrm{T}_{\mathrm{g}}$ superiores ao apresentado por $\mathrm{PET}_{\text {ref, }}$ que apresentou uma $\mathrm{T}_{9}$ de 92,5 \pm 0,1 ${ }^{\circ} \mathrm{C}$. PETC/72 $\mathrm{h}$ apresentou o maior valor de $T_{9}$ dentre todos os materiais obtidos via eletrofiação [111,3 $\pm 0,7^{\circ} \mathrm{C}$ ). Esses resultados indicam que a presença de celulose e/ou lignina dificultou, possivelmente, os movimentos rotacionais de ligações covalentes de segmentos das cadeias de PET. Ainda, com base nos resultados obtidos e a elevada viscosidade apresentada por PETC/72 h [Tabela 3], pode-se concluir que foram estabelecidas intensas interações intermoleculares envolvendo principalmente os grupos hidroxila das cadeias de celulose e grupos carbonila das cadeias de PET.

Pode-se observar também na Figura 39-[b] que, com a adição de lignina à solução de PET e celulose, no preparo de PETCL/48 h e PETCL/72 h, houve um decréscimo nos valores de $T_{9}\left[104,5 \pm 0,4{ }^{\circ} \mathrm{C}\right.$ e 103,5 \pm 0,3 ${ }^{\circ} \mathrm{C}$, respectivamente], comparativamente à PETC/48 h e PETC/72 h [105,5 $\pm 0,5{ }^{\circ} \mathrm{C}$ e 111,3 $\pm 0,7{ }^{\circ} \mathrm{C}$, respectivamente). Destaca-se que PETL/48 h e PETL/72 h, contendo somente o polímero reciclado e lignina em suas composições, apresentaram um valor de $T_{9}$ ligeiramente inferior $\left[101,6 \pm 0,2{ }^{\circ} \mathrm{C}\right.$ e 100,9 $\pm 1,4{ }^{\circ} \mathrm{C}$, respectivamente], em comparação aos materiais contendo a mesma quantidade dessa macromolécula, porém apresentando também em suas composições a celulose [PETCL/48 h e PETCL/72 h, Figura 39-[b]]. Os resultados apresentados na Figura 39-[b] são consistentes e corroboram com o que foi observado para o E' dos materiais [Figura 39-[a]].

Em um estudo realizado anteriormente pelo grupo de pesquisa no qual o presente trabalho se insere, observou-se que na eletrofiação de soluções contendo PET e fibra lignocelulósica de sisal em suas composições [utilizando também o TFA como solvente), 
foram possivelmente obtidas fibras ultrafinas híbridas, devido a eletrofiação parcialmente conjunta do polímero e dos componentes do sisal [SANTOS et al., 2015]. Esta hipótese baseou-se no aumento progressivo da $T_{9}$ e do E', com a adição de sisal à composição dos materiais contendo PET, possivelmente como uma consequência das fortes interações entre os segmentos da cadeia do polímero com os componentes da fibra lignocelulósica, a distâncias intermoleculares [SANTOS et al., 2015). Os resultados da Figura 39-(b) também corroboram com o que foi observado para os materiais de PET/sisal obtidos via eletrofiação [SANTOS et al., 2015]. Observando-se as micrografias de PETC/48 h, PETC/72 h, PETCL/48 h e PETCL/72 h [Figura 34] pode-se identificar uma única rede de fibras ultrafinas, possivelmente devido a eletrofiação conjunta de PET/celulose/lignina e à formação de fibras híbridas.

\subsubsection{Ensaio de resistência à tração}

A Figura 40 apresenta os resultados de resistência à ruptura, módulo de Young e alongamento de PET ret, PETC/48 h, PETC/72 h, PETL/48 h, PETL/72 h, PETCL/48 h e PETCL/72 h. Destaca-se que os mats correspondem a materiais finos e porosos e, no presente estudo, constituídos por fibras não orientadas, o que leva à propriedades de tensão inferiores, por exemplo, a de filmes de composição similar à dos mesmos. No entanto, as propriedades de tensão podem trazer informações importantes, sendo relevante a avaliação das mesmas. 
Figura 40 - [a] Resistência à ruptura, [b] Módulo de Young e [c] Alongamento para os mats PET ré; PETL/48 h; PETL/72 h; PETC/ 48 h; PETC/72 h; PETCL/48 h; PETCL/72 h.

[a]



[b]



[c]

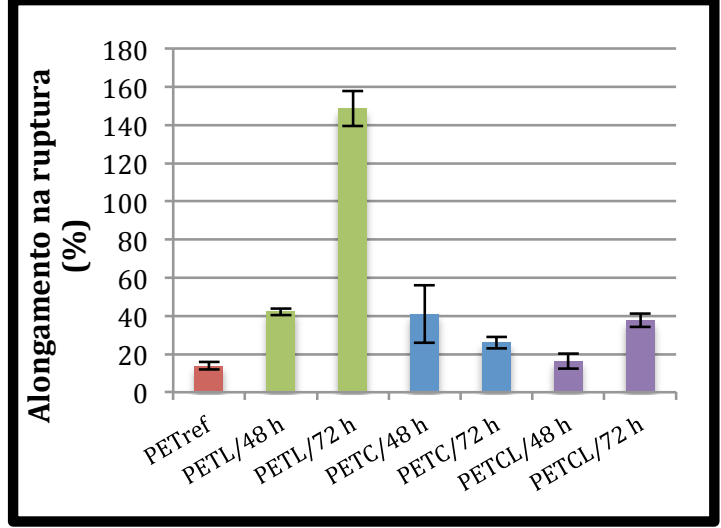

Fonte: Autoria própria.

Observa-se na Figura 40-[a] que $\mathrm{PET}_{\text {ref }}$ apresentou um valor de resistência à ruptura $[1,8 \pm 0,2 \mathrm{MPa}$ ] semelhante ao relatado por Veleirinho, Rei e Lopes-da-Silva [2008] que, em seu estudo, obtiveram para mats de PET, preparados via eletrofiação de solução deste polímero em TFA, um valor de resistência à ruptura de aproximadamente 2,00 MPa. Houve um aumento nos valores de resistência à ruptura com a adição de celulose e/ou lignina à composição dos mats de PET reciclado. PETC/48 h e PETC/72 h apresentaram os maiores valores de resistência à ruptura $[8,5 \pm 0,2 \mathrm{MPa}$ e 9,5 0,6 $\mathrm{MPa}$, respectivamente], em comparação aos demais materiais. Assim, pode-se concluir que a presença de celulose [quando não combinada com lignina] na composição de PETC/48 h e PETC/72 h, favoreceu o estabelecimento de fortes interações intermoleculares entre este polissacarídeo e as cadeias de PET, dificultando, consequentemente, a orientação das cadeias poliméricas com o eixo de tração, durante o estágio final da deformação.

Com relação ainda à Figura 40-[a], os mats preparados utilizando-se um tempo de dissolução de 48 h (PETC/48 h, PETL/48 h e PETCL/48 h) apresentaram uma tendência no sentido de baixos valores de resistência à ruptura, em comparação aos mats preparados com um tempo de dissolução de 72 h (PETC/72 h, PETL/72 h e PETCL/72 h]. Este resultado deve-se, possivelmente, a um aumento do fenômeno de agregação das 
cadeias de polímero com o aumento do tempo de dissolução, o que corrobora os baixos valores de viscosidade dinâmica das soluções preparadas com 48 h, em comparação às soluções preparadas com 72 h [Tabela 3]. Assim, o fenômeno de agregação nas soluções pode ter favorecido interações intermoleculares mais fortes nos mats obtidos à partir dessas soluções.

Observa-se na Figura 40-[b] que houve também um aumento do módulo de Young com a adição de celulose e/ou lignina à composição dos mats de PET reciclado, em comparação à $\mathrm{PET}_{\text {ref. }}$ PETC/72 h apresentou o maior valor de módulo de Young [360,4 \pm 41,5 MPa] dentre todas as amostras. Os resultados apresentados do módulo de Young [Figura 40-[b]] também corroboram o que foi observado para o E' dos materiais [Figura 39-[a]], em que, possivelmente, houve uma atuação efetiva da celulose como agente de reforço dos materiais contendo este polissacarídeo em sua composição [PETC/48 h, PETC/72 h, PETCL/48 h e PETCL/72 h], em comparação à PET ref. Veleirinho, Rei e Lopesda-Silva [2008), em seu estudo, obtiveram um valor de módulo de Young de aproximadamente $50 \mathrm{MPa}$, via ensaio de resistência à tração de mats de PET obtidos via eletrofiação de soluções do polímero em TFA. Esse valor foi superior ao obtido no presente estudo para PET ref, o qual apresentou um valor de módulo de Young de 36,3 \pm 2,1 $\mathrm{MPa}$ [Figura 40-[b]].

$\mathrm{PET}_{\text {ref }}$ apresentou um valor de alongamento na ruptura de 13,8 \pm 1,9\% [Figura 40 [c]] e, em geral, um aumento para essa propriedade foi observado quando celulose e/ou lignina foram adicionados à composição dos mats de PET reciclado. No entanto, nenhuma diferença significativa foi observada nos valores apresentados pelos mats, com exceção de PETL/72 h \{alongamento na ruptura de 148,7 \pm 9,1\% [Figura 40-[c]]\}. Este resultado pode indicar que um longo tempo de dissolução permitiu uma maior inserção de macromoléculas de lignina entre as cadeias de PET, o que favoreceu conformações mais esticadas dessas cadeias durante a deformação de tração. Consequentemente, houve um aumento do valor de alongamento na ruptura de PETL/72 h, em comparação aos demais mats [Figura 40-[c]].

\subsection{Conclusões parciais}

Foram preparados com sucesso mats de fibras ultrafinas/nanofibras via eletrofiação de soluções baseadas em PET reciclado, celulose e/ou lignina, pós dissolução em TFA por 48 h e $72 \mathrm{~h}$.

Em comparação ao que foi apresentado pelo mat $\mathrm{PET}_{\text {ref, }}$ as principais influências da presença de lignina foram na morfologia achatada das fibras, aumento da $T_{g}$ e significante aumento na resistência à ruptura e alongamento na ruptura [especialmente para PETL/72 h]. A presença da celulose resultou em um elevado diâmetro médio das fibras, elevada área média dos poros, assim como baixa porosidade média dos mats. Ainda, com 
relação à influência da presença desse polissacarídeo, a superfície dos mats foi alterada de hidrofóbica para altamente hidrofílica. A resistência à ruptura dos materiais, tanto com 48 h e 72 h de dissolução, foi elevada quando celulose foi adicionada na composição dos mesmos.

Quando foram preparadas soluções de PET contendo celulose e lignina, a solução preparada à partir de $72 \mathrm{~h}$ de dissolução apresentou o mais alto valor de viscosidade dinâmica, e o mat preparado à partir dessa solução apresentou o mais baixo valor de cristalinidade, assim como fibras achatadas e ramificadas. Ainda, PETCL/72 h apresentou um valor de E' e de resistência à ruptura aproximadamente três vezes maior que o apresentado por $\mathrm{PET}_{\text {ref. }}$ Faz-se importante destacar que, até mesmo um mat que não possui todas as propriedades consideradas ideais para esse tipo de material (por exemplo, ausência de fibras achatadas e ramificações], pode encontrar uma determinada aplicação.

Para aplicações dos mats como sistemas de filtração ou em materiais compósitos, por exemplo, diferentes propriedades são requisitadas. Em sistemas de filtração, as propriedades requisitadas (por exemplo, porosidade, área do poro, superfície hidrofóbica/hidrofilica e propriedades de resistência à tração] irão diferir de acordo com o objetivo que se deseja atingir [interceptar partículas finas ou gases orgânicos voláteis ou filtrar líquidos polares ou apolares, por exemplo]. Nas aplicações em compósitos, é muitas vezes requerida um impregnação prévia dos mats por uma resina polimérica líquida. Para esse tipo de aplicação, a porosidade e área dos poros são propriedades importantes, além da superfície do mat ser ajustada para a mesma polaridade da resina, visando obter uma boa interface mat/polímero. Além do mais, o mat deve apresentar boas propriedades mecânicas quando utilizado como agente de reforço em matrizes poliméricas.

As propriedades mencionadas anteriormente foram consideradas no presente estudo e as descobertas resultantes motivarão novas investigações. Assim, os teores de celulose e/ou lignina, assim como outros tempos de preparo das soluções, podem ser explorados visando o desenvolvimento de materiais bio-baseados com propriedades diferentes das apresentadas no presente capítulo. 


\section{Capítulo 3. Eletrofiação de soluções}

\section{preparadas a partir de celulose, lignina e PET reciclado visando a produção de mats com fibras alinhadas}

\subsection{Introdução}

Foi relatado no Capítulo 2 a utilização de PET reciclado, celulose e lignina como matérias-primas para a preparação, via eletrofiação, de nanofibras/fibras ultrafinas, utilizando-se o TFA como solvente.

Como continuidade a esse trabalho prévio realizado [Capítulo 2], no presente capítulo, descreve-se a contribuição conjunta e/ou separada de dois componentes principais de fibras lignocelulósicas, a celulose e a lignina, nas propriedades finais dos mats baseados em PET reciclado, visando a produção de fibras alinhadas.

No presente capítulo utilizou-se como aparato coletor de fibras um tambor metálico rotativo e foram exploradas três diferentes condições/parâmetros de eletrofiação, visando a produção de fibras alinhadas. Destaca-se que para o presente estudo foram eletrofiadas soluções de PET/celulose/lignina em TFA utilizando-se somente o tempo de dissolução de 72 h, com exceção do preparo da solução de referência de PET reciclado que foi de $24 \mathrm{~h}$. Optou-se por utilizar somente um tempo de dissolução de 72 h no preparo das soluções a serem eletrofiadas pois, como observado no Capítulo 2 , os mats preparados via eletrofiação de soluções pós 72 h de dissolução apresentaram, no geral, superiores propriedades mecânicas, tais como superiores valores de E' [a 30 'C] e resistência à ruptura, em comparação com os mats [de composição correspondente] preparados utilizando-se um tempo de $48 \mathrm{~h}$ de dissolução.

Assim, neste capítulo buscou-se, além da produção de fibras alinhadas, fazer uma avaliação da influência das diferentes condições/parâmetros de eletrofiação explorados na orientação das fibras obtidas e nas propriedades finais dos mats produzidos. Também foi avaliada a influência nas propriedades termo-mecânicas e mecânicas quando os materiais foram caracterizados na direção preferencial de alinhamento das fibras e na direção oposta. Ainda, buscou-se também com esses resultados fazer uma comparação das propriedades finais dos mats em que as fibras apresentaram maior grau de orientação, com as propriedades finais dos mats de mesma composição, preparados no Capítulo 2, compostos por fibras orientadas aleatoriamente. 


\subsection{Experimental}

\subsubsection{Materiais}

Os materiais utilizados foram os mesmos descritos no item 2.2.1 do Capítulo 2.

\subsubsection{Métodos}

\subsubsection{Processo de eletrofiação}

As soluções em TFA foram preparadas da mesma forma descrita no Capítulo 2 (para a preparação dos mats PET ret, PETC/72 h, PETL/72 h e PETCL/72 h), utilizando-se o tempo de dissolução de 72 h, com exceção do tempo de preparo da solução referência de PET reciclado, que foi de $24 \mathrm{~h}$. No processo de preparação dos mats, também foi utilizado o mesmo aparato de eletrofiação descrito no Capítulo 2, mas como aparato coletor de fibras foi utilizado um tambor metálico rotativo $[12,5 \times 5,5 \mathrm{~cm}$, comprimento $\times$ largura), de acordo com a representação esquemática da Figura 16. Em todos os casos foi utilizada a voltagem positiva de $25 \mathrm{kV}$, sendo que os parâmetros variados foram a distância entre a ponta da agulha e o coletor, a taxa de vazão da solução e a velocidade de rotação do coletor [a rotação adotada em todos os casos foi a no sentido anti-horário].

A Tabela 6 apresenta as taxas de vazão da solução, distâncias entre a ponta da agulha e o coletor, velocidades de rotação do coletor e os respectivos códigos de referência dos mats preparados.

Tabela 6 -Parâmetros de eletrofiação adotados e os respectivos códigos de referência dos mats preparados.

\begin{tabular}{cccc}
\hline $\begin{array}{c}\text { Taxa de vazão } \\
{\left[\boldsymbol{\mu L} \text { min }^{-1}\right]}\end{array}$ & $\begin{array}{c}\text { Distância ponta } \\
\text { da agulha- } \\
\text { coletor }[\mathbf{c m}]\end{array}$ & $\begin{array}{c}\text { Velocidade de } \\
\text { rotação } \\
\text { (rpm) }\end{array}$ & $\begin{array}{c}\text { Código de } \\
\text { referência }\end{array}$ \\
\hline 25,5 & 8 & 3300 & PET-A1 \\
25,5 & 8 & 3600 & PET-A2 \\
10,5 & 8 & 3300 & PET-A3 \\
25,5 & 8 & 3000 & PETC-A1 \\
25,5 & 8 & 3300 & PETC-A2 \\
10,0 & 6 & 3200 & PETC-A3 \\
25,5 & 8 & 3300 & PETL-A1 \\
25,5 & 8 & 3600 & PETL-A2 \\
10,5 & 8 & 3300 & PETL-A3 \\
25,5 & 8 & 3300 & PETCL-A1 \\
25,5 & 8 & 3600 & PETCL-A2 \\
10,5 & 8 & 3300 & PETCL-A3 \\
\hline
\end{tabular}

Os processos de eletrofiação foram realizados por 40 min a uma temperatura de 25,9 \pm 0,9 ${ }^{\circ} \mathrm{C}$ e umidade relativa de 45,7 $\pm 3,3 \%$. Os mats preparados apresentaram espessura média de 0,10 \pm 0,03 mm, a qual foi determinada utilizando-se um micrômetro. Ainda, os materiais produzidos apresentaram dimensões médias de 3,91 \pm 1,21 x 15,86 $\pm 0,24 \mathrm{~cm}$ (largura x comprimento). 


\subsubsection{Caracterização dos mats}

\subsection{Microscopia Eletrônica de Varredura [MEV]}

As análises de MEV foram realizadas de acordo com o que foi descrito no item

1.2.2.2.2 do Capítulo 1.

\subsubsection{2 Ângulo de contato [AC]}

As análises de AC foram realizadas de acordo com o que foi descrito no item

1.2.2.2.3 do Capítulo 1.

\subsection{Análise Dinâmico-Mecânica [DMA]}

As análises de DMA foram realizadas de acordo com o que foi descrito no item

\subsubsection{5 do Capítulo 1.}

\subsection{Ensaio de resistência à tração}

Os ensaios de resistência à tração foram realizadas de acordo com o que foi descrito no item 2.2.2.3.7do Capítulo 2.

\subsection{Resultados e Discussão}

\subsubsection{Microscopia Eletrônica de Varredura (MEV]}

A Figura 41 apresenta as micrografias, as respectivas imagens codificadas por cores e a escala de orientação de cores, assim como o I.A. e a O.P.M. das fibras para os mats PET-A1, PET-A2 e PET-A3. 
Figura 38 - Micrografias, respectivas imagens codificadas por cores, escala de orientação de cores, I.A. e O.P.M. dos mats PET-A1, PET-A2 e PET-A3.
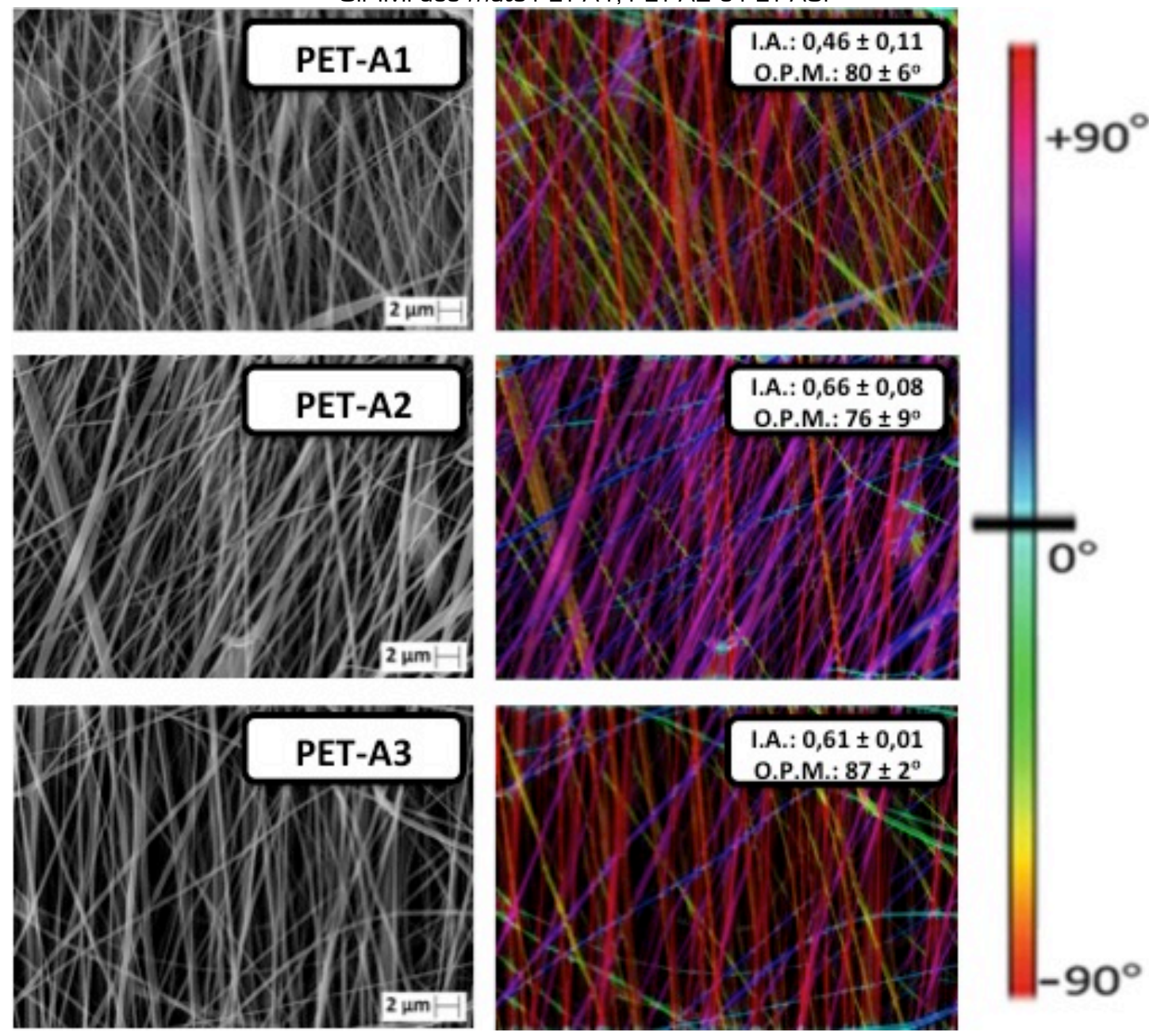

Fonte: Autoria própria.

A Figura 42 mostra os histogramas referentes ao diâmetro das fibras de PET-A1, PET-A2 e PET-A3.

Figura 39 - Histogramas do diâmetro das fibras de PET-A1, PET-A2 e PET-A3.
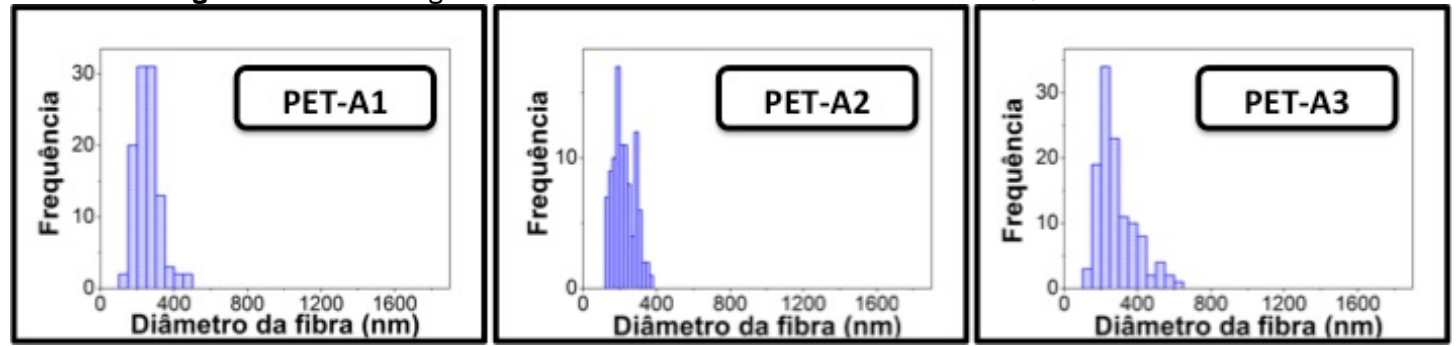

Fonte: Autoria própria.

O diâmetro médio das fibras, área média do poro e porosidade média dos mats obtidos via eletrofiação são apresentados na Figura 43. 
Figura 40 - Diâmetro médio das fibras, área média dos poros e porosidade média dos mats PET-A1, PETA2, PET-A3, PETC-A1, PETC-A2, PETC-A3, PETL-A1, PETL-A2, PETL-A3, PETCL-A1, PETCL-A2 e PETCL-A3.

[a]

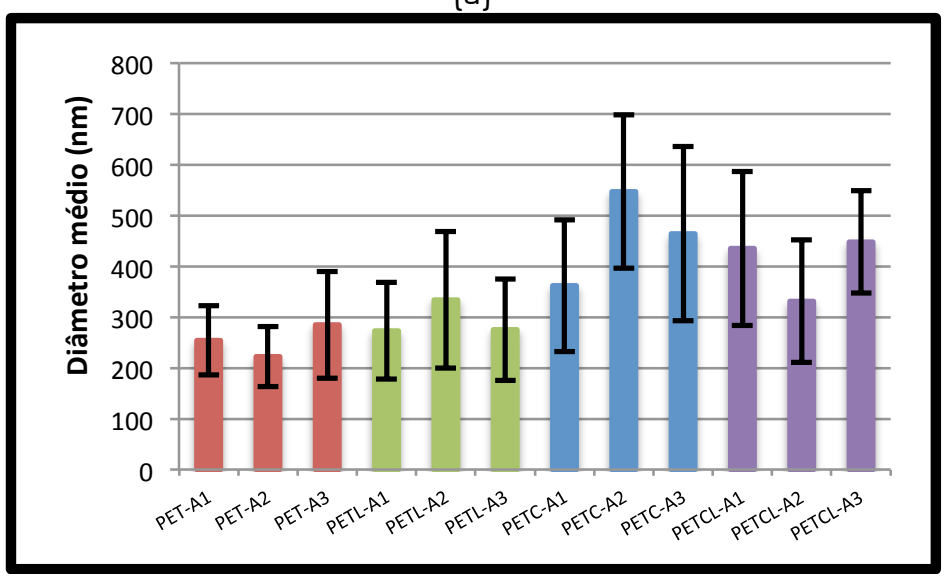

[b]

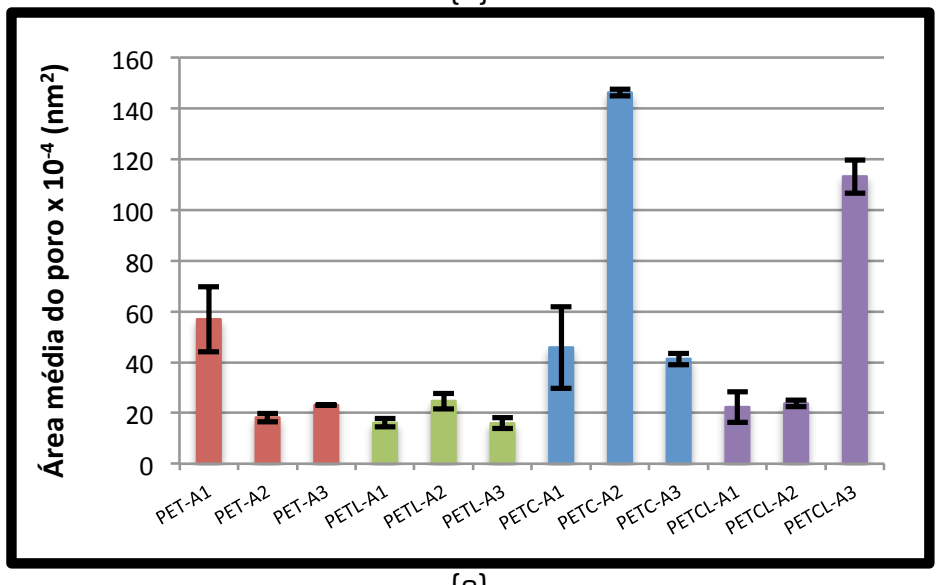

[c]



Fonte: Autoria própria.

Observa-se nas micrografias da Figura 41 redes de fibras contínuas, em geral, homogêneas e sem ramificações. PET-A1, PET-A2 e PET-A3 apresentaram fibras com diâmetro médio sem diferenças significativas [Figura 43-[a]], sendo que PET-A3 apresentou a maior variação dos valores de diâmetro de fibra, em comparação ao apresentado por PET-A1 e PET-A2 [Figura 42).

PET-A1 apresentou o maior valor de área média do poro $\left\{56,9 \pm 12,8 \times 10^{4} \mathrm{~nm}^{2}\right.$ [Figura 43-[b]]\} e a maior porosidade média $\{39,5 \pm 3,2 \%$ [Figura 43-[c]]\}, em 
comparação a PET-A2 e PET-A3 [Figura 43-[c]]. Este resultado é contrário ao observado por Ngadiman et al. (NGADIMAN et al., 2013), os quais avaliaram os fatores que afetam a porosidade de mats de PVA contendo nanopartículas de maghemita $\left[\gamma-\mathrm{Fe}_{2} \mathrm{O}_{3}\right]$. Assim, foram avaliados os principais parâmetros que influenciam a porosidade e, consequentemente, o diâmetro das fibras, pois ambas as propriedades estão intimamente relacionadas. Mats compostos por fibras com diâmetros reduzidos tendem a apresentar uma maior porosidade e, de acordo com o observado pelos autores, os principais parâmetros envolvidos são a voltagem aplicada, a taxa de vazão da solução e a velocidade de rotação do coletor de fibras. No presente estudo PET-A1, PET-A2 e PET-A3 não apresentaram diferenças significativas com relação ao diâmetro médio das fibras [Figura 43-[a]], consequentemente, seria esperado que os materiais apresentassem a mesma tendência com relação a porosidade média [Figura 43-[a]]. Com relação à porosidade média, como mencionado anteriormente, um aumento no diâmetro das fibras leva a uma diminuição da porosidade do mat, resultando em fibras mais compactas devido a liberação de tensões internas relacionadas ao processo de eletrofiação (DIAS et al., 2012).

Os mats PET-A2 e PET-A3 apresentaram maior I.A. [0,66 \pm 0,08 e 0,61 \pm 0,01, respectivamente [Figura 41]], em comparação ao apresentado por PET-A1 [I.A. = 0,46 \pm 0,11 [Figura 41]]. Destaca-se que PET-A1 e PET-A2 foram preparados utilizando-se os mesmos parâmetros de eletrofiação, exceto pela velocidade de rotação do coletor [3300 rpm e 3600 rpm, respectivamente [Tabela 6]]. No entanto, PET-A3 foi preparado utilizando-se a mesma velocidade de rotação empregada no preparo de PET-A1 [3300 rpm, Tabela 6], mas, diferentemente de PET-A1 e PET-A2, foi utilizada uma menor taxa de

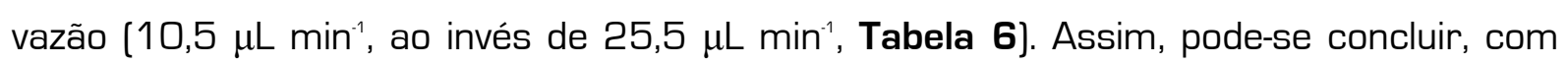
relação a PET-A1 e PET-A2, que o alinhamento das fibras foi favorecido possivelmente pela maior velocidade de rotação do coletor. Destaca-se que, quando a velocidade de rotação do coletor é superior à velocidade de deslocamento do jato de solução no ponto de coleta das fibras, o jato solidificado rapidamente se enrolará no coletor, tornando-se uma fibra alinhada. No entanto, quando a velocidade de rotação do coletor é inferior à velocidade de deslocamento do jato, este se depositará na superfície do coletor em qualquer direção, tornando-se uma fibra orientada aleatoriamente [TONG; WANG, 2011].

Comparando-se as propriedades de PET-A1, PET-A2 e PET-A3 em relação aos demais mats produzidos com o uso do coletor rotativo (mats contendo celulose e/ou lignina em suas composições], observa-se que não houve uma diferença significativa no diâmetro médio das fibras dos materiais [Figura 43-[a]]. Assim, pode-se concluir que as diferentes taxas de vazão da solução utilizadas, assim como as diferentes velocidades de rotação do coletor empregadas [Tabela 6] não influenciaram significativamente essa propriedade. No entanto, PET-A1, PET-A2 e PET-A3 apresentaram, no geral, uma menor variação dos valores de diâmetro das fibras (Figura 42), em comparação aos mats 
contendo celulose e/ou lignina em suas composições (Histogramas, Figuras 45, 47 e 49]. As soluções de PET a serem eletrofiadas apresentaram menores valores de viscosidade dinâmica [Tabela 3], em comparação com as soluções desse polímero reciclado contendo também celulose e/ou lignina [Tabela 3], o que pode ter contribuído para essa menor variação dos valores de diâmetro das fibras de PET-A1, PET-A2 e PET-A3 [Figura 42].

Não foram observadas quaisquer tendências com relação a propriedades como área média do poro [Figura 43-(b]] e porosidade média [Figura 43-[c]] de PET-A1, PET-A2 e PET-A3 em comparação com os demais materiais.

Com relação a $\mathrm{PET}_{\text {ref }}$ (preparado com o uso do coletor estático, Capítulo 2), destaca-se que não houve uma variação significativa no diâmetro médio das fibras desse mat [fibras orientadas aleatoriamente com diâmetro médio de 242,4 \pm 59,1 nm, Figura 33-[a]], em comparação aos diâmetros médios de PET-A1, PET-A2 e PET-A3 \{254,2 \pm $68,1 \mathrm{~nm}, 222,4 \pm 59,1 \mathrm{~nm}$ e 285,0 \pm 105,3 nm, respectivamente [Figura 43-[a]]\}. Assim, pode-se concluir que não houve uma influência significativa nessa propriedade do tipo de coletor [estático ou rotativo] e da taxa de vazão da solução utilizados [foi utilizada na

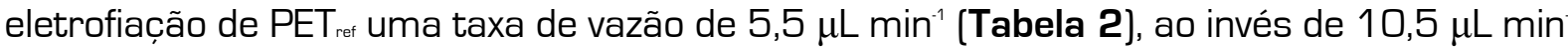
${ }^{1}$ e 25,5 $\mu \mathrm{L} \min ^{-1}$ [Tabela 6]].

$\mathrm{PET}_{\text {ref }}$ apresentou uma menor área média de poro $\left[9,6 \pm 1,1 \times 10^{4} \mathrm{~nm}^{2}\right.$, Figura 33[b]], em comparação ao apresentado por PET-A1, PET-A2 e PET-A3 [Figura 43-[b]]. No entanto, PET $_{\text {ref }}$ apresentou, no geral, uma maior porosidade média [19,0 $\pm 1,1 \%$, Figura 33-[c]], em comparação aos valores de porosidade média de PET-A1, PET-A2 e PET-A3 [Figura 43-[c]].

A Figura 44 apresenta as micrografias, as respectivas imagens codificadas por cores e a escala de orientação de cores, assim como o I.A. e a O.P.M. das fibras dos mats PETC-A1, PETC-A2 e PETC-A3. 
Figura 41 - Micrografias, respectivas imagens codificadas por cores, escala de orientação de cores, I.A. e
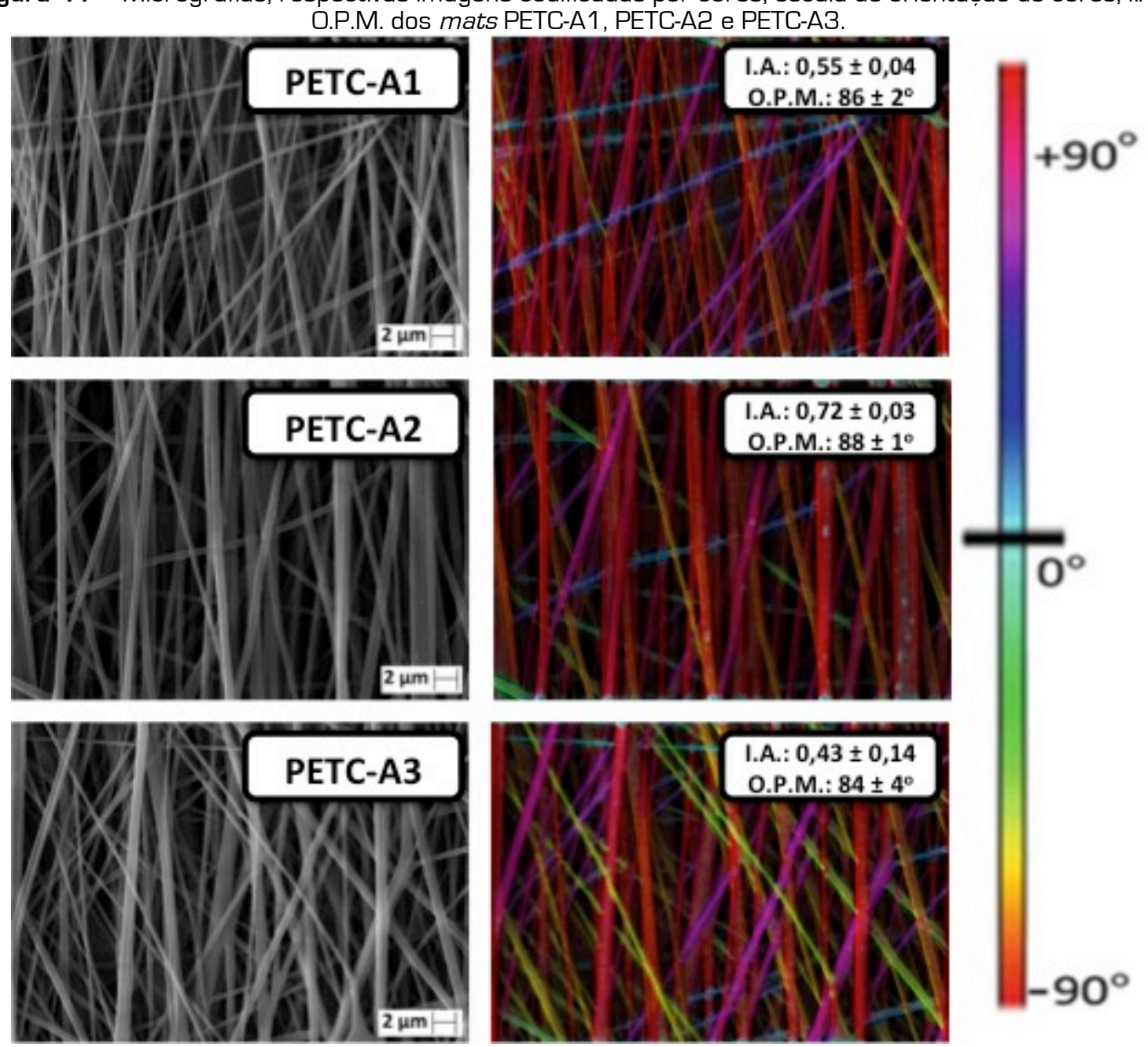

Fonte: Autoria própria.

Na Figura 45 são apresentados os histogramas do diâmetro das fibras de PETCA1, PETC-A2 e PETC-A3.

Figura 42 - Histogramas do diâmetro das fibras de PETC-A1, PETC-A2 e PETC-A3.
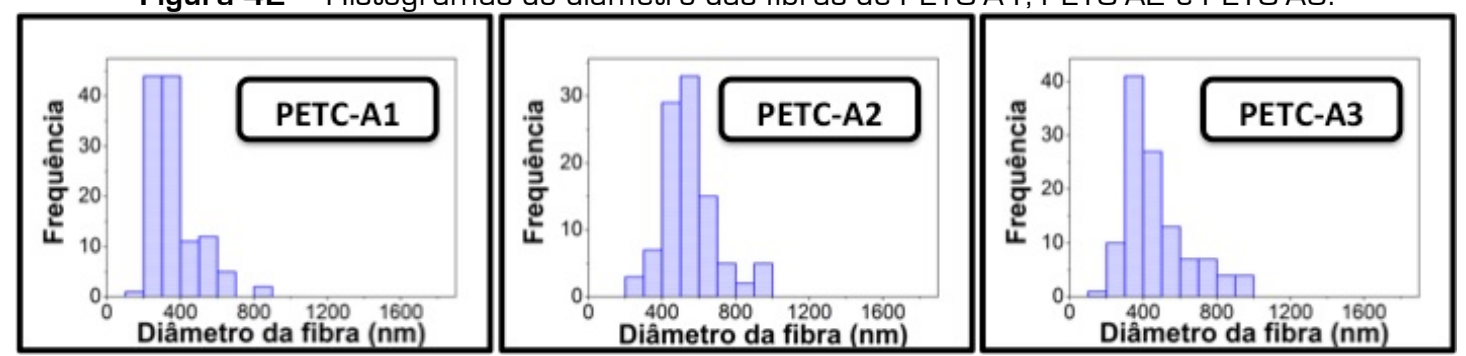

Fonte: Autoria própria.

As micrografias da Figura 44 mostram redes de fibras contínuas, em geral, homogêneas e sem ramificações. PETC-A1, PETC-A2 e PETC-A3 não apresentaram diferenças significativas com relação ao diâmetro médio das fibras [Figura 43-[a]] e também, no geral, com relação à variação dos valores de diâmetro das fibras [Figura 45] e porosidade média dos mats [Figura 43-[c]]. PETC-A2 apresentou o maior valor de área média do poro $\left\{146,2 \pm 1,3 \times 10^{4} \mathrm{~nm}^{2}\right.$ [Figura 43-(b)]\}, em comparação aos valores 
apresentados por PETC-A1 e PETC-A3 $\left\{45,8 \pm 16,1 \times 10^{4} \mathrm{~nm}^{2}\right.$ e 41,3 $\pm 2,3 \times 10^{4} \mathrm{~nm}^{2}$ [Figura 43-[b]]\}.

0 mat PETC-A2 apresentou I.A. [0,72 \pm 0,03 [Figura 44]] superior ao apresentado por PETC-A1 e PETC-A3 [0,55 \pm 0,04 e 0,43 \pm 0,14, respectivamente [Figura 44]]. Assim, pode-se concluir que o maior alinhamento das fibras foi favorecido, principalmente, pela superior velocidade de rotação do coletor na preparação de PETC-A2 [3300 rpm, Tabela 6], em comparação com as velocidades de rotação adotadas no preparo de PETCA1 e PETC-A3 [3000 rpm e 3200 rpm, respectivamente [Tabela 6]].

Ao se comparar as propriedades de PETC-A1, PETC-A2 e PETC-A3 com as apresentadas pelos demais mats preparados utilizando-se o coletor rotativo, destaca-se que, no geral, não houve uma variação significativa no diâmetro médio das fibras desses materiais [Figura 43-[a]]. Assim, pode-se concluir que as diferentes taxas de vazão da solução utilizadas, assim como as diferentes velocidades de rotação do coletor empregadas [Tabela 6] não influenciaram significativamente essa propriedade. Ainda, PETC-A1, PETC-A2 e PETC-A3 apresentaram, no geral, uma maior variação dos valores de diâmetro das fibras (Figura 45], em comparação ao apresentado pelos mats contendo PET e PET/lignina em suas composições [Figura 47 e Figura 49]. As soluções de $\mathrm{PET} /$ celulose a serem eletrofiadas apresentaram maiores valores de viscosidade dinâmica [Tabela 3], em comparação com as soluções de PET e PET / lignina [Tabela 3], o que pode ter contribuído para essa mais ampla variação dos valores de diâmetro das fibras de PETC-A1, PETC-A2 e PETC-A3 [Figura 45].

Destaca-se que não houve uma influência significativa nos valores de diâmetro médio das fibras de PETC-A1, PETC-A2 e PETC-A3 \{362,1 \pm 130,2 nm, 547,2 \pm 151,2 $\mathrm{nm}, 464,3 \pm 172,0 \mathrm{~nm}$, respectivamente [Figura 43-[a]]\} em comparação com o diâmetro médio das fibras, orientadas aleatoriamente, de PETC/72 h [preparado com o uso de coletor estático [Capítulo 2], com fibras com diâmetro médio de 365,9 \pm 139,7 $\mathrm{nm}$, de acordo com a Figura 33-[a]]. Assim, pode-se novamente concluir que o tipo de coletor [rotativo ou estático] e a taxa de vazão da solução utilizados [foi utilizada na

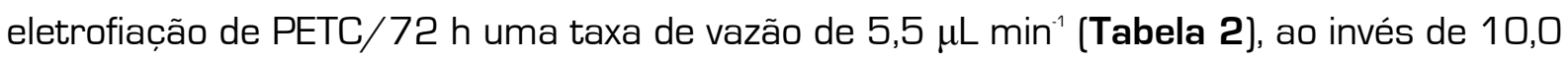
$\mu \mathrm{L} \min ^{-1}$ e 25,5 $\mu \mathrm{L} \min ^{-1}$ [Tabela 6]] não influenciaram significativamente essa propriedade.

PETC-A1, PETC-A2 e PETC-A3 apresentaram superiores valores de área média de poro [Figura 43-[b]] e porosidade média [Figura 43-[c]], em comparação aos valores apresentados por PETC/72 h $\left\{17,8 \pm 1,5 \times 10^{4} \mathrm{~nm}^{2}\right.$ e 10,8 $\pm 1,9 \%$, respectivamente [Figura 33-[b],[c]]\}.

A Figura 46 apresenta as micrografias, as respectivas imagens codificadas por cores e a escala de orientação de cores, assim como o I.A. e a O.P.M. dos mats PETL-A1, PETL-A2 e PETL-A3. 
Figura 43 - Micrografias, respectivas imagens codificadas por cores, escala de orientação de cores, I.A. e
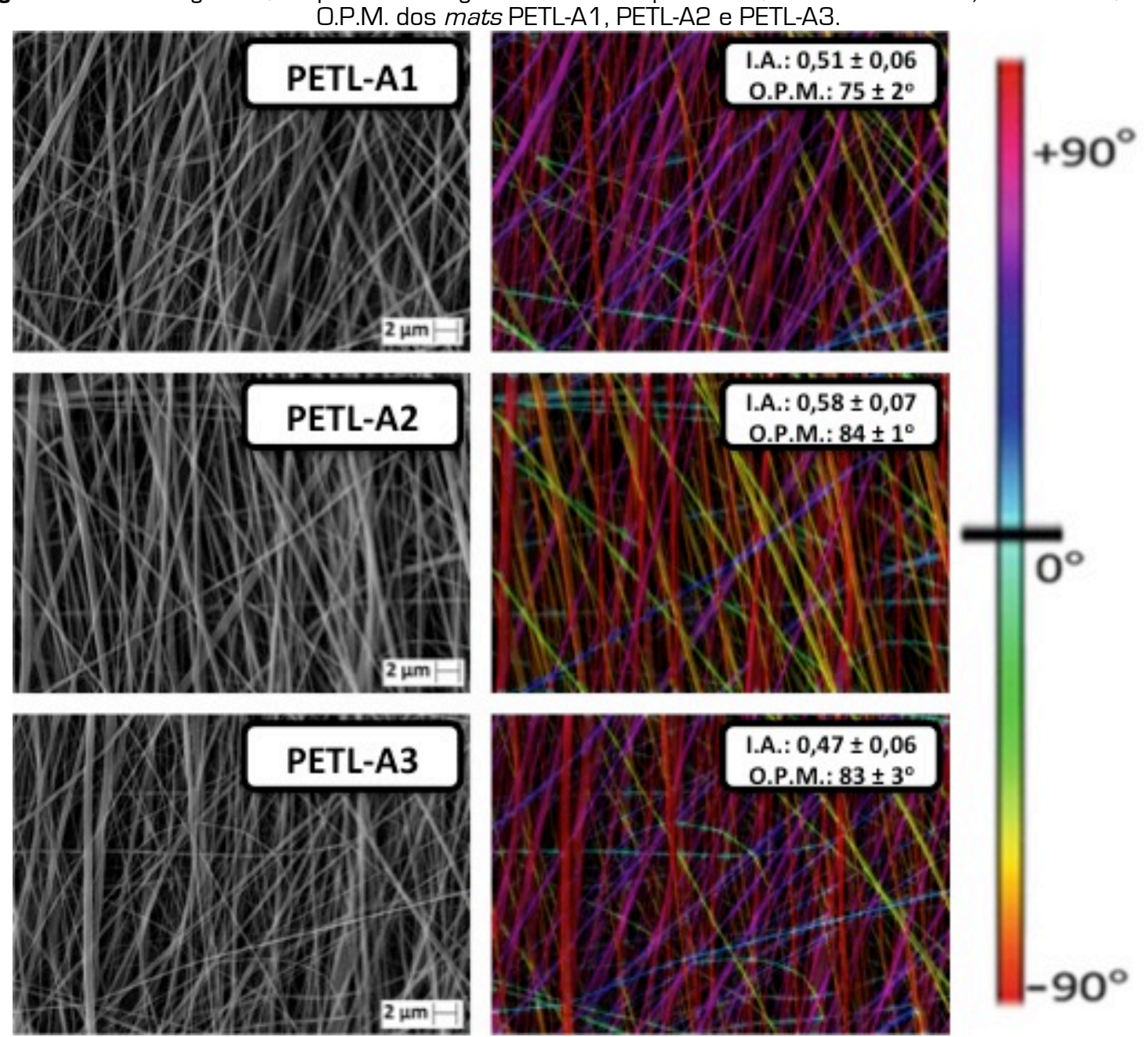

Fonte: Autoria própria.

Observa-se na Figura 47 os histogramas do diâmetro das fibras de PETL-A1, PETLA2 e PETL-A3.

Figura 44 - Histogramas do diâmetro das fibras de PETL-A1, PETL-A2 e PETL-A3.
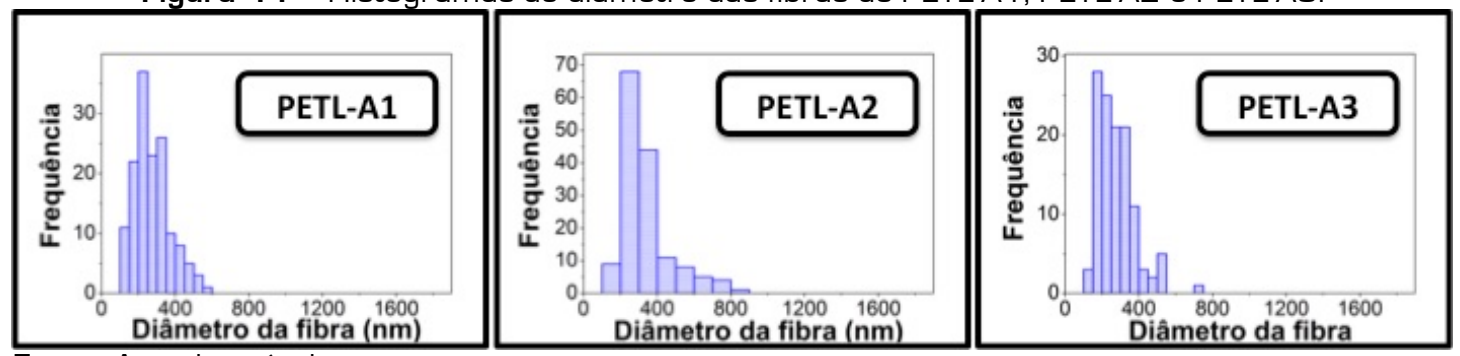

Fonte: Autoria própria.

Pode-se observar nas micrografias da Figura 46 que PETL-A1, PETL-A2 e PETL-A3 apresentaram redes de fibras contínuas, em geral, homogêneas e sem ramificações. Esses mats também não apresentaram diferenças significativas com relação ao diâmetro médio das fibras [Figura 43-[a]], área média do poro [Figura 43-[b]] e porosidade média [Figura 43-[c]].

Também não foram observadas diferenças significativas com relação ao I.A. de 
PETL-A1, PETL-A2 e PETL-A3 [Figura 46]. Assim, pode-se concluir que, neste caso, as diferentes velocidades de rotação do coletor utilizadas no preparo dos materiais [3300 rpm e 3600 rpm, Tabela 6] não influenciaram significativamente essa propriedade.

Ao se comparar as propriedades de PETL-A1, PETL-A2 e PETL-A3 com as apresentadas pelos demais mats preparados com o uso do coletor rotativo, observa-se que não houveram diferenças significativas com relação aos valores de diâmetro médio das fibras formadas [Figura 43-[a]], independentemente das diferentes taxas de vazão da solução utilizadas, assim como as diferentes velocidades de rotação do coletor empregadas [Tabela 6). No entanto, PETL-A1, PETL-A2 e PETL-A3 apresentaram, no geral, uma menor variação dos valores de diâmetro das fibras (Figura 47), em comparação aos mats contendo em suas composições celulose [Figura 45] e este polissacarídeo e lignina [Figura 49]. A solução eletrofiada de PET/lignina apresentou inferior valor de viscosidade dinâmica [Tabela 3], em comparação com as soluções de PET/celulose [Tabela 3] e $\mathrm{PET} /$ celulose/lignina [Tabela 3], o que pode ter contribuído para essa menor variação dos valores de diâmetro das fibras apresentada por PETL-A1, PETL-A2 e PETL-A3 [Figura 47).

Os diferentes tipos de coletores [rotativo e estático] e diferentes taxas de vazão da solução utilizados [foi utilizada na eletrofiação de PETL/72 h uma taxa de vazão de 5,5 $\mu \mathrm{L}$ $\min ^{-1}$ [Tabela 2), ao invés de 10,5 $\mu \mathrm{L} \min ^{-1}$ e 25,5 $\mu \mathrm{L} \min ^{-1}$ [Tabela 6]] novamente não influenciaram significativamente o diâmetro médio das fibras de PETL-A1, PETL-A2 e PETLA3 $\{273,1 \pm 95,3 \mathrm{~nm}, 334,0 \pm 134,2 \mathrm{~nm}$ e $275,5 \pm 100,0 \mathrm{~nm}$, respectivamente [Figura 43-[a]]\}, em comparação ao valor apresentado pelas fibras orientadas aleatoriamente de PETL/72 h [259,5 \pm 64,5 nm, Figura 33-[a], Capítulo 2]. No entanto, os mats preparados com o uso do coletor rotativo apresentaram, no geral, uma maior variação dos valores de diâmetro das fibras (Figura 47), em comparação a PETL/72 h (Figura 35).

As fibras de PETL-A1, PETL-A2 e PETL-A3 [Figura 46] apresentaram morfologia mais cilíndrica, em comparação com as fibras de PETL/72 h (Figura 34), de morfologia mais achatada. Destaca-se que PETL-A1, PETL-A2 e PETL-A3 apresentaram superiores valores de área média de poro [Figura 43-[b]] e porosidade média [Figura 42-[c]] sem diferenças significativas, em comparação aos valores apresentados por PETL/72 h $\{7,9 \pm$ 0,9 x 10 $\mathrm{nm}^{2}$ e 17,4 \pm 1,8\%, respectivamente [Figura 33-[b],(c)]\}.

$\mathrm{Na}$ Figura 48 pode-se observar as micrografias, as respectivas imagens codificadas por cores e a escala de orientação de cores, assim como o I.A. e a O.P.M. dos mats PETCL-A1, PETCL-A2 e PETCL-A3. 
Figura 45 - Micrografias, respectivas imagens codificadas por cores, escala de orientação de cores, I.A. e


Fonte: Autoria própria.

A Figura 49 apresenta os histogramas do diâmetro das fibras de PETCL-A1, PETCL-A2 e PETCL-A3.

Figura 46 - Histogramas do diâmetro das fibras de PETCL-A1, PETCL-A2 e PETCL-A3.
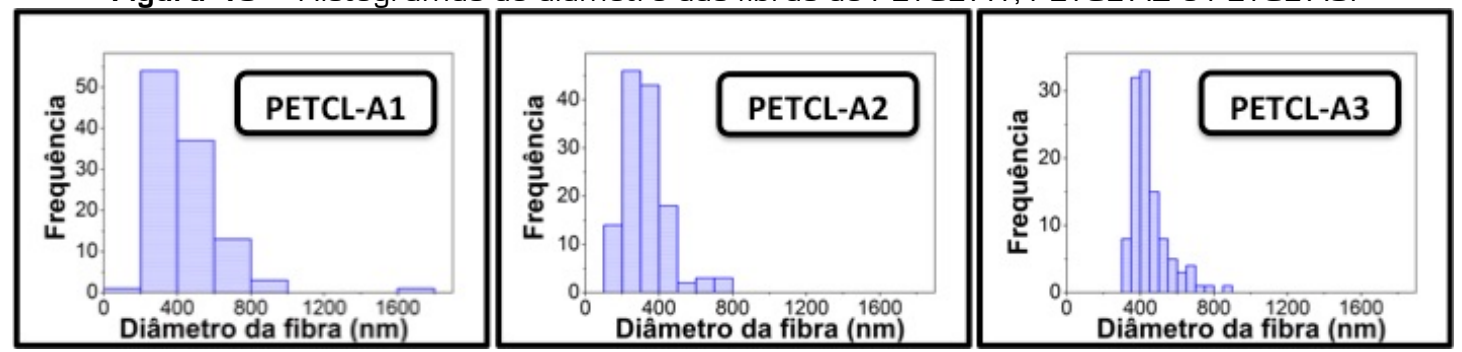

Fonte: Autoria própria.

Foram observadas nas micrografias da Figura $\mathbf{4 8}$ redes de fibras contínuas, em geral, heterogêneas, com algumas ramificações e morfologia mais achatada [em comparação com as fibras de morfologia mais cilíndrica das Figuras 41, 44 e 46). PETCLA1, PETCL-A2 e PETCL-A3 apresentaram fibras com diâmetro médio sem diferenças significativas [Figura 43-[a]], sendo que PETCL-A1 apresentou uma maior variação dos valores de diâmetro de fibra, em comparação ao apresentado por PETCL-A2 e PETCL-A3 
[Figura 49]. Ainda, PETCL-A3 apresentou o maior valor de área média do poro $\{113,2 \pm$ $6,6 \times 10^{4} \mathrm{~nm}^{2}$ [Figura 43-[b]]\} e a maior porosidade média $\{39,5 \pm 2,2 \%$ [Figura 43-[c]]\}, em comparação a PETCL-A1 e PETCL-A2 [Figura 43-[c]].

0 mat PETCL-A1 apresentou superior I.A. [0,56 $\pm 0,03$ [Figura 48]] em comparação ao apresentado por PETCL-A2 e PETCL-A3 [0,49 \pm 0,02 e 0,45 \pm 0,07, respectivamente [Figura 48]]. Assim, pode-se concluir que, neste caso, as diferentes velocidades de rotação do coletor utilizadas no preparo dos materiais [3300 rpm e 3600 rpm, Tabela 6] não influenciaram significativamente essa propriedade, assim como observado para PETL-A1, PETL-A2 e PETL-A3 [Figura 46).

Comparando-se as propriedades de PETCL-A1, PETCL-A2 e PETCL-A3 em relação aos demais mats produzidos com o uso do coletor rotativo, observa-se que não houve uma diferença significativa no diâmetro médio das fibras dos materiais [Figura 43-[a]]. Assim, pode-se concluir que as diferentes taxas de vazão da solução utilizadas, assim como as diferentes velocidades de rotação do coletor empregadas [Tabela 6] não influenciaram significativamente essa propriedade.

Não houve uma variação significativa no diâmetro médio das fibras de PETCL-A1, PETCL-A2 e PETCL-A3 [Figura 43-[a]] em comparação com PETCL/72 h [fibras aleatoriamente orientadas com diâmetro médio de 251,8 \pm 96,9 nm, Figura 33-[a] [Capítulo 2]]. Este fato corrobora a hipótese de que o uso de diferentes tipos de coletores [rotativo e estático], assim como diferentes taxas de vazão da solução [foi utilizada na eletrofiação de PETCL/72 h uma taxa de vazão de 5,5 $\mu \mathrm{L} \min ^{-1}$ (Tabela 2), ao invés de 10,5 $\mu \mathrm{L} \min ^{-1}$ e 25,5 $\mu \mathrm{L} \min ^{-1}$ [Tabela 6]], não influenciaram significativamente essa propriedade.

As fibras de PETCL-A1, PETCL-A2 e PETCL-A3 [Figura 48) apresentaram morfologia menos achatada, assim como menor número de ramificações e ramos curtos de fibra, em comparação com as fibras de PETCL/72 h [Figura 34]. Ainda, no geral, PETCL-A1, PETCL-A2 e PETCL-A3 apresentaram superiores valores de área média de poro [Figura 43-[b]] e porosidade média [Figura 43-[c]] sem diferenças significativas, em comparação aos valores apresentados por PETCL/72 h \{15,0 \pm 4,6 x 10 $\mathrm{nm}^{2}$ e 16,3 \pm $1,2 \%$, respectivamente [Figura 33-[b],[c]]\}.

\subsection{2 Ângulo de contato [AC]}

A Figura $\mathbf{5 0}$ apresenta a dependência com o tempo do AC entre a gota de água e a superfície dos mats. 
Figura 50 - Ângulo de contato aparente em função do tempo entre a gota de água e a superfície dos mats [a] PET-A1, PET-A2 e PET-A3; [b] PETL-A1, PETL-A2 e PETL-A3; [c] PETC-A1, PETC-A2 e PETC-A3; [d] PETCL-

[a] A1, PETCL-A2 e PETCL-A3.



Fonte: Autoria própria.

Na Figura 50-[a] não foram observadas diferenças significativas nos valores de AC em função do tempo para PET-A1, PET-A2 e PET-A3. Os valores de AC em função do tempo dos mats contendo, além de PET reciclado, lignina em suas composições [Figura 50-[b]], também não apresentaram diferenças significativas entre si. Observou-se que os valores do AC das Figuras 50-[a],[b] mantiveram-se praticamente constantes ao longo dos 500 s de análise. Assim, pode-se concluir que esses mats apresentaram superfícies hidrofóbicas, devido à baixa polaridade tanto do PET reciclado, quanto da lignina. Não foram observadas quaisquer tendências que correlacionassem os valores de porosidade média desses materiais [Figura 43-[c]], com os valores de $A C$ em função do tempo apresentados pelos mesmos [Figuras 50-[a],[b]].

Com relação aos mats contendo PET reciclado e celulose em suas composições, estes apresentaram, no geral, diferenças significativas do AC em função do tempo [Figura 50-[c]] . PETC-A2 apresentou o mais rápido decréscimo do AC em função do tempo e, contrariamente, PETC-A1 o mais lento decréscimo desses valores. Este fato pode ser explicado pela maior hidrofilicidade desses materiais, como consequência da presença de celulose [com grupos hidroxila em sua cadeia, Figura 4] em suas composições. Destaca-se que PETC-A2 e PETC-A1 apresentaram valores de porosidades médias semelhantes $\{27,1$ \pm 3,7\% e 22,2 $\pm 2,5 \%$, respectivamente [Figura 43-[c]]\} e sem diferenças significativas, 
em comparação ao valor apresentado por PETC-A3 [19,4 ะ 3,1\%, Figura 43-[c]].

Os mats contendo celulose e lignina em suas composições também apresentaram uma redução do AC em função do tempo [Figura 50-[d]]. PETCL-A3 apresentou o mais rápido decréscimo no valor de $A C$ em função do tempo, sendo o contrário observado para PETCL-A2 [Figura 50-[d]]. Este comportamento pode ser correlacionado com a porosidade média desses mats [Figura 43-[c]]. PETCL-A3 apresentou o maior valor de porosidade média [39,5 \pm 2,2\%, Figura 43-[c]], já PETCL-A2 o menor valor para essa propriedade [14,2 \pm 0,9\%, Figura 43-[c]].

Nas curvas da Figura 50-[c],[d] para os mats contendo celulose, assim como este polissacarídeo e lignina em suas composições, observa-se que os valores de AC atingem com o tempo valores críticos muito pequenos. Assim, não foi possível calcular estes valores até a completa absorção da gota de água pela superfície dos materiais.

Destaca-se que, no geral, houve um decréscimo mais lento dos valores de AC em função do tempo para os mats contendo celulose e lignina em suas composições [Figura 50-[d]], em comparação com o apresentado pelos mats contendo apenas celulose em suas composições [Figura 50-[c]]. Este fato deve-se, possivelmente, à presença lignina, de natureza hidrofóbica, na composição de PETCL-A1, PETCL-A2 e PETCL-A3 [Tabela 2). Não foram observadas quaisquer tendências que pudessem correlacionar a porosidade média de PETCL-A1, PETCL-A2 e PETCL-A3 com os valores apresentados para essa propriedade por PETC-A1, PETC-A2 e PETC-A3 [Figura 43-[c]], ao se comparar os diferentes comportamentos do AC em função do tempo dos mesmos [Figuras 50-[c],[d]].

Os valores de AC em função do tempo dos mats preparados com o uso do coletor rotativo [Figura 50) apresentaram a mesma tendência observada para o AC dos materiais, de mesma composição, mas preparados com a utilização do coletor estático [Figura 36]. No entanto, de acordo com a Figura 50-[c],[d], os mats PETC-A1, PETC-A2, PETC-A3, PETCL-A1, PETCL-A2 e PETCL-A3 apresentaram um decréscimo significantemente mais lento do AC em função do tempo, em comparação com o observado para PETC/72 h e PETCL/72 h [item 2.3.3). Para estes mats ocorreu um rápido decréscimo nos valores de AC após 3 s de deposição da gota de água na superfície dos materiais.

Destaca-se que, no geral, os valores de AC obtidos para os mats preparados com a utilização do coletor rotativo (Figura 50) foram muito divergentes, com relação aos valores de AC apresentados pelos mats preparados utilizando-se o coletor estático. Este fato é suportado pelos maiores valores de desvio-padrão do AC apresentados pelos mats preparados com o coletor rotativo (Figura 50), em comparação com os valores de desviopadrão do AC de PET ref, PETL/72 h, PETC/72 h e PETCL/72 h [item 2.3.3). Ainda, não foi possível observar qualquer tendência que correlaciona-se os valores de porosidade média dos mats preparados com o coletor rotativo [Figura 43-[c]], com o dos mats, de 
composição correspondente, preparados utilizando-se o coletor estático [Figura 33-[c]], e os diferentes valores de AC apresentados pelos mesmos [Figuras $\mathbf{5 0}$ e $\mathbf{3 6}$, respectivamente].

\subsubsection{Análise Dinâmico-Mecânica [DMA]}

A Figura 51 apresenta os resultados de módulo de armazenamento [ $\mathrm{E}$ - 30 'C] dos materiais preparados com a utilização do coletor de tambor metálico rotativo. Os mats foram caracterizados tanto na direção perpendicular ao eixo do coletor [direção preferencial de alinhamento das fibras], quanto na direção paralela ao eixo do coletor [direção oposta ao alinhamento preferencial das fibras].

Figura 47 - Módulo de armazenamento - E' [a $30^{\circ} \mathrm{C}$ ] para os mats [a] PET-A1, PET-A2 e PET-A3; [b] PETLA1, PETL-A2 e PETL-A3; [c] PETC-A1, PETC-A2 e PETC-A3; (d) PETCL-A1, PETCL-A2 e PETCL-A3. Os materiais foram caracterizados tanto na direção preferencial de alinhamento das fibras [siglas contendo a terminação "dir" no final], quanto na direção oposta ao alinhamento preferencial das fibras [siglas contendo a terminação "op" no final).

[a]



[c]



[b]

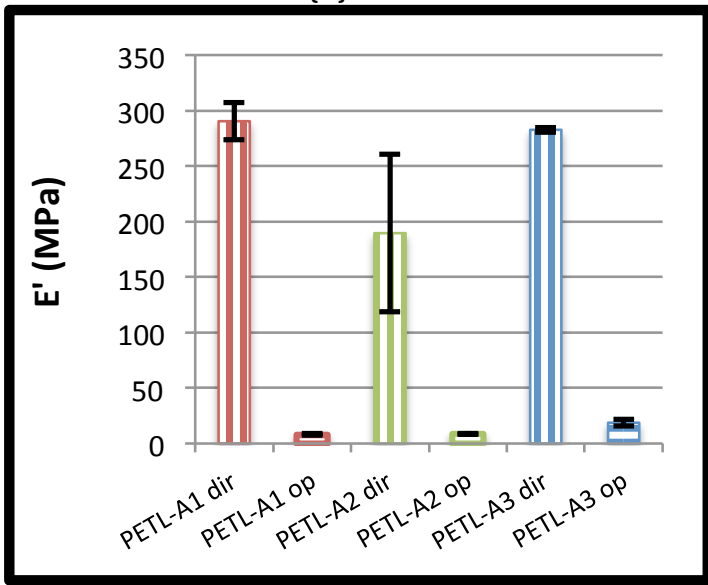

[d]

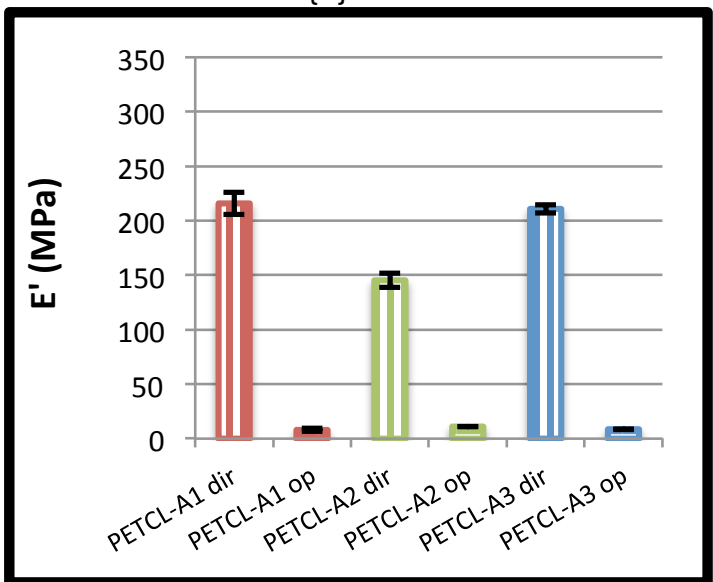

Fonte: Autoria própria.

Na Figura 51 observa-se que os mats caracterizados na direção preferencial de alinhamento das fibras apresentaram valores de E' [a $30{ }^{\circ} \mathrm{C}$ ] muito superiores aos apresentados pelos mats caracterizados na direção oposta, os quais não apresentaram diferenças significativas com relação aos valores de E’. Quando uma força é aplicada na direção preferencial de alinhamento das fibras, estas necessitam apenas de uma rotação 
mínima para se alinharem com relação à direção da tensão aplicada. Consequentemente, uma elevada porcentagem de fibras rapidamente resiste à deformação mecânica, conferindo ao material maior rigidez. Contrariamente, quando a força é aplicada na direção oposta ao alinhamento preferencial das fibras, faz-se necessária uma maior rotação e reorientação das mesmas para que possam se alinhar com o eixo da força aplicada, com consequente maior deformação das mesmas (KUMAR; VASITA, 2017; MUBYANA et al., 2016].

PET-A1 dir apresentou o menor valor de E' [28,0 \pm 7,4 MPa, Figura 51-[a]] dentre todas as amostras caracterizadas na direção preferencial de alinhamento das fibras, e PETC-A2 dir apresentou o maior valor de E' [334,8 \pm 2,5 MPa, Figura 51-[c]] dentre o mesmo conjunto de amostras citado anteriormente. Destaca-se que PETC-A2 apresentou um dos maiores valores de I.A. $[0,72 \pm 0,03$, Figura 41] dentre todos os mats obtidos, o que pode ter contribuído para uma maior resistência mecânica desse material. Como consequência do elevado I.A. apresentado pelo mat PETC-A2 [Figura 41], possivelmente, quando foi aplicada uma força mecânica na direção de alinhamento das fibras, uma elevada porcentagem de fibras rapidamente alinhou-se na direção da tensão aplicada, conferindo maior resistência mecânica a PETC-A2 dir. Ainda, o mat PET-A1 apresentou um dos maiores valores de porosidade média [39,5 \pm 3,2\%, Figura 43-[c]], em comparação aos demais materiais preparados com o uso do coletor rotativo, o que pode ter contribuído para o menor valor de E' (a $30^{\circ} \mathrm{C}$ ] de PET-A1 dir [Figura 51-[a]]. A presença de poros nos materiais pode levar a uma maior concentração de tensões ao redor dos mesmos, com consequentes propriedades mecânicas inferiores.

Pode-se observar também na Figura 51-[a] que PET-A2 dir apresentou o maior valor de E' (a 30 'C], em comparação a PET-A1 dir e PET-A3 dir. PET-A2 também apresentou um I.A. $[0,66 \pm 0,08$, Figura 41] superior ao apresentado por PET-A1 [0,46 \pm 0,11 , Figura 41] e semelhante ao apresentado por PET-A3 $[0,61 \pm 0,01$, Figura 41]. Com relação aos valores de porosidade média apresentados por esses materiais, que podem influenciar significativamente as propriedades mecânicas dos mesmos, os mats PET-A2 e PET-A3 apresentaram porosidades médias sem diferenças significativas entre si $\{12,3 \pm$ $0,2 \%$ e 12,8 \pm 0,7\%, respectivamente [Figura 43-[c]]\}, mas inferiores ao valor de porosidade média de PET-A1 [39,5 \pm 3,2\%, Figura 43-[c]].

PETL-A1 dir e PETL-A3 dir apresentaram os maiores valores de E' em comparação a PETL-A2 dir [Figura 51-[b]], no entanto, o I.A. dessas amostras [Figura 46] não apresentou diferenças significativas. Ainda, esses materiais também não apresentaram diferenças significativas nos valores de porosidade média [Figura 43-[c]].

Como mencionado anteriormente, PETC-A2 dir apresentou o maior valor de E' [Figura 51-[c]] e o maior I.A. [Figura 44], em comparação ao apresentado pelos mats PETC-A1 e PETC-A3 [Figura 51-[c] e Figura 44, respectivamente). Não foi possível 
correlacionar os valores de E' observados para esses mats e a porosidade média dos mesmos, pois estes valores não apresentaram diferenças significativas [Figura 43-[c]].

Com relação às amostras contendo em sua composição celulose e lignina, PETCLA1 dir e PETCL-A3 dir apresentaram os maiores valores de E', em comparação a PETCLA2 dir [Figura 51-[d]]. Destaca-se que, com relação a este grupo de materiais, PETCL-A1 apresentou o maior I.A. [0,56 \pm 0,03, Figura 48], o que pode ter contribuído para o maior valor de E' [a 30 'C] apresentado por esse material, quando caracterizado na direção preferencial de alinhamento das fibras [Figura 51-[d]]. Ainda, com relação à porosidade média dos mats PETCL-A1, PETCL-A2 e PETCL-A3 [Figura 43-[c]], não foi possível correlacionar esta propriedade com os valores apresentados para o E' [a $30{ }^{\circ} \mathrm{C}$ ] desses materiais [Figura 51-[d]].

Observa-se na Figura 51-[a] que PET-A2 dir e PET-A3 dir apresentaram valores de $E^{\prime}[212,0 \pm 10,2 \mathrm{MPa}$ e 76,3 \pm 2,7 MPa, respectivamente] muito superiores ao apresentado por $\mathrm{PET}_{\text {ref }}[23,3 \pm$ 7,1 MPa, Figura 39-[a]]. Isto deve-se, possivelmente, ao fato de que em mats com fibras alinhadas, quando uma força é aplicada na direção preferencial de alinhamento das fibras, há a necessidade de apenas uma rotação mínima para que as fibras se alinhem com relação à direção da tensão aplicada, conforme já mencionado. Consequentemente, uma elevada porcentagem de fibras rapidamente resiste à deformação mecânica. No entanto, em mats com fibras orientadas aleatoriamente [como PET ret, Figura 31], uma maior rotação e reorientação das fibras faz-se necessária para que as mesmas possam se alinhar com o eixo da força aplicada, com consequente maior deformação mecânica dos materiais (KUMAR; VASITA, 2017; MUBYANA et al., 2016]. Ainda, os superiores valores de E' de PET-A2 dir e PET-A3 dir [Figura 51-[a]] também correlacionam-se com os baixos valores de porosidade média apresentados pelos correspondentes mats $\{12,3 \pm 0,2 \%$ e 12,8 \pm 0,7\%, respectivamente [Figura 43-[c]]\}, em comparação ao apresentado por $\operatorname{PET}_{\text {ref }}\{19,0 \pm 1,1 \%$, [Figura 33-[c]]\}.

PETL-A1 dir e PETL-A3 dir apresentaram valores de E' \{290,5 \pm 16,7 MPa e 282,7 \pm 2,2 MPa, respectivamente [Figura 51-[b]]\} superiores ao apresentado por PETL/72 h [112,2 \pm 8,4 MPa, Figura 39-[a]]. Isto deve-se, possivelmente, ao fato de que PETL-A1 dir e PETL-A3 dir são constituídos por fibras alinhadas [Figura 46] e foram ensaiados mecanicamente na direção de alinhamento das mesmas, o que conferiu um maior valor de E' a esses materiais, em comparação ao apresentado pelas fibras orientadas aleatoriamente de PETL/72 h [Figura 34). Destaca-se que os mats PETL-A1, PETL-A3 e PETL/72 h apresentaram valores de porosidade média [Figura 43-[c] e Figura 33-[c], respectivamente] sem diferenças significativas, não sendo possivel correlacionar essa propriedade com os diferentes valores de E' apresentados por esses materiais.

Pode-se observar na Figura 51-[c] que PETC-A2 dir apresentou superior valor de E'

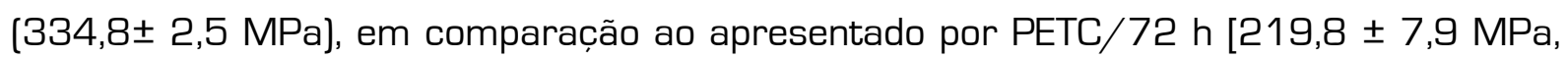
Figura 39-[a]]. Isto deve-se, possivelmente, ao fato de que PETC-A2 dir é constituído por 
fibras alinhadas [Figura 44] e foi caracterizado mecanicamente na direção de alinhamento das fibras, o que conferiu um maior valor de E' a esse material, em comparação ao apresentado por PETC/72 h, constituído por fibras orientadas aleatoriamente [Figura 34]. No entanto, os valores de porosidade média dos mats PETC-A2 e PETC/72 h [27,1 \pm $3,7 \%$ e 10,8 \pm 1,9\%, respectivamente] não corroboram essa tendência observada para o E' desses materiais [Figura 51-[c] e Figura 39-[a]].

PETCL-A1 dir e PETCL-A3 dir apresentaram valores de E' $\{215,9 \pm 10,1 \mathrm{MPa}$ e 210,9 \pm 3,7 MPa [Figura 51-[d]]\} semelhantes ao apresentado por PETCL/72 h [201,5 \pm 6,6 MPa, Figura 39-[a]]. No entanto, PETCL/72 h apresentou um valor de E' superior a PETCL-A2 dir [145,3 \pm 6,7 MPa, Figura 51-(d)]. Os valores de porosidade média apresentados por esses materiais [Figura 33-[c] e Figura 43-[c]] não correlacionam-se com o que foi observado para o E' dos mesmos [Figura 39-[a] e Figura 51-[d]].

Todos os materiais preparados utilizando o coletor rotativo e caracterizados na direção oposta ao alinhamento preferencial das fibras apresentaram valores de E' a 30 'C [Figura 51], no geral, inferiores aos apresentados pelos mats, de composição correspondente, preparados com a utilização do coletor estático [Figura 39-[a]]. Este fato é consequência, possivelmente, da necessidade de uma maior rotação e reorientação das fibras dos materiais caracterizados na direção oposta ao alinhamento preferencial das mesmas, para que ocorra o alinhamento das fibras com o eixo da força aplicada. Assim, consequentemente, há uma maior deformação desses materiais, preparados utilizando-se o coletor rotativo, e caracterizados na direção oposta ao alinhamento preferencial das fibras, em comparação aos mats, constituídos por fibras orientadas aleatoriamente e preparados com o uso do coletor estático.

A Figura 52 apresenta os resultados de temperatura de transição vítrea do PET reciclado [ $T_{9}$, obtida à partir do máximo da curva de tan $\delta$ ] dos mats preparados com a utilização do coletor de tambor metálico rotativo. 
Figura 48 - $\mathrm{T}_{9}$ dos mats [a] PET-A1, PET-A2 e PET-A3; [b] PETL-A1, PETL-A2 e PETL-A3; [c] PETC-A1, PETCA2 e PETC-A3; (d) PETCL-A1, PETCL-A2 e PETCL-A3. Os materiais foram caracterizados tanto na direção preferencial de alinhamento das fibras [siglas contendo a terminação "dir" no final], quanto na direção oposta ao alinhamento preferencial das fibras [siglas contendo a terminação "op" no final).

[a]

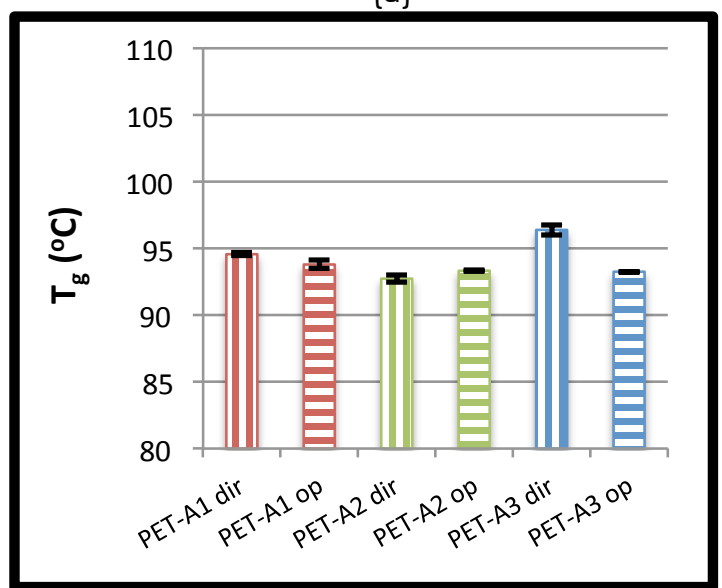

[c]

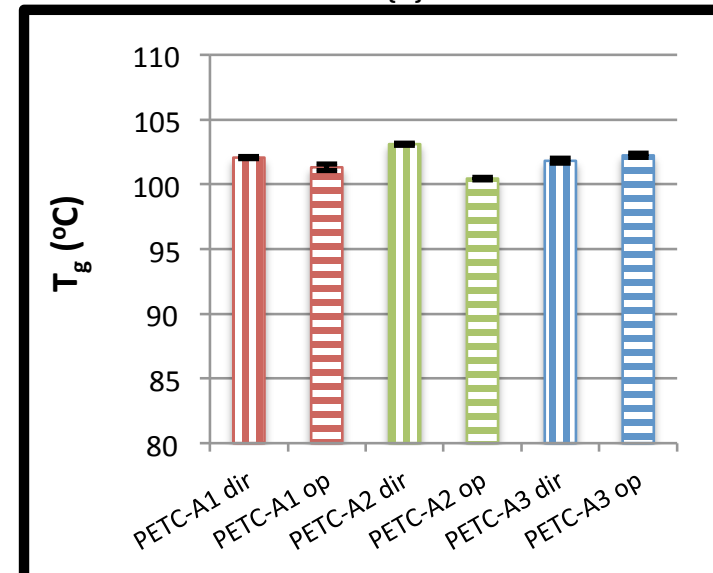

Fonte: Autoria própria. [b]



[d]

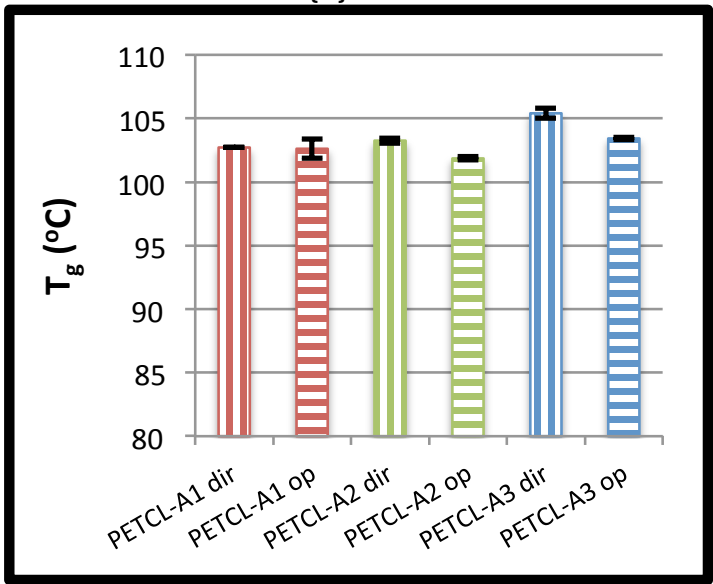

Na Figura 52 não foram observadas diferenças significativas nos valores de $T_{9}$ dos mats de mesma composição, caracterizados tanto na direção preferencial de alinhamento das fibras, quanto na direção oposta. Os mats contendo PET reciclado e, além desse polímero, lignina em suas composições, não apresentaram diferenças significativas com relação aos valores de $\mathrm{T}_{9}$ [Figura 52-[a],(b]]. No entanto, os mats contendo celulose [combinada ou não com lignina] em suas composições apresentaram valores mais elevados de $T_{9}$ [Figura 52-[c],[d]]. Assim, pode-se concluir que esse aumento no valor de $T_{9}$ para esses mats deve-se às interações intermoleculares, envolvendo principalmente os grupos hidroxila das cadeias de celulose e grupos carbonila das cadeias de PET. Esses resultados indicam que a presença de celulose dificultou, possivelmente, os movimentos rotacionais de ligações covalentes de segmentos das cadeias de PET, deslocando a $T_{9}$ para valores de temperatura mais altos. Destaca-se que PETCL-A3 dir apresentou o maior valor de $T_{9}$ dentre todos os mats [105,4 \pm 0,4 ${ }^{\circ} \mathrm{C}$, Figura 52-[d]].

Os mats contendo somente PET em suas composições [PET-A1, PET-A2 e PET-A3] não apresentaram, no geral, diferenças significativas nos valores de $T_{9}$ [Figura 52-[a]], em 
comparação ao apresentado pelas fibras orientadas aleatoriamente de $\mathrm{PET}_{\text {ref }}[92,6 \pm 0,1$

${ }^{\circ} \mathrm{C}$, Figura 39-[b]]. Os mats contendo, além de PET, lignina em suas composições [PETL-A1, PETL-A2 e PETL-A3], apresentaram, no geral, valores de $T_{9}$ [Figura 52-[b]] inferiores ao apresentado pelas fibras orientadas aleatoriamente de PETL/72 h $\left[T_{g}=100,9 \pm 1,4{ }^{\circ} \mathrm{C}\right.$, Figura 39-[b]]. Já os mats contendo PET e celulose em suas composições [PETC-A1, PETC-A2 e PETC-A3] apresentaram valores inferiores de $T_{9}$ [Figura 52-[c]], em comparação às fibras orientadas aleatoriamente de PETC/72 h $\left[T_{9}=111,3 \pm 0,8{ }^{\circ} \mathrm{C}\right.$, Figura 39-[b]]. Ainda, no geral, os mats contendo celulose e lignina em suas composições [PETCL-A1, PETCL-A2 e PETCL-A3] apresentaram valores de $T_{9}$ [com exceção de PETCL-A3 dir, Figura 52-[d]] sem diferenças significativas em comparação ao apresentado pelas fibras orientadas aleatoriamente de PETCL/72 h $\left[\mathrm{T}_{9}=103,5 \pm 0,3{ }^{\circ} \mathrm{C}\right.$, Figura 39-(b)].

\subsubsection{Ensaio de resistência à tração}

A Figura 53 apresenta os resultados de resistência à ruptura dos mats preparados com a utilização do coletor rotativo. Destaca-se novamente que os mats correspondem a materiais finos e porosos e, no presente estudo, os mesmos foram caracterizados com relação à resistência à tração tanto na direção perpendicular ao eixo do coletor de tambor metálico rotativo [direção preferencial de alinhamento das fibras], quanto na direção paralela ao eixo do coletor [direção oposta ao alinhamento preferencial das fibras]. 
Figura 49 - Resistência à ruptura dos mats [a] PET-A1, PET-A2 e PET-A3; [b] PETL-A1, PETL-A2 e PETL-A3; [c] PETC-A1, PETC-A2 e PETC-A3; (d) PETCL-A1, PETCL-A2 e PETCL-A3. Os materiais foram caracterizados tanto na direção preferencial de alinhamento das fibras [siglas contendo a terminação "dir" no final], quanto na direção oposta ao alinhamento preferencial das fibras (siglas contendo a terminação "op" no final).

[a]

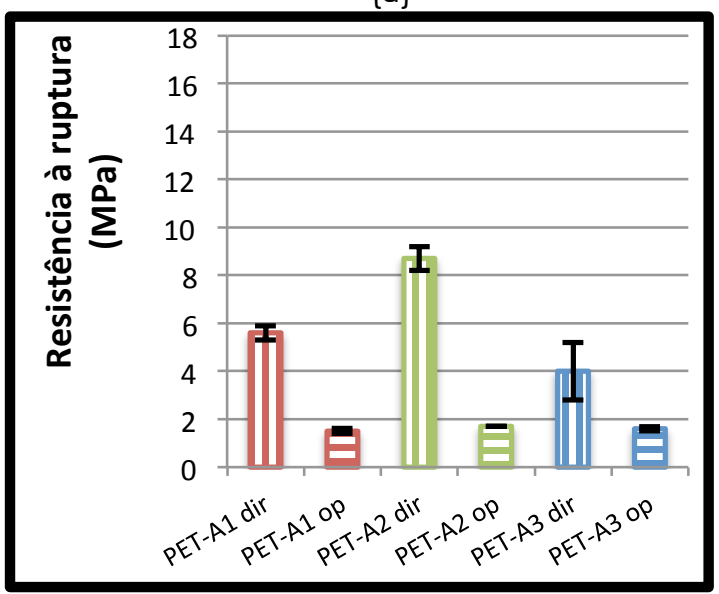

\section{[c]}

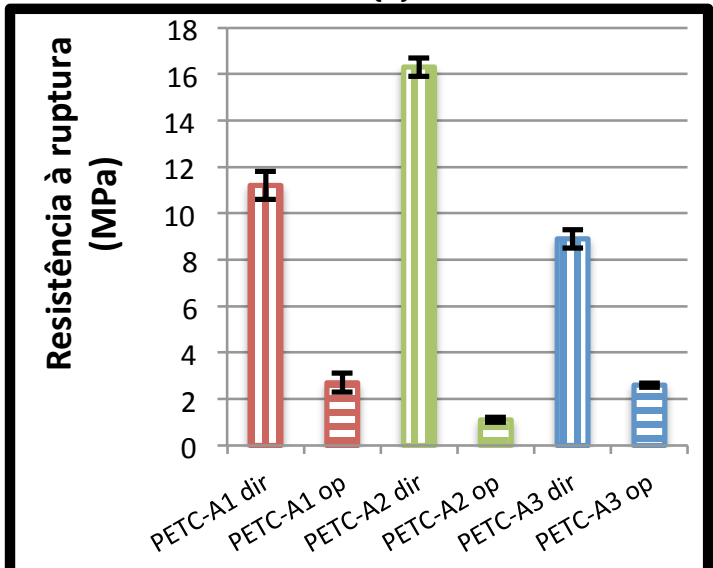

Fonte: Autoria própria. [b]



[d]

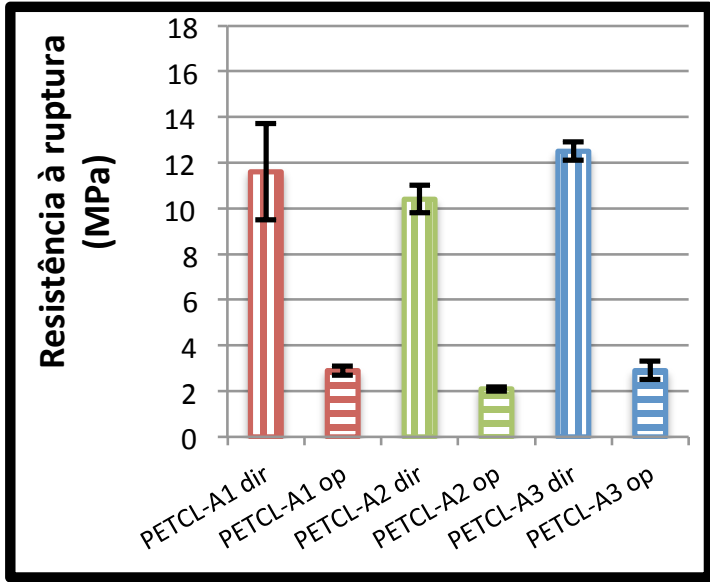

Observa-se na Figura $\mathbf{5 3}$ que os valores de resistência à ruptura dos materiais, caracterizados na direção preferencial de alinhamento das fibras, foram muito superiores aos valores apresentados pelos materiais, de mesma composição, caracterizados na direção oposta. Este resultado corrobora a tendência observada para o E' (a 30 'C] desses materiais [Figura 51]. Assim, pode-se concluir novamente que, quando uma força é aplicada na direção preferencial de alinhamento das fibras, uma elevada porcentagem de fibras rapidamente resiste à deformação mecânica, conferindo ao material uma elevada resistência. Contrariamente, quando a força é aplicada na direção oposta ao alinhamento preferencial das fibras há uma menor resistência mecânica das mesmas (KUMAR; VASITA, 2017; MUBYANA et al., 2016].

Observou-se também na Figura $\mathbf{5 3}$ que os valores de resistência à ruptura dos mats, caracterizados na direção preferencial de alinhamento das fibras, foram mais divergentes, em comparação aos valores apresentados pelos materiais, de composição correspondente, caracterizados na direção oposta ao alinhamento preferencial das fibras. Este fato é suportado ao compararmos os desvios-padrão, no geral, superiores, 
apresentados pelos materiais caracterizados na direção preferencial de alinhamento das fibras, em comparação com os inferiores valores de desvio-padrão apresentados pelos materiais caracterizados na direção oposta ao alinhamento [Figura 53].

Na Figura 53 observa-se que PET-A3 dir apresentou o menor valor de resistência à ruptura [4,0 \pm 1,2 $\mathrm{MPa}$, Figura 53-[a]], dentre todas as amostras caracterizadas na direção preferencial de alinhamento das fibras. Para este mesmo grupo de materiais, PETC-A2 dir apresentou o maior valor de resistência à ruptura [16,3 \pm 0,4 MPa, Figura 53-[c]]. PETC-A2 dir também apresentou o maior valor de E' dentre todos os materiais preparados com o uso do coletor rotativo [Figura 51-[c]] e um dos maiores valores de I.A. $[0,72 \pm 0,03$, Figura 44]. Assim, novamente, pode-se concluir que, como consequência do elevado I.A. apresentado pelo mat PETC-A2 [Figura 41]), possivelmente, quando foi aplicada uma força mecânica na direção de alinhamento das fibras, uma elevada porcentagem de fibras rapidamente alinhou-se na direção da tensão aplicada, conferindo maior resistência mecânica a PETC-A2 dir. Ainda, não foi observada qualquer tendência com relação à resistência à ruptura desses materiais (Figura 53) e a porosidade média dos mesmos [Figura 43-[c]].

PET-A2 dir apresentou o maior valor de resistência à ruptura $[8,7 \pm 0,5 \mathrm{MPa}$, Figura 53-[a]], em comparação a PET-A1 dir e PET-A3 dir \{5,6 \pm 0,3 MPa e 4,0 \pm 1,2 $\mathrm{MPa}$, respectivamente [Figura 53-[a]]\}. Este resultado corrobora a tendência observada para o E', a 30 'C, desses materiais [Figura 51-[a]]. Ainda, de acordo com a Figura 41, PET-A2 apresentou um dos maiores valores de I.A. [0,66 $\pm 0,08]$, em comparação aos demais materiais contendo somente PET reciclado em suas composições. 0 mat PET-A2 também apresentou, de acordo com a Figura 43-[c], um dos menores valores de porosidade média [12,3 $\pm 0,2 \%$ ] dentre esse conjunto de materiais considerado. Destacase que a porosidade média dos materiais pode influenciar significantemente as propriedades mecânicas dos mesmos. Assim, em um ensaio mecânico, os poros podem atuar como "amplificadores de tensão", devido a maior concentração de tensões ao redor dos mesmos, levando muitas vezes a propriedades mecânicas inferiores.

PETL-A1 dir, e PETL-A3 dir apresentaram maiores valores de resistência à ruptura $\{9,2 \pm$ 0,3 MPa e 9,1 \pm 1,4 MPa, respectivamente [Figura 53-[b]]\}, em comparação ao apresentado por PETL-A2 dir [6,5 \pm 0,5 MPa, Figura 53-(b)]. Este resultado corrobora a tendência observada para o E', a 30 'C, desses materiais [Figura 51-[b]]. Também não foram observadas diferenças significativas com relação ao I.A. desses materiais [Figura 46] e com relação aos valores de porosidade média apresentados pelos mesmos [Figura 43-[c]].

Como mencionado anteriormente, PETC-A2 dir apresentou o maior valor de resistência à ruptura [16,3 \pm 0,4 MPa, Figura 53-[c]], em comparação a todos os materiais preparados com o uso do coletor rotativo. Este resultado corrobora a tendência 
observada para o E', a $30{ }^{\circ} \mathrm{C}$, desses materiais [Figura 51]. 0 mat PETC-A2, de acordo com a Figura 44, também apresentou o maior I.A. [0,72 \pm 0,03], em comparação a PETCA1 e PETC-A3. Ainda, não foram observadas diferenças significativas nos valores de porosidade média desses mats [Figura 43-[c]].

PETCL-A1 dir, PETCL-A2 dir e PETCL-A3 dir, no geral, não apresentaram diferenças significativas com relação aos valores de resistência à ruptura $\{11,6 \pm 2,1 \mathrm{MPa}, 10,4 \pm$ 0,6 MPa e 12,5 \pm 0,4 MPa, respectivamente [Figura 53-[d]]\}. Este resultado corrobora, em parte, a tendência observada para o E', a 30 'C, desses materiais [Figura 51-(d)]. Para esse conjunto de materiais, PETCL-A1 dir e PETCL-A3 dir apresentaram os maiores valores de $\mathrm{E}$ ' (a 30 'C) e sem diferenças significativas entre os mesmos $\{215,9 \pm 10,1$ $\mathrm{MPa}$ e 210,9 \pm 3,8 MPa, respectivamente [Figura 51-[d]]\}. Destaca-se que não foram observadas quaisquer tendências, com relação ao I.A. dos mats PETCL-A1, PETCL-A2 e PETCL-A3 [Figura 48], assim como com relação à porosidade média desses materiais [Figura 43-[c]], que possam ser correlacionadas com os valores de resistência à ruptura apresentados pelos mesmos [Figura 53-[d]].

PET-A1 dir, PET-A2 dir e PET-A3 dir apresentaram valores de resistência à ruptura $\{5,6 \pm$ 0,3 MPa, 8,7 \pm 0,5 MPa e 4,0 \pm 1,2 MPa, respectivamente [Figura 53-[a]]\} superiores ao apresentado pelas fibras orientadas aleatoriamente de $\operatorname{PET}_{\text {ref }}[1,8 \pm 0,2$ $\mathrm{MPa}$, Figura 40-[a]]. Ainda, o valor de resistência à ruptura apresentado por $\mathrm{PET}_{\text {ref }}$ [Figura 40-[a]] foi, no geral, semelhante aos valores de resistência à ruptura apresentados pelos mats de mesma composição, mas caracterizados na direção oposta ao alinhamento preferencial das fibras [Figura 53-[a]]. Este resultado corrobora, em parte, o que foi


pelos materiais, de composição correspondente, mas preparados com o uso do coletor rotativo [Figura 51-[a]]. Para esta propriedade, PET-A2 dir e PET-A3 dir apresentaram valores de $E^{\prime}\{212,0 \pm 10,2 \mathrm{MPa}$ e 76,3 \pm 2,7 MPa, respectivamente [Figura 51-[a]]\} muito superiores ao apresentado por $\mathrm{PET}_{\text {ref }}[23,3 \pm$ 7,1 MPa, Figura 39-[a]]. Com relação à porosidade média desses materiais, assim como a influência desta propriedade na resistência mecânica dos mesmos, observa-se que os mats PET-A2 e PET-A3 apresentaram baixos valores de porosidade média $\{12,3 \pm 0,2 \%$ e 12,8 \pm 0,7\%, respectivamente [Figura 43-[c]]\}, em comparação ao apresentado por $\operatorname{PET}_{\text {ref }}[19,0 \pm 1,1 \%$, Figura 33-[c]].

PETL-A1 dir e PETL-A3 dir apresentaram valores de resistência à ruptura $\{9,2 \pm$ 0,3 MPa e 9,1 \pm 1,4 MPa, respectivamente [Figura 53-[b]]\} superiores ao apresentado por PETL/72 h [7,0 $\pm 0,3$ MPa, Figura 40-[a]]. A mesma tendência foi observada ao compararmos o E', a 30 'C, desses materiais [Figura 51-[b] e Figura 39-[a]]. Ainda, não foram observadas diferenças significativas nos valores de porosidade média dos mats PETL-A1, PETL-A2 e PETL-A3 [Figura 43-[c]], em comparação ao apresentado por $\mathrm{PETL} / 72$ h [Figura 33-[c]], não sendo possivel correlacionar esta propriedade com a 
resistência à ruptura desses materiais.

PETC-A1 dir e PETC-A2 dir apresentaram valores de resistência à ruptura $\{11,2 \pm$ 0,6 MPa e 16,3 \pm 0,4 MPa, respectivamente [Figura 53[c]]\} superiores ao apresentado por PETC/72 h [9,5 \pm 0,6 MPa, Figura 40-[a]]. Esta tendência foi, em parte, corroborada pelos valores apresentados de E' (a $30{ }^{\circ} \mathrm{C}$ ) por esses materiais. Assim, PETC-A2 dir apresentou superior valor de E' [334,8 \pm 2,5 MPa, Figura 51-[c]], em comparação ao apresentado por PETC/72 h [219,8 \pm 7,9 MPa, Figura 39-[a]]. No entanto, não foi possivel correlacionar a porosidade média dos mats PETC-A1, PETC-A2 e PETC-A3 [Figura 43-[c]], assim como do mat PETC/72 h [Figura 33-[c]], com os diferentes valores de resistência à ruptura apresentados por esses materiais.

PETCL-A1 dir, PETCL-A2 dir e PETCL-A3 dir apresentaram valores de resistência à ruptura $\{11,6 \pm 2,1 \mathrm{MPa}, 10,4 \pm 0,6 \mathrm{MPa}$ e 12,5 \pm 0,4 MPa, respectivamente [Figura 53-[d]]\} superiores ao apresentado por PETCL/72 h [7,4 \pm 0,3 MPa, Figura 40-[a]]. Este resultado não corrobora a tendência observada ao compararmos o E', a 30 'C, desses materiais [Figura 51-[d] e Figura 39-[a]]. Não se pode deixar de considerar que os valores de porosidade média apresentados por esses materiais [Figura 43-[c] e Figura 33-[c]] não correlacionam-se com o que foi observado para a resistência à ruptura dos mesmos [Figura 53-[d] e Figura 40-[a]].

Mazinani, Ajji e Dubois [2010], em seu estudo, obtiveram mats de fibras alinhadas de PET via eletrofiação de soluções desse polímero em TFA/DCM, na concentração de 10\% [massa/massa]. Esses materiais apresentaram valores de resistência à ruptura, na direção preferencial de alinhamento das fibras [com diâmetro médio de $827 \pm 195 \mathrm{~nm}$ ] e na direção oposta ao alinhamento, de aproximadamente 5,8 $\mathrm{MPa}$ e 3,8 $\mathrm{MPa}$, respectivamente. Ao se comparar estes valores com os apresentados pelos mats PET-A1, PET-A2 e PET-A3 [Figura 53-[a]], preparados via eletrofiação de soluções de PET/TFA na concentração de aproximadamente 9\% [massa/massa], observamos que, para os materiais caracterizados na direção preferencial de alinhamento das fibras \{com diâmetros médios [Figura 43-[a]] inferiores ao obtido por Mazinani, Ajji e Dubois [2010]\}, os valores foram semelhantes, com exceção de PET-A2 dir que apresentou uma resistência à ruptura de 8,7 \pm 0,5 MPa [Figura 53-[a]]. Com relação aos valores de resistência à ruptura apresentados pelos mats caracterizados na direção oposta ao alinhamento das fibras, no presente estudo, foram obtidos valores inferiores a 3,8 MPa. Destaca-se que a porosidade média dos mats preparados por Mazinani, Ajji e Dubois [2010] não foi informada, o que impossibilita uma análise comparativa mais detalhada.

A Figura 54 apresenta os resultados do módulo de Young dos mats preparados com a utilização do coletor rotativo. 
Figura 50 - Módulo de Young dos mats [a] PET-A1, PET-A2 e PET-A3; [b] PETL-A1, PETL-A2 e PETL-A3; [c] PETC-A1, PETC-A2 e PETC-A3; [d] PETCL-A1, PETCL-A2 e PETCL-A3. Os materiais foram caracterizados tanto na direção preferencial de alinhamento das fibras [siglas contendo a terminação "dir" no final], quanto na direção oposta ao alinhamento preferencial das fibras [siglas contendo a terminação "op" no final].

[a]

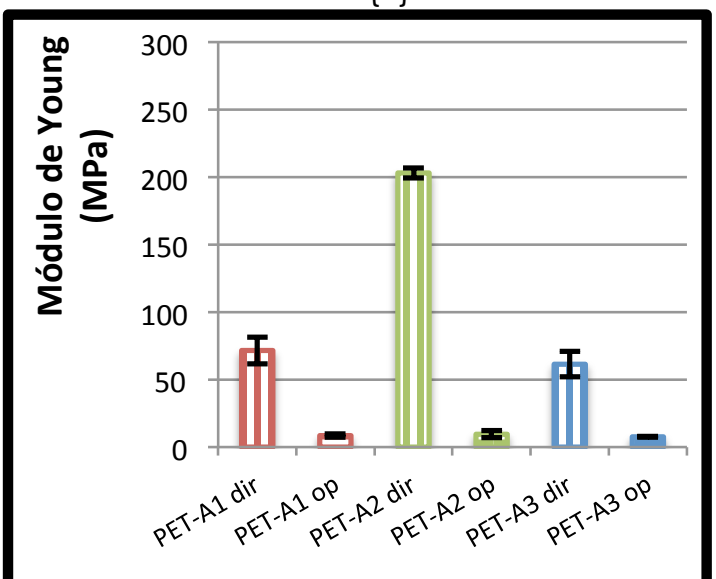

[c]

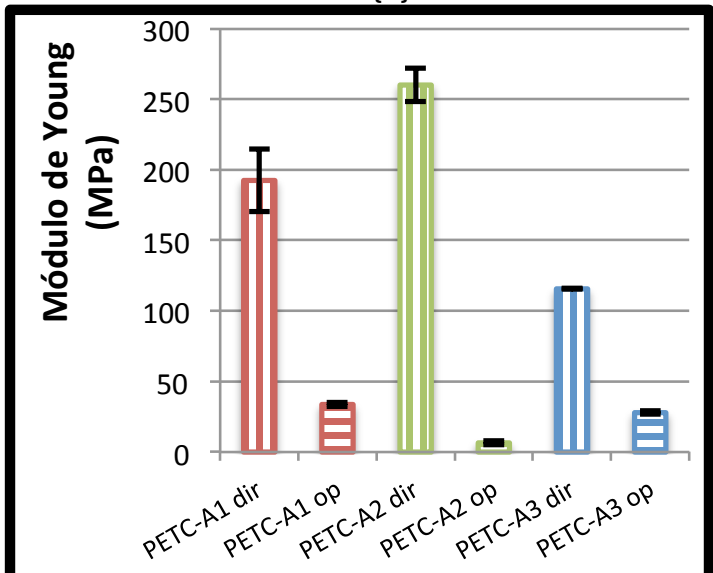

Fonte: Autoria própria. [b]

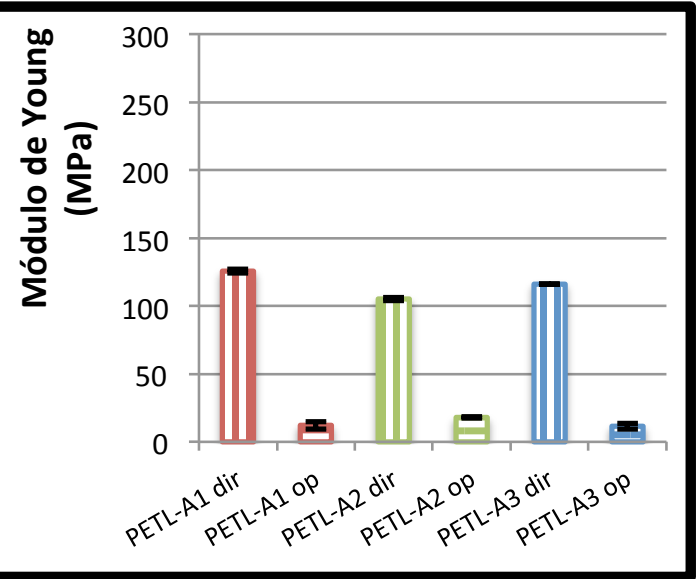

[d]

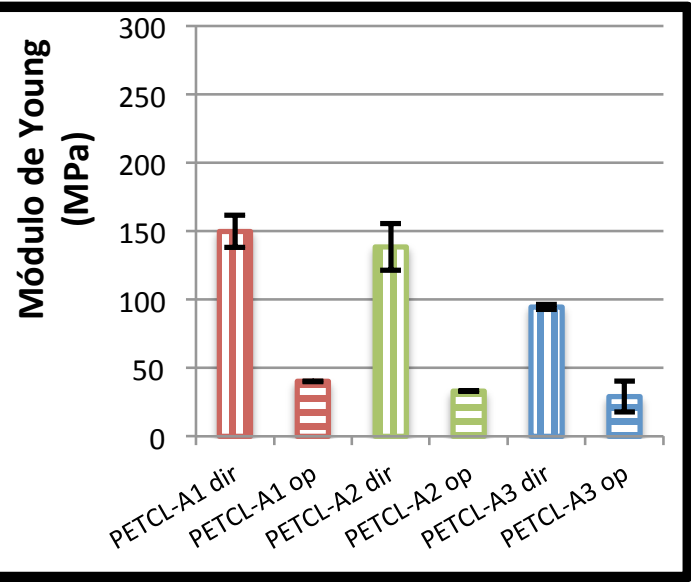

Pode-se observar na Figura 54 a mesma tendência apresentada pelos materiais com relação ao E' [Figura 51], assim como para a resistência à ruptura dos mesmos [Figura 53]. Os mats, caracterizados na direção preferencial de alinhamento das fibras, apresentaram superiores valores de módulo de Young, em comparação ao apresentado pelos materiais caracterizados na direção oposta.

PET-A1 dir e PET-A3 dir apresentaram os menores valores de módulo de Young $\{71,6 \pm 10,0 \mathrm{MPa}$ e 61,4 \pm 9,3 MPa, respectivamente [Figura 54-[a]]\} dentre todos os materiais caracterizados na direção preferencial de alinhamento das fibras [Figura 54]. Contrariamente, PETC-A2 dir apresentou o maior valor de módulo de Young [260,0 \pm 11,8 $\mathrm{MPa}$, Figura 54-[c]] dentre todas as amostras preparadas com o uso do coletor rotativo [Figura 54]. Novamente, estes resultados corroboram o que foi observado, tanto para o E', a $30{ }^{\circ} \mathrm{C}$, desses materiais [Figura 51], quanto para a resistência à ruptura dos mesmos [Figura 53].

No geral, todos os materiais de mesma composição, caracterizados na direção preferencial de alinhamento das fibras (Figura 54), apresentaram a mesma tendência 
para o módulo de Young observada para o E', a 30 C, desses materiais (Figura 51), assim como para a resistência à ruptura dos mesmos [Figura 53]. No entanto, os materiais contendo celulose e lignina em suas composições apresentaram uma tendência diferente para os valores do módulo de Young, do que a observada para o E' desses materiais [Figura 51-[d]], assim como para a resistência à ruptura dos mesmos [Figura 53-[d]]. Assim, PETCL-A1 dir e PETCL-A2 dir apresentaram superiores valores de módulo de Young $\{149,6 \pm 11,6 \mathrm{MPa}$ e 138,3 \pm 17,2 MPa, respectivamente [Figura 54-[d]]\}, em comparação ao apresentado por PETCL-A3 dir [94,4 \pm 1,8 MPa, Figura 54-[d]].

Destaca-se que os mats, de mesma composição, caracterizados na direção oposta ao alinhamento preferencial das fibras, no geral, não apresentaram diferenças significativas em seus valores de módulo de Young (Figura 54). Esta tendência também foi observada para o E', a 30 'C, desses materiais [Figura 51], assim como para a resistência à ruptura dos mesmos [Figura 53].

PET-A1 dir, PET-A2 dir e PET-A3 dir apresentaram superior valor de módulo de Young $\{71,6 \pm 10,0 \mathrm{MPa}, 203,2 \pm 3,7 \mathrm{MPa}$ e 61,4 \pm 9,3 MPa, respectivamente [Figura 54-[a]]\}, em comparação ao apresentado por $\mathrm{PET}_{\text {ret }}[36,3 \pm 2,1 \mathrm{MPa}$, Figura 40-(b)], de mesma composição, mas com fibras orientadas aleatoriamente. PETL-A1 dir, PETL-A2 dir e PETL-A3 dir também apresentaram superiores valores de módulo de Young \{125,7 \pm 1,4 MPa, 105,2 \pm 1,2 MPa e 116,1 \pm 0,1 MPa, respectivamente [Figura 54-(b)]\}, em comparação ao valor apresentado por PETL/72 h [66,9 \pm 5,6 MPa, Figura 40-[b]]. Ainda, PETCL-A1 dir, PETCL-A2 dir e PETCL-A3 dir também apresentaram superiores valores de módulo de Young $\{149,6 \pm 11,6 \mathrm{MPa}, 138,3 \pm 17,2 \mathrm{MPa}$ e 94,4 \pm 1,8 MPa [Figura 54[d]]\}, em comparação ao apresentado por PETCL/72 h [67,5 ะ 9,8 MPa, Figura 40-[b]].

Contrária à tendência observada ao se comparar os valores de módulo de Young dos mats preparados com a utilização do coletor rotativo [e caracterizados na direção preferencial de alinhamento das fibras], com o valor apresentado pelos mats de fibras orientadas aleatoriamente [de mesma composição], PETC-A1 dir, PETC-A2 dir e PETC-A3 dir apresentaram inferiores valores de módulo de Young \{192,4 \pm 22,1 MPa, 260,0 \pm 11,8 MPa e 115,6 \pm 0,3 MPa, respectivamente [Figura 54-[c]]\}, em comparação ao apresentado por PETC/72 h [360,4 \pm 41,5 MPa, Figura 40-(b)]. No entanto, PETC/72 h apresentou inferior porosidade média [10,8 \pm 1,9\%, Figura 33-[c]], em comparação ao apresentado pelos mats de mesma composição, mas contendo fibras orientadas em uma direção preferencial de alinhamento [Figura 43-[c]]. Este fato pode ter influenciado na tendência observada para o módulo de Young desses materiais [Figura 54-[b] e Figura 40-[b]].

Mazinani, Ajji e Dubois (2010), em seu estudo, obtiveram mats de fibras alinhadas de PET via eletrofiação de soluções desse polímero em TFA/DCM, na concentração de 10\% (massa/massa]. Esses materiais apresentaram valores de módulo de Young, na 
direção preferencial de alinhamento das fibras [com diâmetro médio de $827 \pm 195 \mathrm{~nm}$ ] e na direção oposta ao alinhamento, de aproximadamente $135 \mathrm{MPa}$ e $35 \mathrm{MPa}$, respectivamente. Ao se comparar estes valores com os apresentados pelos mats PET-A1, PET-A2 e PET-A3 [Figura 53-[a]], preparados via eletrofiação de soluções de PET/TFA na concentração de aproximadamente 9\% [massa/massa), observamos que, para os materiais caracterizados na direção preferencial de alinhamento das fibras, os valores foram superiores aos obtidos no presente estudo, com exceção de PET-A2 dir que apresentou um valor de módulo de Young de 203,2 \pm 3,7 MPa [Figura 53-[a]]. Com relação aos valores de módulo de Young apresentados pelos mats caracterizados na direção oposta ao alinhamento das fibras, no presente estudo, foram obtidos valores inferiores a $35 \mathrm{MPa}$.

Morris et al. [2014], em seu estudo, obtiveram mats de fibras alinhadas de PET [I.A. superior a 0,9] via eletrofiação de soluções desse polímero em TFA/DCM, nas concentrações de 10\% e 20\% (massa/volume). Esses materiais, com concentrações de $10 \%$ e 20\% de PET [e porosidade média de aproximadamente 80\%], apresentaram valores de módulo de Young de 211,0 MPa e 290,0 MPa, respectivamente. Estes valores foram, no geral, muito superiores aos apresentados no presente estudo pelos mats PETA1, PET-A2 e PET-A3 [Figura 54-[a]], preparados via eletrofiação de soluções de PET/TFA na concentração de 15\% (massa/volume] e com porosidades médias de 39,5 $\pm 3,2 \%$, 12,3 \pm 0,2\% e 12,8 \pm 0,7\%, respectivamente [Figura 43-[c]].

A Figura 55 apresenta os resultados do alongamento na ruptura dos mats preparados com a utilização do coletor rotativo. 
Figura 51 - Alongamento na ruptura dos mats [a] PET-A1, PET-A2 e PET-A3; (b) PETL-A1, PETL-A2 e PETLA3; [c] PETC-A1, PETC-A2 e PETC-A3; [d] PETCL-A1, PETCL-A2 e PETCL-A3. Os materiais foram caracterizados tanto na direção preferencial de alinhamento das fibras [siglas contendo a terminação "dir" no final], quanto na direção oposta ao alinhamento preferencial das fibras [siglas contendo a terminação "op"

[a]

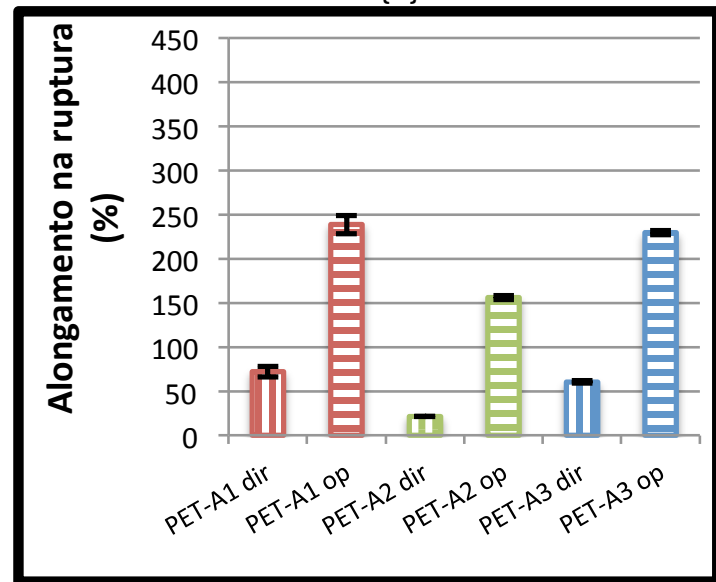

[c]

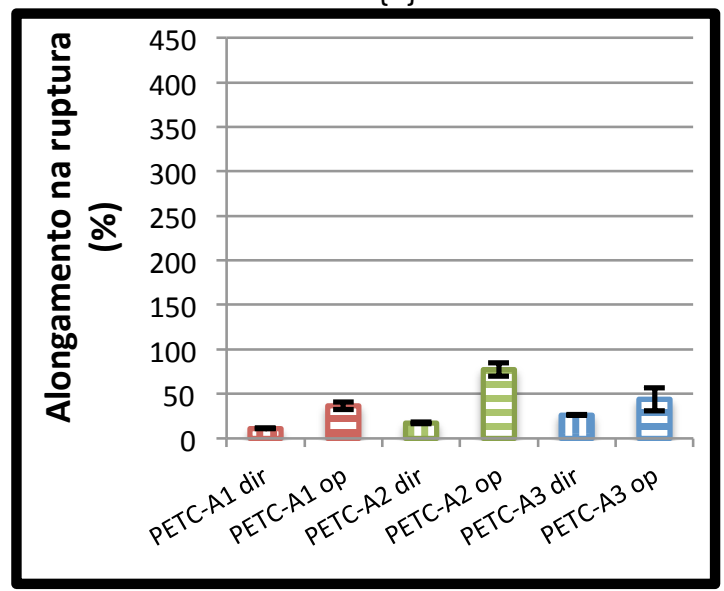

Fonte: Autoria própria. no final).

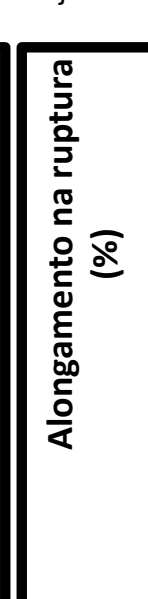

(b)

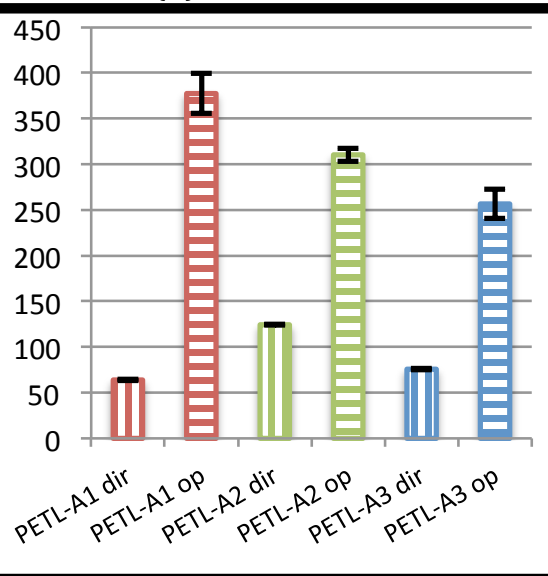

[d]

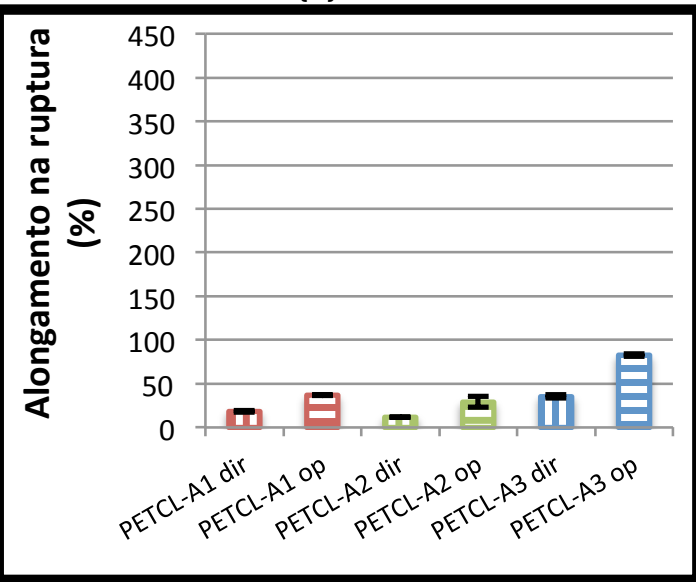

Na Figura 55 observa-se uma tendência oposta à apresentada para o E', a 30 'C [Figura 51], a resistência à ruptura [Figura 53] e para o módulo de Young [Figura 54] de PET-A1, PET-A2, PET-A3, PETL-A1, PETL-A2, PETL-A3, PETC-A1, PETC-A2, PETC-A3, PETCLA1, PETCL-A2 e PETCL-A3. Para todas as amostras, os materiais ensaiados na direção paralela ao eixo do coletor [direção oposta ao alinhamento preferencial das fibras] apresentaram maiores valores de alongamento na ruptura, em comparação com os materiais ensaiados na direção preferencial de alinhamento das fibras. Assim, quando uma força mecânica é aplicada na direção oposta ao alinhamento preferencial das fibras, faz-se necessária uma maior rotação e reorientação das mesmas para que possam se alinhar com o eixo da tensão aplicada, conforme mencionado anteriormente. Consequentemente, há um maior alongamento desses materiais, em comparação aos materiais em que a força mecânica é aplicada na direção preferencial de alinhamento das fibras (KUMAR; VASITA, 2017; MUBYANA et al., 2016].

Observa-se na Figura $\mathbf{5 5}$ que, no geral, os valores de alongamento na ruptura para 
os materiais ensaiados na direção oposta ao alinhamento preferencial das fibras mostraram-se mais divergentes, em comparação com os valores apresentados pelos materiais ensaiados na direção preferencial de alinhamento. Este fato é suportado ao levarmos em consideração os maiores valores de desvio-padrão apresentados pelas amostras ensaiadas na direção oposta ao alinhamento das fibras, em comparação com os valores de desvio-padrão das amostras ensaiadas na direção preferencial de alinhamento [Figura 55].

Pode-se observar na Figura 55 que, no geral, PETL-A1, PETL-A2 e PETL-A3 apresentaram os maiores valores de alongamento na ruptura [Figura 55-[b]], em comparação com as demais amostras. Diferentemente, PETC-A1, PETC-A2 e PETC-A3 apresentaram, no geral, os menores valores de alongamento na ruptura [Figura 55-[c]], em comparação com as demais amostras [Figura 55]. Destaca-se que os valores de alongamento na ruptura de PETC-A1, PETC-A2 e PETC-A3 [Figura 55-[c]] foram muito semelhantes, no geral, aos apresentados por PETCL-A1, PETCL-A2 e PETCL-A3 [Figura 55-[d]]. Assim, pode-se concluir que a inserção de lignina à composição dos mats de PET reciclado resultou em uma maior separação entre as cadeias de PET, facilitando a movimentação de segmentos de sua cadeia, com consequente aumento da flexibilidade dos materiais. No entanto, a adição de celulose à composição dos mats, como observado principalmente pelos elevados valores de E' [Figura 51-[c]] e do módulo de Young [Figura 54-[c]] de PETC-A1, PETC-A2 e PETC-A3, levou a um aumento substancial na rigidez dos materiais, com consequente diminuição da flexibilidade dos mesmos [Figura 55-[c]].

Observa-se na Figura 55-[a] que PET-A1 op e PET-A3 op apresentaram os maiores valores de alongamento na ruptura [238,6 \pm 10,5\%, 229,4 $\pm 2,7 \%$, respectivamente]. Com relação aos materiais da Figura 55-[b], PETL-A1 op apresentou o maior valor de alongamento na ruptura [377,3 $\pm 22,1 \%$ ]. Este também foi o maior valor dentre todos os apresentados pelos materiais preparados com o uso do coletor rotativo [Figura 55]. Podese observar na Figura 55-[c] que PETC-A2 op apresentou o maior valor de alongamento na ruptura [77,3 $\pm 7,4 \%]$. PETC-A2 op também apresentou um dos menores valores de módulo de Young [6,5 \pm 1,3 MPa, Figura 54-[c]] dentre as amostras preparadas com o uso do coletor rotativo, o que corrobora o elevado valor de alongamentona ruptura desse material. Ainda, observa-se na Figura 55-[d] que PETCL-A3 op apresentou o maior valor de alongamento na ruptura $[82,7 \pm 1,5 \%]$ dentre os materiais contendo celulose e lignina em suas composições.

Destaca-se que para os materiais contendo PET [Figura 55-[a]] e este polímero e lignina [Figura 55-[b]] em suas composições, houve uma significativa diferença entre os valores de alongamento na ruptura entre os materiais caracterizados na direção preferencial de alinhamento das fibras e os caracterizados na direção oposta. Ainda, para os materiais contendo celulose [Figura 55-[c]], combinada ou não com lignina [Figura 55[d]], em suas composições, não foram observadas diferenças significativas nos valores de 
alongamento na ruptura, tanto para os materiais caracterizados na direção preferencial de alinhamento das fibras, quanto para os caracterizados na direção oposta.

Não se pode deixar de considerar que a tendência observada para o alongamento na ruptura de mats de fibras alinhadas [Figura 55) foi, no geral, semelhante à apresentada com relação aos valores de alongamento na ruptura dos mats de fibras orientadas aleatoriamente PET ret, PETL/72 h, PETC/72 h e PETCL/72 h [Figura 40-[c]].

Todos os materiais, contendo somente PET em suas composições, e preparados com o uso do coletor rotativo apresentaram superiores valores de alongamento na ruptura [Figura 55-[a]], em comparação ao apresentado por PET $_{\text {ref }}[13,8 \pm$ 1,9\%, Figura 40-[c]]. PETL-A1 op, PETL-A2 op e PETL-A3 op apresentaram superiores valores de alongamento na ruptura $\{377,3 \pm 22,1 \%, 310,2 \pm 7,1 \%$ e $256,5 \pm 16,0 \%$, respectivamente [Figura 55-[b]]\}, em comparação ao apresentado por PETL/72 h [148,7 \pm 9,1\%, Figura 40-[c]]. PETC-A1 op, PETC-A2 op e PETC-A3 op também apresentaram superiores valores de alongamento na ruptura $\{36,6 \pm 4,2 \%, 77,3 \pm 7,4 \%$ e 44,0 \pm 13,0\%, respectivamente [Figura 55-[c]]\}, em comparação ao apresentado por PETC/72 h [25,9 \pm 2,9\%, Figura 40-[c]]. Ainda, PETCL-A3 op apresentou um valor de alongamento na ruptura $[82,7 \pm 1,5 \%$, Figura 55-[d] $]$ superior ao apresentado pelo mat PETCL/72 h [37,6 \pm 3,6\%, Figura 40-[c]].

Mazinani, Ajji e Dubois [2010], em seu estudo, obtiveram mats de fibras alinhadas de PET via eletrofiação de soluções desse polímero em TFA/DCM, na concentração de $10 \%$ [massa/massa]. Esses materiais apresentaram valores de alongamento na ruptura, na direção preferencial de alinhamento das fibras [com diâmetro médio de $827 \pm 195$ $\mathrm{nm}$ ] e na direção oposta ao alinhamento, sem diferenças significativas e de aproximadamente $400 \%$. Ao se comparar este valor com os apresentados pelos mats PET-A1, PET-A2 e PET-A3 [Figura 53-[a]], preparados via eletrofiação de soluções de PET/TFA na concentração de aproximadamente 9\% [massa/massa), observamos que, para os materiais caracterizados na direção preferencial de alinhamento das fibras, o valor foi muito superior aos obtidos no presente estudo [Figura 53-[a]]. Com relação aos valores de alongamento na ruptura apresentados pelos mats caracterizados na direção oposta ao alinhamento das fibras, no presente estudo, foram obtidos valores também inferiores a $400 \%$.

\subsection{Conclusões parciais}

Pode-se concluir que foram preparados com sucesso mats baseados em PET reciclado, celulose e/ou lignina, pós dissolução em TFA por 72 h, com a utilização de um coletor de tambor metálico rotativo. Variando-se parâmetros como a velocidade de rotação do coletor e a taxa de vazão da solução durante o processo de eletrofiação, foram preparados mats, no geral, com I.A. das fibras superior a 0,50, ou seja, com mais de $50 \%$ 
das fibras alinhadas em uma direção preferencial. Destaca-se que PETC-A2 apresentou um I.A. de 0,72 \pm 0,03, maior valor de I.A. dentre todos os mats preparados. Contrariamente, PETC-A3 apresentou um I.A. de 0,43 \pm 0,14, um dos menores valores de I.A. dentre todos os materiais preparados.

Observou-se, no geral, uma tendência de maior alinhamento das fibras conforme aumentou a velocidade de rotação do coletor, mantendo-se constantes os demais parâmetros de eletrofiação. Ainda, a adição de lignina à composição dos mats contendo celulose dificultou, no geral, o alinhamento das fibras. PETCL-A1, PETCL-A2 e PETCL-A3 apresentaram, no geral, inferiores valores de I.A. ( 0,56 $\pm 0,03,0,49 \pm 0,02$ e 0,45 \pm 0,07 , respectivamente].

Os mats caracterizados na direção preferencial de alinhamento das fibras apresentaram superiores propriedades mecânicas, em comparação aos mats, de mesma composição, caracterizados na direção oposta. Ainda, PETC-A2 dir que, conforme mencionado anteriormente, apresentou o maior I.A. dentre todos os materiais, também apresentou valores superiores de E' [a 30 'C], resistência à ruptura e módulo de Young. Destaca-se que a $T_{g}$ dos materiais não sofreu influência da direção em que os mesmos foram ensaiados. No geral, ao se comparar os valores de $T_{9}$ dos mats de fibras alinhadas com os valores apresentados pelos mats, de mesma composição, compostos por fibras orientadas aleatoriamente, observou-se que, com exceção dos mats contendo lignina ou celulose em suas composições, os demais materiais não apresentaram diferenças significativas para essa propriedade. 


\section{Capítulo 4. Preparação via eletrofiação de materiais baseados em PET reciclado, CNCs e OM: fibras alinhadas e não alinhadas}

\subsection{Introdução}

Como citado anteriormente, CNCs vem sendo utilizados como material de reforço de nanofibras/fibras ultrafinas baseadas em uma extensa variedade de matrizes poliméricas (ARRIETA et al., 2016; KAMPEERAPAPPUN, 2016; SANTAMARIA-ECHART et al., 2017; WANASEKARA et al., 2016]. O presente capítulo, até onde se tem conhecimento, pela primeira vez relata a preparação, via eletrofiação, de compósitos baseados em nanofibras/fibras ultrafinas de PET reciclado reforçados com CNCs.

Em compósitos constituídos por uma matriz polimérica reforçados por fibras lignocelulósicas, ou CNCs, a natureza hidrofílica das fibras pode afetar as propriedades de adesão com a matriz, quando esta tem natureza hidrofóbica. Uma boa interação entre o agente de reforço e a matriz em um compósito é altamente desejável, pois caso não aconteça, pode levar a insatisfatórias propriedades mecânicas desses materiais [CASTRO et al., 2017; CHEN et al., 2016; DE OLIVEIRA SANTOS et al., 2014]. Em contraposição às modificações químicas em um compósito, tanto da matriz hidrofóbica, quanto do agente de reforço, por exemplo via tratamentos de superfície [CISNEROS-LÓPEZ et al., 2017; SWAIN; BISWAS, 2017], o uso de compatibilizantes, especialmente aqueles de origem natural, surge como uma promissora alternativa [CASTRO et al., 2017; DE OLIVEIRA SANTOS et al., 2014].

Castro et al. [OLIVEIRA DE CASTRO et al., 2015], em seu estudo, prepararam nanocompósitos de biopolietileno reforçados por CNCs, utilizando OM, dentre outros óleos vegetais, como agentes compatibilizantes entre a matriz e os nanocristais. Neste estudo observou-se que a presença de OM, na concentração de 3\% em massa, levou a materiais menos opacos, melhorou a dispersão dos CNCs na matriz polimérica, assim como contribuiu para uma maior resistência à tração dos materiais. Neste contexto, no presente estudo, utilizou-se o OM, de origem natural e atóxico, visando avaliar a ação do mesmo como agente compatibilizante entre o PET reciclado, de natureza predominantemente hidrofóbica, e os CNCs, de caráter predominantemente hidrofílico. Destaca-se que o OM é constituído majoritariamente pelo ácido ricinoléico, o qual apresenta em sua cadeia grupos de caráter hidrofóbico/hidrofílico com afinidade tanto pelo PET reciclado, quanto pelos CNCs. 
Serão descritos no presente capítulo compósitos constituídos por fibras orientadas aleatoriamente e também fibras orientadas em uma direção preferencial de alinhamento, e para tal foram utilizados dois tipos distintos de coletores de fibra, um coletor estático e outro constituído por um tambor metálico rotativo. Neste estudo, buscou-se avaliar não somente a ação dos CNCs como agentes de reforço do PET, a ação do OM como compatibilizante entre o polímero reciclado e CNCs, mas também visou-se avaliar a influência do alinhamento das fibras nas propriedades finais dos mats compósitos produzidos.

\subsection{Experimental}

\subsubsection{Materiais}

Os CNCs [em sua forma seca] foram adquiridos da University of Maine [Orono, E.UA.].

○ OM foi obtido através da empresa A. Azevedo Indústria e Comércio de Óleos Ltda. [São Paulo, S.P.].

\subsubsection{Métodos}

\subsubsection{Processo de eletrofiação}

As soluções em TFA foram preparadas da seguinte forma: [a] solução de referência de PET reciclado [15 $\mathrm{g} \mathrm{dL}^{-1}$ ]; [b] solução contendo uma mistura de PET reciclado/óleo de mamona [OM] a uma concentração fixa de PET [15 $\mathrm{g} \mathrm{dL}^{-1}$, mesma concentração utilizada na preparação da solução de referência do polímero reciclado] e 2,5\% de OM [com relação à massa de polímero reciclado]; [c] solução contendo uma mistura de PET reciclado/CNC a uma concentração fixa de PET $\left[15 \mathrm{~g} \mathrm{dL}^{-1}\right.$ ] e 10\% de CNCs [com relação à massa de polímero reciclado); (d) solução contendo uma mistura de PET reciclado/OM/CNC nas concentrações fixas de $15 \mathrm{~g} \mathrm{dL}^{-1}$, 2,5\% e 10\%, respectivamente [destaca-se novamente que os teores de OM e CNC foram determinados com relação à massa de polímero reciclado utilizada].

Com base em um estudo prévio de Santos et al. [2015], foi escolhida a concentração/tempo de dissolução de $15 \mathrm{~g} \mathrm{dL}^{-1} / 24 \mathrm{~h}$ para a preparação da solução de referência de PET reciclado. Esses parâmetros se mostraram os mais adequados para o processo de eletrofiação desse polímero reciclado. Com relação aos teores de OM e CNC, ambos foram determinados pós estudo em que esses parâmetros foram variados até que fossem obtidas as concentrações mais adequadas de ambos para a eletrofiação das soluções. Ainda, para as soluções [b], [c] e [d] o OM e/ou CNCs foram adicionados somente após 24 h de dissolução do PET reciclado em TFA. Na preparação das soluções [b] e [c] o OM e os CNCs foram dispersos na mistura de PET reciclado/TFA via agitação mecânica, à temperatura ambiente, por 30 min e imediatamente após foi realizado o 
processo de eletrofiação, a fim de que os CNCs não se dissolvessem no meio. 0 tempo de dispersão de 30 min foi escolhido com base em um estudo prévio em que outros tempos de dispersão tanto do OM, como dos CNCs, também foram avaliados. Na preparação da solução [d] inicialmente o OM foi disperso na mistura de PET reciclado/TFA, da mesma forma que na solução [b] e, após os 30 min, foram dispersos os CNCs, de acordo com o mesmo procedimento adotado no preparo da solução [c].

O processo de eletrofiação foi realizado utilizando-se um aparato de eletrofiação ECDIG da IME Technologies [Geldrop, Holanda]. As soluções a serem eletrofiadas foram acondicionadas em tubos capilares, com diâmetro interno de $1 \mathrm{~mm}$ e diâmetro externo de $1,6 \mathrm{~mm}$, os quais foram conectados a uma bomba para o controle da taxa de vazão da solução. Foi utilizada a taxa de vazão de 25,5 $\mu \mathrm{L} \min ^{-1}$ em todos os casos, com exceção da solução de referência a ser eletrofiada de PET reciclado, em que a taxa de vazão utilizada foi de 5,5 $\mu \mathrm{L} \min ^{-1}$ (a qual se mostrou mais adequada para a eletrofiação do polímero reciclado, utilizando-se como aparato coletor de fibras um coletor estático].

A agulha metálica [com 0,45 mm de diâmetro interno] foi então conectada a uma fonte de tensão com voltagem positiva de $25 \mathrm{kV}$. A distância entre a ponta da agulha e o coletor foi de $8 \mathrm{~cm}$ em todos os casos. Como aparato coletor de fibras, foram utilizadas chapas delgadas de vidro acopladas ao contra eletrodo [coletor estático metálico] e também foi utilizado um coletor de tambor metálico rotativo $[12,5 \times 5,5 \mathrm{~cm}$, comprimento $\times$ largura], de acordo com a representação esquemática da Figura 16. Destaca-se que a velocidade de rotação do coletor adotada foi de 3600 rpm.

A Tabela 7 apresenta a composição dos mats preparados, tipo de coletor utilizado e os respectivos códigos de referência.

Tabela 7 - Composição dos mats preparados, tipo de coletor utilizado e os respectivos códigos de

\begin{tabular}{|c|c|c|c|c|}
\hline $\begin{array}{c}\text { PET } \\
\text { reciclado } \\
\text { [g dL'-1] }\end{array}$ & $\begin{array}{c}\text { OM } \\
\text { [\% com relação à } \\
\text { massa de PET] }\end{array}$ & $\begin{array}{c}\text { CNC } \\
\text { [\% com relaccão à } \\
\text { massa de PET] }\end{array}$ & $\begin{array}{l}\text { Tipo de } \\
\text { coletor }\end{array}$ & $\begin{array}{l}\text { Código de } \\
\text { referência }\end{array}$ \\
\hline 15,00 & - & - & estático & $P E T_{\text {ref }}$ \\
\hline 15,00 & 2,5 & - & estático & $\mathrm{PET} / \mathrm{OM}$ \\
\hline 15,00 & - & 10,0 & estático & $\mathrm{PET} / \mathrm{CNC}$ \\
\hline 15,00 & 2,5 & 10,0 & estático & $\mathrm{PET} / \mathrm{OM} / \mathrm{CNC}$ \\
\hline 15,00 & - & - & rotativo & PET-A \\
\hline 15,00 & 2,5 & - & rotativo & PET/OM-A \\
\hline 15,00 & - & 10,0 & rotativo & $\mathrm{PET} / \mathrm{CNC}-\mathrm{A}$ \\
\hline 15,00 & 2,5 & 10,0 & rotativo & $\mathrm{PET} / \mathrm{OM} / \mathrm{CNC}-\mathrm{A}$ \\
\hline
\end{tabular}

Em todos os casos, o processo de eletrofiação foi realizado por 40 min a uma temperatura de $26,1 \pm 1,4{ }^{\circ} \mathrm{C}$ e umidade relativa de 48,3 $\pm 2,5 \%$. Os mats preparados apresentaram espessura média de 0,12 \pm 0,04 mm, a qual foi determinada utilizando-se um micrômetro. Ainda, os materiais produzidos apresentaram dimensões médias de 3,60 \pm 0,97 x 15,17 \pm 0,82 cm [largura x comprimento]. 


\subsubsection{Caracterização dos mats}

4.2.2.2.1 Espectroscopia na região do Infravermelho [IV]

A obtenção dos espectros na região do Infravermelho foi realizada de acordo com o que foi descrito no item 1.2.2.2.1 do Capítulo 1.

4.2.2.2.2 Microscopia Eletrônica de Varredura [MEV]

As análises de MEV foram realizadas de acordo com o que foi descrito no item 1.2.2.2.2 do Capítulo 1.

\subsubsection{3 Ângulo de contato $[A C]$}

As análises de AC foram realizadas de acordo com o que foi descrito no item 1.2.2.2.3 do Capítulo 1 .

\subsection{Termogravimetria [TG]}

As análises termogravimétricas foram realizadas de acordo com o que foi descrito no item 1.2.2.2.4 do Capítulo 1.

\subsection{Calorimetria Exploratória Diferencial [DSC]}

As análises de DSC foram realizadas de acordo com o que foi descrito no item 2.2.2.3.5 do Capítulo 2 .

\subsection{Análise Dinâmico-Mecânica [DMA]}

As análises de DMA foram realizadas de acordo com o que foi descrito no item

\subsubsection{5 do Capítulo 1 .}

\subsection{Ensaio de resistência à tração}

Os ensaios de resistência à tração foram realizadas de acordo com o que foi descrito no item 2.2.2.3.7 do Capítulo 2.

\subsection{Resultados e Discussão}

\subsubsection{Espectroscopia na região do Infravermelho [IV]}

A Figura 56 apresenta os espectros de IV para os mats PET ref, PET/OM, PET/CNC e PET/OM/CNC. 
Figura 52 - Espectros de IV para PET ree, $\mathrm{PET} / \mathrm{OM}, \mathrm{PET} / \mathrm{CNC}$ e PET/OM/CNC.



Fonte: Autoria própria.

Na Figura 56 observa-se que o espectro de PET/OM apresenta as mesmas bandas observadas no espectro de PET ref. No entanto, a banda em aproximadamente $3430 \mathrm{~cm}^{-1}$ [atribuída à deformação axial da ligação - $\mathrm{O}-\mathrm{H}$ ) apresenta-se de forma mais intensa no espectro de PET/OM. Este fato deve-se, possivelmente, à presença de OM na composição do mat PET/OM. O OM, constituído majoritariamente por ácido ricinoléico, apresenta em sua estrutura grupos hidroxila e a presença destes grupos pode ser observada no espectro do OM [banda intensa em aproximadamente $3430 \mathrm{~cm}^{-1}$, Figura não mostrada].

Com relação ao espectro de PET/CNC [Figura 56], pode-se observar que o mesmo também apresenta as mesmas bandas/picos presentes no espectro de PET ret. No entanto, a banda em aproximadamente $3430 \mathrm{~cm}^{-1}$ (característica dos grupos hidroxila] apresentase de forma mais intensa no espectro de PET/CNC, devido à presença dos CNCs na composição deste mat. Observa-se no espectro dos CNCs (Figura não mostrada) uma banda larga e intensa na região de $3400 \mathrm{~cm}^{-1}$, característica dos grupos hidroxila. Destaca-se que o espectro de PET/OM/CNC [Figura 56] apresentou-se de forma muito semelhante ao espectro de PET/CNC [Figura 56].

\subsubsection{Microscopia Eletrônica de Varredura (MEV]}

A Figura 57 apresenta as micrografias dos mats PET ref, PET/OM, PET/CNC e $\mathrm{PET} / \mathrm{OM} / \mathrm{CNC}$, preparados com o uso do coletor estático. 
Figura 53 - Micrografias de PET ref, PET/OM, PET/CNC e PET/OM/CNC.
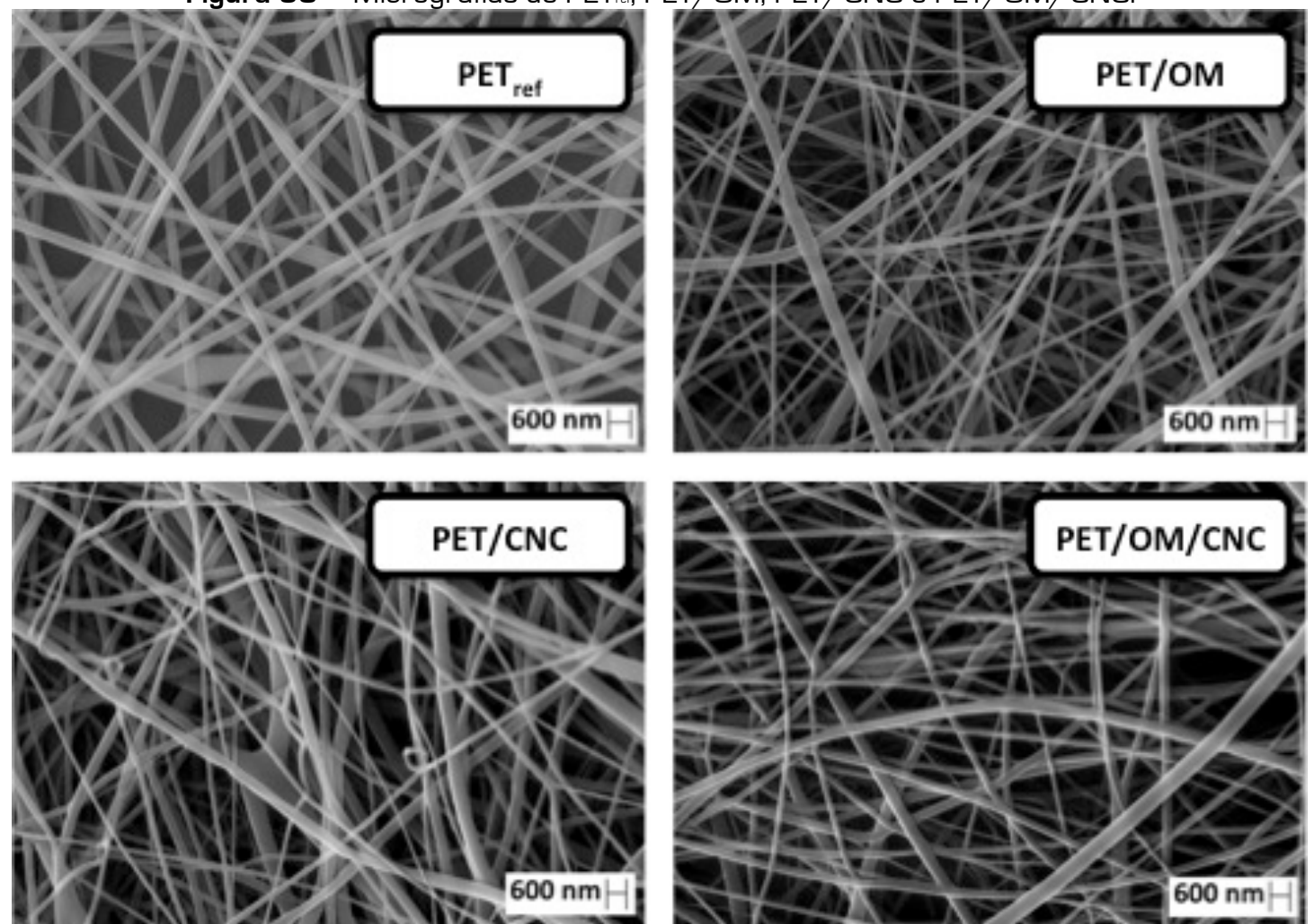

Fonte: Autoria própria.

Observa-se na Figura 58 os histogramas do diâmetro das fibras de PET ret, PET/OM, $\mathrm{PET} / \mathrm{CNC}$ e PET/OM/CNC. 
Figura 54 - Histogramas do diâmetro das fibras de PET ref, PET/OM, PET/CNC e PET/OM/CNC.
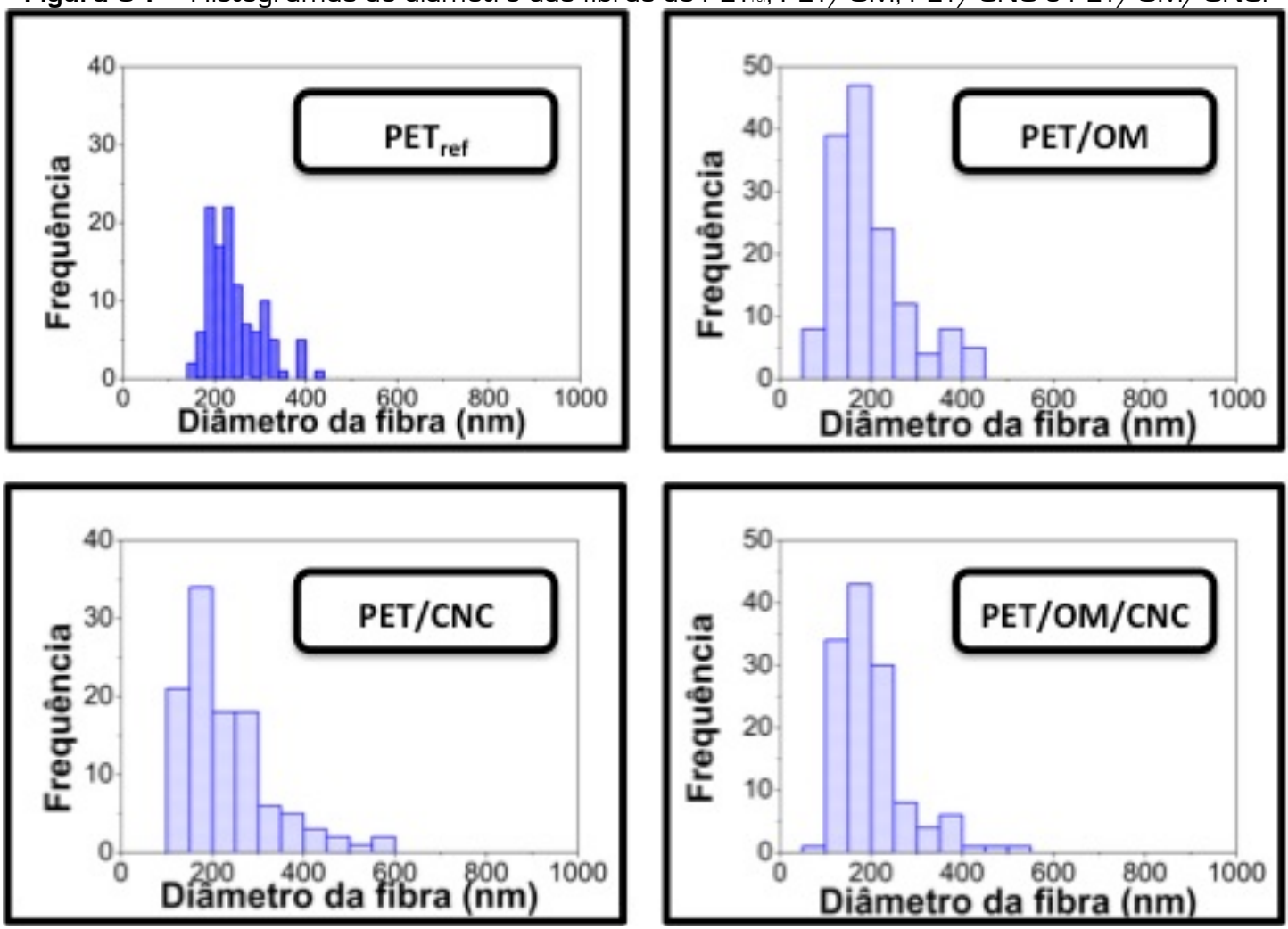

Fonte: Autoria própria.

O diâmetro médio das fibras, área média do poro e porosidade média dos mats obtidos via eletrofiação são apresentados na Figura $\mathbf{5 9 .}$ 
Figura 55 - Diâmetro médio das fibras, área média do poro e porosidade média dos mats PET re, PET/OM, $\mathrm{PET} / \mathrm{CNC}$, PET/OM/CNC, PET-A, PET/OM-A, PET/CNC-A e PET/OM/CNC-A.

(a)

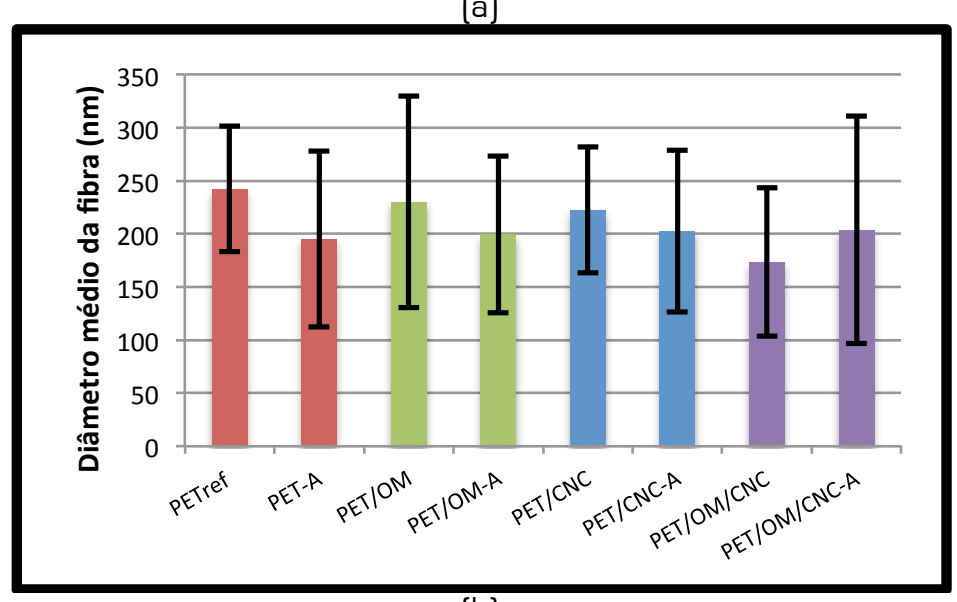

[b]

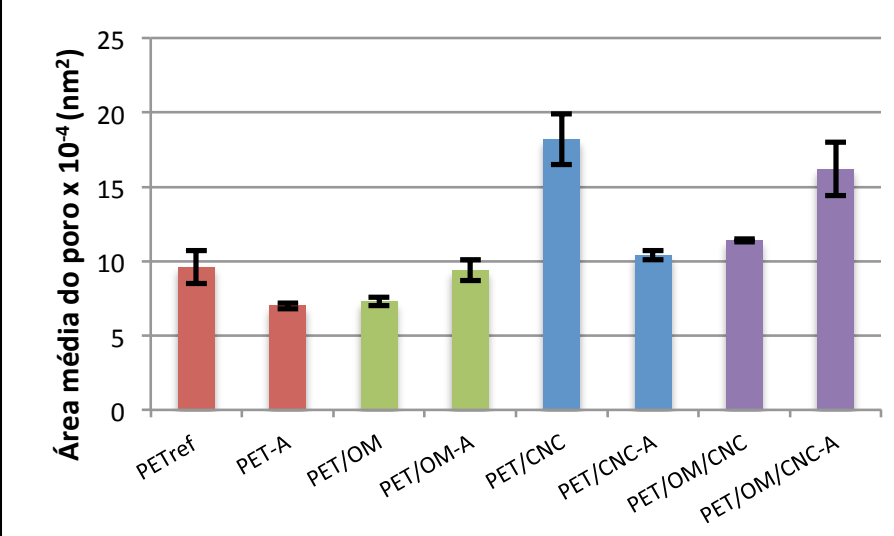

[c]

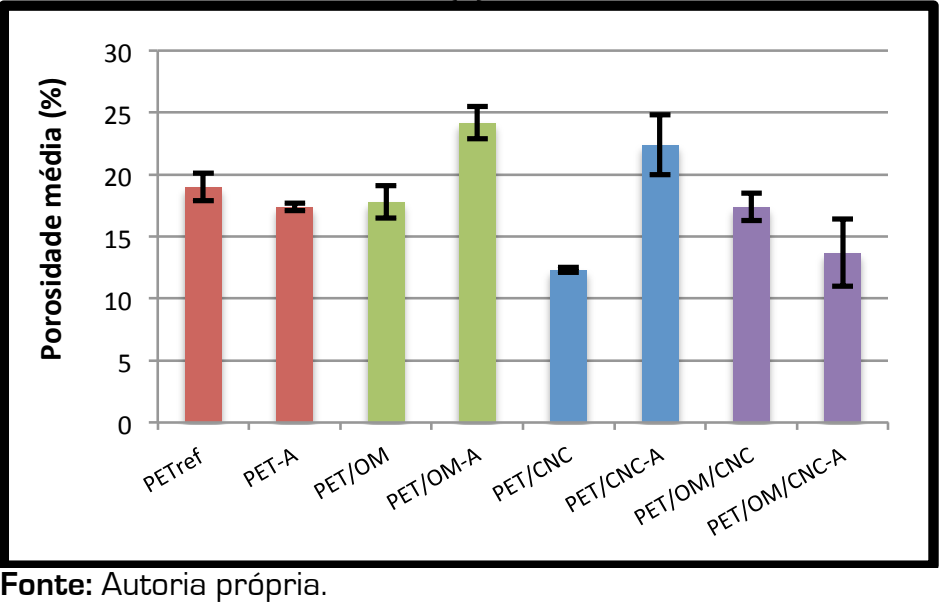

Pode-se observar nas micrografias da Figura 57, para os mats produzidos com o uso do coletor estático, uma rede de fibras contínuas, heterogênea, em geral, sem ramificações, composta por nanofibras [com exceção de PET ref e PET/CNC] e fibras ultrafinas. Observa-se na Figura 58 que, com a adição de CNCs à composição dos materiais, houve uma maior variação nos diâmetros de fibra de PET/CNC e $\mathrm{PET} / \mathrm{OM}$ /CNC, em comparação a PET ret e PET/OM. Ainda, de acordo com a Figura 59-[a], não foi observada uma tendência de aumento no diâmetro médio das fibras de PET/CNC e 
$\mathrm{PET} / \mathrm{OM} / \mathrm{CNC}$ com a adição de CNCs à composição dos mesmos, em comparação a $\mathrm{PET}_{\text {ref }}$ e PET/OM.

Observa-se na Figura 57 que a presença de CNCs e OM na composição dos mats $\mathrm{PET} / \mathrm{OM}, \mathrm{PET} / \mathrm{CNC}$ e PET/OM/CNC levou a fibras com morfologia menos cilíndrica, em contraposição às fibras de $P E T_{\text {ret. }}$ Durante o processo de eletrofiação, no jato de líquido ejetado através da agulha, pode-se formar uma fina camada polimérica. Após a formação desta camada, há a evaporação do solvente de seu interior e o colapso da pressão atmosférica com o tubo formado. Assim, consequentemente, a secção circular do tubo torna-se elíptica, ocorrendo a formação de fibras com morfologia mais achatada [KOOMBHONGSE; LIU; RENEKER, 2001].

Destaca-se que não foi observada uma influência significativa da presença de CNCs e OM na composição dos mats, nos valores de área média dos poros e porosidade média de PET/OM e PET/OM/CNC [Figura 59-[b],[c], respectivamente]. No entanto, o mat $\mathrm{PET} / \mathrm{CNC}$ apresentou uma elevada área média do poro [18,2 $\pm 1,7 \times 10^{4} \mathrm{~nm}^{2}$, Figura 59[b]] e inferior porosidade média [12,3 \pm 0,2\%, Figura 59-[b]], em comparação aos demais mats preparados com o uso do coletor estático.

A Figura 60 apresenta as micrografias, as respectivas imagens codificadas por cores e a escala de orientação de cores, assim como o I.A. e a O.P.M. das fibras para os mats, preparados com o uso do coletor rotativo, PET-A, PET/OM-A, PET/CNC-A e PET/OM/CNC-A. 
Figura 60 - Micrografias, respectivas imagens codificadas por cores, escala de orientação de cores, I.A. e O.P.M. dos mats PET-A, PET/OM-A, PET/CNC-A e PET/OM/CNC-A.
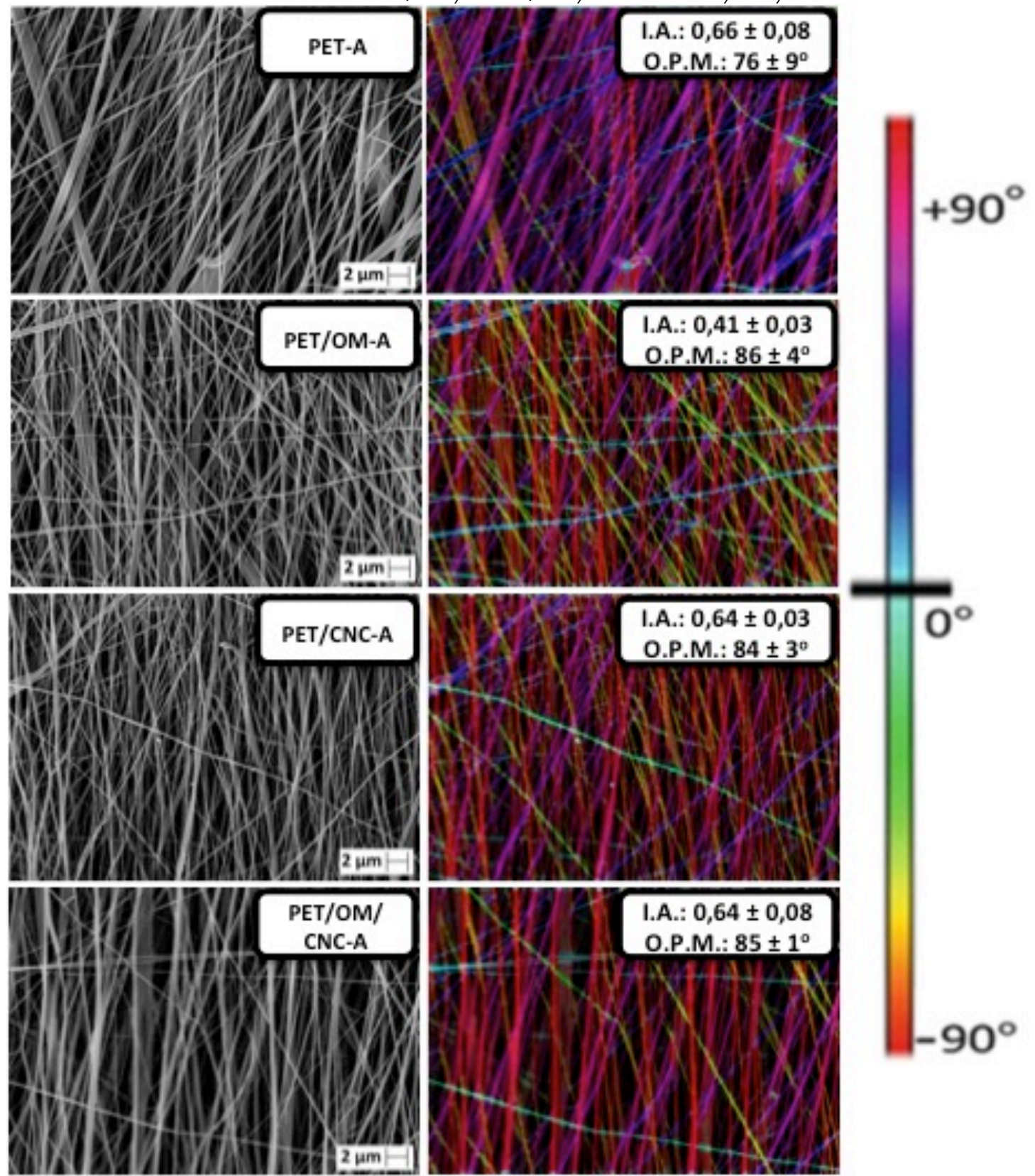

Fonte: Autoria própria.

Observa-se na Figura 61 os histogramas do diâmetro das fibras de PET-A, PET/OM-A, PET/CNC-A e PET/OM/CNC-A. 

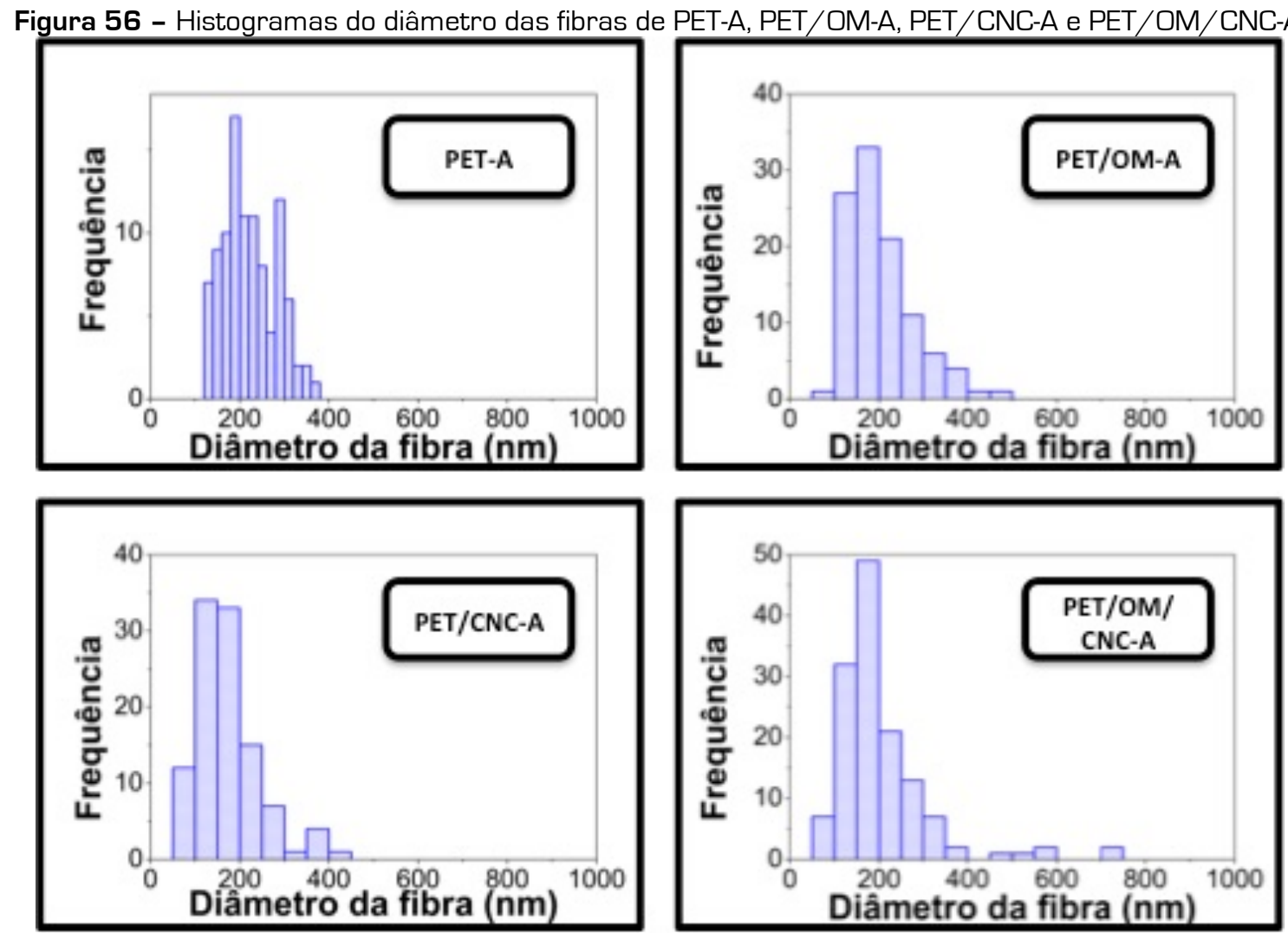

Fonte: Autoria própria.

Pode-se observar nas micrografias da Figura $\mathbf{6 0}$ para os mats preparados com a utilização do coletor rotativo, assim como observado para os mats preparados utilizandose o coletor estático (Figura 57), uma rede de fibras contínuas, heterogênea, sem ramificações, composta por nanofibras [com exceção de PET-A, da mesma forma que $\mathrm{PET}_{\text {ret }}$ [Figura 57]] e fibras ultrafinas. Assim, de acordo com os histogramas do diâmetro de fibra da Figura 61, e como observado também nos histogramas da Figura 58, a adição de CNCs (e também OM] na composição dos mats levou a uma maior variação nos diâmetros das fibras. Este aumento foi significantemente mais pronunciado para as fibras de PET/OM/CNC-A, as quais apresentaram diâmetros variando de aproximadamente 90 $\mathrm{nm}$ até $730 \mathrm{~nm}$, maior que a variação de diâmetros apresentada pelas fibras do mat de mesma composição, mas preparado com a utilização do coletor estático [PET/OM/CNC, diâmetro das fibras variando de aproximadamente 100-510 nm [Figura 58]].

De acordo com os valores de diâmetro médio das fibras apresentados na Figura 59-[a], não houve uma tendência de aumento nesses valores com a adição de CNCs à composição de PET/CNC-A e PET/OM/CNC-A [de maneira similar ao observado para os mats PET/CNC e PET/OM/CNC, Figura 59-[a]]. No entanto, assim como observado nas micrografias da Figura 57, a presença de CNCs e OM na composição dos mats da Figura 60 levou a fibras com morfologia mais achatada, em comparação às fibras cilíndricas de PET-A.

Com a adição de CNCs e/ou OM na composição dos mats PET/OM-A, PET/CNC-A 
e PET/OM/CNC-A houve um aumento na área média do poro desses materiais $\{9,4 \pm 0,7$ $\times 10^{4} \mathrm{~nm}^{2}, 10,4 \pm 0,3 \times 10^{4} \mathrm{~nm}^{2}$ e 16,2 $\pm 1,8 \times 10^{4} \mathrm{~nm}^{2}$, respectivamente [Figura 59-[b]], em comparação a PET-A [7,0 $\pm 0,2 \times 10^{4} \mathrm{~nm}^{2}$, Figura 59-[b]]. Com relação à porosidade média desses materiais, não foi possivel observar uma tendência relacionada à presença de CNCs e/ou OM na composição dos mesmos.

De acordo com os resultados da Figura 59-[a],[c], o uso de um coletor de fibras rotativo no processo de eletrofiação, ao invés de um coletor estático, não influenciou de forma significativa os valores de diâmetro médio e porosidade média dos mats PET-A, PET/OM-A, PET/CNC-A e PET/OM/CNC-A, em comparação com os valores apresentados para essas propriedades por PET ref, PET/OM, PET/CNC e PET/OM/CNC. No entanto, a utilização de diferentes tipos de coletores de fibras influenciou os valores de área média do poro dos materiais [Figura 59-[b]], sem que quaisquer tendências pudessem ser observadas. Ainda, não foi observado para os mats preparados com a utilização do coletor rotativo qualquer influência da presença de CNCs e OM no alinhamento das fibras produzidas [I.A., Figura 60]. Com exceção de PET/OM-A, observouse na Figura 60 que os demais mats apresentaram valores do I.A. superiores e semelhantes.

\subsection{3 Ângulo de contato [AC]}

A Figura 62 apresenta a dependência com o tempo do AC entre a gota de água e a superfície dos mats.

Figura 57 - Ângulo de contato aparente em função do tempo entre a gota de água e a superfície dos mats

[a] Preparados com a utilização do coletor estático e [b] Preparados com a utilização do coletor rotativo.

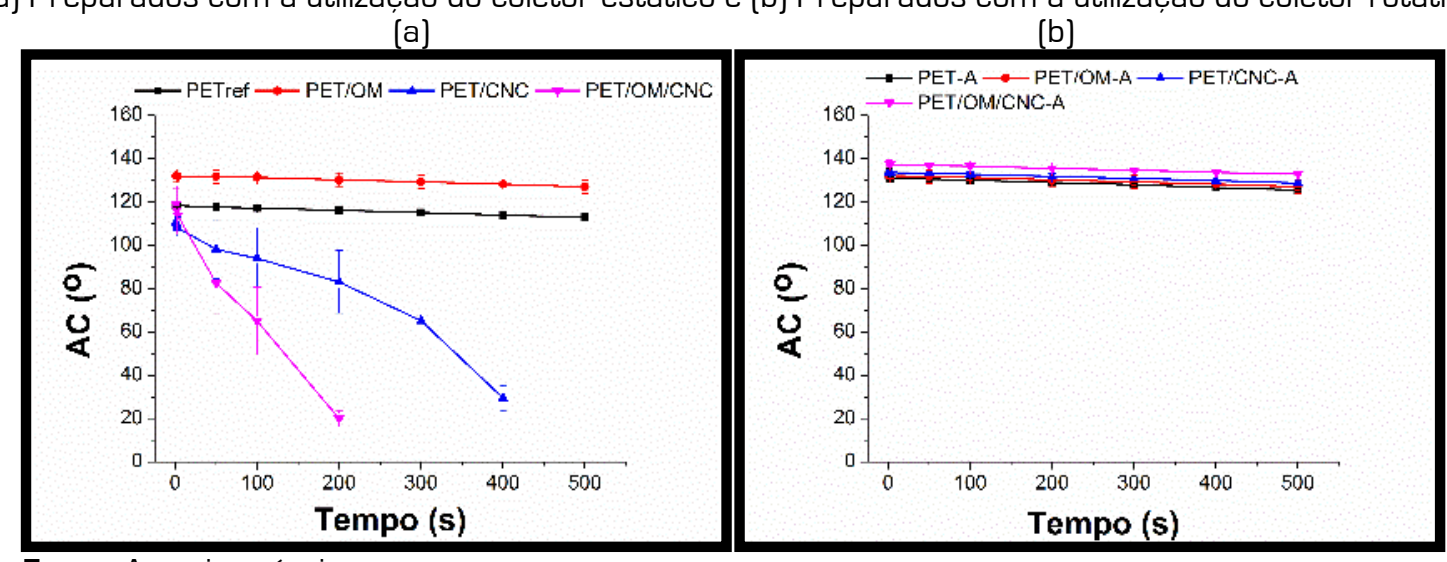

Fonte: Autoria própria.

Na Figura 62-[a] observa-se um decréscimo mais acentuado do AC em função do tempo para os mats PET/CNC e PET/OM/CNC. Assim, pode-se concluir que a adição de CNCs [com grupos hidroxila em suas cadeias, Figura 6] à composição dos mats levou a materiais mais hidrofílicos. Ainda, possivelmente, com a adição de OM [com grupos hidroxila em sua cadeia, Figura 66] à composição do mat contendo PET reciclado e CNCs, houve um aumento no caráter hidrofílico da superfície do material e, consequentemente, $\mathrm{PET} / \mathrm{OM} / \mathrm{CNC}$ apresentou um decréscimo mais rápido do AC em função do tempo, em 
comparação a PET/CNC [Figura 62-[a]].

Os mats $\mathrm{PET}_{\text {ref }}$ e PET/OM apresentaram apenas uma pequena redução nos valores de $A C$ ao longo dos 500 s de análise [Figura 62-[a]]. Este fato deve-se, possivelmente, às superfícies hidrofóbicas desses materiais devido, principalmente, à baixa polaridade do PET reciclado (que sobrepuja, neste caso, a presença de grupos polares na estrutura do OM].

Nas curvas da Figura 62-[a] para os mats PET/CNC e PET/OM/CNC observa-se que os valores de $\mathrm{AC}$ atingem com o tempo valores críticos muito pequenos. Assim, não foi possivel calcular estes valores até a completa absorção da gota de água pela superfície dos materiais.

Na Figura 62-[b], contrariamente à tendência apresentada para o AC em função do tempo dos mats preparados com o uso do coletor estático [Figura 62-[a]], não foi possível observar a influência da presença dos CNCs nos valores do AC dos mats preparados utilizando-se o coletor rotativo. Assim, para estes materiais houve apenas uma pequena redução do $A C$ em função do tempo, como consequência da superfície hidrofóbica dos mesmos. Os mats preparados com o uso do coletor rotativo não apresentaram diferenças significativas nos valores de AC em função do tempo [Figura 62[b]].

Com base nos resultados apresentados na Figura 62-[b], pode-se concluir que nas fibras de PET produzidas com o uso do coletor rotativo, os CNCs encontram-se principalmente no interior das mesmas, predominando as características hidrofóbicas do PET na superfície do material. Nas fibras de PET produzidas utilizando-se o coletor estático, os resultados indicam que os CNCs encontram-se principalmente na superfície do material, predominando o caráter hidrofílico dos CNCs, com consequente impacto nos valores de $\mathrm{AC}$ apresentados por esses materiais [Figura 62-[a]].

Destaca-se que não foi observada qualquer correlação entre a porosidade média [Figura 59-[c]] e o AC em função do tempo, tanto dos mats preparados com o uso do coletor estático [Figura 62-[a]], como dos mats preparados com a utilização do coletor rotativo [Figura 62-[b]].

\subsubsection{Termogravimetria [TG]}

A Figura 63 apresenta as curvas TG e dTG dos mats PET ref, PET/OM, PET/CNC e PET/OM/CNC. 
Figura 58 - Curvas [a] TG e [b] dTG dos mats $\mathrm{PET}_{\text {ref, }} \mathrm{PET} / \mathrm{OM}$, PET/CNC e PET/OM/CNC [atmosfera de $\mathrm{N}_{2}$, fluxo de $50 \mathrm{~mL} \min ^{-1}$ e taxa de aquecimento de $10{ }^{\circ} \mathrm{C} \mathrm{min}^{-1}$ ]. [a]

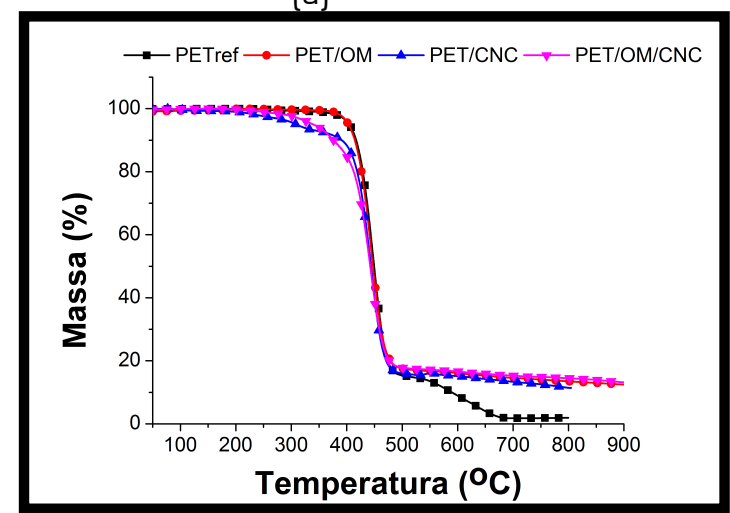

Fonte: Autoria própria. [b]

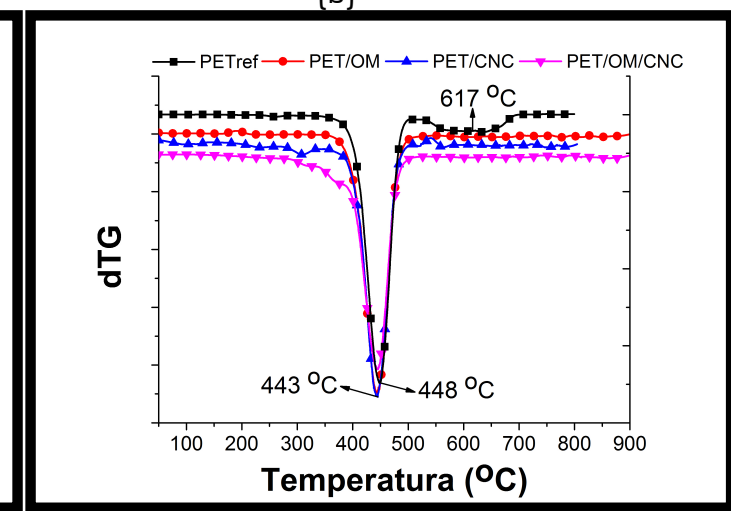

A Tabela 8 apresenta as temperaturas características de decomposição térmica e as perdas de massa correspondentes dos mats PET ref, PET/OM, PET/CNC e PET/OM/CNC.

Tabela 8 - Temperaturas características da decomposição térmica e correspondentes perdas de massa dos mats $\mathrm{PET}_{\text {ret, }} \mathrm{PET} / \mathrm{OM}$, PET/CNC e PET/OM/CNC.

\begin{tabular}{|c|c|c|c|c|c|c|c|c|}
\hline \multirow[t]{2}{*}{ Amostra } & \multicolumn{5}{|c|}{ Estágio I } & \multicolumn{3}{|c|}{ Estágio II } \\
\hline & $\begin{array}{c}\text { Intervalo } \\
\left.{ }^{\circ} \mathrm{C}\right]\end{array}$ & $\begin{array}{c}\mathrm{T}_{\text {onset }} \\
{\left[{ }^{\circ} \mathrm{C}\right]^{*}}\end{array}$ & $\begin{array}{c}\mathrm{T}_{\mathrm{p}} \\
{\left[{ }^{\circ} \mathrm{C}\right]^{\star *}}\end{array}$ & $\begin{array}{c}\text { WL } \\
{[\%] \star * *}\end{array}$ & $\begin{array}{c}\text { Intervalo } \\
\left.{ }^{\circ} \mathrm{C}\right]\end{array}$ & $\begin{array}{l}T_{\text {onset }} \\
{\left[{ }^{\circ} \mathrm{C}\right]}\end{array}$ & $\begin{array}{c}\mathrm{T}_{\mathrm{p}} \\
{\left[{ }^{\circ} \mathrm{C}\right]}\end{array}$ & $\begin{array}{l}\text { WL } \\
{[\%]}\end{array}$ \\
\hline $\mathrm{PET}_{\text {ref }}$ & $338-504$ & 418 & 448 & 84 & $530-690$ & 554 & 617 & 13 \\
\hline PET/OM & $310-545$ & 413 & 443 & 83 & - & - & - & - \\
\hline PET/CNC & $269-577$ & 411 & 443 & 82 & - & - & - & - \\
\hline $\mathrm{PET} / \mathrm{OM} / \mathrm{CNC}$ & $105-547$ & 402 & 443 & 83 & - & - & - & - \\
\hline
\end{tabular}

Nas curvas dTG dos mats PET/OM, PET/CNC e PET/OM/CNC [Figura 63-[d]] foi observado um único estágio de perda de massa, com os mesmos valores de $T_{p}\left(443{ }^{\circ} \mathrm{C}\right.$, Tabela 8) e perdas de massa semelhantes [aproximadamente 80\%, Tabela 8). Este estágio pode ser atribuído à decomposição do PET, via cisões aleatórias de ligações éster em sua cadeia principal, com consequente formação de diferentes oligômeros (DIMITROV et al., 2013; JENEKHE; LIN; SUN, 1983). No entanto, com a adição de CNCs à composição de PET/CNC e PET/OM/CNC, houve uma ligeira diminuição da estabilidade térmica desses mats [de acordo com os valores de $T_{\text {onset, }}$ Tabela 8) em comparação aos mats contendo somente PET reciclado e o mesmo combinado com OM [PET ref, PET/OM, respectivamente [valores de $T_{\text {onset, }}$ Tabela 8)]. Destaca-se que a decomposição térmica dos CNCs inicia a uma temperatura inferior [ $\mathrm{T}_{\text {onset }}=295^{\circ} \mathrm{C}$, Curvas TG e dTG não mostradas] à do PET reciclado $\left\{T_{\text {onset }}=413^{\circ} \mathrm{C}\right.$, curva dTG [Figura 27-[a]]\}, o que justifica a menor estabilidade térmica dos materiais em que os CNCs estão presentes.

\subsubsection{Calorimetria Exploratória Diferencial [DSC]}

A Figura 64 apresenta as curvas DSC dos mats PET ref, PET/OM, PET/CNC e 
PET/OM/CNC.

Figura 59 - Curvas DSC dos mats PET ret $_{\text {ret }} \mathrm{PET} / \mathrm{OM}, \mathrm{PET} / \mathrm{CNC}$ e PET/OM/CNC (atmosfera de Ne, fluxo de 50 $\mathrm{mL} \min ^{-1}$ e taxa de aquecimento de $10{ }^{\circ} \mathrm{C}$ min $\left.^{-1}\right]$.

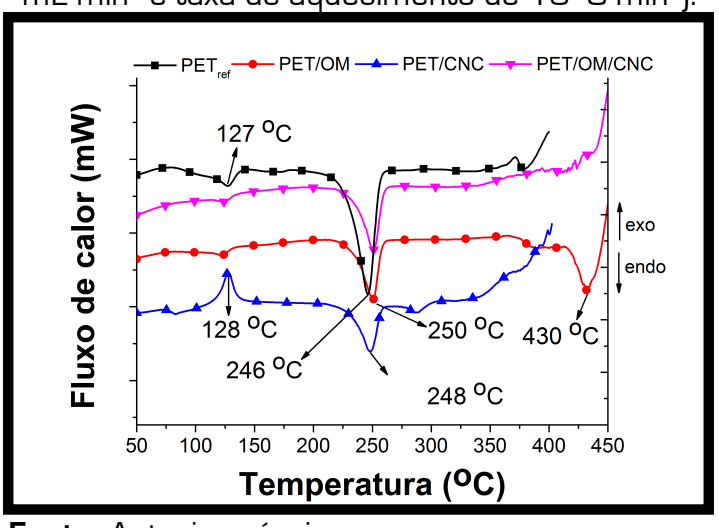

Fonte: Autoria própria.

Os valores de temperatura de fusão $\left[\mathrm{T}_{\mathrm{m}}\right]$, entalpia de fusão $\left[\Delta \mathrm{H}_{\mathrm{f}}\right]$ e cristalinidade $\left[\mathrm{I}_{c}\right]$ para o PET presente nos mats $\mathrm{PET}_{\text {ref, }} \mathrm{PET} / \mathrm{OM}$, PET/CNC e PET/OM/CNC estão apresentados na Tabela $\mathbf{9}$.

Tabela $9-\mathrm{T}_{\mathrm{m}}, \mathrm{H}_{\mathrm{f}}$ e $\mathrm{I}_{\mathrm{c}}$ de PET $\mathrm{Tef}_{\mathrm{re}}$ PET/OM, PET/CNC e PET/OM/CNC.

\begin{tabular}{|c|c|c|c|}
\hline Amostra & $\mathrm{T}_{\mathrm{m}}\left[{ }^{\circ} \mathrm{C}\right]^{\star}$ & $\Delta \mathrm{H}_{\mathrm{f}}\left[\mathrm{J} \mathrm{g}^{-1}\right]^{\star *}$ & I. $[\%]^{\star \star \star}$ \\
\hline $\mathrm{PET}_{\text {ref }}$ & 246 & 64,5 & 46 \\
\hline $\mathrm{PET} / \mathrm{OM}$ & 250 & 76,3 & 56,2 \\
\hline $\mathrm{PET} / \mathrm{CNC}$ & 248 & 62,7 & 49,2 \\
\hline $\mathrm{PET} / \mathrm{OM} / \mathrm{CNC}$ & 250 & 87,0 & 69,8 \\
\hline
\end{tabular}

' $\mathrm{T}_{\mathrm{m}}=$ Temperatura de fusão; " $\Delta \mathrm{H}_{\mathrm{t}}=$ entalpia de fusão; " $\mathrm{I}_{\mathrm{c}}=$ Cristalinidade.

Na Figura 64 observa-se que PET/OM apresentou, além do pico endotérmico intenso em $250{ }^{\circ} \mathrm{C}$, referente à fusão da fração cristalina do PET, um pico endotérmico intenso em $430{ }^{\circ} \mathrm{C}$. Este pico pode estar associado à volatilização/decomposição dos ésteres de ácidos graxos que compõem o $\mathrm{OM}$, sendo o principal deles o éster do ácido ricinoléico (DE OLIVEIRA SANTOS et al., 2014).

Observou-se nas curvas DSC da Figura 64 que com a adição de CNCs às composições de PET/CNC e PET/OM/CNC, não houve um deslocamento significativo na temperatura do pico endotérmico intenso, referente à fusão da fração cristalina do PET reciclado.

A presença do OM e CNCs na composição dos mats não influenciou significativamente o valor de $T_{m}$ do PET $\left[T_{m}\right.$ do PET reciclado $=248{ }^{\circ} \mathrm{C}$ e $T_{m}$ de $P E T_{\text {ref }}=246$ ${ }^{\circ} \mathrm{C}$ [Tabela 4]]. De maneira semelhante, a presença dos CNCs na composição dos materiais não apresentou um impacto significativo na cristalinidade dos mesmos [cálculo do Ic, item 2.2.2.3.5 [Capitulo 2)]. Assim, de acordo com a Tabela 9, PET/CNC apresentou um $I_{c}$ de 49,2\%, sem diferenças significativas para o valor apresentado por $\mathrm{PET}_{\text {ref }}\left[\mathrm{l}_{\mathrm{c}}=46 \%\right.$, Tabela 9) e pelo PET reciclado de partida $\left[\mathrm{l}_{c}=49 \%\right.$ ). No entanto, a adição de OM à composição dos materiais influenciou significativamente a cristalinidade dos mesmos. $\mathrm{PET} / \mathrm{OM}$ e PET/OM/CNC apresentaram valores de cristalinidade de 56,2\% e 69,8\%, respectivamente [Tabela 9]. Estes valores foram superiores ao apresentado por $\mathrm{PET}_{\text {ref }}$ 


\section{[46\%, Tabela 9].}

\subsubsection{Análise Dinâmico-Mecânica [DMA]}

A Figura 65 apresenta os resultados de $\mathrm{E}^{\prime}$ (a 30 'C) e da $\mathrm{T}_{9}$ dos mats preparados com a utilização do coletor estático, assim como dos materiais preparados com o uso do coletor rotativo. Destaca-se que os mats preparados com o uso do coletor rotativo foram caracterizados, tanto na direção perpendicular ao eixo do coletor [direção preferencial de alinhamento das fibras], quanto na direção paralela ao eixo do mesmo [direção oposta ao alinhamento preferencial das fibras].

Figura 60 - [a] E' [a 30 `C] e [b] Ts dos mats preparados com a utilização do coletor estático; (c) E' [a 30 `C] e (d) $T_{9}$ dos mats preparados com a utilização do coletor rotativo. Estes materiais foram caracterizados tanto na direção preferencial de alinhamento das fibras (siglas contendo a terminação "dir" no final], quanto na direção oposta ao alinhamento preferencial das fibras [siglas contendo a terminação "op" no final].

(a)

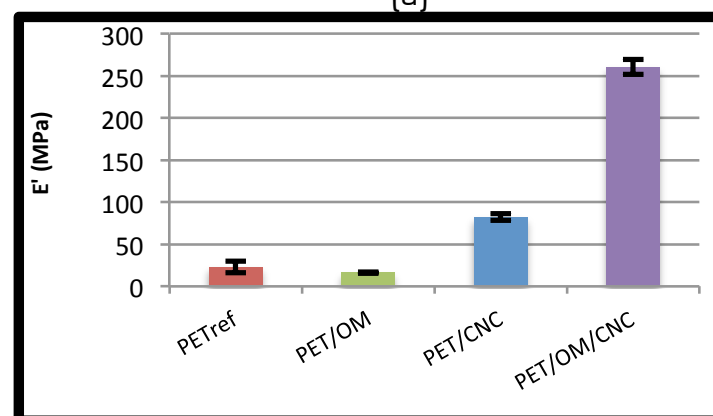

[c]



Fonte: Autoria própria.

\section{[b]}

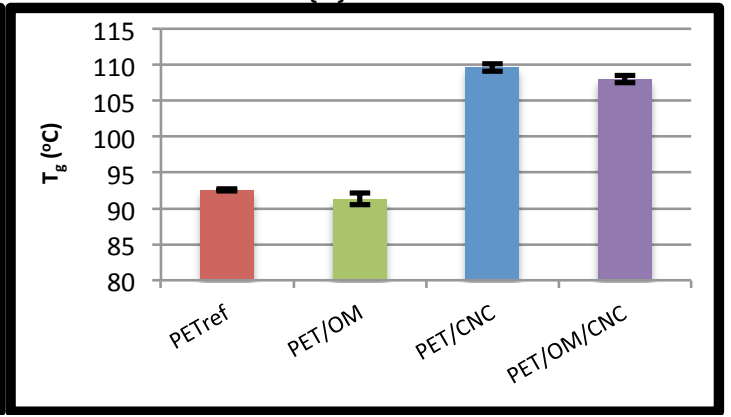

[d]

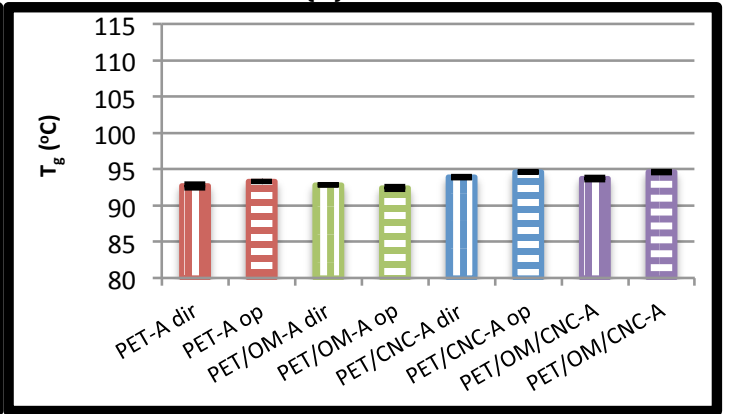

Observa-se na Figura 65-(a) que houve um aumento no valor de E' [a 30 'C) com a adição de CNCs, tanto na composição do mat PET/CNC, quanto na composição de PET/OM/CNC. PET/CNC apresentou um E' de 82,2 \pm 3,8 MPa, já PET/OM/CNC apresentou um valor superior de E' de 260,8 \pm 8,9 MPa [e também uma maior cristalinidade [ $I_{c}=69,8 \%$, Tabela 9], em comparação aos demais materiais]. Assim, podese concluir que os CNCs reforçaram mecanicamente as nanofibras/fibras ultrafinas de PET. Houve um consequente aumento da rigidez desses materiais devido a um possível decréscimo da mobilidade de segmentos das cadeias do polímero reciclado, com o estabelecimento de interações intermoleculares do tipo ligação hidrogênio entre os grupos presentes na estrutura do PET e dos CNCs.

Os resultados da Figura 65-[a] indicam que o OM presente na composição do mat 
contendo CNCs [PET/OM/CNC) atuou como agente compatibilizante entre o PET e os nanocristais. O OM [constituído por aproximadamente $90 \%$ de ácido ricinoléico) em sua estrutura possui cadeias hidrocarbônicas com afinidade pelas cadeias de PET e também apresenta grupos polares com afinidade pelos grupos hidroxila presentes nos CNCs [Figura 66]. Assim, via interações hidrofóbicas e via ligações hidrogênio, o OM possivelmente aumentou a dispersão dos CNCs na solução de PET/TFA, e posteriormente nos mats obtidos, levando a um reforço mais efetivo pelos nanocristais.

Figura 61 - Interações entre o PET/OM/CNCs.

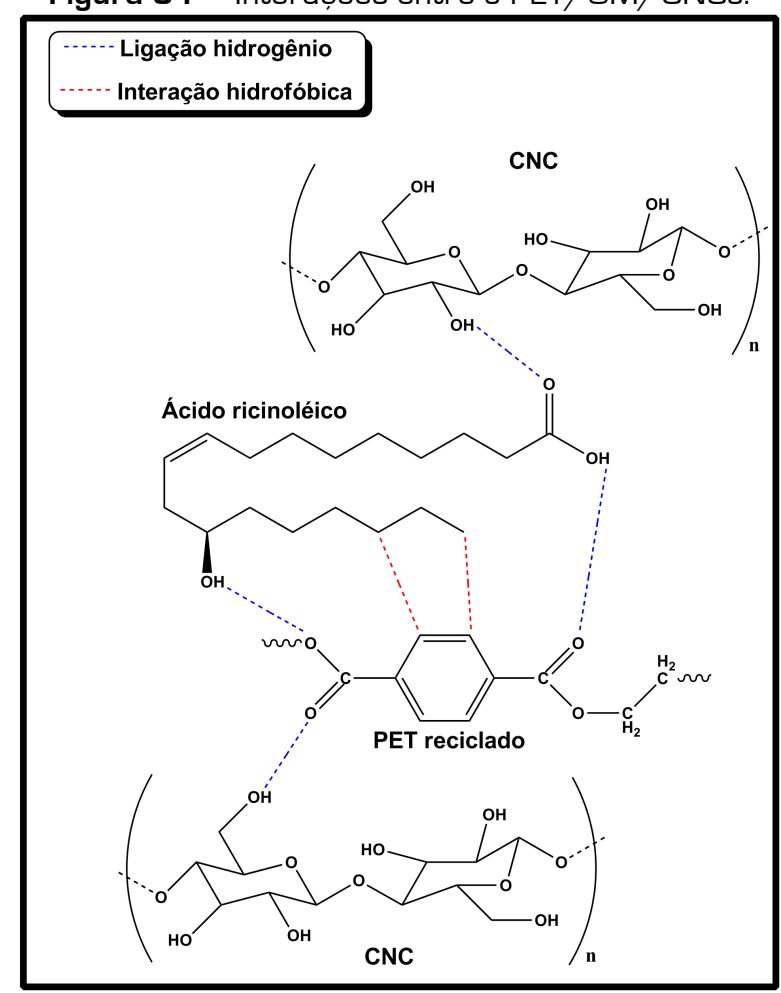

Fonte: Autoria própria.

Observa-se que o valor de E' (a 30 ㄷ] de PET/CNC [82,2 \pm 3,8 MPa, Figura 65[a]], contendo CNCs em uma concentração de 10\% em massa com relação à massa de PET, é inferior ao valor de E' dos mats PETC/48 h e PETC/72 h \{138,3 $\pm 12,8 \mathrm{MPa}$ e 219,8 \pm 7,9 MPa, respectivamente [Figura 39-[a]]\}, preparados via eletrofiação de solução de PET reciclado e celulose (em uma concentração em massa de 8,7\% com relação à massa de PET] dissolvidos em TFA. Assim, pode-se concluir que houve um reforço mais efetivo dos materiais nos quais as cadeias de celulose estavam dissolvidas na solução que gerou o mat, em comparação ao reforço proporcionado por esse polissacarídeo, suspenso na solução que gerou o mat PET/CNC, na forma de nanocristais.

Destaca-se que não se observou correlação entre os valores de E' (a 30 'C) dos materiais preparados com o uso do coletor estático [Figura 65-[b]], com os valores de porosidade média apresentados pelos mesmos [Figura 59-[c]].

Pode-se observar na Figura 65-[b] que houve um aumento nos valores de $T_{9}$ com a 
adição de CNCs à composição dos mats PET/CNC e PET/OM/CNC. Assim, possivelmente, houve um decréscimo da mobilidade dos segmentos das cadeias do PET, devido ao estabelecimento de fortes interações intermoleculares com grupos polares presentes na estrutura dos CNCs, como mencionado anteriormente. PET/CNC e $\mathrm{PET} / \mathrm{OM} / \mathrm{CNC}$ não apresentaram diferenças significativas em seus valores de $T_{9}\{109,6 \pm$ $0,5{ }^{\circ} \mathrm{C}$ e $108,0 \pm 0,5{ }^{\circ} \mathrm{C}$, respectivamente [Figura 65-[b]]\}. Destaca-se que não houve também uma diferença significativa nos valores de $\mathrm{T}_{9}$ de $\mathrm{PET}$ ref $\mathrm{P}$ PET/OM \{92,6 \pm 0,1 ${ }^{\circ} \mathrm{C}$ e 91,3 \pm 0,8 ${ }^{\circ} \mathrm{C}$, respectivamente [Figura 65-(b)]\}. Ainda, não foi observada qualquer variação ao se comparar o valor de $T_{9}$ de PET/CNC [109,6 \pm 0,5 C, Figura 65-(b)], contendo CNCs em uma concentração de 10\% em massa com relação à massa de PET, com os valores apresentados por PETC/48 h e PETC/72 h \{105,5 \pm 0,5 ${ }^{\circ} \mathrm{C}$ e 111,3 \pm $0,7{ }^{\circ} \mathrm{C}$, respectivamente [Figura 39-[b]]\}, preparados via eletrofiação de solução de PET reciclado e celulose [em uma concentração em massa de 8,7\% com relação à massa de PET] dissolvidos em TFA.

Com relação aos valores de E' dos mats preparados utilizando-se o coletor rotativo [Figura 65-[c]], os materiais caracterizados na direção preferencial de alinhamento das fibras apresentaram valores superiores de E' [a 30 'C], em comparação aos mats caracterizados na direção oposta. Este fato pode ser atribuído à existência de interações intermoleculares intensas entre as cadeias que constituem as fibras alinhadas, as quais proporcionam uma maior resistência à forças mecânicas, quando estas são aplicadas ao longo da direção de alinhamento das fibras. Ainda, quando uma força é aplicada na direção preferencial de alinhamento das fibras, estas necessitam apenas de uma rotação mínima para se alinharem com relação à direção da força aplicada. Consequentemente, uma elevada porcentagem de fibras rapidamente resiste à deformação mecânica, conferindo ao material uma elevada rigidez. Contrariamente, quando a força é aplicada na direção oposta ao alinhamento preferencial das fibras, faz-se necessária uma maior rotação e reorientação das mesmas para que possam se alinhar com o eixo da força aplicada, com consequente menor rigidez das mesmas (KUMAR; VASITA, 2017; MUBYANA et al., 2016].

PET-A dir apresentou o maior valor de E' [212,0 \pm 10,2 MPa, Figura 65-[c]] dentre os mats preparados com o uso do coletor rotativo. Esse valor também foi superior ao apresentado pelo mat de mesma composição, mas preparado com o uso do coletor estático $\left\{\right.$ PET $_{\text {ret, }} E^{\prime}=23,3 \pm 7,1 \mathrm{MPa}$ [Figura 65-[a]]\}. Não foi possível correlacionar os valores de E' [a 30 'C] dos materiais preparados com o uso do coletor rotativo [Figura 65[c]], com os valores de porosidade média apresentados pelos mesmos [Figura 59-[c]].

Observa-se na Figura 65-[d] que não houve diferença significativa nos valores de $T_{g}$ dos mats preparados com o uso do coletor rotativo, em função da direção das fibras. Assim, pode-se concluir que a caracterização dos mats, na direção preferencial de alinhamento das fibras e na direção oposta, não influenciou o valor dessa propriedade, que 
é consequência de movimentos de rotação de segmentos das cadeias de PET que constituem as regiões não cristalinas das fibras. Por outro lado, os valores de $T_{g}$ da Figura 65-[d] para os mats, contendo CNC ou CNC/OM em suas composições, foram inferiores aos apresentados pelos mats de mesma composição, mas preparados com a utilização do coletor estático [Figura 65-[b]]. Estes resultados indicam que os movimentos de rotação de segmentos das cadeias de PET, que constituem as regiões não cristalinas das fibras, foram facilitados quando os mats foram gerados no tambor rotativo, e na presença de CNC ou CNC/OM. Este resultado sugere que os segmentos de PET presentes nas regiões não cristalinas destes mats estão mais afastados, quando CNC ou CNC/OM estão presentes, facilitando o movimento de rotação em torno das ligações covalentes simples e, portanto, diminuindo o valor de $\mathrm{T}_{\mathrm{g}}$.

\subsubsection{Ensaio de resistência à tração}

A Figura 67 apresenta os resultados de resistência à ruptura dos mats preparados com a utilização do coletor estático, assim como dos mats preparados com a utilização do coletor rotativo. Novamente, destaca-se que os mats preparados com o uso do coletor rotativo foram caracterizados tanto na direção perpendicular ao eixo do coletor [direção preferencial de alinhamento das fibras], quanto na direção paralela ao eixo do mesmo [direção oposta ao alinhamento preferencial das fibras]. 
Figura 62 - Resistência à ruptura para os mats [a] Preparados com a utilização do coletor estático e [b] Preparados com a utilização do coletor rotativo. Estes materiais foram caracterizados tanto na direção preferencial de alinhamento das fibras [siglas contendo a terminação "dir" no final], quanto na direção oposta ao alinhamento preferencial das fibras (siglas contendo a terminação "op" no final). [a]



Fonte: Autoria própria.

[b]

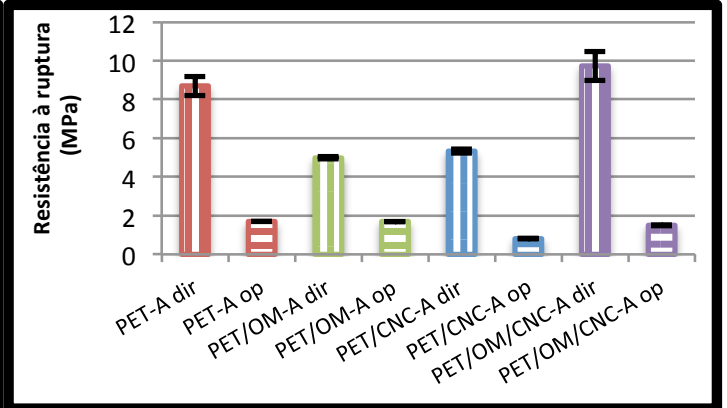

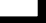

Pode-se observar na Figura 67-[a] que houve um aumento da resistência à ruptura com a adição dos CNCs à composição de PET/CNC e PET/OM/CNC. PET/CNC e PET/OM/CNC não apresentaram diferenças significativas nos valores de resistência à ruptura [4,6 \pm 0,5 MPa e 5,3 \pm 0,1 MPa, respectivamente]. Assim, pode-se concluir que os CNCs atuaram como agentes de reforço das fibras de PET levando ao estabelecimento de fortes interações intermoleculares entre estes polissacarídeos e as cadeias de PET [Figura 66]. Consequentemente, essas interações dificultaram a orientação das cadeias poliméricas com o eixo de tração, durante o estágio final da deformação, justificando os valores mais elevados de resistência à ruptura de PET/CNC e PET/OM/CNC [Figura 67[a]]. Destaca-se que para essa propriedade não foi possível observar uma influência significativa, tanto do OM como agente compatibilizante entre os CNCs e o PET reciclado, como da cristalinidade das amostras [Tabela 9].

Observa-se que o valor de resistência à ruptura de PET/CNC $[4,6 \pm$ 0,5 MPa, Figura 67-[a]], contendo CNCs em uma concentração de 10\% em massa com relação à massa de PET, foi inferior ao apresentado pelos mats PETC/48 h e PETC/72 h \{8,5 \pm 0,2 MPa e 9,5 \pm 0,6 MPa, respectivamente [Figura 40-[a]]\}, preparados via eletrofiação de solução de PET reciclado e celulose (em uma concentração em massa de 8,7\% com relação à massa de PET] dissolvidos em TFA. Essa tendência corrobora com o que foi observado ao compararmos o E' (a 30 'C] desses materiais [Figura 65-[a] e Figura 39[a]]. Assim, pode-se concluir que houve um reforço mais efetivo dos materiais nos quais as cadeias de celulose estavam dissolvidas na solução que gerou os mats, em comparação ao reforço proporcionado por esse polissacarídeo, em sua forma nanocristalina, suspenso na solução que gerou o mat PET/CNC.

Na Figura 67-[b] observa-se que os mats preparados com o uso do coletor rotativo apresentaram superiores valores de resistência à ruptura quando caracterizados na direção preferencial de alinhamento das fibras, em comparação aos materiais caracterizados na direção oposta. Assim, pode-se concluir que, como mencionado anteriormente, quando a força mecânica foi aplicada na direção preferencial de 
alinhamento das fibras uma elevada porcentagem de fibras rapidamente resistiu à deformação mecânica, conferindo ao material uma elevada resistência. Contrariamente, quando a força foi aplicada na direção oposta ao alinhamento preferencial das fibras, foi necessária uma maior rotação e reorientação das mesmas para se alinharem com o eixo da força aplicada, com consequente menor resistência mecânica do material.

De acordo com a Figura 67-(b), PET-A dir e PET/OM/CNC-A dir apresentaram os maiores [e semelhantes] valores de resistência à ruptura [8,7 \pm 0,5 $\mathrm{MPa}$ e 9,73 \pm 0,75 $\mathrm{MPa}$, respectivamente]. Destaca-se que os mats PET-A e PET/OM/CNC-A apresentaram os menores valores de porosidade média $\{17,4 \pm 0,3 \%$ e 13,7 $\pm 2,7 \%$, respectivamente [Figura 59-[c]]\}, em comparação ao apresentado pelos demais materiais preparados com o uso do coletor rotativo [Figura 59-[c]]. Ainda, os valores de resistência à ruptura de PETA dir e PET/OM/CNC-A dir [Figura 67-[b]] foram superiores aos apresentados por PET ref $_{\text {e }}$ $\mathrm{PET} / \mathrm{OM} / \mathrm{CNC}\{1,8 \pm 0,2 \mathrm{MPa}$ e 5,3 \pm 0,1 MPa, respectivamente [Figura 67-[a]]\}, os quais apresentam a mesma composição, no entanto, foram preparados com a utilização do coletor estático.

A Figura 68 apresenta os resultados do módulo de Young dos mats preparados com a utilização do coletor estático, assim como dos mats preparados com a utilização do coletor rotativo.

Figura 63 - Módulo de Young para os mats [a] Preparados com a utilização do coletor estático e [b] Preparados com a utilização do coletor rotativo. Estes materiais foram caracterizados tanto na direção preferencial de alinhamento das fibras (siglas contendo a terminação "dir" no final), quanto na direção oposta ao alinhamento preferencial das fibras (siglas contendo a terminação "op" no final).

[a]

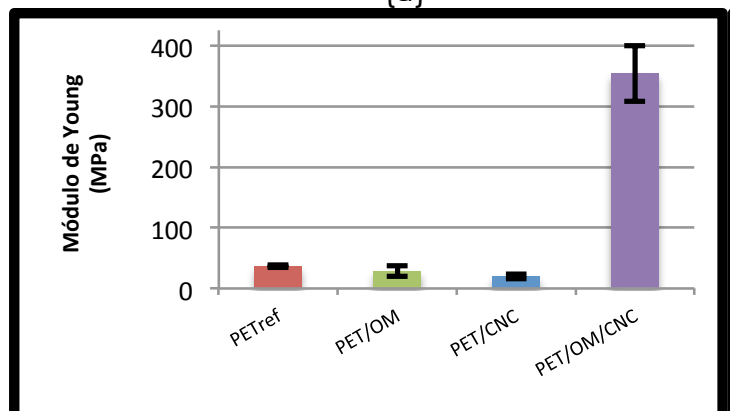

Fonte: Autoria própria. [b]



Observa-se na Figura 68-[a] a significativa influência do OM como agente compatibilizante entre o PET reciclado e os CNCs, levando, consequentemente, a um reforço mais efetivo do polímero reciclado pelos CNCs. Assim, PET/OM/CNC apresentou um valor de módulo de Young [354,2 \pm 46,1 MPa, Figura 68-[a]] muito superior aos valores apresentados pelos demais mats [Figura 68-[a]]. Este resultado corrobora o elevado valor de E' apresentado por esse mat [260,8 \pm 8,9 MPa, Figura 65-[a]], assim como o elevado valor de cristalinidade apresentado pelo mesmo $\left(l_{c}=69,8 \%\right.$, Tabela 9).

Foi observada a mesma tendência apresentada para as propriedades de E' la 30 ${ }^{\circ} \mathrm{C}$ ] e resistência à ruptura, ao compararmos os valores de módulo de Young de PET/CNC [contendo CNCs em uma concentração de 10\% em massa com relação à massa de PET], 
com os valores apresentados por PETC/48 h e PETC/72 h, preparados via eletrofiação de solução de PET reciclado e celulose (em uma concentração em massa de 8,7\% com relação à massa de PET] dissolvidos em TFA. Assim, PET/CNC apresentou inferior valor de módulo de Young [19,9 \pm 3,9 MPa, Figura 68-[a]], em comparação ao apresentado pelos mats PETC/48 h e PETC/72 h $\{168,0 \pm 60,6 \mathrm{MPa}$ e 360,4 \pm 41,5 MPa, respectivamente [Figura 40-[b]]\}. Este fato demonstra que houve, possivelmente, um reforço mais efetivo dos materiais nos quais as cadeias de celulose estavam dissolvidas na solução que gerou os mats, em comparação ao reforço proporcionado por esse polissacarídeo, em sua forma nanocristalina, suspenso na solução que gerou o mat $\mathrm{PET} / \mathrm{CNC}$.

Com relação aos valores do módulo de Young dos mats preparados com o uso do coletor rotativo [Figura 68-[b]], observa-se que houve um aumento desses valores para os mats caracterizados na direção preferencial de alinhamento das fibras, em oposição ao apresentado pelos mats caracterizados na direção oposta. Assim, novamente, pode-se concluir que, quando a força mecânica foi aplicada na direção preferencial de alinhamento das fibras uma elevada porcentagem de fibras rapidamente resistiu à deformação mecânica, conferindo aos materiais superiores valores de módulo de Young. Contrariamente, quando a força foi aplicada na direção oposta ao alinhamento preferencial das fibras, foi necessária uma maior rotação e reorientação das mesmas para se alinharem com o eixo da força aplicada, consequentemente, os materiais apresentaram menores valores de módulo de Young.

De acordo com a Figura 68-[b], PET-A dir apresentou o maior valor de módulo de Young $[203,2 \pm 3,7 \mathrm{MPa}]$, o que corrobora o superior valor de $\mathrm{E}^{\prime}[212,0 \pm 10,2 \mathrm{MPa}$, Figura 65-[c]] apresentado por esse mat, em comparação aos valores apresentados pelos demais materiais preparados com o uso do coletor rotativo [Figura 65-[c]]. Destacase que o valor do módulo de Young apresentado por PET-A dir foi superior ao apresentado pelo mat de mesma composição, mas preparado com o uso do coletor estático $\left\{P E T_{\text {ref, }}\right.$ 36,3 \pm 2,1 MPa [Figura 68-[a]]\}.

A Figura 69 apresenta os resultados do alongamento na ruptura dos mats preparados com a utilização do coletor estático, assim como dos mats preparados com a utilização do coletor rotativo. 
Figura 64 - Alongamento na ruptura para os mats [a] Preparados com a utilização do coletor estático e [b] Preparados com a utilização do coletor rotativo. Estes materiais foram caracterizados tanto na direção preferencial de alinhamento das fibras (siglas contendo a terminação "dir" no final], quanto na direção oposta ao alinhamento preferencial das fibras (siglas contendo a terminação "op" no final).

[a]

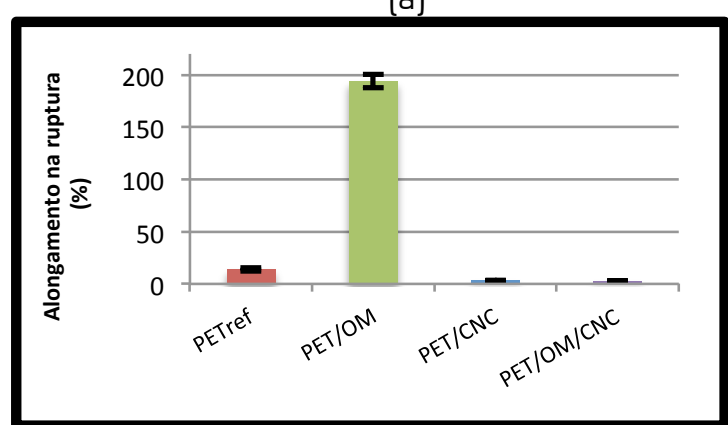

Fonte: Autoria própria. [b]

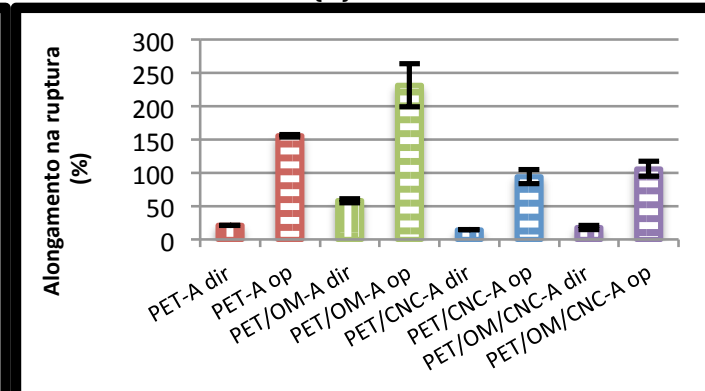

Pode-se observar na Figura 69-[a] que PET/OM apresentou superior valor de alongamento na ruptura [193,9 \pm 6,6\%], em comparação aos valores apresentados pelos demais mats preparados com o uso do coletor estático. PET/CNC e PET/OM/CNC, contendo CNCs em suas composições, apresentaram os menores valores de alongamento na ruptura $[3,1 \pm 0,1 \%$ e $2,6 \pm 0,2 \%$, respectivamente], o que corrobora a elevada rigidez apresentada por esses materiais \{superiores valores de E' [Figura 65-[a]] e módulo de Young [Figura 68-[a]]\}. Este fato também está de acordo com a elevada cristalinidade apresentada por PET/OM/CNC [ $\mathrm{I}_{c}=69,8 \%$, Tabela 9). Assim, possivelmente, a adição do OM à solução de PET/TFA levou a uma inserção de moléculas que constituem o óleo entre as cadeias do PET, o que favoreceu conformações mais estendidas dessas cadeias durante a deformação de tração. Consequentemente, houve um aumento do valor do alongamento na ruptura de PET/OM em comparação aos demais materiais.

Observa-se que o valor de alongamento na ruptura de PET/CNC [3,1 \pm 0,1\%, Figura 69-[a]], contendo CNCs em uma concentração de 10\% em massa com relação à massa de PET, foi inferior ao apresentado pelos mats PETC/48 h e PETC/72 h $\{40,9 \pm$ $15,1 \%$ e 25,9 $\pm 2,9 \%$, respectivamente [Figura 40-[c]]\}, preparados via eletrofiação de solução de PET reciclado e celulose (em uma concentração em massa de 8,7\% com relação à massa de PET] dissolvidos em TFA.

Na Figura 69-[b] observa-se que houve um aumento dos valores de alongamento na ruptura para os mats caracterizados na direção oposta ao alinhamento preferencial das fibras, em oposição ao observado para os mats caracterizados na direção contrária. Assim, provavelmente, quando a força mecânica foi aplicada na direção oposta ao alinhamento preferencial das fibras, foi necessária uma maior rotação e reorientação das mesmas para que pudessem se alinhar com o eixo da tensão aplicada. Consequentemente, houve um maior alongamento dos materiais, em comparação aos materiais em que a força mecânica foi aplicada na direção preferencial de alinhamento 
das fibras.

De acordo com a Figura 69-[b], PET/OM-A op apresentou o maior valor de alongamento na ruptura [231,7 $\pm 32,2 \%$, acompanhando a tendência observada para essa propriedade para o mat de mesma composição, mas preparado com o uso do coletor estático $\{\mathrm{PET} / \mathrm{OM}$, Alongamento na ruptura = 193,6 \pm 6,6\% [Figura 69-[a]]\}.

\subsection{Conclusões parciais}

Foram preparados com êxito mats compósitos constituídos por nanofibras/fibras ultrafinas orientadas aleatoriamente e em uma direção preferencial de alinhamento, via eletrofiação de soluções em TFA de PET reciclado, CNCs e OM.

Não foi observada qualquer influência da presença dos CNCs na composição dos mats, preparados com o uso do coletor rotativo, na orientação das fibras produzidas.

Os CNCs apresentaram uma ação efetiva como agentes de reforço das nanofibras/fibras ultrafinas de PET, com relação às superiores propriedades mecânicas apresentadas pelos materiais produzidos com o uso do coletor estático.

Destaca-se a ação significativa do OM, de origem natural e atóxico, como agente compatibilizante entre o PET reciclado e os CNCs. Esta ação foi observada principalmente com relação aos valores superiores de E' e módulo de Young [consequentemente maior rigidez] de PET/OM/CNC, em comparação aos valores apresentados pelos demais mats preparados utilizando-se o coletor estático.

Os materiais compósitos preparados, além de possuírem elevada área superficial e porosidade, assim como boas propriedades mecânicas, apresentam elevado potencial para serem utilizados em aplicações de alta performance, como em alguns sistemas de filtração, por exemplo. 


\section{Conclusões gerais}

O presente trabalho, como pretendido, levou ao preparo, de forma pioneira, até onde se tem conhecimento, de materiais, via técnica de eletrofiação, baseados em PET reciclado, fibra lignocelulósica de sisal e seus constituintes majoritários, celulose [também na forma nanocristalina] e lignina.

Também foram preparados com êxito, via eletrofiação, até onde se tem conhecimento, também pela primeira vez, compósitos baseados em PET reciclado e CNCs como agentes de reforço. No preparo desses materiais avaliou-se também o uso do OM, de origem renovável e biodegradável, como agente compatibilizante entre o polímero reciclado [de natureza predominantemente hidrofóbica] e os CNCs [os quais apresentam elevado caráter hidrofílico].

Destaca-se que, além da preparação de fibras ultrafinas e nanofibras orientadas aleatoriamente, foi possível também a preparação de materiais compostos por fibras alinhadas (com a utilização de um coletor de fibras de tambor metálico rotativo no processo de eletrofiação]. Assim, foi possivel avaliar a influência da orientação e grau de alinhamento das fibras nas propriedades finais dos materiais produzidos, principalmente com relação às propriedades mecânicas.

Com a eletrofiação de soluções mistas baseadas em PET reciclado e fibra lignocelulósica de sisal [nativa, sem qualquer pré-tratamento], os componentes macromoleculares da fibra lignocelulósica e as cadeias de PET, possivelmente, foram eletrofiados juntos, com a consequente produção de fibras híbridas, além daquelas geradas somente pelos componentes do sisal ou apenas pelas cadeias de PET. A eletrofiação separada do componente celulósico do sisal levou à obtenção de nanofibras com diâmetros muito reduzidos, muitas vezes inferiores a $50 \mathrm{~nm}$. Ainda, destacam-se as superiores propriedades mecânicas [principalmente com relação à rigidez dos materiais] apresentadas pelos mats de PET reciclado (compostos por fibras orientadas aleatoriamente e alinhadas], conforme aumentou-se o teor de sisal na composição dos mesmos.

O alinhamento das fibras, no geral, impactou as propriedades de todos os mats, comparativamente aqueles constituídos por fibras sem orientação preferencial. Quando os materiais foram caracterizados na direção preferencial de alinhamento das fibras, houve um significativo aumento, por exemplo, na rigidez dos mesmos, em comparação aos materiais de mesma composição caracterizados na direção oposta e, no geral, em comparação aos materiais compostos por fibras orientadas aleatoriamente (preparados com o uso do coletor estático]. 
Com a eletrofiação de soluções com diferentes razões de fibra de sisal/polímero reciclado, foi possivel controlar a molhabilidade dos materiais produzidos, de caráter predominantemente hidrofóbico até altamente hidrofílico (com o aumento da razão de sisal/PET reciclado na composição dos materiais].

No presente trabalho foi possivel avaliar e controlar as propriedades finais dos mats produzidos via eletrofiação de soluções baseadas em PET reciclado, com a adição conjunta e separada dos constituintes majoritários da fibra de sisal (celulose e lignina). Assim, observou-se a significativa contribuição da celulose nas propriedades finais dos materiais, principalmente nos superiores valores de $E^{\prime}, T_{g}$, resistência à ruptura e módulo de Young, assim como no aumento do caráter hidrofílico dos mesmos.

A presença de lignina na composição dos materiais apresentou significativa influência na morfologia achatada das fibras, no maior alongamento na ruptura e no aumento do caráter hidrofóbico dos materiais. Também foi possivel avaliar os diferentes tempos de dissolução [48 h e 72 h] no preparo das soluções a serem eletrofiadas de $\mathrm{PET} /$ celulose/lignina e o consequente impacto dessa variação nas propriedades finais dos materiais eletrofiados.

0 preparo com sucesso de mats compostos por fibras alinhadas e baseados em PET reciclado/celulose/lignina possibilitou, como pretendido, a avaliação da influência das diferentes condições/parâmetros de eletrofiação explorados na orientação e nas propriedades finais das fibras obtidas. Assim, observou-se, no geral, uma tendência de maior alinhamento das fibras conforme aumentou-se a velocidade de rotação do coletor, mantendo-se constantes os demais parâmetros de eletrofiação.

Como pretendido no presente trabalho, os CNCs atuaram efetivamente como agentes de reforço das nanofibras/fibras ultrafinas de PET reciclado, levando a superiores propriedades mecânicas desses materiais compósitos. Também foi possível avaliar a ação significativa do OM como agente compatibilizante entre o polímero reciclado e os CNCs, contribuindo para o aumento nos valores de E' e módulo de Young, por exemplo, dos materiais.

Assim, em linhas gerais, pode-se concluir que os objetivos traçados para o presente trabalho foram atingidos, visando a valorização da biomassa lignocelulósica de sisal e do PET reciclado, com a consequente valorização do seu processo de reciclagem. Os materiais preparados no presente estudo apresentam uma vasta gama de possíveis aplicações, nas quais fibras ultrafinas/nanofibras [alinhadas ou não alinhadas] de PET reciclado, preparadas à partir da biomassa lignocelulósica e seus principais constituintes, podem ser empregadas como membranas (de filtração do ar, por exemplo], filmes [como os estruturados em camadas do tipo "sanduíche"], como substituintes de matrizes extracelulares em áreas como a engenharia de tecidos e como agentes de reforço em nano compósitos. 


\section{Sugestões para trabalhos futuros}

- A partir dos resultados do presente estudo poderiam ser produzidos mats baseados em PET reciclado visando-se explorar os efeitos nas propriedades finais desses materiais de outras concentrações tanto de celulose, quanto de lignina;

- Novas investigações poderiam ser realizadas buscando-se avaliar a influência no grau de alinhamento das fibras [I.A.] de outros parâmetros de eletrofiação, com relação a taxa de vazão da solução, distância ponta da agulha-coletor e velocidade de rotação do coletor de tambor metálico rotativo. Esta etapa poderia ser realizada tanto para o conjunto de materiais baseados em PET reciclado/fibra lignocelulósica de sisal, quanto para os baseados no polímero reciclado contendo celulose e/ou lignina e OM e/ou CNCs;

- Poderiam ser exploradas novas concentrações de CNCs/OM na preparação dos mats e a influência das mesmas nas propriedades finais dos materiais. 


\section{Referências Bibliográficas}

AGARWAL, S. R.; SUNDARRAJAN, S.; RAMAKRISHNA, S. Functionalized Cellulose: PET Polymer Fibers with Zeolites for Detoxification Against Nerve Agents. Journal of Inorganic Materials, v. 27, n. 3, p. 332-336, 2012.

AHN, Y.; KANG, Y.; PARK, B.; KU, M. K.; LEE, S. H.; KIM, H. Influence of lignin on rheological behaviors and electrospinning of polysaccharide solution. Journal of Applied Polymer Science, v. 131, n. 7, p. 1-7, 2014.

AHN, Y.; LEE, S. H.; KIM, H. J.; YANG, Y.-H.; HONG, J. H.; KIM, Y.-H.; KIM, H. Electrospinning of lignocellulosic biomass using ionic liquid. Carbohydrate Polymers, v. 88, n. 1, p. 395-398, 2012.

ARRIETA, M. P.; LÓPEZ, J.; LÓPEZ, D.; KENNY, J. M.; PEPONI, L. Biodegradable electrospun bionanocomposite fibers based on plasticized PLA???PHB blends reinforced with cellulose nanocrystals. Industrial Crops and Products, v. 93, p. 290-301, 2016.

AZIZI SAMIR, M. A. S.; ALLOIN, F.; DUFRESNE, A. Review of Recent Research into Cellulosic Whiskers, Their Properties and Their Application in Nanocomposite Field.

Biomacromolecules, v. 6, n. 2, p. 612-626, 2005.

BAE, J.; BAEK, I.; CHOI, H. Mechanically enhanced PES electrospun nanofiber membranes [ENMs] for microfiltration: The effects of ENM properties on membrane performance.

Water Research, v. 105, p. 406-412, 2016.

BAJI, A.; MAI, Y. W.; WONG, S. C.; ABTAHI, M.; CHEN, P. Electrospinning of polymer nanofibers: Effects on oriented morphology, structures and tensile properties. Composites Science and Technology, v. 70, n. 5, p. 703-718, 2010.

BARONCINI, E. A.; KUMAR YADAV, S.; PALMESE, G. R.; STANZIONE, J. F. Recent advances in bio-based epoxy resins and bio-based epoxy curing agents. Journal of Applied Polymer Science, v. 133, n. 45, p. 1-19, 2016.

BILLMEYER JR., F. W. Ciencia de los polimeros. [s.l.] Editorial Reverte, 1995.

BÖRJESSON, M.; WESTMAN, G. Branching of hemicelluloses through an azetidinium salt ring-opening reaction. Carbohydrate Research, v. 428, p. 23-30, 2016.

BOUAZIZ, F.; KOUBAA, M.; BEN JEDDOU, K.; KALLEL, F.; BOISSET HELBERT, C.; KHELFA, A.; ELLOUZ GHORBEL, R.; ELLOUZ CHAABOUNI, S. Water-soluble polysaccharides and hemicelluloses from almond gum: Functional and prebiotic properties. International Journal of Biological Macromolecules, v. 93, p. 359-368, 2016.

CAI, J.; CHEN, J.; ZHANG, Q.; LEI, M.; HE, J.; XIAO, A.; MA, C.; LI, S.; XIONG, H. Well-aligned cellulose nanofiber-reinforced polyvinyl alcohol composite film: Mechanical and optical properties. Carbohydrate Polymers, v. 140, p. 238-245, 2016.

CASSU, S. N.; FELISBERTI, M.I. Dynamic mechanical behavior and rexations in polymers and polymeric blends. Química Nova, v. 28, n. 2, p. 255-263, 2005.

CASTRO, D. O.; PASSADOR, F.; RUVOLO-FILHO, A.; FROLLINI, E. Use of castor and canola oils in "biopolyethylene" curauá fiber composites. Composites Part A: Applied Science and 
Manufacturing, v. 95, p. 22-30, 2017.

CHANG, C. H.; HUANG, W. Y.; LAI, C. H. HSU, Y. M.; YAO, Y. H.; CHEN, T. Y.; WU, J. Y.; PENG, S. F.; LIN, Y. H. Development of novel nanoparticles shelled with heparin for berberine delivery to treat Helicobacter pylori. Acta Biomaterialia, v. 7, n. 2, p. 593-603, 2011.

CHEN, R. S.; AHMAD, S.; GAN, S.; SALLEH, M. N.; AB GHANI, M. H.; TARAWNEH, M. A. Effect of polymer blend matrix compatibility and fibre reinforcement content on thermal stability and flammability of ecocomposites made from waste materials. Thermochimica Acta, v. 640, p. 52-61, 2016.

CHENG, J.; JUN, Y.; QIN, J.; LEE, S. H. Electrospinning versus microfluidic spinning of functional fibers for biomedical applications. Biomaterials, v. 114, p. 121-143, 2017.

CISNEROS-LÓPEZ, E. O.; GONZÁLEZ-LÓPEZ, M. E.; PÉREZ-FONSECA, A. A.; GONZÁLEZNÚÑEZ, R.; RODRIGUE, D.; ROBLEDO-ORTIZZ, J. R. Effect of fiber content and surface treatment on the mechanical properties of natural fiber composites produced by rotomolding. Composite Interfaces, v. 24, n. 1, p. 35-53, 2017.

COSTA, R. G. F.; OLIVEIRA, J. E. DE; PAULA, G. F. DE; MEDEIROS, E. S. DE; RIBEIRO, C.; MATTOSO, L. H. C.; PICCIANI, P. H. DE S. Eletrofiação de Polímeros em Solução. Parte I: Fundamentação Teórica. Polímeros, v. 22, p. 170́-177, 2012.

DA SILVA, C. G.; GRELIER, S.; PICHAVANT, F.; FROLLINI, E.; CASTELLAN, A. Adding value to lignins isolated from sugarcane bagasse and Miscanthus. Industrial Crops and Products, v. 42, n. 1, p. 87-95, 2013.

DE OLIVEIRA, F.; DA SILVA, C. G.; RAMOS, L. A.; FROLLINI, E. Phenolic and lignosulfonatebased matrices reinforced with untreated and lignosulfonate-treated sisal fibers. Industrial Crops and Products, v. 96, p. 30-41, 2017.

DE OLIVEIRA SANTOS, R. P.; CASTRO, D. O.; RUVOLO-FILHO, A. C.; FROLLINI, E. Processing and thermal properties of composites based on recycled PET, sisal fibers, and renewable plasticizers. Journal of Applied Polymer Science, v. 131, n. 12, p. 1-13, 2014.

DEITZEL, J. .; KLEINMEYER, J.; HARRIS, D.; BECK TAN, N. . The effect of processing variables on the morphology of electrospun nanofibers and textiles. Polymer, v. 42, n. 1, p. 261-272, 2001.

DEL MAR CASTRO LÓPEZ, M.; ARES PERNAS, A. I.; ABAD LÓPEZ, M. J.; LATORRE, A. L.; LÓPEZ VILARIÑO, J. M.; GONZÁLEZ RODRÍGUEZ, M. V. Assessing changes on poly[ethylene terephthalate] properties after recycling: Mechanical recycling in laboratory versus postconsumer recycled material. Materials Chemistry and Physics, v. 147, n. 3, p. 884894, 2014.

DEMIR, M. M.; YILGOR, I.; YILGOR, E.; ERMAN, B. Electrospinning of polyurethane fi bers. Polymer, v. 43, n. 11, p. 3303-3309, 2002.

DIAS, J. C.; RIBEIRO, C.; SENCADAS, V.; BOTELHO, G.; RIBELLES, J. L. G.; LANCEROSMENDEZ, S. Influence of fiber diameter and crystallinity on the stability of electrospun poly[1lactic acid] membranes to hydrolytic degradation. Polymer Testing, v. 31, n. 6, p. 770776, 2012 .

DIMITROV, N.; KRATOFIL KREHULA, L.; PTIČEK SIROČIĆ, A.; HRNJAK-MURGIĆ, Z. Analysis of recycled PET bottles products by pyrolysis-gas chromatography. Polymer Degradation and Stability, v. 98, n. 5, p. 972-979, 2013.

DONG, B.; JIANG, H.; MANOLACHE, S.; WONG, A. C. L.; DENES, F. S. Plasma-Mediated 
Grafting of Poly[ethylene glycol] on Polyamide and Polyester Surfaces and Evaluation of Antifouling Ability of Modified Substrates. Langmuir, v. 23, n. 13, p. 7306-7313, 2007.

DONG, D.; SUN, J.; HUANG, F.; GAO, Q.; WANG, Y.; LI, R. Using trifluoroacetic acid to pretreat lignocellulosic biomass. Biomass and Bioenergy, v. 33, n. 12, p. 1719-1723, 2009.

DOUSTGANI, A. Effect of electrospinning process parameters of polycaprolactone and nanohydroxyapatite nanocomposite nanofibers. Textile Research Journal, v. 85, n. 14, p. 1445-1454, 2015.

EBRINGEROVÁ, A.; HEINZE, T. Xylan and xylan derivatives - biopolymers with valuable properties, 1. Naturally occurring xylans structures, isolation procedures and properties. Macromolecular Rapid Communications, v. 21, n. 9, p. 542-556, 2000.

EICHHORN, S. J. Cellulose nanowhiskers: promising materials for advanced applications.

Soft Matter, v. 7, n. 2, p. 303-315, 2011.

ELAZZOUZI-HAFRAOUI, S.; NISHIYAMA, Y.; PUTAUX, J.-L.; HEUX, L.; DUBREUIL, F.; ROCHAS, C. The Shape and Size Distribution of Crystalline Nanoparticles Prepared by Acid Hydrolysis of Native Cellulose. Biomacromolecules, v. 9, n. 1, p. 57-65, 2008.

EZATPOUR, H. R.; SAJJADI, S. A.; SABZEVAR, M. H.; HUANG, Y. Investigation of microstructure and mechanical properties of Al6061-nanocomposite fabricated by stir casting. Materials and Design, v. 55, p. 921-928, 2014.

FANG, X.; RENEKER, D. H. DNA fibers by electrospinning. Journal of Macromolecular Science, Part B, v. 36, n. 2, p. 169-173, 1997.

FANTA, G. F.; ABBOTT, T. P.; HERMAN, A. I.; BURR, R. C.; DOANE, W. M. Hydrolysis of wheat straw hemicellulose with trifluoroacetic acid. Fermentation of xylose withPachysolen tannophilus. Biotechnology and Bioengineering, v. 26, n. 9, p. 1122-1125, 1984.

FEOFILOVA, E. P.; MYSYAKINA, I. S. Lignin: Chemical structure, biodegradation, and practical application [a review]. Applied Biochemistry and Microbiology, v. 52, n. 6, p. 573-581, 2016.

FONG, H.; CHUN, l.; RENEKER, D. H. Beaded nanofibers formed during electrospinning. Polymer, v. 40, p. 4585-4592, 1999.

GABRIEL, L. P.; RODRIGUES, A. A.; MACEDO, M.; JARDINI, A. L.; MACIEL FILHO, R. Electrospun polyurethane membranes for Tissue Engineering applications. Materials Science and Engineering C, v. 72, p. 113-117, 2017.

GOMES, D. S.; SILVA, A. N. R. S.; MORIMOTO, N. I.; MENDES, L. T. F.; FURLAN, R.; RAMOS, I. Characterization of an Electrospinning Process Using Different PAN/DMF Concentrations. Polímeros: Ciência e Tecnologia, v. 17, n. 3, p. 206-211, 2007.

GREINER, A.; WENDORFF, J. H. Electrospinning: A Fascinating Method for the Preparation of Ultrathin Fibers. Angewandte Chemie International Edition, v. 46, n. 30, p. 56705703, 2007.

HÄRDELIN, L.; THUNBERG, J.; PERZON, E.; WESTMAN, G.; WALKENSTRÖM, P.; GATENHOLM, P. Electrospinning of cellulose nanofibers from ionic liquids: The effect of different cosolvents. Journal of Applied Polymer Science, v. 125, n. 3, p. 1901-1909, 2012. 
HASEGAWA, M.; ISOGAI, A.; ONABE, F.; USUDA, M. Dissolving states of cellulose and chitosan in trifluoroacetic acid. Journal of Applied Polymer Science, v. 45, n. 10, p. 1857 1863, 1992.

HE, X.; XIAO, Q.; LU, C.; WANG, Y.; ZHANG, X.; ZHAO, J.; ZHANG, W.; ZHANG, X.; DENG, Y. Uniaxially Aligned Electrospun All-Cellulose Nanocomposite Nanofibers Reinforced with Cellulose Nanocrystals: Scaffold for Tissue Engineering. Biomacromolecules, v. 15, n. 2, p. 618-627, 2014.

HOU, L.; UDANGAWA, W. M. R. N.; POCHIRAJU, A.; DONG, W.; ZHENG, Y.; LINHARDT, R. J.; SIMMONS, T. J. Synthesis of Heparin-Immobilized, Magnetically Addressable Cellulose Nanofibers for Biomedical Applications. ACS Biomaterials Science and Engineering, v. 2, n. 11, p. 1905-1913, 2016.

HUANG, Z. M.; ZHANG, Y. Z.; KOTAKI, M.; RAMAKRISHNA, S. A review on polymer nanofibers by electrospinning and their applications in nanocomposites. Composites Science and Technology, v. 63, p. 2223-2253, 2003.

ISOLDI, A. B. G. Estudo do efeito da dose de radioesterilização sobre as propriedades do polítereftalato de etileno] - pet reciclado. 2003. 72 f. Dissertação [Mestrado em ciências] - Instituto de Pesquisas Energéticas e Nucleares, Universidade de São Paulo, São Paulo, 2003.

JAEGER, R.; SCHÖNHERR, H.; VANCSO, G. J. Chain Packing in Electro-Spun Poly[ethylene oxide] Visualized by Atomic Force Microscopy. Macromolecules, v. 29, n. 23, p. 76347636, 1996.

JAHANBAANI, A. R.; BEHZAD, T.; BORHANI, S.; DARVANJOOGHI, M. H. K. Electrospinning of cellulose nanofibers mat for laminated epoxy composite production. Fibers and Polymers, v. 17, n. 9, p. 1438-1448, 2016.

JENEKHE, S. A.; LIN, J. W.; SUN, B. Kinetics of the thermal degradation of polyethylene terephthalate. Thermochimica Acta, v. 61, n. 3, p. 287-299, mar. 1983.

JOSHI, M. K.; TIWARI, A. P.; PANT, H. R.; SHRESTHA, B. K.; KIM, H. J.; PARK, C. H.; KIM, C. S. In Situ Generation of Cellulose Nanocrystals in Polycaprolactone Nanofibers: Effects on Crystallinity, Mechanical Strength, Biocompatibility, and Biomimetic Mineralization. ACS Applied Materials \& Interfaces, v. 7, n. 35, p. 19672-19683, 2015.

JUNG, K.-H.; HUH, M.-W.; MENG, W.; YUAN, J.; HYUN, S. H.; BAE, J.-S.; HUDSON, S. M.; KANG, I.-K. Preparation and antibacterial activity of PET/chitosan nanofibrous mats using an electrospinning technique. Journal of Applied Polymer Science, v. 105, n. 5, p. 28162823, 2007.

JUNOH, H.; JAAFAR, J.; NOORUL, M.; MOHD, A.; ISMAIL, A. F.; HAFIZ, M.; OTHMAN, D.; RAHMAN, M. A.; YUSOF, N.; NORHAYATI, W.; SALLEH, W.; ILBEYGI, H. A Review on the Fabrication of Electrospun Polymer Electrolyte Membrane for Direct Methanol Fuel Cell. Journal of Nanomaterials, v. 2015, p. 1-16, 2014.

KAMPEERAPAPPUN, P. The electrospun polyhydroxybutyrate fibers reinforced with cellulose nanocrystals: Morphology and properties. Journal of Applied Polymer Science, v. 133, n. 20, p. 1-7, 2016.

KANG, Y.; AHN, Y.; LEE, S. H.; HONG, J. H.; KU, M. K.; KIM, H. Lignocellulosic nanofiber prepared by alkali treatment and electrospinning using ionic liquid. Fibers and Polymers, $v$. 14, n. 4, p. 530-536, 2013.

KATTA, P.; ALESSANDRO, M.; RAMSIER, R. D.; CHASE, G. G. Continuous Electrospinning of 
Aligned Polymer Nanofibers onto a Wire Drum Collector. Nano Letters, v. 4, n. 11, p. 2215-2218, 2004.

KAYACI, F.; AYTAC, Z.; UYAR, T. Surface modification of electrospun polyester nanofibers with cyclodextrin polymer for the removal of phenanthrene from aqueous solution. Journal of Hazardous Materials, v. 261, p. 286-294, 2013.

KE, H. Preparation of electrospun LA-PA/PET/Ag form-stable phase change composite fibers with improved thermal energy storage and retrieval rates via electrospinning and followed by UV irradiation photoreduction method. Fibers and Polymers, v. 17, n. 8, p. 1198-1205, 2016.

KHEZLI, S.; ZANDI, M.; BARZIN, J. Fabrication of electrospun nanocomposite polyethersulfone membrane for microfiltration. Polymer Bulletin, v. 73, n. 8, p. 22652286, 2016.

KHOONKARI, M.; HAGHIGHI, A. H.; SEFIDBAKHT, Y.; SHEKOOHI, K.; GHADERIAN, A. Chemical Recycling of PET Wastes with Different Catalysts. International Journal of Polymer Science, v. 2015, p. 1-11, 2015.

KIM, C. W.; KIM, D. S.; KANG, S. Y.; MARQUEZ, M.; JOO, Y. L. Structural studies of electrospun cellulose nanofibers. Polymer, v. 47, n. 14, p. 5097-5107, 2006.

KIM, J.-H.; SHIM, B. S.; KIM, H. S.; LEE, Y.-J.; MIN, S.-K.; JANG, D.; ABAS, Z.; KIM, J. Review of nanocellulose for sustainable future materials. International Journal of Precision

Engineering and Manufacturing-Green Technology, v. 2, n. 2, p. 197-213, 2015.

KONWARH, R.; KARAK, N.; MISRA, M. Electrospun cellulose acetate nanofibers: The present status and gamut of biotechnological applications. Biotechnology Advances, v. 31, n. 4, p. 421-437, 2013.

KOOMBHONGSE, S.; LIU, W.; RENEKER, D. H. Flat Polymer Ribbons and Other Shapes by Electrospinning. Journal of Polymer Science: Part B: Polymer Physics, v. 39, p. 25982606, 2001.

KUMAR, P.; VASITA, R. Understanding the relation between structural and mechanical properties of electrospun fiber mesh through uniaxial tensile testing. Journal of Applied Polymer Science, v. 134, n. 26, p. 1-11, 2017.

KUPPAN, P.; SETHURAMAN, S.; KRISHNAN, U. M. Interaction of human smooth muscle cells with nanofibrous scaffolds: Effect of fiber orientation on cell adhesion, proliferation, and functional gene expression. Journal of Biomedical Materials Research - Part A, v. 103, n. 7, p. 2236-2250, 2015.

LAVIELLE, N.; HÉBRAUD, A.; SCHLATTER, G.; THÖNY-MEYER, L.; ROSSI, R. M.; POPA, A.-M. Simultaneous Electrospinning and Electrospraying: A Straightforward Approach for Fabricating Hierarchically Structured Composite Membranes. ACS Applied Materials \& Interfaces, v. 5, n. 20, p. 10090-10097, 2013.

LEE, E. R.; CHO, J. W. Near infrared laser-heated electrospinning and mechanical properties of poly[ethylene terephthalate]/multi-walled carbon nanotube nanofibers. RSC Adv., v. 5, n. 96, p. 78476-78482, 2015.

LEE, J. S.; CHOI, K. H.; GHIM, H. DO; KIM, S. S.; CHUN, D. H.; KIM, H. Y.; LYOO, W. S. Role of molecular weight of atactic poly[vinyl alcohol] [PVA] in the structure and properties of PVA nanofabric prepared by electrospinning. Journal of Applied Polymer Science, v. 93, n. 4, p. 1638-1646, 2004. 
LI, D.; XIA, Y. Electrospinning of Nanofibers: Reinventing the Wheel? Advanced Materials, v. 16, n. 14, p. $1151-1170,2004$.

LI, G.; ZHAO, Y.; LV, M.; SHI, Y.; CAO, D. Super hydrophilic poly[ethylene terephthalate] [PET]/poly[vinyl alcohol] [PVA] composite fibrous mats with improved mechanical properties prepared via electrospinning process. Colloids and Surfaces A:

Physicochemical and Engineering Aspects, v. 436, p. 417-424, 2013.

LI, X.; DING, B.; LIN, J.; YU, J.; SUN, G. Enhanced Mechanical Properties of Superhydrophobic Microfibrous Polystyrene Mats via Polyamide 6 Nanofibers. The Journal of Physical Chemistry C, v. 113, n. 47, p. 20452-20457, 2009.

LI, Z:; WANG, C. Effects of Working Parameters on Electrospinning. In: One-Dimensional Nanostructures Electrospinning Technique and Unique Nanofibers. SpringerBriefs in Materials. Berlin, Heidelberg: Springer Berlin Heidelberg, 2013. p. 141.

LIU, Y.; ZHOU, J.; FU, W.; ZHANG, P.; PAN, X.; XIE, E. In situ synthesis of CoSx@carbon coreshell nanospheres decorated in carbon nanofibers for capacitor electrodes with superior rate and cycling performances. Carbon, v. 114, p. 187-197, 2017.

MA, Z.; KOTAKI, M.; YONG, T.; HE, W.; RAMAKRISHNA, S. Surface engineering of electrospun polyethylene terephthalate [PET] nanofibers towards development of a new material for blood vessel engineering. Biomaterials, v. 26, n. 15, p. 2527-2536, 2005.

MARIANO, M.; CERCENÁ, R.; SOLDI, V. Thermal characterization of cellulose nanocrystals isolated from sisal fibers using acid hydrolysis. Industrial Crops \& Products, v. 94, p. 454462, 2016.

MAZINANI, S.; AJJI, A.; DUBOIS, C. Fundamental study of crystallization, orientation, and electrical conductivity of electrospun PET/carbon nanotube nanofibers. Journal of Polymer Science, Part B: Polymer Physics, v. 48, n. 19, p. 2052-2064, 2010.

MEDEIROS, E. S.; MATTOSO, L. H. C.; ITO, E. N.; GREGORSKI, K. S.; ROBERTSON, G. H.; OFFEMAN, R. D.; WOOD, D. F.; ORTS, W. J.; IMAM, S. H. Electrospun Nanofibers of Poly[vinyl alcohol] Reinforced with Cellulose Nanofibrils. Journal of Biobased Materials and Bioenergy, v. 2, n. 3, p. 231-242, 2008.

MIT-UPPATHAM, C.; NITHITANAKUL, M.; SUPAPHOL, P. Ultrafine Electrospun Polyamide-6 Fibers: Effect of Solution Conditions on Morphology and Average Fiber Diameter.

Macromolecular Chemistry and Physics, v. 205, n. 17, p. 2327-2338, 2004.

MONTAÑO-LEYVA, B.; RODRIGUEZ-FELIX, F.; TORRES-CHÁVEZ, P.; RAMIREZ-WONG, B.; LÓPEZ-CERVANTES, J.; SANCHEZ-MACHADO, D. Preparation and Characterization of Durum Wheat [Triticum durum] Straw Cellulose Nanofibers by Electrospinning. Journal of Agricultural and Food Chemistry, v. 59, n. 3, p. 870-875, 2011.

MOON, R. J.; MARTINI, A.; NAIRN, J.; SIMONSEN, J.; YOUNGBLOOD, J. Cellulose nanomaterials review: structure, properties and nanocomposites. Chemical Society Reviews, v. 40, n. 7, p. 3941, 2011.

MORRIS, G. E.; BRIDGE, J. C.; ELTBOLI, O. M. I.; LEWIS, M. P.; KNOX, A. J.; AYLOTT, J. W.; BRIGHTLING, C. E.; GHAEMMAGHAMI, A. M.; ROSE, F. R. A. J. Human airway smooth muscle maintain in situ cell orientation and phenotype when cultured on aligned electrospun scaffolds. American Journal of Physiology - Lung Cellular and Molecular Physiology, v. 307, n. 1, p. L38-L47, 2014.

MORRISON, I. M.; STEWART, D. Plant cell wall fragments released on solubilisation in 
trifluoroacetic acid. Phytochemistry, v. 49, n. 6, p. 1555-1563, 1998.

MUBYANA, K.; KOPPES, R. A.; LEE, K. L.; COOPER, J. A.; CORR, D. T. The influence of specimen thickness and alignment on the material and failure properties of electrospun polycaprolactone nanofiber mats. Journal of Biomedical Materials Research - Part A, v. 104, n. 11, p. 2794-2800, 2016.

NASOURI, K.; SHOUSHTARI, A. M.; MOJTAHEDI, M. R. M. Effects of polymer/solvent systems on electrospun polyvinylpyrrolidone nanofiber morphology and diameter. Polymer Science Series A, v. 57, n. 6, p. 747-755, 2015.

NGADIMAN, N. H. A.; NOORDIN, M. Y.; IDRIS, A.; KURNIAWAN, D. Effect of Electrospinning Parameters Setting towards Fiber Diameter. Advanced Materials Research, v. 845, p. 985-988, 2013.

NIMZ, H. Beech Lignin-Proposal of a Constitutional Scheme. Angewandte Chemie International Edition in English, v. 13, n. 5, p. 313-321, 1974.

OLIVEIRA DE CASTRO, D.; FROLLINI, E.; RUVOLO-FILHO, A.; DUFRESNE, A. “Green polyethylene" and Curauá Cellulose nanocrystal based nanocomposites: Effect of vegetable oils as coupling agent and processing technique. Journal of Polymer Science, Part B:

Polymer Physics, p. 1010-1019, 2015.

PEDDIREDDY, K. R.; CAPRON, I.; NICOLAI, T.; BENYAHIA, L. Gelation Kinetics and Network Structure of Cellulose Nanocrystals in Aqueous Solution. Biomacromolecules, v. 17, n. 10, p. 3298-3304, 2016.

PELIPENKO, J.; KRISTL, J.; JANKOVIĆ, B.; BAUMGARTNER, S.; KOCBEK, P. The impact of relative humidity during electrospinning on the morphology and mechanical properties of nanofibers. International Journal of Pharmaceutics, v. 456, p. 125-134, 2013.

PENG, S.; LI, L.; KONG YOONG LEE, J.; TIAN, L.; SRINIVASAN, M.; ADAMS, S.; RAMAKRISHNA, S. Electrospun carbon nanofibers and their hybrid composites as advanced materials for energy conversion and storage. Nano Energy, v. 22, p. 361-395, 2016.

PENG, Y.; LIU, R.; CAO, J. Characterization of surface chemistry and crystallization behavior of polypropylene composites reinforced with wood flour, cellulose, and lignin during accelerated weathering. Applied Surface Science, v. 332, p. 253-259, 2015.

PERESIN, M. S.; VESTERINEN, A. H.; HABIBI, Y.; JOHANSSON, L. S.; PAWLAK, J. J.; NEVZOROV, A. A.; ROJAS, O. J. Crosslinked PVA nanofibers reinforced with cellulose nanocrystals: Water interactions and thermomechanical properties. Journal of Applied Polymer Science, v. 131, n. 11, p. 1-12, 2014.

PUTTI, M.; SIMONET, M.; SOLBERG, R.; PETERS, G. W. M. Electrospinning poly[عcaprolactone] under controlled environmental conditions: Influence on fiber morphology and orientation. Polymer [United Kingdom), v. 63, p. 189-195, 2015.

REDDY, N.; YANG, Y. Biofibers from agricultural byproducts for industrial applications. Trends in Biotechnology, v. 23, n. 1, p. 22-27, 2005.

RENEKER, D. H.; CHUN, I. Nanometre diameter fibres of polymer, produced by electrospinning. Nanotechnology, v. 7, n. 3, p. 216-223, 1996.

RENEKER, D. H.; YARIN, A. L. Electrospinning jets and polymer nanofibers. Polymer, v. 49, n. 10, p. 2387-2425, 2008. 
RIVERO, P. J.; URRUTIA, A.; GOICOECHEA, J.; ARREGUI, F. J. Nanomaterials for Functional Textiles and Fibers. Nanoscale Research Letters, v. 10, n. 1, p. 501,. 2015.

RODRIGUES, B. V. M. Valorização de fibras de sisal: síntese de ésteres de celulose e preparação de materiais. 2014. 260 f. Tese[Doutorado em ciências] - Instituto de Química de São Carlos, Universidade de São Paulo, São Carlos, 2014.

RODRIGUES, B. V. M.; RAMIRES, E. C.; SANTOS, R. P. O.; FROLLINI, E. Ultrathin and nanofibers via room temperature electrospinning from trifluoroacetic acid solutions of untreated lignocellulosic sisal fiber or sisal pulp. Journal of Applied Polymer Science, v. 132, n. 16, p. 1-8, 2015.

RODRIGUES, B. V. M.; SILVA, A. S.; MELO, G. F. S.; VASCONSCELLOS, L. M. R.; MARCIANO, F. R.; LOBO, A. O. Influence of low contents of superhydrophilic MWCNT on the properties and cell viability of electrospun poly [butylene adipate-co-terephthalate] fibers. Materials Science and Engineering C, v. 59, p. 782-791, 2016.

ROJAS, O. J.; MONTERO, G. A.; HABIBI, Y. Electrospun nanocomposites from polystyrene loaded with cellulose nanowhiskers. Journal of Applied Polymer Science, v. 113, n. 2, p. 927-935, 2009 .

SANTAMARIA-ECHART, A.; UGARTE, L.; GONZALEZ, K.; MARTIN, L.; IRUSTA, L.; GONZALEZ, A.; CORCUERA, M. A.; ECEIZA, A. The role of cellulose nanocrystals incorporation route in waterborne polyurethane for preparation of electrospun nanocomposites mats.

Carbohydrate Polymers, v. 166, p. 146-155, 2017.

SANTOS, R. P. DE O. Compósitos baseados em PET reciclado, fibras de sisal e plasticizantes oriundos de fontes renováveis: estudo do processamento e propriedades destes materiais. 2012. 157 f. Dissertação [Mestrado em ciências] - Escola de Engenharia de São Carlos, Universidade de São Paulo, São Carlos, 2012.

SANTOS, R. P. O.; RODRIGUES, B. V. M.; RAMIRES, E. C.; RUVOLO-FILHO, A. C.; FROLLINI, E. Bio-based materials from the electrospinning of lignocellulosic sisal fibers and recycled PET. Industrial Crops and Products, v. 72, p. 69-76, 2015.

SCHMETZ, Q.; MANIET, G.; JACQUET, N.; TERAMURA, H.; OGINO, C.; KONDO, A.; RICHEL, A. Comprehension of an organosolv process for lignin extraction on Festuca arundinacea and monitoring of the cellulose degradation. Industrial Crops and Products, v. 94, p. 308317, 2016.

SEN, S.; PATIL, S.; ARGYROPOULOS, D. S. Thermal properties of lignin in copolymers, blends, and composites: a review. Green Chem., v. 17, n. 11, p. 4862-4887, 2015.

SHI, H. H.; NAGUIB, H. E. Highly flexible binder-free core-shell nanofibrous electrode for lightweight electrochemical energy storage using recycled water bottles. Nanotechnology, v. 27, n. 32, p. 325402, 2016.

SILVERSTEIN, R. M.; BASSLER, G. C.; MORRIL, T. C. Identificação espectrométrica de compostos orgânicos. 5th. ed. Rio de Janeiro: LTC, 1994.

SINGH, S. K.; DHEPE, P. L. Isolation of lignin by organosolv process from different varieties of rice husk: Understanding their physical and chemical properties. Bioresource Technology, v. 221, p. 310-317, 2016.

SPIRIDON, I.; POPA, V. I. Hemicelluloses: Major sources, properties and applications. In:BELGACEM, M. N.; GANDINI, A. Monomers, Polymers and Composites from Renewable Resources. 1st ed. Elsevier, 2008. cap. 13, p. 289-304. 
STRAIN, I. N.; WU, Q.; POURRAHIMI, A. M.; HEDENQVIST, M. S.; OLSSON, R. T.; ANDERSSON, R. L. Electrospinning of recycled PET to generate tough mesomorphic fibre membranes for smoke filtration. Journal of Materials Chemistry A, v. 3, n. 4, p. $1632-$ 1640, 2015.

SULTANA, N.; ZAINAL, A. Cellulose acetate electrospun nanofibrous membrane: fabrication, characterization, drug loading and antibacterial properties. Bulletin of Materials Science, v. 39, n. 2, p. 337-343, 2016.

SUPTHANYAKUL, R.; KAABBUATHONG, N.; CHIRACHANCHAI, S. Random poly[butylene succinate-co-lactic acid] as a multi-functional additive for miscibility, toughness, and clarity of PLA/PBS blends. Polymer, v. 105, p. 1-9, 2016.

SWAIN, P. T. R.; BISWAS, S. A comparative analysis of physico-mechanical, water absorption, and morphological behaviour of surface modified woven jute fiber composites. Polymer Composites, p. 1-9, 2017.

TASHIRO, K.; KOBAYASHI, M. Theoretical evaluation of three-dimensional elastic constants of native and regenerated celluloses: role of hydrogen bonds. Polymer, v. 32, n. 8, p. 1516-1526, 1991.

TATAR, F.; TUNÇ, M. T.; DERVISOGLU, M.; CEKMECELIOGLU, D.; KAHYAOGLU, T. Evaluation of hemicellulose as a coating material with gum arabic for food microencapsulation. Food Research International, v. 57, p. 168-175, 2014.

TAYLOR, G. Electrically Driven Jets. Proceedings of the Royal Society A: Mathematical, Physical and Engineering Sciences, v. 313, n. 1515, p. 453-475, 1969.

THAKUR, V. K.; THAKUR, M. K. Processing and characterization of natural cellulose fibers/thermoset polymer composites. Carbohydrate Polymers, v. 109, p. 102-117, 2014.

TONG, H.-W.; WANG, M. An investigation into the influence of electrospinning parameters on the diameter and alignment of poly[hydroxybutyrate-co-hydroxyvalerate) fibers. Journal of Applied Polymer Science, v. 120, n. 3, p. 1694-1706, 2011.

VALLEJOS, M. E.; PERESIN, M. S.; ROJAS, O. J. All-Cellulose Composite Fibers Obtained by Electrospinning Dispersions of Cellulose Acetate and Cellulose Nanocrystals. Journal of Polymers and the Environment, v. 20, n. 4, p. 1075-1083, 2012.

VELEIRINHO, B.; COELHO, D. S.; DIAS, P. F.; MARASCHIN, M.; PINTO, R.; CARGNINFERREIRA, E.; PEIXOTO, A.; SOUZA, J. A; RIBEIRO-DO-VALLE, R. M.; LOPES-DA-SILVA, J. A. Foreign body reaction associated with PET and PET/chitosan electrospun nanofibrous abdominal meshes. PloS one, v. 9, n. 4, p. e95293, 2014.

VELEIRINHO, B.; LOPES-DA-SILVA, J. A. Application of electrospun poly[ethylene terephthalate] nanofiber mat to apple juice clarification. Process Biochemistry, v. 44, n. 3, p. 353-356, 2009.

VELEIRINHO, B.; REI, M. F.; LOPES-DA-SILVA, J. A. Solvent and concentration effects on the properties of electrospun poly[ethylene terephthalate] nanofiber mats. Journal of Polymer Science Part B: Polymer Physics, v. 46, n. 5, p. 460-471, 2008.

WANASEKARA, N. D.; SANTOS, R. P. O.; DOUCH, C.; FROLLINI, E.; EICHHORN, S. J. Orientation of cellulose nanocrystals in electrospun polymer fibres. Journal of Materials Science, v. 51, n. 1, p. 218-227, 2016. 
WANG, W.; LI, N.; LI, G.; LI, S.; WANG, W.; WANG, A.; CONG, Y.; WANG, X.; ZHANG, T. Synthesis of Renewable High-Density Fuel with Cyclopentanone Derived from Hemicellulose. ACS Sustainable Chemistry \& Engineering, v. 5, n. 2, p. 1812-1817, 2017.

WANG, Y.; YANG, X.; LIU, W.; ZHANG, F.; CAI, Q.; DENG, X. Controlled release behaviour of protein-loaded microparticles prepared via coaxial or emulsion electrospray. Journal of microencapsulation, v. 30, n. 5, p. 490-7, 2013.

WANG, Z:; PAN, Z. Preparation of hierarchical structured nano-sized/porous polyllactic acid] composite fibrous membranes for air filtration. Applied Surface Science, v. 356, p. 1168-1179, 2015.

WEI, W.; YEH, J.-T.; LI, P.; LI, M.-R.; LI, W.; WANG, X.-L. Effect of nonsolvent on morphologies of polyamide 6 electrospun fibers. Journal of Applied Polymer Science, v. 118, n. 5, p. 3005-3012, 2010.

WELLEN, R. M. R. Effect of Polystyrene on Poly [ Ethylene Terephthalate ] Crystallization. v. 17, n. 6, p. 1620-1627, 2014.

YANG, W.; SOUSA, A. M. M.; FAN, X.; JIN, T.; LI, X.; TOMASULA, P. M.; LIU, L. Electrospun ultra-fine cellulose acetate fibrous mats containing tannic acid-Fe3+ complexes.

Carbohydrate Polymers, v. 157, p. 1-7, 2016.

YARIN, A. L. Free Liquid Jets and Films: Hydrodynamics and Rheology. New York: Longman Scientific \& Technical, 1993.

YARIN, A. L.; KATAPHINAN, W.; RENEKER, D. H. Branching in electrospinning of nanofibers. Journal of Applied Physics, v. 98, n. 6, 2005.

YE, M.; KIM, S.; PARK, K. Issues in long-term protein delivery using biodegradable microparticles. Journal of Controlled Release, v. 146, n. 2, p. 241-260, 2010.

YU, S. IL; KI, S.; HWA, M. \&; SHIN, S. Nanocellulose size regulates microalgal flocculation and lipid metabolism. Nature Publishing Group, n. October, p. 1-9, 2016.

YUN, G. Y.; KIM, H. S.; KIM, J.; KIM, K.; YANG, C. Effect of aligned cellulose film to the performance of electro-active paper actuator. Sensors and Actuators, A: Physical, v. 141, n. 2, p. 530-535, 2008.

ZANDER, N. E.; GILLAN, M.; SWEETSER, D. Recycled PET nanofibers for water filtration applications. Materials, v. 9, n. 4, p. 1-10, 2016.

ZHANG, C.; YUAN, X.; WU, L.; HAN, Y.; SHENG, J. Study on morphology of electrospun poly[vinyl alcohol] mats. European Polymer Journal, v. 41, n. 3, p. 423-432, 2005.

ZHANG, H.; LI, H.; YANG, F.; WANG, T.; GAO, J.; JIANG, T. Preparation of cross-linked polyvinyl alcohol nanospheres and the synthesization of low-fouling modified membranes. Separation and Purification Technology, v. 77, n. 1, p. 162-170, 2011.

ZHANG, J.; SONG, M.; WANG, X.; WU, J.; YANG, Z:; CAO, J.; CHEN, Y.; WEI, Q. Preparation of a cellulose acetate/organic montmorillonite composite porous ultrafine fiber membrane for enzyme immobilization. Journal of Applied Polymer Science, v. 133, n. 33, 2016.

ZHANG, Y. Q.; XIE, B. J.; GAN, X. Advance in the applications of konjac glucomannan and its derivatives. Carbohydrate Polymers, v. 60, n. 1, p. 27-31, 2005. 